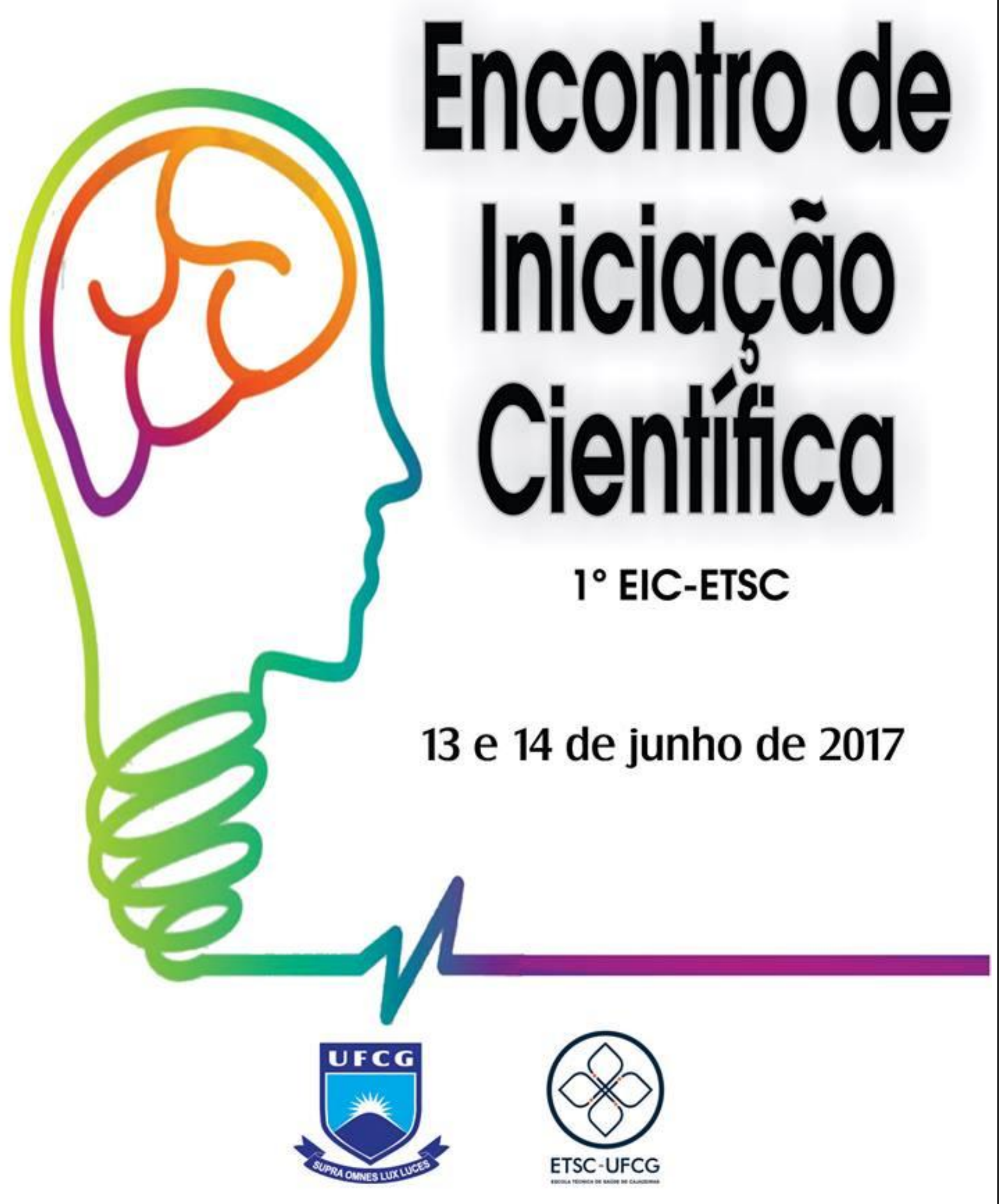

ESCOLA TÉCNICA DE SAÚDE DE CAJAZEIRAS

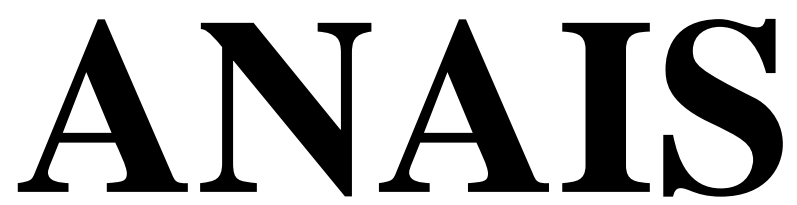



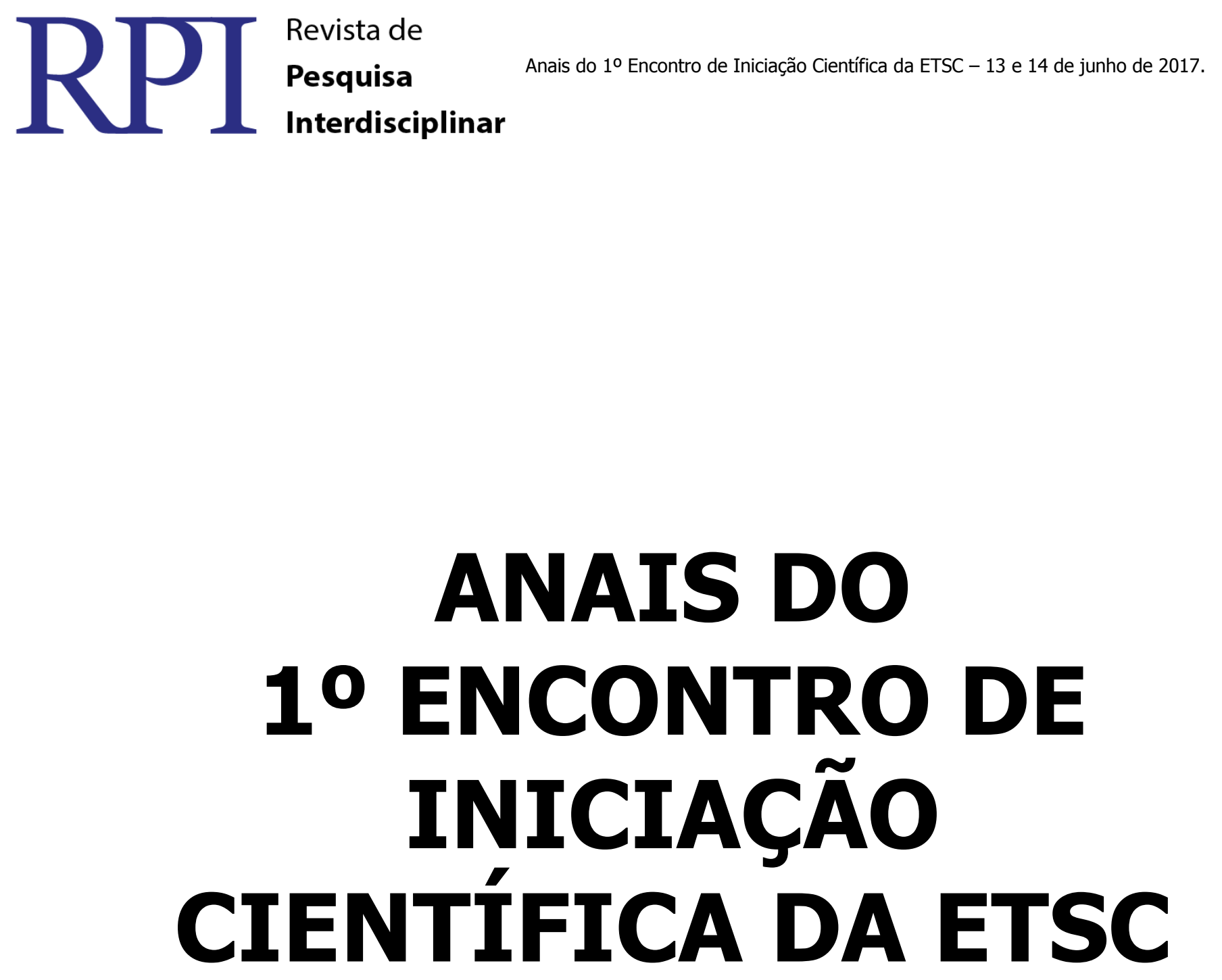

Realizado em 13 e 14 de junho de 2017

Cajazeiras

RPI Revista de Pesquisa Interdisciplinar, Cajazeiras, v. 2, Edição Especial, 2017. 


\author{
REITOR \\ Vicemário Simões \\ VICE-REITOR \\ Camilo Allyson Simões de Farias \\ PRÓ-REITOR DE PESQUISA E EXTENSÃo \\ Onireves Monteiro de Castro \\ DIRETOR DO CENTRO DE FORMAÇÃO DE PROFESSORES \\ Antônio Fernandes Filho \\ VICE-DIRETOR DO CENTRO DE FORMAÇÃO DE PROFESSORES \\ Carlos Davdson Pinheiro \\ DIRETOR DA ETSC \\ Welington Bezerra de Sousa
}

COORDENADOR DE PESQUISA E EXTENSÃO DA ETSC

Antunes Ferreira da Silva

COORDENADORA DO CURSO TÉCNICO EM SAÚDE BUCAL

Alana Kelly Maia Macedo Nobre de Lima

COORDENADORA DO CURSO TÉCNICO EM ENFERMAGEM

Olga Feitosa Braga

\author{
COORDENADOR DO ENSINO MÉDIO \\ Raimundo Gonçalo Cariri
}




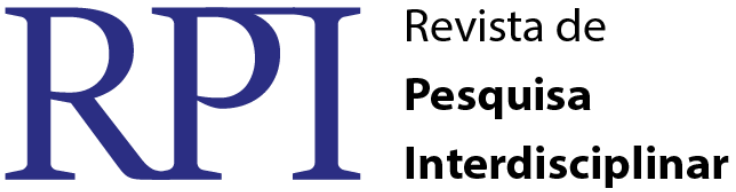

Comissão organizadora do evento:

Prof. Me. Antunes Ferreira da Silva

Prof. Me. Welington Bezerra de Sousa

Profa. Dra. Giliara Carol Diniz Gomes de Luna Gurgel

Luciana Freire Pinto

Edvânia da Silva Cardoso

Comissão Científica (avaliação dos resumos):

GT's:

Profa. Dra. Ilana Sanamaika Queiroga

Prof. Dr. José Ferreira de Lima Junior

Profa Esp. Olga Feitosa Braga Teixeira

Profa. Ma. Fabiana Lucena Rocha

Prof. Dr. Altemar Lobão de Sousa Junior

Profa. Esp. Sâmea Damásio da Mota Silva

Banners:

Profa. Dra. Maria do Carmo Alustau Fernandes

Profa. Esp. Gerlane Cristinne Bertino Veras

Profa. Ma. Alana Kelly Maia Nobre de Lima

Prof. Dr. Ernani Martins dos Santos Filho

Prof. Me. Raimundo Gonçalo Cariri

Apresentação cultural

Profa. Ma. Klébia Seliane Pereira de Souza

Profa. Dra. Thalyta de Paula Pereira Lima

Aluno(a)s bolsistas (monitore(a)s):

Antônia Bezerra de Sousa

Fernanda Raquel Rolim Gomes

Tatiana da Silva Gomes

Fabielly Bezerra de Sousa

Francisca Joyce P. da Silva

Pedro Manuel N. Nogueira

Laura Almeida de Araújo

Erlaine da Silva Andrade

Francisco Canuto Martins

Dayse Kelly Feitosa Rolim
Mikaelle Paulino da Silva Geiciane Pamplona dos Santos Joyce Layanne Gomes da Silva Maria Gesca Pereira da Silva

Maira Pereira de Sousa

Sarah Gabriela Cabral Teixeira

Rodrigues

Francisco Martins da Costa

Luanda Monteiro da Costa

Ronaldo Fernandes 


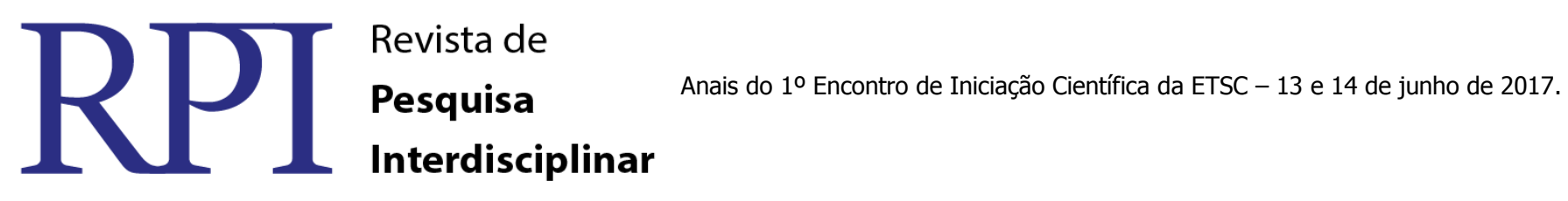

\section{Anais do $1^{\circ}$ Encontro de Iniciação Científica da ETSC}

\section{ISSN XXXX-XXXX}

Dados Internacionais de Catalogação na Publicação (CIP)

Escola Técnica de Saúde de Cajazeiras - ETSC

E56

Encontro de Iniciação Científica da Escola Técnica de Saúde de Cajazeiras (1,2017: Cajazeiras - PB)

Anais do $1^{\circ}$ Encontro de Iniciação Científica da Escola Técnica de Saúde de Cajazeiras,

13 a 14 de junho de 2017/ Antunes Ferreira da Silva

(Organizador) - Cajazeiras: ETSC, 2017

ISSN 2526-3560: (ONLINE)

Encontro realizado pela Coordenação de Pesquisa e Extensão - CPE

1. Pesquisa Científica 2. Conhecimento Científico

I. Silva, Antunes Ferreira da II. Escola Técnica de Saúde de Cajazeiras III Título

\section{ENDEREÇO PARA CORRESPONDÊNCIA}

Coordenação de Pesquisa e Extensão (CPE)

Escola Técnica de Saúde de Cajazeiras (ETSC)

Universidade Federal de Campina Grande (UFCG)

Rua Sérgio Moreira de Figueiredo, sn - Casas Populares

Cajazeiras/PB - Brasil - CEP: 58900-000

Telefone: (83)3532.3200/2061/2070 ramal 27

E-mail: eicetsc@gmail.com

CDU:

001.8

\section{APRESENTAÇÃO}

O compromisso com uma educação pública de qualidade é a principal "causa de ser" da Escola Técnica de Saúde de Cajazeiras (ETSC) desde sua criação, no início 
da década de 70. Objetivando contribuir para a formação de cidadãos, promovendo ensino, pesquisa e extensão através de uma prática pedagógica holística, currículo atualizado, tecnologias modernas e um sistema eficiente de apoio ao estudante, que visa o sucesso na vida profissional, social e pessoal de nossa clientela, a ETSC continua tão pioneira quanto na época de sua criação em relação à oferta não só das ações que configuram o ensino por meio de seus cursos de nível médio e os técnicos em enfermagem e saúde bucal, mas também na consolidação das práticas de extensão e pesquisa.

Com esta primeira edição, iniciamos uma série de muitos encontros de iniciação científica que tem como objetivo principal o incentivo à produção acadêmica e científica, especialmente no que diz respeito à publicização dos resultados obtidos pelo(a)s pesquisadore(a)s que compõem nosso quadro docente e discente.

Nas palavras do Plano Nacional de Extensão (2000), a ETSC desponta a caminho de "[...] um novo rumo [...] de contribuir significativamente para a mudança da sociedade". E é neste intuito que esta instituição passa a tratar com a seriedade que lhe é devida o tripé ensino, pesquisa e extensão.

Ressaltem-se algumas características básicas da ETSC: a primeira é sua qualidade reconhecida tanto na aprovação por parte do INEP, ao fim de cada Exame Nacional do Ensino Médio (atualmente, somos a sétima melhor escola do estado da Paraíba, a melhor escola pública da Paraíba e a sétima melhor escola pública do Nordeste), quanto na aprovação dos egressos de nossos cursos técnicos em concursos públicos da região e empregabilidade do(a)s mesmo(a)s na vida profissional, depois de formados; a segunda é sua marca registrada: uma instituição séria, à frente do seu tempo e do que dela se espera, que, acima de tudo, preza pela qualidade dos serviços que presta.

O êxito citado é resultado do trabalho realizado por todos os discentes, servidores professores e servidores técnico-administrativos envolvidos e vinculados à ETSC neste tempo, bem como é fruto também das muitas pesquisas decorrentes dos projetos de extensão e de pesquisa que mantemos em nossos quadros. 
À todo(a)s, pois, desejamos uma boa leitura e que estes resumos expandidos que ora apresentamos suscitem o gosto pela pesquisa e pela discussão, que tanto enriquecem e oxigenam a vida acadêmica do ensino médio e técnico.

Prof. Me. Antunes Ferreira da Silva

Coordenador de Pesquisa e Extensão da ETSC

Organizador geral do evento 


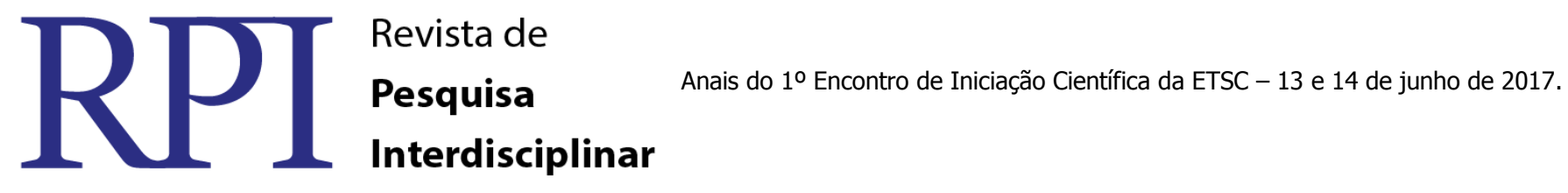

\section{SUMÁRIO}

\section{ENFERMAGEM NA SAÚDE COLETIVA}

1.1 O LÚDICO COMO MEIO AFETIVO/ HUMANIZADOR DA RELAÇÃO: PROFISSIONAIS DA SAÚDE E CRIANÇAS E ADOLESCENTES HOSPITALIZADOS - 9 Marlla Héllen do Nascimento Araújo

1.2 CASOS NOVOS DE TUBERCULOSE NO BRASIL - 23

Lana Lívia Peixoto Linard

1.3 CONFLITOS INTERPESSOAIS NA PRÁTICA GERENCIAL DO ENFERMEIRO NA ATENÇÃO BÁSICA - 27

Rayara Cibelle Ribeiro da Silva

1.4 SUPERVISÃO COMO PRÁTICA GERENCIAL NA ATENÇÃO BÁSICA: DISCURSO DOS ENFERMEIROS - 32

Paloma Karen Holanda Brito

1.5 SAÚDE DO HOMEM: REFLEXÃO ACERCA DA POLÍTICA NACIONAL DE ATENÇÃO INTEGRAL A SAÚDE DO HOMEM E AS DIFICULDADES PARA IMPLANTAÇÃO - 37

Cryslanny de Sousa Maciel e Silva

1.6 CASOS NOTIFICADOS DE TUBERCULOSE EM HOMENS NO ESTADO DA PARAÍBA - BRASIL - 42

José Augusto de Sousa Rodrigues

1.7 PROPORÇÃO DE CONTATOS EXAMINADOS DOS CASOS DE HANSENÍASE NAS REGIÕES DO BRASIL - 47

Maria Joyce Tavares Alves

1.8 TENDÊNCIA DA MORBIDADE POR PNEUMONIA NA REGIÃO NORDESTE - 50 Maria Joyce Tavares Alves

1.9 ACIDENTES COM ANIMAIS PEÇONHENTOS: EPIDEMIOLOGIA DAS NOTIFICAÇÕES NA REGIÃO NORDESTE NO PERÍODO DE 2010-2015 - 54

Wagner Maciel Sarmento

1.10 TRATAMENTO FARMACOLÓGICO DOS IDOSOS COM HIPERTENSÃO ARTERIAL SISTÊMICA: RELATO DE EXPERIÊNCIA - 59

Gabriella Silva Nogueira

1.11 PRÁTICAS DE TRABALHO DE AGENTE COMUNITÁRIO DE SAÚDE: ORIENTADOR DE AÇÕES, SERVIÇOS E CUIDADOS EM SAÚDE - 63

Aricles Millane Gomes Batista 


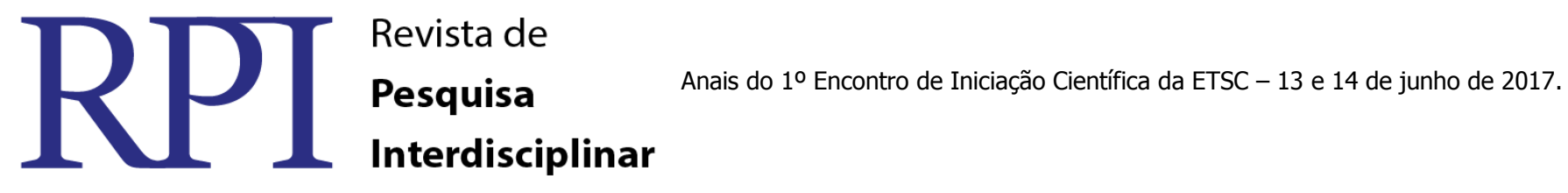

1.12 A IDENTIDADE DO IDOSO ESTAMPADA NO ENVELHECER: O QUE TRÁS A LITERATURA? - 67

Andressa Pereira do Carmo

1.13 REALIZAÇAO PRECOCE DO EXAME PAPANICOLAOU PARA DETECÇAO DO HPV 70

Francisco Assis Cavalcante Júnior

1.14 PROCESSO DE TRABALHO DO AGENTE COMUNITÁRIO DE SAÚDE: CONSTRUÇÃO COLETIVA DO CUIDADO COMO ESTRATÉGIA PARA FORTALECER O VÍNCULO COM A COMUNIDADE NA ATENÇÃO BÁSICA - 74

Geísa Batista Leandro

1.15 CARACTERÍSTICAS EPIDEMIOLÓGICAS DE CASOS NOVOS DE HANSENÍASE EM CAJAZEIRAS, PARAÍBA - 79

Bruno Neves da Silva

1.16 ROTINA DE ENFERMAGEM PARA RECEBIMENTO DE MATERIAL DE USO DOMICILIAR: RELATO DE EXPERIÊNCIA - 84

Bruno Neves da Silva

1.17 CARACTERÍSTICAS DA PREVALÊNCIA DA TOXOPLASMOSE GESTACIONAL: REVISÃO SISTEMATIZADA DA LITERATURA - 89

Bruno Neves da Silva

\section{ASSISTÊNCIA DE ENFERMAGEM}

2.1 PRÁTICAS INTEGRATIVAS E COMPLEMENTARES NA ASSISTÊNCIA DE ENFERMAGEM: ESTUDO REFLEXIVO - 95

Maísa Galdino Pereira

2.2 PRIMEIROS SOCORROS: PROCESSO EDUCATIVO PARA DOCENTES, DISCENTES E TÉCNICOS ADMINISTRATIVOS DE UMA INSTITUIÇÃO DE ENSINO - 15

Edson da Silva Oliveira

2.3 FATORES ASSOCIADOS AO DESENVOLVIMENTO DE ESTRESSE EM ENFERMEIROS - 100

Jovelina Fernandes dos Santos

2.4 REFLEXÕES ACERCA DA NECESSIDADE DE UMA ASSISTÊNCIA HUMANIZADA A PACIENTES E FAMILIARES NA UNIDADE DE TERAPIA INTENSIVA INFANTIL - 105 Irislândia de Oliveira Batista

2.5 ATUAÇÃO DOS PROFISSIONAIS DE ENFERMAGEM NA HUMANIZAÇÃO DO PARTO $-109$

Thaciane Maria F. de Souza 


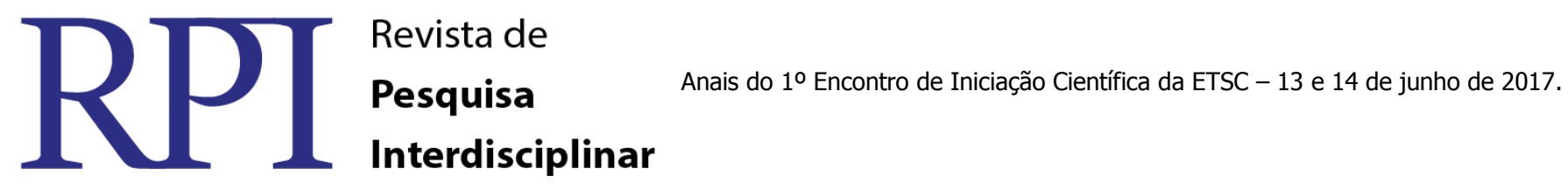

2.6 HERPES ZOSTER NA INFÂNCIA UMA HERANÇA MATERNA - 114

Maísa Galdino Pereira

2.7 PERFIL CLÍNICO-EPIDEMIÓLOGICO DA MENINGITE NA PARAÍBA

Jeysica Paloma Medeiros dos Santos

2.8 APLICAÇÃO DO PROCESSO DE ENFERMAGEM EM CLÍNICA MÉDICA: RELATO DE EXPERIÊNCIA - 119

Bruno Neves da Silva

\section{SAÚDE BUCAL}

3.1 PROMOÇÃO DE SAÚDE BUCAL EM BEBÊS - 125

Luana Raquel Araújo Sifrônio

3.2 CONHECIMENTO DE GESTANTES SOBRE SAÚDE BUCAL:

UMA REVISÃO DA LITERATURA - 128

Dayse Kelly Feitoza Rolim

3.3 TRANSTORNOS ALIMENTARES: MANIFESTAÇÕES ORAIS NA ANOREXIA NERVOSA E BULIMIA NERVOSA - 131

Antonia Bezerra de Sousa

3.4 TRAUMATISMOS NA DENTÇÃO DECÍDUA: EPIDEMIOLOGIA E CONSEQUENCIAS 135

Ana Joice da Silva Alves

3.5 PROMOÇÃO DA SAÚDE BUCAL EM PACIENTES COM NECESSIDADES ESPECIAIS 139

Maria Quitéria Tavares de Araújo

\section{CIÊNCIAS HUMANAS E LINGUAGENS}

4.1 AÇÕES, RAZÕES E CAUSAS: ENTENDENDO DONALD DAVIDSON E O PROBLEMA DA CAUSAÇÃO MENTAL

Felipe Pacélly Silva Cabral

4.2 SOBRE FILOSOFIA CLÍNICA - 147

Francisca Ana Lívia Rodolfo da Silva

4.3 ALMEJADA POR TODOS : A FELICIDADE - 149

Atilyo Lima Barroso

4.4 DE OLHO NO TEMPO - 153

Edigley Cardoso Ferreira Júnior

RPI Revista de Pesquisa Interdisciplinar, Cajazeiras, v. 2, Edição Especial, 2017. 


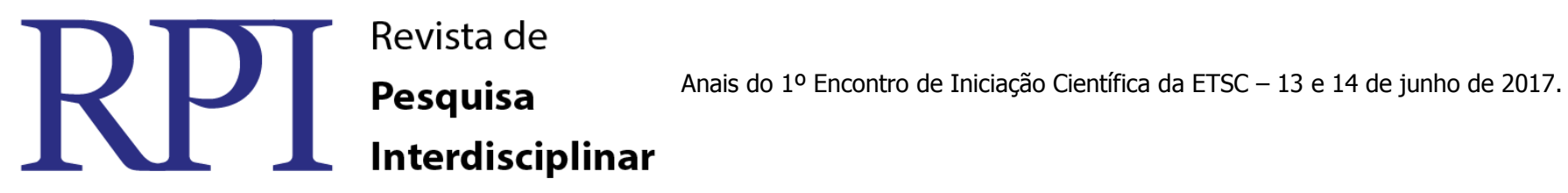

4.5 A FELICIDADE E O SOFRIMENTO EM ARTHUR SCHOPENHAUER - 161

Maria Eduarda Oliveira Rangel

4.6 COMO ENTENDER A FILOSOFIA CLÍNICA - 163

Beatriz Soares Silva

4.7 FILOSOFIA DE ARTHUR SHOPENHAUER E BERTRAND RUSSELL SOBRE O CONCEITO DE FELICIDADE - 165

Maely Moreira de Abrantes

4.8 REGISTROS RUPESTRES EM COMUNIDADE RURAL DO ALTO SERTÃO PARAIBANO - 169

Roberto Ramon Queiroz de Assis

4.9 IDENTIDADE PESSOAL NA FILOSOFIA CLÍNICA - 172

Virna Menezes Rolim

4.10 FILOSOFIA CLÍNICA - 175

Victor Rhuan Maximino Silva Vieira

4.11 A PERCEPÇÃO DA FILOSOFIA CIENTÍFICA SEGUNDO ARISTÓTELES - 177

Carlos Henrique França de Macêdo Gomes

4.12 A VONTADE COMO ELEMENTO DEFINITIVO DOS SENTIDOS SEGUNDO ARTHUR SCHOPENHAUER - 180

Anna Clara Lira de Moura

4.13 A CONCEPÇÃO DE MORTE E O INTRÍNSECO ELO COM O SER SEGUNDO OS PRINCÍPIOS DA FILOSOFIA SCHOPENHAUERIANA - 182

Maria Laura Dantas Nóbrega

4.14 FILOSOFIA CLÍNICA, UMA REFLEXÃO IMPORTANTE SOBRE O SER HUMANO 185

Karina Estrela Egídio

4.15 TRANSVALORAÇÃO E AMOR FATI DE FRIEDRICH NIETZSCHE - 188

Francisco Filipy Fernandes Rocha

4.16 LINHAS DE PENSAMENTOS DO BEHAVIORISMO - 190

Ana Beatriz da Silva Batista

4.17 ALIANÇA ENTRE SENSIBILIDADE E RAZÃO: NOVO PARADIGMA DA PROGRAMAÇÃ̃O - 192

Marcela Eduarda Gomes Grande

4.18 O AMOR EM SCHOPENHAUER - 195

Iohanna Mélo de Araújo

RPI Revista de Pesquisa Interdisciplinar, Cajazeiras, v. 2, Edição Especial, 2017. 


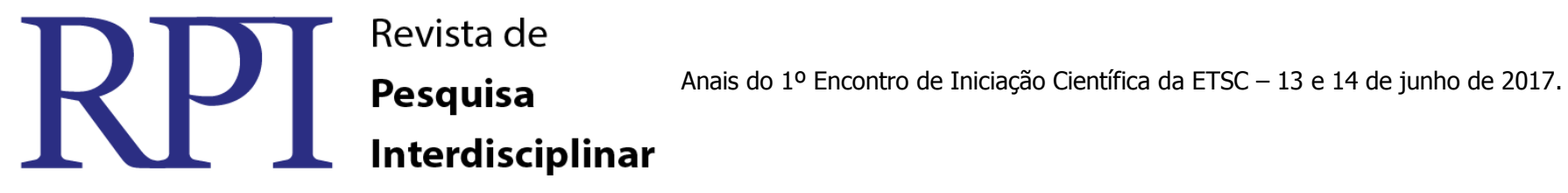

4.19 A FILOSOFIA APLICDA AO INDIVÍDUO - 197

Andressa de Lima Lucena

\section{CIÊNCIAS EXATAS E DA NATUREZA}

5.1 CULTIVO DE PLEUROTUS SPP. EM RESÍDUOS DE PAPEL DE ESCRITÓRIO: AVALIAÇÃO DO CRESCIMENTO MICELIAL E COLONIZAÇÃO DOS SUBSTRATOS - 200 Laura Almeida de Araújo 


\section{$\int\left[\begin{array}{l}\text { Revista de } \\ \text { Pesquisa } \\ \text { Interdisciplinar }\end{array}\right.$}

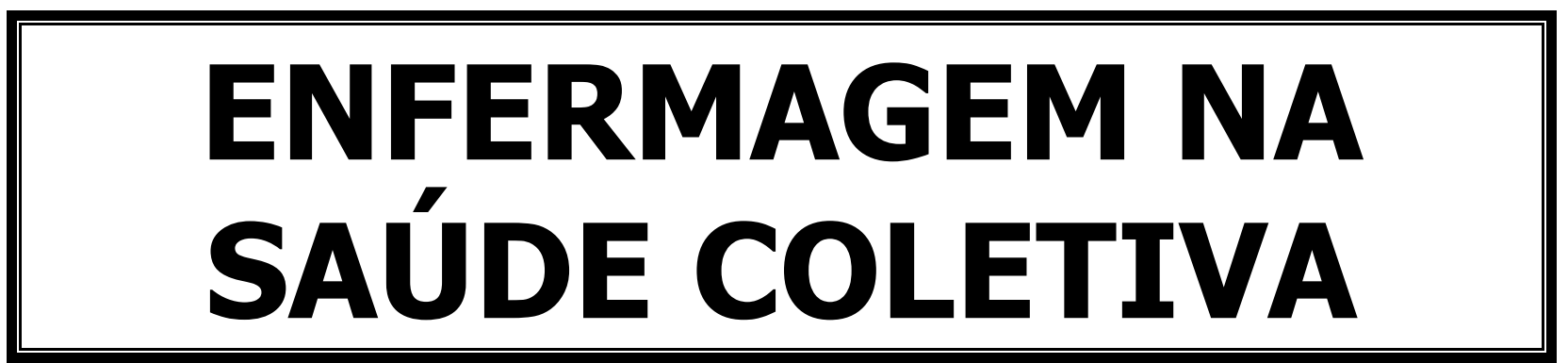

RPI Revista de Pesquisa Interdisciplinar, Cajazeiras, v. 2, Edição Especial, 2017. 


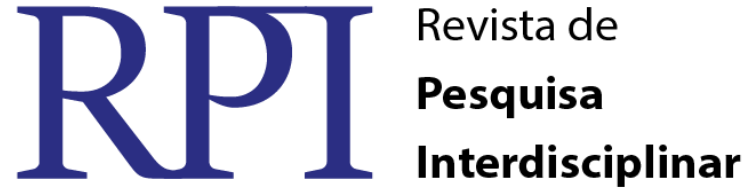

\section{O LÚDICO COMO MEIO AFETIVO/ HUMANIZADOR DA RELAÇÃO: PROFISSIONAIS DA SAÚDE E CRIANÇAS E ADOLESCENTES HOSPITALIZADOS}

\author{
LINHA DE PESQUISA: Enfermagem na saúde coletiva - Banner.
}

MARLLA HÉLLEN DO NASCIMENTO ARAÚJO, Graduanda em Medicina, Universidade Federal de Capina Grande RAYSA DA SILVA FREITAS, discente CTSB/UFCG ANDRESSA PEREIRA DO CARMO, Graduanda em Enfermagem, Universidade Federal de Campina Grande. ANÚBES PEREIRA DE CASTRO, Doutora em Saúde Pública, Universidade Federal de Campina Grande ALANA KELLY MAIA MACEDO NOBRE DE LIMA, Mestre em Odontologia, Universidade Federal de Campina Grande

\section{INTRODUÇÃO}

O período de hospitalização é marcante na vida de qualquer pessoa. Imagina-se que, para a criança e adolescente, por sua vez, é mais significativo pelo não reconhecimento do ambiente hospitalar e pela impossibilidade de realizar suas atividades do cotidiano, como brincar e ir à escola, alterando a sua rotina (OLIVEIRA et al., 2009). Diante disso, o caráter lúdico desencadeado na relação entre profissionais de saúde e paciente evidencia uma aproximação com o ambiente pedagógico das escolas por trabalhar a afetividade.

O termo "afetividade" significa o conjunto de fenômenos psíquicos que se manifestam sob a forma de emoções, paixões e sentimentos, acompanhados de dor ou prazer, satisfação ou insatisfação, dentre outros antagonismos (FERREIRA, 1999). Dessa maneira, a afetividade é um estado de interação e afinidade profunda entre os indivíduos, necessária na interação no ambiente hospitalar por exercitar um perfil humanístico.

É nesse contexto que amenizar os traumas sofridos tem bastante relevância. Visto que, a hospitalização realiza-se, normalmente, em uma atmosfera de tensão e insegurança à criança e aos seus acompanhantes, acarretando situações desagradáveis, a ambos, pelo cenário de dor, ansiedade, medo, além de sensações de abandono e culpa (BETTINELLI; WASKIEVICZ; ERDAMNN, 2013).

O presente estudo visa compreender a importância do brinquedo no ambiente hospitalar de pediatria e a sua contribuição para crianças hospitalizadas, de forma a amenizar o sofrimento e reduzir o tempo de internação, através de brincadeiras lúdicas e recreativas. 


\section{$\mathrm{RPP}$}

Anais do $1^{\circ}$ Encontro de Iniciação Científica da ETSC - 13 e 14 de junho de 2017.

Bem como, analisar a ferramenta da ludicidade como meio de humanização e afetividade. Pois, é íntima a relação entre os jogos e o raciocínio organizado, a concentração e a resolução de problemas em uma visão universal (BORIN, 1996).

Sarmento (2014), ao elucidar Piaget, afirma que cada componente do ambiente da criança causa nela um tipo de afetividade, que é síntese das provocações causadas pelo próprio componente. Ou seja, no hospital, por exemplo, cada personagem reflete um sentimento na criança que a ajuda a constituir seu caráter.

Um perfil afetivo-universal de interação entre profissionais da saúde e crianças hospitalizadas se mostra bastante interessante quanto ao quesito supracitado, tendo em vista os estágios de desenvolvimentos psicológicos (personalismo/puberdade e adolescência), para que, as experiências do âmbito hospitalar não venham a causar danos futuros.

A Teoria Psicogenética de Henri Wallon divide-se nesta lógica de idades: de 0 a 1 ano, trata-se de impulsivo-emocional; de 1 a 3 anos sensório-motor e projetivo; de 3 a 6 anos personalismo; de 6 a 11 anos categorial; e, de 11 anos a mais puberdade e adolescência (MAHONEY; ALMEIDA, 2005). Em concordância com o autor, os estágios afetivos estão intimamente associados ao personalismo da puberdade e adolescência. Diante disso, deve-se imaginar que trabalhar a ludicidade nesses estágios influencia o desenvolvimento cognitivo e facilita o exercício do profissional da saúde, corroborando, assim, com o Método Clínico Centrado na Pessoa (MCCP).

\section{OBJETIVO DO TRABALHO}

Compreender a importância do lúdico como instrumento de humanização e como facilitador da relação dos profissionais da saúde e os pacientes infantojuvenil, por meio do seu caráter afetivo conforme a Teoria Psicogenética de Henri Wallon.

\section{MATERIAIS E MÉTODOS}

Para responder ao objetivo do trabalho, realizamos estudo de abordagem qualitativa, utilizando-se de uma revisão de literatura. Para Mancini e Sampaio (2006), a análise e a síntese das informações disponibilizadas por todos os estudos relevantes publicados sobre um tema são as características de uma revisão de literatura. Tais características visam resumir o corpo de conhecimento existente e levar a concluir sobre o assunto de interesse. Existem diversos tipos de estudos de revisão e cada um deles segue uma metodologia específica. 


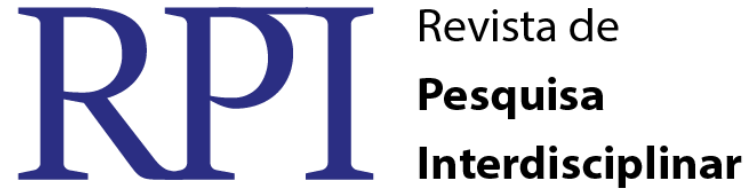

Anais do $1^{\circ}$ Encontro de Iniciação Científica da ETSC - 13 e 14 de junho de 2017.

Neste estudo, optou-se pela revisão narrativa, que não utiliza critérios sofisticados para a busca de informações na literatura. Adicionalmente, apesar da seleção dos estudos e a interpretação das informações estarem sujeitas à subjetividade dos autores, é proposta a construção de uma contextualização do problema apresentado e realização de uma análise crítica do mesmo.

A busca do material foi realizada em bancos de dados específicos para elaboração dos textos, através de leituras sobre o tema. Os bancos de dados informatizados foram MEDLINE, PePsic, SciELO e consulta manual em periódicos da área. A busca dos artigos deu-se por meio do uso das palavras-chave, a saber, humanização e afetividade, ludicidade nos hospitais, humanização da assistência pediátrica, o brinquedo no ambiente hospitalar, dentre outras.

A próxima etapa constituiu-se da determinação do material de interesse à pesquisa. Nesse momento, realizamos o balanceamento do material lido, de forma mais profunda e exploratória. Posteriormente, procedemos à leitura do tipo analítica que é feita com base nos textos selecionados, com finalidade de ordenar as informações contidas nas fontes, de forma que estas possibilitem a obtenção de respostas. Desse modo, foi possível elencar o material, extrair dos textos temas de interesse para esta pesquisa e relacioná-los ao objetivo proposto.

\section{RESULTADOS E DISCUSSÃO}

O importante papel do lúdico no mundo da criança tem levado vários estudiosos/profissionais de diferentes áreas, a lançarem mão deste recurso em benefício das crianças hospitalizadas. Tendo em vista que, ao brincar no hospital, a criança altera o ambiente em que se encontra, aproximando-o de sua realidade cotidiana, o que pode ter um efeito bastante positivo em relação a sua hospitalização, devido ao caráter terapêutico assumido pelas atividades lúdicas (MOTTA; ENUMO, 2006).

De acordo com pesquisas levantadas para este trabalho, as oportunidades trazidas pelo brincar, como a afetividade e a humanização, têm-se mostrado positivamente. Pois, é através da participação como sujeito ativo das brincadeiras que crianças e adolescentes amenizam o seu sofrimento, se socializam com outras crianças, tornando-se colegas de brincadeiras, sorriem e se distraem, porque "os brinquedos são importantes como agentes de socialização, o convite para brincar. Mas o essencial é brincar, mesmo na ausência do brinquedo", outro aspecto observado é a diminuição do stress, tornado as crianças mais interativas, além da 


\section{$\int\left[\begin{array}{l}\text { Revista de } \\ \text { Pesquisa } \\ \text { Interdisciplinar }\end{array}\right.$}

Anais do $1^{\circ}$ Encontro de Iniciação Científica da ETSC - 13 e 14 de junho de 2017.

melhor adesão das crianças ao tratamento e aos cuidados dos profissionais da saúde (OLIVEIRA, 2007)..

No contexto do trabalho lúdico elencado à afetividade, Mahoney e Almeida (2005), ao afirmar que a afetividade é a predisposição de ser afetado por causas internas ou externas e que a emoção é o recurso precursor da ligação entre o orgânico e o social, trazem à tona os principais pontos da Teoria Psicogenética de Henri Wallon: "A teoria aponta três momentos marcantes, sucessivos na evolução da afetividade: emoção, sentimento e paixão" (Id., 2005), e ainda. Outrossim, Wallon (1975) afirma que "Os meios em que vive a criança e aqueles com que ela sonha constituem a 'forma' que molda sua pessoa”.

As pesquisas também evidenciaram o caráter educativo que o hospital pode assumir, tendo em vista a quebra da rotina escolar na vida dos hospitalizados. Dessa maneira, os profissionais brinquedistas devem trabalhar também o desenvolvimento cognitivo das crianças por meio da afetividade, pois, segundo Miranda (2012), ele deve estar abraçado pela alegria e prazer proporcionados no ato de brincar. Assim, o cuidado estará direcionado apenas ao corpo, mas ao ser em sua integralidade, para não comprometimento da saúde psíquica (CUNHA, 2013).

Somado a isso, Vigotski (1999) mostra que desenvolvimento do pensamento é estruturalmente importante para todo o sistema da atividade das funções psíquicas, portanto, estudar os meios da afetividade como método psicopedagógico no ambiente escolar é de suma importância, visto que, características significativas ao desenvolvimento cognitivo e ao progresso dos dotes mentais podem se abordadas.

\section{CONCLUSÕES}

Faz-se necessário pesquisar e analisar a Teoria Psicogenética de Henri Wallon para que, em pesquisas futuras, venha a desenvolver um perfil adequado com finalidade de atender positivamente às necessidades afetivas que demandam os estágios de personalismo e puberdade/adolescência. Com o propósito de evitar no processo de hospitalização uma eventual interferência negativa no desenvolvimento cognitivo dos pacientes.

O lúdico oportuniza a criança a aprender de uma maneira prazerosa, o que contribui no desenvolvimento cognitivo da criança e com o entendimento da realidade. Quando essa ação é direcionada e mediada por um adulto (profissional da saúde), acaba por beneficiar ambos, pois os pacientes aceitam com facilidade o tratamento oferecido, contribuindo com o exercício dos profissionais. 
Nesse contexto, os funcionários percebem as contribuições do lúdico na recuperação das crianças e consideram o brincar não apenas uma prática sem objetivos, e sim como um apoio no processo de humanizar das ações no hospital.

Por fim, percebemos que o trabalho conjunto entre os profissionais da saúde, brinquedistas, crianças e adolescentes hospitalizados e família proporcionam a possibilidade de troca de experiências, aprendizagem contínua, desenvolvimento de mecanismos e métodos com maior eficácia para a melhora do ambiente hospitalar, pois ambos caminham juntos.

PALAVRAS-CHAVE: Humanização e afetividade. pacientes. psicognitivo. relação PSpaciente infantojuvenil.

\section{AGRADECIMENTOS}

À Pró- Reitoria de Pesquisa e Extensão da Universidade Federal de Campina Grande que coordena e executa políticas de extensão universitária. Agradeço também a Alana Kelly M. M. N. de Lima, coordenadora do projeto de extensão Integração Ensino-Serviço na Humanização do cuidado às Crianças e Adolescentes Hospitalizados, a qual me deu a oportunidade de participar do projeto citado, como bolsista, e, assim, aprimorar o meu saber acerca da hospitalização infanto-juvenil.

\section{REFERÊNCIAS}

BARBOSA OLIVEIRA, L. D. B.; GABARRA, L. M.; MARCON, C.; JULIA LAITANO COELHO SILVA, J. L. C.; MACCHIAVERNI, J. A brinquedoteca hospitalar como fator de promoção no desenvolvimento infantil: relato de experiência. Rev. bras. crescimento desenvolv. hum. v.19 n.2 São Paulo, 2009.

BORIN, J. Jogos e resolução de problemas: uma estratégia para as aulas de matemática. São Paulo: IME-USP, 1996.

CUNHA, N. H. S. O significado da Brinquedoteca Hospitalar. In Brinquetodeca Hospitalar, isto é humanização. Rio de Janeiro: Wak editora, 2013.

FERREIRA, A. B. H. Novo dicionário da língua portuguesa. Nova Fronteira, 1999.

MAHONEY, A. A.; ALMEIDA, L. R. Afetividade e processo ensino-aprendizagem: contribuições de Henri Wallon. Psic. da Ed., São Paulo, 2005.

MANCINI, M. C.; SAMPAIO, R. F. Quando o objeto de estudo é a literatura: estudos de revisão. Rev. Bras. Fisioter. vol.10. n. 4. São Carlos, 2006. 


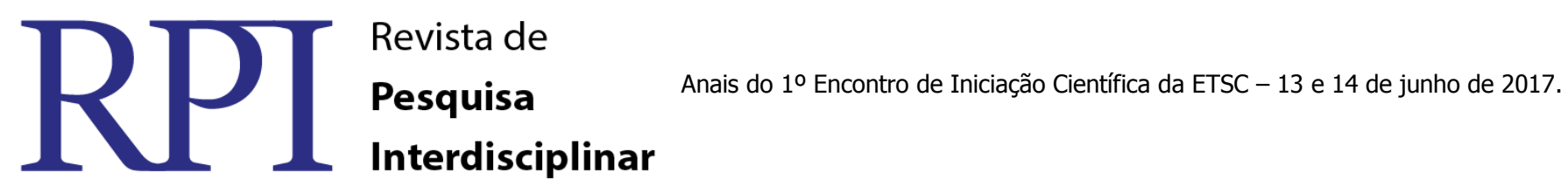

MIRANDA, S. No Fascínio do jogo, a alegria de aprender. Linhas Críticas, v. 8, n.4, 2012.

MOTTA, A. B.; ENUMO, S. R. F. Brincar no Hospital: Estratégia de enfrentamento da Hospitalização Infantil. Psicologia em Estudo. Maringá, v.9. n1, p19-29, 2004.

OLIVEIRA, V. B. de. O lúdico na realidade hospitalar. In Brinquedoteca Hospitalar. Isto é humanização. Rio de Janeiro: Wak Editora, 2007.

SARMENTO, N. E. G. Afetividade e aprendizagem. Monografia. Porto Alegre, 2014.

VYGOTSKY, L. S. O desenvolvimento psicológico na infância. São Paulo: Martins Fontes, 1999

WALLON, H. Psicologia e educação da infância. Lisboa: Estampa, 1975. 
PRIMEIROS SOCORROS: PROCESSO EDUCATIVO PARA DOCENTES, DISCENTES E TÉCNICOS ADMINISTRATIVOS DE UMA INSTITUIÇÃO DE ENSINO

LINHA DE PESQUISA: Assistência de Enfermagem (exposição em banner)

EDSON DA SILVA OLIVEIRA, estudante, Escola Técnica de Saúde de Cajazeiras. JOSEPH GABRIEL C. DO NASCIMENTO, estudante, Escola Técnica de Saúde de

Cajazeiras.

MARILENA MARIA DE SOUZA, doutora, professora da Escola Técnica de Saúde de Cajazeiras.

LAURITA DA SILVA CARTAXO, doutoranda, professora da Escola Técnica de Saúde de

Cajazeiras.

\section{INTRODUÇÃO}

No espaço escolar os acidentes constituem preocupação constante, sendo fundamental que os professores e aqueles que cuidam das crianças/adolescentes saibam como agir frente a esses eventos, procurando assim, evitar as complicações decorrentes de procedimentos inadequados, impedindo diversas situações e desgastes entre alunos e todo corpo profissional da escola. O trabalho teve como objetivo, verificar o conhecimento dos docentes, discentes e técnicos administrativos sobre primeiros socorros antes e após processo educativo. Além de possuir como objetivos específicos, sensibilizar alunos, professores e profissionais quanto à importância dos primeiros socorros; mostrar o funcionamento dos serviços especializados no atendimento de urgência/emergência; instruir quanto à ressuscitação cardiopulmonar, queimaduras, hemorragias, ferimento leves e superficiais, ferimentos extensos e profundos, fraturas e convulsões. Nesse sentido, este projeto viabilizou a produção de conhecimentos teoria-prática, além de possibilitar aos alunos exercitarem a cidadania e a reflexão crítica sobre a temática. Com essa iniciativa e difusão para aplicabilidade dos primeiros socorros, percebe-se então a importância da promoção de ações educativas como o intuito de discutir os potenciais de riscos e os mais frequentes no cotidiano escolar, bem como estimular a autonomia dos profissionais acerca dos primeiros cuidados em situações de urgência/emergência.

\section{MATERIAL E MÉTODOS}


Trata-se de um estudo de caráter exploratório e descritivo, quantitativo, realizado na ETSC/CFP/UFCG, a população do estudo foi composta por docentes, discentes e técnicos administrativos, da ETSC, escolhidos de forma aleatória. Amostra foi formada por docentes, discentes e técnicos administrativos, da ETSC totalizando 62 sujeitos, sendo 10 docentes, 50 discentes e 02 técnicos administrativos que concordaram em participar do estudo, tiveram aceitação dos responsáveis e preencherem os pré-requisitos de inclusão e exclusão.

O instrumento utilizado foi um roteiro estruturado, chamado pré-teste e pós-teste contendo questões objetivas contendo 54 questões inerentes aos conteúdos sobre primeiros socorros. Esta pesquisa foi desenvolvida em três etapas. Na primeira etapa, foi aplicado um roteiro estruturado denominado pré-teste, que avaliou os conhecimentos prévios dos participantes acerca de primeiros socorros. Foram selecionados para a primeira etapa do pré-teste 10 docentes, 50 discentes e 02 técnicos administrativos. Na segunda etapa, foi realizada nos dias 20 de abril, 16 e 23 de maio de 2016, onde foram ministradas as ações educativas, abordando os temas em pauta. Na terceira etapa foi aplicado o roteiro denominado pós-teste com a finalidade de averiguar a eficácia da educação sobre primeiros socorros

\section{Resultados e Discussão}

A partir dos itens investigados, a caracterização do perfil dos participantes do estudo, demonstram os aspectos sociodemográficos dos sujeitos envolvidos na pesquisa, sob critérios biológicos e sociais, bem como econômico e intelectual.

Após análise, os resultados mostraram que a prevalência de idade foi dos participantes entre 15 e 16 anos totalizando 37,5\% do total geral, no que diz respeito ao sexo, prevaleceu o sexo feminino, perfazendo $80 \%$ do apanhado geral. Quanto a cor, $52,5 \%$ se alto declararam pardos enquanto os indicadores de renda mostram a predominância do salário mínimo, totalizando assim, 52,5\% dos participantes da pesquisa.

Tabela 1- Conhecimento sobre avaliação primária e parada cardiorrespiratória (PCR), antes e após a ação educativa, em cada grupo - Cajazeiras - PB, 2016.

\begin{tabular}{c|c|c|c|c}
\hline \multicolumn{5}{c}{ Primeiros Socorros } \\
\hline Antes da & Percentual & Após a Ação & Percentual & Acréscimo \\
Ação & $(\%)$ & Educativa & $(\%)$ & Total \\
\hline
\end{tabular}




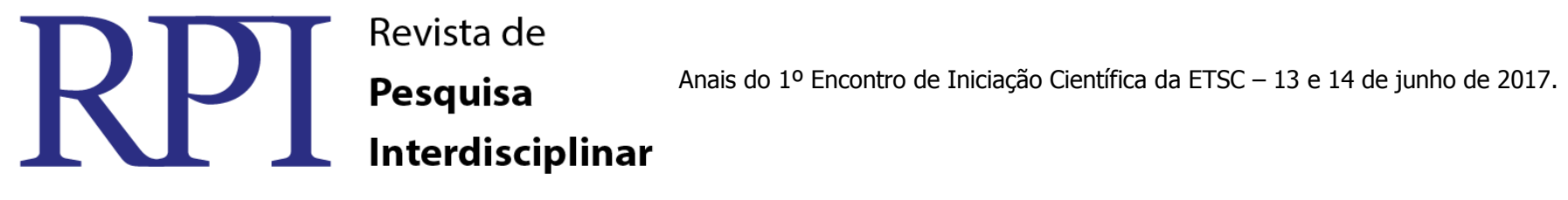

\begin{tabular}{|c|c|c|c|c|}
\hline Educativa & & & & \\
\hline $\begin{array}{c}\text { Grupo A }\left(\mathrm{n}^{\circ}\right. \\
40)\end{array}$ & $77,9 \%$ & $\begin{array}{c}\text { Grupo A }\left(\mathrm{n}^{\circ}\right. \\
40)\end{array}$ & $84,5 \%$ & $6,6 \%$ \\
\hline $\begin{array}{c}\text { Grupo B }\left(\mathrm{n}^{\circ}\right. \\
9)\end{array}$ & $68,5 \%$ & $\begin{array}{c}\text { Grupo B }\left(\mathrm{n}^{\circ}\right. \\
9)\end{array}$ & $77,7 \%$ & $9,2 \%$ \\
\hline
\end{tabular}

Fonte: Dados da pesquisa (2016).

No que diz respeito ao Suporte Básico de Vida, os números mostram que a diferença do percentual de acerto das proposições nos grupos A e B não apresentaram diferenças significativas e não causaram surpresa, pois este resultado mostra que a maioria dos participantes tinha conhecimento acerca da avaliação primária e das compressões torácicas. Porém, destacamos na tabela um acréscimo de 9,2\% no conhecimento dos participantes do grupo B após a ação educativa, e de 6,6\% no grupo A.

Tabela 2- Conhecimento sobre obstrução de vias aéreas por corpo estranho (OVACE), antes e após a ação educativa, em cada grupo - Cajazeiras - PB, 2016.

\begin{tabular}{|c|c|c|c|c|}
\hline \multicolumn{5}{|c|}{ Primeiros Socorros } \\
\hline $\begin{array}{l}\text { Antes da } \\
\text { Ação } \\
\text { Educativa }\end{array}$ & $\begin{array}{c}\text { Percentual } \\
\text { (\%) }\end{array}$ & $\begin{array}{l}\text { Após a Ação } \\
\text { Educativa }\end{array}$ & $\begin{array}{c}\text { Percentual } \\
(\%)\end{array}$ & $\begin{array}{c}\text { Acréscimo } \\
\text { Total }\end{array}$ \\
\hline $\begin{array}{c}\text { Grupo A }\left(\mathrm{n}^{\circ}\right. \\
40)\end{array}$ & $59,2 \%$ & $\begin{array}{c}\text { Grupo A }\left(\mathrm{n}^{\circ}\right. \\
40)\end{array}$ & $86,2 \%$ & $27 \%$ \\
\hline $\begin{array}{c}\text { Grupo B }\left(\mathrm{n}^{\circ}\right. \\
9)\end{array}$ & $61,1 \%$ & $\begin{array}{c}\text { Grupo B }\left(\mathrm{n}^{\circ}\right. \\
9)\end{array}$ & $77,7 \%$ & $16,6 \%$ \\
\hline
\end{tabular}

Fonte: Dados da pesquisa (2016).

No que tange os conhecimentos sobre obstrução das vias aéreas por copos estranhos (OVACE), observamos na tabela os percentuais apresentados antes e após a ação educativa, destacamos neste o aumento significativo do conhecimento dos participantes do grupo A, tendo este um acréscimo total de $27 \%$ após a ação educativa.

Tabela 3- Conhecimento sobre desmaio (síncope) e hipoglicemia, antes e após a ação educativa, em cada grupo - Cajazeiras - PB, 2016.

\begin{tabular}{c|c|c|c|c}
\hline \multicolumn{5}{c}{ Primeiros Socorros } \\
\hline Antes da & Percentual & Após a Ação & Percentual & Acréscimo \\
Ação & $(\%)$ & Educativa & $(\%)$ & Total \\
Educativa & & & & \\
\hline Grupo A (no & $84 \%$ & Grupo A $\left(\mathrm{n}^{\circ}\right.$ & $95 \%$ & $11 \%$ \\
\hline
\end{tabular}




\section{$\mathrm{RPP}$}

\begin{tabular}{c|c|c|c|c}
\hline 40$)$ & & $40)$ & & \\
\hline Grupo B (n & $88,8 \%$ & Grupo B $\left(\mathrm{n}^{\mathbf{o}}\right.$ & $100 \%$ & $11,2 \%$ \\
$9)$ & & $9)$ & & \\
\hline
\end{tabular}

Fonte: Dados da pesquisa (2016).

Na tabela 3, no que diz respeito à síncope e Hipoglicemia, os resultados mostram que no Grupo A, após a ação educativa o número de acertos foi significativo, tendo um acréscimo total de $11 \%$. Quanto ao grupo B destacamos o percentual após ação educativa, que após os conhecimentos repassados, todos os participantes acertaram todas as questões, fechando assim o pós teste com $100 \%$ de acertos.

Tabela 4- Conhecimento sobre queimaduras, antes e após a ação educativa, em cada grupo - Cajazeiras - PB, 2016.

\begin{tabular}{|c|c|c|c|c|}
\hline \multicolumn{5}{|c|}{ Primeiros Socorros } \\
\hline $\begin{array}{c}\text { Antes da } \\
\text { Ação } \\
\text { Educativa }\end{array}$ & $\begin{array}{c}\text { Percentual } \\
(\%)\end{array}$ & $\begin{array}{c}\text { Após a Ação } \\
\text { Educativa }\end{array}$ & $\begin{array}{c}\text { Percentual } \\
(\%)\end{array}$ & $\begin{array}{c}\text { Acréscimo } \\
\text { Total }\end{array}$ \\
\hline $\begin{array}{c}\text { Grupo A }\left(\mathrm{n}^{\circ}\right. \\
40)\end{array}$ & $90,7 \%$ & $\begin{array}{c}\text { Grupo A }\left(\mathrm{n}^{\circ}\right. \\
40)\end{array}$ & $95,3 \%$ & $4,6 \%$ \\
\hline $\begin{array}{c}\text { Grupo B }\left(\mathrm{n}^{\circ}\right. \\
9)\end{array}$ & $95,2 \%$ & $\begin{array}{c}\text { Grupo B }\left(\mathrm{n}^{\circ}\right. \\
9)\end{array}$ & $96,8 \%$ & $1,6 \%$ \\
\hline
\end{tabular}

Fonte: Dados da pesquisa (2016).

Para as Queimaduras, destacamos, na tabela 4, que as diferenças no número de acertos no grupo A onde houve alteração no número de acertos após a ação educativa, adquirindo um aumento em seu percentual geral de $4,5 \%$. No que se refere ao grupo B, os participantes já detinham bastante conhecimento acerca do tema, para tanto, houve ainda um acréscimo total de 1,6\% após a ação educativa.

Tabela 5- Conhecimento sobre choque elétrico, antes e após a ação educativa, em cada grupo - Cajazeiras - PB, 2016.

\begin{tabular}{|c|c|c|c|c|}
\hline \multicolumn{5}{|c|}{ Primeiros Socorros } \\
\hline $\begin{array}{l}\text { Antes da } \\
\text { Ação } \\
\text { Educativa }\end{array}$ & $\begin{array}{l}\text { Percentual } \\
\qquad \%)\end{array}$ & $\begin{array}{l}\text { Após a Ação } \\
\text { Educativa }\end{array}$ & $\begin{array}{l}\text { Percentual } \\
\qquad \%)\end{array}$ & $\begin{array}{c}\text { Acréscimo } \\
\text { Total }\end{array}$ \\
\hline $\begin{array}{c}\text { Grupo A }\left(\mathrm{n}^{\circ}\right. \\
40)\end{array}$ & $70,3 \%$ & $\begin{array}{c}\text { Grupo A }\left(\mathrm{n}^{\circ}\right. \\
40)\end{array}$ & $89,2 \%$ & $18,9 \%$ \\
\hline Grupo B $\left(n^{\circ}\right.$ & $79,3 \%$ & Grupo B ( $\mathrm{n}^{\circ}$ & $90,4 \%$ & $11,1 \%$ \\
\hline
\end{tabular}


Fonte: Dados da pesquisa (2016)

No que diz respeito a choque elétrico, na tabela 5, os resultados mostram que a diferença nos números de acertos dos grupos A e B antes e após a ação educativa. No Grupo A, tiveram diferença significativa de $18,9 \%$ no apanhado geral. O Grupo B, teve com escore significativo de $11,1 \%$ após a Ação.

Tabela 6- Conhecimento sobre choque anafilático, antes e após a ação educativa, em cada grupo - Cajazeiras - PB, 2016.

\begin{tabular}{|c|c|c|c|c|}
\hline \multicolumn{5}{|c|}{ Primeiros Socorros } \\
\hline $\begin{array}{l}\text { Antes da } \\
\text { Ação } \\
\text { Educativa }\end{array}$ & $\begin{array}{c}\text { Percentual } \\
(\%)\end{array}$ & $\begin{array}{c}\text { Após a Ação } \\
\text { Educativa }\end{array}$ & $\begin{array}{c}\text { Percentual } \\
(\%)\end{array}$ & $\begin{array}{c}\text { Acréscimo } \\
\text { Total }\end{array}$ \\
\hline $\begin{array}{c}\text { Grupo A }\left(\mathrm{n}^{\circ}\right. \\
40)\end{array}$ & $66,6 \%$ & $\begin{array}{c}\text { Grupo A }\left(\mathrm{n}^{\circ}\right. \\
40)\end{array}$ & $69,1 \%$ & $2,5 \%$ \\
\hline $\begin{array}{c}\text { Grupo B }\left(\mathrm{n}^{\circ}\right. \\
9)\end{array}$ & $77,7 \%$ & $\begin{array}{c}\text { Grupo B }\left(\mathrm{n}^{\circ}\right. \\
9)\end{array}$ & $81,4 \%$ & $3,7 \%$ \\
\hline
\end{tabular}

No choque anafilático, os resultados mostram que a diferença do número de acertos dos grupos A e B não apresentaram diferenças significativas, pois este resultado mostra que a maioria dos participantes já tinha conhecimento acerca do choque anafilático. Destacamos porém, um acréscimo total de apenas 2,5\% no apanhado geral do grupo A e de 3,7\% do Grupo B após a ação educativa.

Tabela 7- Conhecimento sobre cortes e perfurações, antes e após a ação educativa, em cada grupo - Cajazeiras - PB, 2016.

\begin{tabular}{|c|c|c|c|c|}
\hline \multicolumn{5}{|c|}{ Primeiros Socorros } \\
\hline $\begin{array}{l}\text { Antes da } \\
\text { Ação } \\
\text { Educativa }\end{array}$ & $\begin{array}{c}\text { Percentual } \\
\text { (\%) }\end{array}$ & $\begin{array}{c}\text { Após a Ação } \\
\text { Educativa }\end{array}$ & $\begin{array}{c}\text { Percentual } \\
\text { (\%) }\end{array}$ & $\begin{array}{c}\text { Acréscimo } \\
\text { Total }\end{array}$ \\
\hline $\begin{array}{c}\text { Grupo A }\left(\mathrm{n}^{\circ}\right. \\
40)\end{array}$ & $76 \%$ & $\begin{array}{c}\text { Grupo A }\left(\mathrm{n}^{\circ}\right. \\
40)\end{array}$ & $94 \%$ & $18 \%$ \\
\hline $\begin{array}{c}\text { Grupo B }\left(\mathrm{n}^{\circ}\right. \\
9)\end{array}$ & $84,4 \%$ & $\begin{array}{c}\text { Grupo B }\left(\mathrm{n}^{\circ}\right. \\
9)\end{array}$ & $88,8 \%$ & $4,4 \%$ \\
\hline
\end{tabular}

Fonte: Dados da pesquisa (2016).

No que tange as lesões de pele, destacamos na tabela 7 os conhecimentos dos grupos A e B antes e após a ação educativa. Avaliando estes dados, percebemos um aumento bastante significativo nos conhecimentos dos participantes do grupo A, onde 


\section{$\mathrm{RPP}$}

ates da ação o percentual era de $76 \%$, o que nos indica que os participantes já tinham conhecimento acerca do tema, após a ação, esse número subiu para 94\%, perfazendo um acréscimo total de $18 \%$ do conhecimento geral adquirido. No que diz respeito ao grupo B, esse percentual teve um aumento de $4,4 \%$.

Tabela 8- Conhecimento sobre crise convulsiva, antes e após a ação educativa, em cada grupo - Cajazeiras - PB, 2016.

\begin{tabular}{|c|c|c|c|c|}
\hline \multicolumn{5}{|c|}{ Primeiros Socorros } \\
\hline $\begin{array}{c}\text { Antes da } \\
\text { Ação } \\
\text { Educativa }\end{array}$ & $\begin{array}{c}\text { Percentual } \\
(\%)\end{array}$ & $\begin{array}{c}\text { Após a Ação } \\
\text { Educativa }\end{array}$ & $\begin{array}{c}\text { Percentual } \\
(\%)\end{array}$ & $\begin{array}{c}\text { Acréscimo } \\
\text { Total }\end{array}$ \\
\hline $\begin{array}{c}\text { Grupo A }\left(\mathrm{n}^{\circ}\right. \\
40)\end{array}$ & $64,3 \%$ & $\begin{array}{c}\text { Grupo A }\left(\mathrm{n}^{\circ}\right. \\
40)\end{array}$ & $91,8 \%$ & $27,5 \%$ \\
\hline $\begin{array}{c}\text { Grupo B }\left(\mathrm{n}^{\circ}\right. \\
9)\end{array}$ & $75 \%$ & $\begin{array}{c}\text { Grupo B }\left(\mathrm{n}^{\circ}\right. \\
9)\end{array}$ & $86,1 \%$ & $11,1 \%$ \\
\hline
\end{tabular}

Fonte: Dados da pesquisa (2016).

A temática crise convulsiva, na tabela 8 os resultados mostram que houve diferença no número de acertos após ação educativa nos dois grupos, tanto o A quanto o $\mathrm{B}$, sendo que encontramos nesta tabela o maior acréscimo percentual de toda a pesquisa, onde no grupo A, os participantes após terem recebido todo o treinamento e respondido as questões contidas no pós teste, apresentaram um acréscimo de 27,5\% do total geral. Quanto ao grupo B, esse aumento perfaz 11,1\% do aparato total.

Tabela 9- Conhecimento sobre fraturas, entorses e luxações, antes e após a ação educativa, em cada grupo - Cajazeiras - PB, 2016.

\begin{tabular}{|c|c|c|c|c|}
\hline \multicolumn{5}{|c|}{ Primeiros Socorros } \\
\hline $\begin{array}{c}\text { Antes da Ação } \\
\text { Educativa }\end{array}$ & Percentual (\%) & $\begin{array}{l}\text { Após a Ação } \\
\text { Educativa }\end{array}$ & $\begin{array}{c}\text { Percentual } \\
\text { (\%) }\end{array}$ & $\begin{array}{c}\text { Acréscimo } \\
\text { Total }\end{array}$ \\
\hline Grupo A $\left(n^{\circ} 40\right)$ & $82,5 \%$ & $\begin{array}{c}\text { Grupo A }\left(\mathrm{n}^{\circ}\right. \\
40)\end{array}$ & $91,7 \%$ & $9,7 \%$ \\
\hline Grupo B $\left(n^{\circ} 9\right)$ & $80,9 \%$ & Grupo B ( $\left.\mathrm{n}^{\circ} 9\right)$ & $92,1 \%$ & $11,2 \%$ \\
\hline
\end{tabular}

Fonte: Dados da pesquisa (2016).

Quanto aos conhecimentos sobre fraturas, entorses e luxações os resultados mostram que a diferença no número de acertos dos grupos $\mathrm{A}$ e $\mathrm{B}$ antes e após a ação educativa, portanto os participantes da pesquisa já detinham conhecimento sobre as práticas de primeiros socorros. Porém o reforço desse conhecimento ficou evidente no percentual geral da tabela, onde a mesma nos mostra que para o grupo A houve um 


\section{$\mathrm{RPP}$}

reforço do conhecimento em 9,7\% do percentual geral. Enquanto que o grupo B, apresenta um acréscimo maior, com um aumento de 11,2\% do total geral.

Tabela 10- Conhecimento sobre todos os temas abordados, antes e após a ação educativa, em cada grupo e de todos os participantes no geral - Cajazeiras - PB, 2016.

\section{Primeiros Socorros}

\begin{tabular}{|c|c|c|c|c|}
\hline $\begin{array}{c}\text { Antes da Ação } \\
\text { Educativa }\end{array}$ & Percentual (\%) & $\begin{array}{l}\text { Após a Ação } \\
\text { Educativa }\end{array}$ & $\begin{array}{c}\text { Percentual } \\
\text { (\%) }\end{array}$ & $\begin{array}{c}\text { Acréscimo } \\
\text { Total }\end{array}$ \\
\hline Grupo A (no 40) & $76,2 \%$ & $\begin{array}{c}\text { Grupo A }\left(\mathrm{n}^{\circ}\right. \\
40)\end{array}$ & $89,3 \%$ & 13,10 \\
\hline Grupo B (no 9) & $76,3 \%$ & Grupo B (n $\left.{ }^{\circ} 9\right)$ & $87,7 \%$ & $11,4 \%$ \\
\hline $\begin{array}{c}\text { Grupo A e B }\left(\mathrm{n}^{\circ}\right. \\
49)\end{array}$ & $76,2 \%$ & $\begin{array}{c}\text { Grupo A e B } \\
\left(n^{\circ} 49\right)\end{array}$ & $89,1 \%$ & $12,9 \%$ \\
\hline
\end{tabular}

Fonte: Dados da pesquisa (2016).

Na tabela 10 encontramos os dados gerais de toda a pesquisa, no grupo A houve um acréscimo total geral de todas as temáticas de $13,1 \%$, já no grupo B esse acréscimo foi de 11,4\%. Após analisar os dados dos grupos separados, encontramos de forma conjunta, um acréscimo de 12,9\% no conhecimento de todos os participantes após o processo educativo, nos indicando um ótimo resultado e nos mostrando que as ações educativas são ótimas medidas para transmissão de conhecimento.

\section{CONCLUSÕES}

Constatou-se nesse trabalho que os participantes já detinham conhecimento acerca dos temas abordados, porém, as atividades deste possibilitaram uma expansão de conhecimento acerca do ensino das medidas de primeiros socorros, fazendo com que docentes discentes e técnicos administrativos da instituição se tornassem importantes multiplicadores destes conhecimentos, frente as mais diversas situações que exijam um atendimento imediato.

Durante as ações educativas, foi notório o entusiasmo dos participantes, visto que a exposição de conhecimento adotada pelos bolsistas foram as mais sucintas possíveis, de uma forma que qualquer leigo pudesse entender. A presença de manequins vivos, ferimentos artificiais, uma simulação de acidente com apoio do SAMU e Corpo de Bombeiros, revelou-se êxito na comunicação tornou o processo educativo dinâmico e mais interessante, atingimos os objetivos entre articuladores e participantes. 
Desse modo, espera-se que este trabalho contribua para a produção e fonte de mais pesquisas, na prática e no atendimento pré-hospitalar, atuando no socorro imediato a pessoas em situações adversas e/ou acidentes, a propagação dos temas repassados ao público alvo, sejam ponte que ligação entre conhecimento científico ao conhecimento popular.

\section{AGRADECIMENTOS}

Ao Programa de Bolsas de Iniciação Científica Ensino Médio (PIBIC-EM);

A Universidade Federal de Campina Grande - UFCG;

A direção e a todo corpo docente, discente e demais funcionários da Escola Técnica de Saúde de Cajazeiras - ETSC;

Ao Serviço de Atendimento Móvel de Urgência - SAMU;

Ao $5^{\circ}$ Batalhão de Corpo de Bombeiros.

\section{REFERÊNCIAS}

. Ministério da Saúde. Manual de Primeiros Socorros. Rio de Janeiro. Fundação Oswaldo Cruz, 2003.

. Ministério da Saúde (BR). Conselho Nacional de Saúde. Diretrizes e Normas

Regulamentadoras da Pesquisa Envolvendo Seres Humanos: Resolução 466/12. Brasília (DF). Disponível em <http://:www.ufrgs.br>. Acesso em 20 mai. 2012.

Corpo de Bombeiros do Paraná. Manual do Atendimento Pré-Hospitalar - SIATE /CBPR (2011).

JÚNIOR E. M. L., NOVAES F. N., Piccolo N. S., SERRA M. C. V. F. Tratado de queimaduras no paciente agudo. São Paulo: Atheneu; 2008.

LEITÃO, F.B.P. et al. Prevenção e atendimento inicial do trauma e doenças cardiovasculares: um programa de ensino. Revista Brasileira de Educação Médica, v. 32, n. 4, p. 419-423, 2008.

PERGOLE, A.M.; ARAUJO, I.E.M. O leigo e o Suporte básico de Vida. Rev.Escola de Enfermagem da USP. V.43, n.2, p. 335-4, 2009.

ROSSI L, A.; FERREIRA, E.; COSTA, E. C. F. B.; BERGAMASCO, E. C.; CAMARGO, C. Prevenção de queimaduras: percepção de pacientes e de seus familiares. Ver. Latino-Am Enfermagem. 2003. 


\section{CASOS NOVOS DE TUBERCULOSE NO BRASIL}

ÁREA TEMÁTICA: Enfermagem na Saúde Coletiva.

FORMATO DE APRESENTAÇÃO DO RESUMO: Exposição Oral.

LANA LÍVIA PEIXOTO LINARD, Acadêmica do Curso de Enfermagem, Universidade Federal de Campina grande.

DANIELE PEREIRA SOARES, Acadêmica do Curso de Enfermagem, Universidade Federal de Campina grande.

GUSTAVO COÊLHO DE OLIVEIRA, Acadêmico do Curso de Enfermagem, Universidade Federal de Campina grande.

THALINE INGRID MARQUES MENEZES PEREIRA, Acadêmica do Curso de Enfermagem, Universidade Federal de Campina grande.

GERLANE CRISTINNE BERTINO VÉRAS, Mestranda em Enfermagem pela Universidade Regional do Cariri, Docente da Universidade Federal de Campina grande.

\section{INTRODUÇÃO}

A tuberculose é uma doença infectocontagiosa causada pelo Mycobacterium tuberculosis, transmitida em sua maioria pelas vias aéreas, constituindo um grande problema de saúde pública nos países em desenvolvimento. De caráter curável e prevenível, a tuberculose é uma doença ainda negligenciada, causando preocupação às autoridades sanitárias (FREITAS et al., 2016).

Em registro de casos novos de tuberculose, 9,27 milhões de casos novos de tuberculose são registrados no mundo com média de 80 mil casos por ano (BARBOSA, 2014). O Brasil ocupa o $17^{\circ}$ lugar entre 22 países responsáveis por $80 \%$ dos casos de tuberculose no mundo, com prevalência estimada em 58 casos por 100.000 habitantes, sendo sua proliferação associada aos fatores socioeconômicos e às condições de vida da população (BRASIL, 2015).

Constata-se que a tuberculose mesmo sendo considerada uma doença de fácil diagnóstico, que possui tratamento acessível a toda população e cura a maioria dos casos onde a terapêutica é corretamente realizada, ainda é vista com estigma, dificultando assim o diagnóstico e a cura.

O processo patológico da tuberculose reflete significativamente na qualidade de vida das pessoas acometidas por esta doença, uma vez que o aumento da prevalência da 
tuberculose está diretamente relacionado ao saneamento básico, deficiência na alimentação, moradia, desemprego e subdesemprego (FREITAS et al., 2016).

No contexto da atenção a tuberculose, os serviços de saúde exercem papel de suma importância na detecção, avaliação e acompanhamento às pessoas acometidas pela tuberculose (ANTUNES et al., 2016). Muito dos recursos existentes na atenção primária a saúde, ainda se apresentam insuficientes na abordagem dos casos de tuberculose, visto a necessidade da detecção precoce para evitar a disseminação do bacilo de Koch (BRASIL, 2011).

\section{OBJETIVO DO TRABALHO}

Investigar o perfil dos casos novos de tuberculose no Brasil.

\section{MATERIAIS E MÉTODOS}

Trata-se de um estudo de base secundária, transversal, com abordagem quantitativa, realizado no período de setembro de 2016 a partir de dados coletados por meio do Sistema Nacional de Agravos de Notificação (SINAN) disponíveis de forma online pelo Departamento de Informática do Sistema Único de Saúde (DATASUS). A amostra constituiu-se das notificações de casos novos de tuberculose registrados do ano de 2012 ao ano de 2015 no Brasil.

Os dados foram analisados descritivamente em frequência absoluta e relativa, sendo posteriormente discutidos a luz da literatura pertinente.

\section{RESULTADOS E DISCUSSÃO}

Observou-se a ocorrência de 427.432 casos novos de tuberculose no Brasil, destes $67,9 \%$ (290.385) eram do sexo masculino; 77,8\% (332.582) com faixa etária entre 20 a 59 anos; 45,3\% (193.682) aconteceram na Região Sudeste; 29,4\% (125.614) eram analfabetos; $83,7 \%$ (357.937) com a forma clínica pulmonar; 63,4\% (270.817) receberam alta por cura.

O sexo masculino ainda é o mais afetado pela tuberculose, fato decorrente pela falta de cuidado adequado de sua saúde, além de estar mais exposto aos fatores de risco para a doença quando comparado ao sexo feminino (BARBOSA, 2014; FREITAS et al., 2016). Em relação 
às informações encontradas sobre a idade, os valores registrados seguem o padrão nacional, demonstrando um predomínio na fase mais ativa da vida (FREITAS et al., 2016).

Quanto à região de maior prevalência dos casos, deve-se levar em conta a densidade demográfica, que é a maior do país (IBANES; JUNIOR' N.C, 2014). A prevalência em analfabetos confirma que a baixa escolaridade é um fator de risco considerável para a ocorrência desta doença (BARBOSA, 2014). A forma clínica que mais ocorreu foi a pulmonar, por ser o órgão de entrada do bacilo e pela presença do oxigênio em maior quantidade (CAMPOS, 2006). A alta por cura ainda encontra-se abaixo do preconizado pelo Ministério da Saúde que é de 85\% (BRASIL, 2011).

\section{CONCLUSÃO}

Constatou-se um elevado número de casos novos de tuberculose em pessoas do sexo masculino, com idade entre 20 e 59 anos, analfabetos e com predominância na Região Sudeste, despontando a necessidade de se trabalhar de forma mais ativa e eficaz na atenção primária a saúde, visto a sua alta prevalência e sua associação às condições sociais, caracterizando-se ainda como grave problema de saúde pública.

Dessa forma, torna-se necessário que o profissional de saúde conheça o perfil dos pacientes para que possa traçar metas que aumente a prevenção, o diagnóstico precoce e o acompanhamento adequado dos pacientes. $\mathrm{O}$ enfermeiro exerce um papel fundamental neste processo, inclusive melhorando o vínculo entre o paciente, seus familiares e a equipe de saúde.

PALAVRAS-CHAVE: Atenção Primária à saúde. Perfil de saúde. Tuberculose.

\section{REFERÊNCIAS}

ALMEIDA, A.A. et al. Perfil clínico-epidemiológico de casos de tuberculose. Revista de Enfermagem UFPE, p. 1007-1017, 2015. Disponível em: <www.revista.ufpe.br/revistaenfermagem/index.php/revista/article/download/.../13549>Acess o em: 14 de novembro de 2016.

ANDADRE et al. Contribuição dos profissionais da atenção primária à saúde para o autocuidado apoiado aos portadores de tuberculose. J. res.: fundam. care. Online. jul./set. vol.8, n.3, p. 4857-4863, $2016 . \quad$ Disponivel em: <http://www.seer.unirio.br/index.php/cuidadofundamental/article/view/4466/pdf>. Acesso em: 11 de novembro de 2016. 


\section{$\mathrm{RPP}$}

ANTUNES et al. The user with respiratory symptoms of tuberculosis in the primary care: assessment of actions according to national recommendations. Rev Rene.May-June; vol.17, n.3, p. 409-15, 2016. Disponivel em: <http://www.revistarene.ufc.br/revista/index.php/revista/article/view/2280/pdf>. Acesso em: 11 de novembro de 2016.

BARBOSA, D.R.M. et al. Características epidemiológicas, clínicas e espaciais de casos notificados de tuberculose em área hiperendêmica do nordeste do Brasil. Revista de Epidemiologia e Controle de Infecção. 2014, vol. 4, n. 3, p. 186-191. Disponivel em: <https://online.unisc.br/seer/index.php/epidemiologia/article/view/4205>. Acesso em: $14 \mathrm{de}$ $\underline{\text { novembro de } 2016 .}$

BRASIL. Ministério da Saúde. Boletim Epidemiológico da tuberculose. Brasília, Ministério da Saúde: 2015.

Ministério da Saúde. Tuberculose na Atenção Primária à Saúde / Ministério da Saúde, Secretaria de Atenção à Saúde, Departamento de Atenção Básica. - 2. ed. - Brasília : Ministério da Saúde, 2011.

CAMPOS, Hisbello S. Etiopatogenia da tuberculose e formas clínicas. Pulmão RJ vol.15, n.1, p.29-35, 2006. Disponível em: $<$ http://sopterj.com.br/profissionais/ educacao continuada/curso tuberculose 2.pdf $>$. Acesso em: 14 de novembro de 2016.

FREITAS, W.M.T.M. et al. Perfil clínico-epidemiológico de pacientes portadores de tuberculose atendidos em uma unidade municipal de saúde de Belém, Estado do Pará, Brasil. Rev Pan-Amaz Saude,vol.7, n.2, p.45-50, 2016. Disponível em: <http://scielo.iec.pa.gov.br/scielo.php?script=sci_arttext\&pid=S2176-62232016000200045> . Acesso em: 11 de novembro de 2016.

IBANES, A.S.; JUNIOR' N.C. Análise do comportamento epidemiológico da tuberculose na região metropolitana de São Paulo, SP, frente à estratégia do tratamento diretamente observado, no período de 2001 a 2008. BEPA, Bol. epidemiol. Paul, São Paulo, vol.11 n.122, 2014.

Disponível

em:

$<$ http://periodicos.ses.sp.bvs.br/scielo.php?script=sci arttext\&pid=S180642722014000200001\&lng=pt\&nrm=iso $>$. Acesso em: 14 de novembro de 2016.

OBLITAS, F.Y.M. et al. Nursing's role in tuberculosis control: a discussion from the perspective of equity. Rev. Latino-Am. Enfermagem, vol.18, n.1, p.130-138, 2010. Disponível em: <http://dx.doi.org/10.1590/S0104-11692010000100020>. Acesso em: 14 de novembro de 2016. 


\section{CONFLITOS INTERPESSOAIS NA PRÁTICA GERENCIAL DO ENFERMEIRO NA ATENÇÃO BÁSICA \\ ÁREA TEMÁTICA: Enfermagem na Saúde Coletiva. Exposição oral.}

RAYARA CIBELLE RIBEIRO DA SILVA ${ }^{1}$, Acadêmica de enfermagem, Universidade Federal de Campina Grande (Apresentadora). PALOMA KAREN HOLANDA BRITO², Acadêmica de enfermagem, Universidade Federal de Campina.

LEANDRO NONATO DA SILVA SANTOS ${ }^{2}$, Acadêmico de enfermagem, Universidade Federal de Campina Grande.

JAINE DA SILVA BATISTA ${ }^{3}$, Enfermeira. Universidade Federal de Campina Grande. MARCELO COSTA FERNANDES ${ }^{4}$, Professor Dr., Universidade Federal de Campina

Grande (Orientador).

\section{INTRODUÇÃO}

O gerenciamento é classificado como um dos principais métodos para organização, administração e bom funcionamento dos serviços e instituições de saúde. O ato de gerenciar demanda conhecimentos e habilidades técnicas; trata-se de competência estratégica, permitindo assim, bons resultados nos serviços prestados. Ele deve estar presente em todos os níveis de saúde, nessa perspectiva, necessita de vários atores sociais a fim de construir um projeto que atenda a demanda da população de forma integral possibilitando um olhar sensível de mudanças (VANDERLEI, 2007).

Na Atenção Básica (AB) gerenciar é indispensável, mantém o serviço articulado e integrado, buscando analisar, decidir, agir, fazer acontecer, prever e avaliar na busca por resultados satisfatórios. No contexto da saúde a gerência é executada em nível local, nesse caso, dentro de uma unidade de saúde (BRASIL, 2006; CASTANHEIRA, 1996; MISHIMA, 2003;).

A Atenção Básica é a porta de entrada preferencial do Sistema Único de Saúde (SUS) e é definida como assistência sanitária para todo e qualquer indivíduo e família da comunidade, é garantida através do acesso universal, articulada segundo os problemas refletidos na população, de caráter resolutivo por ser o primeiro nível de contato com a rede de saúde (LERMEN JUNIOR, 2013).

É de suma importância conhecer e compreender a dimensão gerencial, além de entender como a mesma deve ser realizada pelos enfermeiros, no intuito de perceber se está condizente com o que é preconizado nesse nível de atenção. O enfermeiro, em seu processo de trabalho, pode e deve desenvolver o papel de gerenciador, no entanto, nessa pesquisa destaca-se a Estratégia de Saúde da Família (ESF), considerada principal meio de atendimento no nível de atenção primaria pela Política Nacional de Atenção Básica (PNAB) (FERNANDES; SILVA, 2013).

Desse modo, pode-se dizer que o enfermeiro vem traçando um importante caminho na sua atuação gerencial conduzindo e dando visibilidade ao SUS, motivando e instigando a participação de toda a equipe de saúde na criação e organização dos serviços, qualificando os serviços oferecidos para a comunidade a fim de atender todas as demandas (FERNANDES et al, 2010).

É importante destacar alguns fatores que prejudicam o trabalho do enfermeiro na $A B$, como por exemplo, a alta demanda, sobrecarga de trabalhos burocráticos, precariedade nos 


\section{$\mathrm{RPP}$}

Anais do $1^{\circ}$ Encontro de Iniciação Científica da ETSC - 13 e 14 de junho de 2017.

insumos e modelos assistenciais que influenciam o distanciamento dos profissionais das práticas gerenciais.

Assim sendo, a gerência de enfermagem mostra-se com um instrumento significativo no processo de trabalho de saúde, facilitando a organização dos serviços prestados, de forma eficiente e eficaz, buscando evitar assistência centralizada e fragmentada.

\section{OBJETIVO}

Averiguar a percepção dos enfermeiros na Atenção Básica sobre os conflitos interpessoais na prática gerencial.

\section{METODOLOGIA}

Estudo de natureza descritiva com abordagem qualitativa, realizado na Atenção Básica do município de Cajazeiras, no estado da Paraíba. Atualmente encontram-se cadastradas 19 Unidades de Saúde da Família nesse município. Como participantes do estudo, obteve-se 15 enfermeiros que compõem um total de 23 Equipes de Saúde da Família, lotadas nas 19 Unidades de Saúde da Família da Atenção Básica de Cajazeiras-PB. O único critério de inclusão da pesquisa foi trabalhar há mais de um ano como enfermeiro na Atenção Básica. Como critérios de exclusão adotou-se, estar de férias, licença-maternidade ou afastado por alguma doença.

A coleta de dados foi realizada mediante entrevista semiestruturada, com a finalidade de adquirir informações para a análise, a partir das impressões individuais sobre questões ligadas aos objetivos do estudo. Dessa forma, as coletas foram realizadas de maneira individual apresentando questões tanto objetivas (perfil dos sujeitos) quanto subjetivas (temática proposta), respeitando a livre expressão de suas representações e significações. As entrevistas foram gravadas com a autorização dos entrevistados e transcritas.

Como ferramenta de análise e organização das falas proferidas pelos enfermeiros nas entrevistas, utilizou-se o processo metodológico do Discurso do Sujeito Coletivo (DSC). Esse método soma-se às ideias agrupando o pensamento coletivo diante do discurso.

A pesquisa teve inicio após a aprovação do Comitê de Ética em Pesquisa (CEP) da Universidade Federal de Campina Grande campus Cajazeiras, sob o número do processo 1.642. 763, acontecendo, entre os meses de julho e agosto de 2016, em local reservado nas Unidades Básicas de Saúde. A participação no estudo iniciou-se mediante a assinatura do Termo de Consentimento Livre e Esclarecido (TCLE). 


\section{$\mathrm{RPP}$}

\section{RESULTADOS E DISCUSSÃO}

Como referência para a discussão acerca dos conflitos interpessoais na prática do gerenciamento do enfermeiro na atenção básica, foi levado em consideração o Discurso do Sujeito Coletivo, obtendo assim, quatro enfermeiros nessa categoria. A mesma foi destacada pelo seguinte discurso:

"Administrar as pessoas, que onde a gente tem muita dificuldade e complica muito, tem hora que ninguém quer lhe ouvir, nem lhe atender, aí fica complicado. $O$ que dificulta muitas vezes é a falta de diálogo entre a equipe! Os problemas com funcionários, às vezes tem muita "picuinha" um com o outro e acaba prejudicando o andamento do serviço porque um não está gostando de alguma coisa, chega e não conversa, ainda tem esse problema, não com todos, mas com alguns. Minha dificuldade é essa. Tem coisas que deveriam ser realizadas, mas não mudam”.

Diante do discurso, entendemos que nem sempre a relação interpessoal é harmoniosa, podendo gerar conflitos. Dessa forma, faz-se necessário a atuação do gerenciador, a fim de evitar desgastes na equipe que refletem negativamente nos serviços prestados aos usuários.

O conflito é inerente em qualquer ambiente de trabalho, em especial nas instituições de saúde, em que o processo de trabalho é consumido no momento de sua produção. Contudo podem desencadear impactos negativos e positivos, variando de acordo com as experiências e condutas utilizadas para a resolução dos mesmos (MISHIMA, 2003).

Cada membro na equipe de saúde possui suas atribuições, logo, é importante a interação da equipe, visto que se deve evitar o cuidado fragmentado. Com isso é imprescindível haver diálogo e negociação entre todas as partes da assistência.

Gerenciar uma Unidade Básica de Saúde compreende articular e fazer, isso engloba vários saberes. Repensar novas escolhas é um ótimo aliado nesse processo, de maneira que foque em ações integradas, agregando eficiência e tendo como consequência uma boa prestação de serviço, logo, saúde de qualidade para os usuários (FERNANDES et al., 2010). Trabalhando dessa maneira é possível construir uma relação harmoniosa, podendo assim atribuir caráter positivo ao conflito, influenciando no crescimento da assistência.

O relacionamento é algo complexo, em especial no trabalho. Cada ser humano possui peculiaridades, anseios e experiências diferentes, formando opiniões que possam ser contrárias. Com isso, é importante a criação de estratégias que previnam tais conflitos, para isso a gerência deve resolver as diferenças utilizando métodos proficientes e facilitadores que levem a integração e harmonia da equipe (LIMA et al., 2014). 


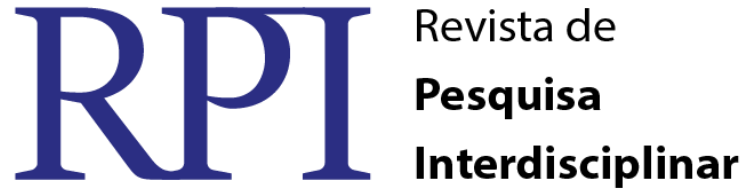

Em vista disso, o relacionamento positivo e equilibrado entre a equipe do trabalho é imprescindível para uma boa prática dos funcionários e bom resultado no funcionamento da unidade. Portanto, o enfermeiro gerente é de suma importância nesse processo e deve possuir um olhar crítico-reflexível sobre os demais membros da equipe, articulando sempre o diálogo e resolubilidade dos conflitos.

\section{CONCLUSÃO}

No decorrer do estudo foi possível identificar o papel do enfermeiro como gerenciador no processo de trabalho. Destaca-se como umas das principais funções da gerência a forma como esses profissionais lidam com os conflitos.

$\mathrm{Na}$ pesquisa verificaram-se as condições intervenientes na prática gerencial do enfermeiro, dentre as negativas estavam presentes alguns fatores como a sobrecarga de trabalho, falta de insumos e os conflitos interpessoais, ocasionado através das peculiaridades de cada indivíduo, no qual as diferenças podem ocasionar alguns problemas.

É considerável a criação de projetos de gerenciamento que deem subsídios aos conflitos interpessoais, de maneira que priorize a assistência prestada aos usuários e forneça resolução a esses conflitos. O estímulo de pesquisas acerca do enfermeiro gerente também se faz necessário, uma vez que o mesmo vem cada vez mais ganhando espaço nessa área.

PALAVRAS-CHAVE: atenção básica. conflitos interpessoais. enfermeiro. gerenciamento.

\section{REFERÊNCIAS}

BRASIL, Ministério da Saúde. Portaria no 399, de 22 de fevereiro de 2006. Divulga o pacto pela saúde 2006 - Consolidação do SUS e aprova as diretrizes Operacionais do referido Pacto. Diário Oficial da União. Brasília, 2006.

CASTANHEIRA, E. R. L. Gerência do trabalho em saúde: desenvolvimento histórico da administração em saúde nos serviços públicos do Estado de São Paulo [dissertação] São Paulo, 1996.

FERNANDES, M. C. et al.Análise da atuação do enfermeiro na gerência de unidades básicas de saúde. Rev. bras. enferm., Brasília, v. 63, n. 1, fev. 2010. 


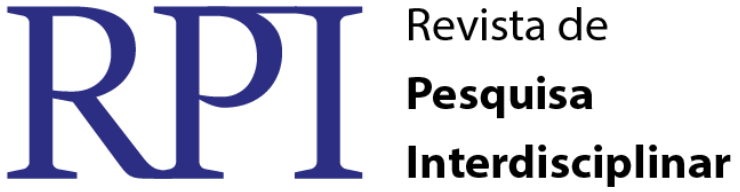

FERNANDES, M. C.; SILVA, L. M. S.; MOREIRA, T. M. M.; SILVA, M. R. F. Fatores intervenientes na gerência do cuidado do enfermeiro: estudo descritivo. Online braz $\mathrm{j}$ nurs. v.12, n. 2, p. 522-33, 2013.

LERMEN, J. N.; NORMAN, A. H. Medicina familiar y comunitaria y salud de la familia en Brasil: una estrategia para ofrecer atención primaria de salud para todos. Medwave, Chile, v.13, n.1,p.1-8,2013.

LIMA, A. M. V. et al. Supervisão de trabalhadores de enfermagem em unidade básica de saúde. Trab. educ. saúde, Rio de Janeiro, v. 12, n. 3, p. 577-593, dez. 2014.

MISHIMA, S. M. A gerência de serviços de atenção primária à saúde como instrumento para a reorganização da assistência à saúde - o caso do Programa de Saúde da Família [tese de livre docência]. Ribeirão Preto, 2003.

VANDERLEI, M.I.G.; ALMEIDA, M.C.P. A concepção e prática dos gestores e gerentes da estratégia de saúde da família. Ciência \& Saúde Coletiva, Rio de Janeiro, v.12, n.2, p. 443453, Mar/Abr. 2007. 


\title{
$\mathrm{RPP}$
}

\section{SUPERVISÃO COMO PRÁTICA GERENCIAL NA ATENÇÃO BÁSICA: DISCURSO DOS ENFERMEIROS}

\author{
ÁREA TEMÁTICA: Saúde Coletiva \\ Exposição oral
}

PALOMA KAREN HOLANDA BRITO ${ }^{1}$. Acadêmica de enfermagem da Universidade Federal de Campina Grande. Apresentadora.

GEISA BATISTA LEANDRO ${ }^{2}$. Acadêmica de enfermagem da Universidade Federal de Campina Grande.

RAYARA CIBELLE RIBEIRO DA SILVA ${ }^{3}$. Acadêmica de enfermagem da Universidade Federal de Campina Grande.

JAINE DA SILVA BATISTA ${ }^{4}$. Enfermeira. Formada pela Universidade Federal de Campina Grande. MARCELO COSTA FERNANDES ${ }^{5}$. Enfermeiro. Docente da Universidade Federal de Campina Grande.

\section{INTRODUÇÃO}

A Política Nacional de Atenção Básica foi aprovada pela Portaria no 648/2006 e regulamentada pela Portaria 2.488/2011, o que ocasionou em avanços na Atenção Básica $(\mathrm{AB})$ e nas Redes de Atenção. A Política também proporcionou progressão nas ações de promoção da saúde, além de equidade, intersetorialidade e melhora na qualidade dos serviços (BRASIL, 2012).

A Atenção Primária à Saúde (APS) deve ser a porta de entrada para a rede de serviços, ou seja, o primeiro contato dos usuários ao Sistema de Saúde e esta tem como foco principal, o cuidado integral, isto é, observar o sujeito em toda sua totalidade, além de promover um cuidado longitudinal. (BRASIL, 2012). Assim, a AB é definida como um conjunto de ações que engloba a promoção de saúde, prevenção de doenças, tratamento e reabilitação e manutenção da saúde. (BRASIL, 2011).

As atividades cotidianas da profissão de enfermagem são pouco discutidas pela categoria. Além das funções assistenciais, na AB, o enfermeiro desempenha papel gerencial, por ser o responsável pelos procedimentos administrativos, além de garantir circunstâncias necessárias para executar um serviço de qualidade (HAUSMANN, 2009). A dimensão 


\section{$\int\left[\begin{array}{l}\text { Revista de } \\ \text { Pesquisa } \\ \text { Interdisciplinar }\end{array}\right.$}

Anais do $1^{\circ}$ Encontro de Iniciação Científica da ETSC - 13 e 14 de junho de 2017.

gerencial é bastante complexa e é um mecanismo de sistematização e efetivação das ações nas instituições de saúde.

Portanto, a gerência é uma ferramenta significativa do processo de trabalho gerencial, pois é através dela que o enfermeiro apropria-se como líder da equipe e tem a função de organizar a infraestrutura e planejamento do serviço, coordenar a atividades dos profissionais de saúde (CHRISTOVAM, 2001; PINHEIRO, 2003), além de estruturar os meios promover assistência à saúde de qualidade com eficiência, estabelecendo modelos singulares para fornecer saúde (KAWATA et al, 2009).

O profissional de enfermagem considera-se como principal agente desse processo gerencial, na Estratégia Saúde da Família (ESF), e colabora para a estabilização do SUS (BACKES et al., 2012). Há atividades de gerência em todos os níveis de atenção, porém o estudo se restringe a Atenção Básica.

\section{OBJETIVO DO TRABALHO}

Compreender a visão dos enfermeiros frente à supervisão como prática gerencial na Atenção Básica.

\section{MATERIAIS E MÉTODOS}

Estudo de natureza descritiva com abordagem qualitativa. A pesquisa foi realizada na Atenção Básica no município de Cajazeiras, Paraíba. Nesta cidade estão cadastradas 19 Unidades de Saúde da Família. Os participantes dessa pesquisa são 15 enfermeiros dos 23 que compõem as 19 Unidades de Saúde da Atenção Básica da cidade. A coleta de dados ocorreu por meio de entrevista semiestruturada. A entrevista foi realizada individualmente e foram gravadas com a autorização dos entrevistados.

Para organizar os dados obtidos nas entrevistas, utilizou-se do processo metodológico do Discurso do Sujeito Coletivo (DSC), o qual obtém-se a soma de ideias que expõem o pensamento do coletivo, através do discurso. O uso desta ferramenta permite analisar o material coletado, e retirar deste as Ideias Centrais (IC) e suas Expressões-Chave (ECH).

Para analisar o conteúdo extraído dos depoimentos, realizou-se uma leitura das falas e posteriormente, foram realizadas leituras sucessivas afim de verificar os núcleos de sentido relacionados as perguntas que compõem o roteiro da entrevista. A pesquisa iniciou-se após a aprovação do projeto pelo Comitê de Ética em Pesquisa (CEP) da Universidade Federal de Campina Grande, sob o número do processo 1.642.763, entre os meses de julho e agosto de 


\section{$\mathrm{RPP}$}

Anais do $1^{\circ}$ Encontro de Iniciação Científica da ETSC - 13 e 14 de junho de 2017.

2016. Para participar do estudo, os enfermeiros assinaram o Termo de Consentimento Livre e Esclarecido (TCLE)

\section{RESULTADOS E DISCUSSÃO}

O discurso dos enfermeiros foi construído a partir da fala de onze enfermeiros, sendo representados a partir do discurso a seguir.

"Você tem que supervisionar sua equipe, supervisionar o trabalho das ACS's, organizar materiais para funcionamento da UBS, a questão dos técnicos, a questão do médico, a questão do auxiliar de serviços gerais, da vacinadora, recepção [...]. A questão de resolver os problemas encontrados na ESF, que especificamente é exclusividade do enfermeiro da unidade atentar para avaliá-los e orientá-los no que se deve ou não fazer."

Com base neste discurso, percebe-se a importância do enfermeiro como líder do processo gerencial, no âmbito da $\mathrm{AB}$. Comparando à literatura, observa-se na fala dos enfermeiros que as atividades gerenciais de supervisão são realizadas fundamentalmente por eles nas ESF, como supervisionar os agentes comunitários de saúde, técnicos de enfermagem, recepcionista, médico, isso é, todos os profissionais da equipe de saúde são fiscalizados pelo enfermeiro da unidade.

Possuindo a função de supervisionar a equipe, o profissional de enfermagem atua também na resolução dos problemas que surgem na unidade. É ele o responsável por atender as demandas, ouvir os demais profissionais e buscar a solução o mais rápido possível. Para desempenhar tal função, o enfermeiro faz uso de sua sabedoria, direcionando-se à equipe de saúde para buscar aperfeiçoamento dos serviços prestados e atender as necessidades da população que faz uso da ESF.

Organização, planejamento e coordenação são algumas das atividades privativas do enfermeiro, conforme a Lei $\mathrm{n}^{\mathrm{o}}$ 7.498, de 25 de junho de 1986. Portanto, o enfermeiro exerce a atividade gerencial de supervisão com respaldo legal (BRASIL, 1986). Porém, esse profissional não deve apenas supervisionar no sentido de observar e controlar, ele deve apresentar dimensões de educação, objetivando o crescimento profissional da equipe.

\section{CONCLUSÕES}


Dentre as principais atividades de gerência do enfermeiro, tem-se a supervisão. Sendo assim, percebeu-se no discurso que o enfermeiro é essencial para que o serviço seja realizado e organizado de forma adequada, objetivando a implantação de novos modelos de gerenciamento que estejam focados em atender as necessidades dos usuários. Porém, é de fundamental importância que o enfermeiro saiba atuar de forma dinâmica e flexível, buscando a participação e o diálogo coletivamente.

Faz-se, portanto, necessário estimular pesquisas sobre o tema e divulgar para a comunidade científica as funções desempenhadas pelo enfermeiro, que além de realizar papel assistencial, possui a função de coordenar a equipe, não só na atenção básica, como também nos outros níveis de atenção.

PALAVRAS-CHAVE: atenção primária à saúde. estratégia saúde da família. enfermagem. gerência. supervisão.

\section{REFERÊNCIAS}

BACKES, D. S.; BACKES, M.S.; ERDMANN, A.L.; BÜSCHER, A. O papel profissional do enfermeiro no Sistema Único de Saúde: da saúde comunitária à estratégia de saúde da família. Ciência \& Saúde Coletiva, Rio de Janeiro, v. 17, n. 1, p. 223-30, 2012.

BRASIL. Conselho Federal de Enfermagem. Lei no 7.498, de 25 de Junho de 1986. Dispõe sobre a Regulamentação do Exercício Profissional da Enfermagem e dá outras providências. Diário Oficial da União, Brasília, 26 de junho de 1986.

BRASIL, Ministério da Saúde. Secretaria de Atenção à Saúde. Departamento de Atenção Básica. Política Nacional de Atenção Básica. Ministério da Saúde, 2012.

BRASIL. Portaria n ${ }^{\circ}$ 2.488, de 21 de outubro de 2011. Aprova a Política Nacional de Atenção Básica, estabelecendo a revisão de diretrizes e normas para a organização da Atenção Básica, para a Estratégia Saúde da Família (ESF) e o Programa de Agentes Comunitários de Saúde (PACS). Diário Oficial da União, 2011.

CHISTOVAM, B.P.; SANTOS, I. Os desafios da gerência do enfermeiro no nível de saúde. Rev.Enferm.UERJ, v.12, n.1, p. 66-70, 2004.

HAUSMANN, M.; PEDUZZI, M. Articulação entre as dimensões gerencial e assistencial do processo de trabalho do enfermeiro. Texto Contexto Enferm. Florianópolis, v. 12, n. 2, p. 258, abr-jun, 2009.

KAWATA, L.S. et al. O trabalho cotidiano da enfermeira na saúde da família: utilização de ferramentas da gestão. Texto Contexto Enfermagem, Florianópolis, v.18, n.2, p.313-320, abr/jun. 2009. 
PINHEIRO, R.; MATTOS, R.A. Construção da integralidade: cotidiano, saberes e práticas em saúde. Rio de janeiro: UERJ, IMS - ABRASCO, 2003. 


\section{SAÚDE DO HOMEM: REFLEXÃO ACERCA DA POLÍTICA NACIONAL DE ATENÇÃO INTEGRAL A SAÚDE DO HOMEM E AS DIFICULDADES PARA IMPLANTAÇÃO ÁREA TEMÁTICA: ENFERMAGEM NA SAÚDE COLETIVA}

(Forma de apresentação: oral)

CRYSLANNY DE SOUSA MACIEL E SILVA ${ }^{1}$, Acadêmica de Enfermagem, pela Universidade Federal de Campina Grande, campus Cajazeiras - PB. (APRESENTADOR).

LEANDRO NONATO DA SILVA SANTOS ${ }^{2}$, Acadêmico de Enfermagem, pela Universidade Federal de Campina Grande, campus Cajazeiras - PB;

GEÍSA BATISTA LEANDRO ${ }^{3}$, Acadêmica de Enfermagem, pela Universidade Federal de Campina Grande, campus Cajazeiras - PB;

RAYARA CIBELLE RIBEIRO DA SILVA4, Acadêmica de Enfermagem, pela Universidade Federal de Campina Grande, campus Cajazeiras - PB;

MARCELO COSTA FERNANDES, Professor Doutor em Cuidados Clínicos em Enfermagem e Saúde, Docente da Universidade Federal de Campina Grande, da Unidade Acadêmica de Enfermagem UAENF, campus de Cajazeiras - PB. (ORIENTADOR).

\section{INTRODUÇÃO}

As diferenças em saúde entre o gênero masculino e feminino têm sido artefato de grande interesse da comunidade científica representado por estudos que analisam diferenciais de morbimortalidade e utilização dos serviços de saúde, os quais apresentam como constatação que no Brasil as mulheres vivem mais que os homens e buscam mais os serviços de saúde. (AQUINO, 2006 apud SILVA et, al. 2013). Com isso, de acordo com Araújo et, al. 2014, acredita-se que, o público masculino, desconheça as práticas de saúde e os serviços ofertados na atenção primária, além disso, não se enxergam como atores sociais inseridos dentro das instituições de saúde, culminando para a não procura dos mesmos.

Após analisar as condições de saúde do homem, o Ministério da Saúde do Brasil, instituiu a Politica Nacional de Atenção Integral a Saúde do Homem (PNAISH), com a finalidade de facilitar e ampliar o acesso da população masculina aos serviços de saúde. A politica possui como objetivo promover a melhoria da qualidade de assistência para o público masculino tendo como foco principal, jovens e adultos na faixa etária entre 20 e 59 anos, 


\section{$\int\left[\begin{array}{l}\text { Revista de } \\ \text { Pesquisa } \\ \text { Interdisciplinar }\end{array}\right.$}

Anais do $1^{\circ}$ Encontro de Iniciação Científica da ETSC - 13 e 14 de junho de 2017.

contribuído para redução da morbimortalidade o aumento da expectativa de vida (BRASIL, 2009).

Diante do conteúdo exposto considera-se importante uma reflexão sobre a Politica Nacional de Atenção Integral a Saúde do Homem (PNAISH), bem como das dificuldades que envolvem falhas na implantação da mesma. As principais dificuldades encontradas são a reduzida procura do público masculino pelos serviços de saúde, ausência de preparo da equipe do serviço para atuar de acordo com a proposta da política; e a pouca participação dos eixos governamentais. Em meios às essas dificuldades faz-se necessário explanar a importância da politica e preparar os profissionais para estarem aptos a captar e assistir ao público alvo da politica, bem como incentivas e cobrar a participação das esferas governamentais (RAMALHO, et. al, 2010).

Não obstante deve-se conhecer a importância da efetivação da política e de sua contribuição para melhoria na qualidade da assistência a saúde do homem, bem como trabalhar em cima das dificuldades da implantação da mesma, visando alcançar com êxito os objetivos estipulados.

\section{OBJETIVO DO TRABALHO}

Refletir a cerca da Política Nacional de Atenção Integral a Saúde do Homem e as dificuldades para implantá-la.

\section{MATERIAIS E MÉTODO}

Trata-se de um estudo teórico-reflexivo, construído com base na leitura crítica da PNAISH, em documentos oficiais do Ministério da Saúde e em trabalhos científicos, que referenciam a Politica Nacional de Atenção Integral a Saúde do Homem. A presente produção teórica assemelha-se da abordagem qualitativa, considerando-se a compreensão e estudo de trabalhos teóricos obtidos por meio de pesquisa bibliográfica realizada.

A construção deste trabalho foi norteada nos pressupostos da revisão de literatura, onde foi incluída a pesquisa bibliográfica, por meio do qual se realizou uma pesquisa exploratória e sistemática de documentos em formato eletrônico presentes em um avaliador independente na Biblioteca Virtual em Saúde (BVS), e para tal utilizou-se os seguintes descritores: Atenção primária, Enfermagem, Política pública e Saúde do homem.

Identificou-se 70 artigos, destes foram pré-selecionados 24 e por meio dos critérios de inclusão estabelecidos: relevância temática, publicações diversas nos últimos dez anos e equivalência ao objetivo do estudo, foi consolidado com a leitura na integra de 8 artigos, onde foi incluído nesta reflexão teórica apenas quatro publicações. Foram utilizadas, também, 


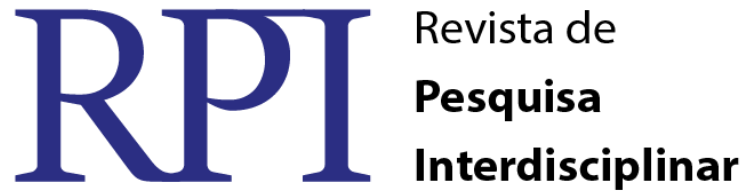

outras fontes de informação, como documentos oficiais do Ministério da Saúde do Brasil. Após a aglomeração dos dados foi feito um fichamento com pontos importantes e em sequencia a elaboração do presente trabalho. Essa busca aconteceu em novembro de 2016, quando foram encontrados 70 trabalhos na Biblioteca Virtual em Saúde (BVS) e 02 nos documentos oficiais do Ministério da Saúde, conforme descrição no quadro 1:

Quadro 1 - Trabalhos encontrados nas bases de dados, disponibilizados pela Biblioteca Virtual em Saúde (BVS) e Ministério da Saúde (MS).

\begin{tabular}{|l|l|}
\hline BASE DE DADOS & TOTAL DE ARTIGOS ENCONTRADOS \\
\hline SCIELO & 36 \\
\hline MEDLINE & 20 \\
\hline BDENF-ENFERMAGEM & 14 \\
\hline MINIST. SAÚDE & 02 \\
\hline
\end{tabular}

Fonte: Biblioteca Virtual em Saúde (BVS); Ministério da Saúde, 2016.

\section{RESULTADOS E DISCUSSÃO}

Durante a leitura da Politica e do material bibliográfico selecionado, observou-se a devida importância da execução Politica Nacional de Atenção Integral a Saúde do Homem (PNAISH) nos serviços de saúde, observou-se também que existem lacunas a serem preenchidas para o êxito da implantação da mesma, lacunas essas que devem ser preenchidas através do esforço e participação das equipes de saúde, da população e das esferas de gestão. Enfatizou-se a importância da atenção básica no processo de implantação e execução da PNAISH tendo em vista que a mesma consiste na porta de entrada dos serviços de saúde do SUS.

Atentou-se para a relevância dos recursos humanos e físicos para receber e acolher o usuário público alvo da politica. Identificou-se a necessidade da capacitação profissional, ampliação da unidade e participação das esferas de gestão visando eliminar as barreiras e dificuldades para implantação da politica dado ênfase nesse trabalho.

A política de saúde do homem se articula de forma direta com a politica de atenção básica, obedecendo a uma lógica hierarquizada de atenção à saúde, sendo esse um instrumento importante que propõe uma mudança na maneira de assisti-lo. Ela preconiza uma assistência integral na qual a saúde do homem também seja prioridade no sistema de saúde, onde a Atenção Básica tem função importante nesse processo, sendo essa responsável pela prevenção e promoção da saúde. Nesse cenário de atuação a equipe precisa conhecer a politica e trabalhar em conjunto, criando estratégias e adaptando a unidade para que venha atrair o homem para com a busca ao serviço (TEIXEIRA et, al. 2014). 


\section{$\int\left[\begin{array}{l}\text { Revista de } \\ \text { Pesquisa } \\ \text { Interdisciplinar }\end{array}\right.$}

Anais do $1^{\circ}$ Encontro de Iniciação Científica da ETSC - 13 e 14 de junho de 2017.

Nesta perspectiva a Estratégia Saúde da Família se constitui numa importante ferramenta para implantação da PNAISH no Brasil, uma vez que consiste em uma estratégia de reorientação do modelo assistencial de saúde vigente no Brasil, onde a atenção passa do foco curativista e hospitalocêntrico para a atenção primária à saúde, atuando na promoção e prevenção da saúde (BRASIL, 2011).

A PNAISH também chama a atenção para as competências de cada esfera de gestão, com a finalidade de reorganizar os serviços de saúde, tendo como consequência a produção de um cuidado integral ao homem. Com isso reconhece-se a importância de um trabalho interdisciplinar com permanente comunicação horizontal, tendo em vista que o trabalho fragmentado e isolado entre os membros da equipe de saúde consiste em barreiras que pode dificultar a implementação e efetivação de tal política (RAMALHO, et. al, 2014).

\section{CONCLUSÕES}

A Política Nacional de Atenção Integral a Saúde do Homem apresenta a importância de incentivar o usuário masculino a manter o autocuidado, sendo a politica uma ferramenta que contribui para melhoria da qualidade de vida do homem, se trabalhada no dia-a-dia de unidades de saúde. Deparamo-nos no dia a dia com dificuldades para a implantação dessa politica, dentre elas estão a baixa procura do homem pelos serviços sendo consequência do despreparo das instituições de saúde, estes relacionados a estrutura e aos recursos humanos, esse despreparo por sua vez sendo consequência do baixo envolvimento das esferas de gestão.

A assistência prestada ao público alvo da politica é muito reduzida o que leva a equipe a rever as suas práticas criando estratégias juntamente com outros setores ligados unidade de saúde, para a captação do usuário, essas estratégias vão desde a disseminação de informações de saúde do homem na comunidade e na sociedade, bem como formação de grupos com rodas de conversa com o público alvo, adaptar a unidade com cartazes, panfletos informativos e sala para encontros, investir em educação permanente da equipe com a finalidade de aprimorar os conhecimentos e por fim incentivar e cobrar a participação das esferas governamentais.

Portanto é necessário que a politica seja implantada sendo essa um instrumento que vem contribuir para melhoria e ampliação na qualidade de assistência à saúde do homem, e culminando com êxito dos objetivos da mesma.

\section{PALAVRAS-CHAVE}

Atenção primária. Enfermagem. Política de publica. Saúde do homem.

\section{REFERÊNCIAS}




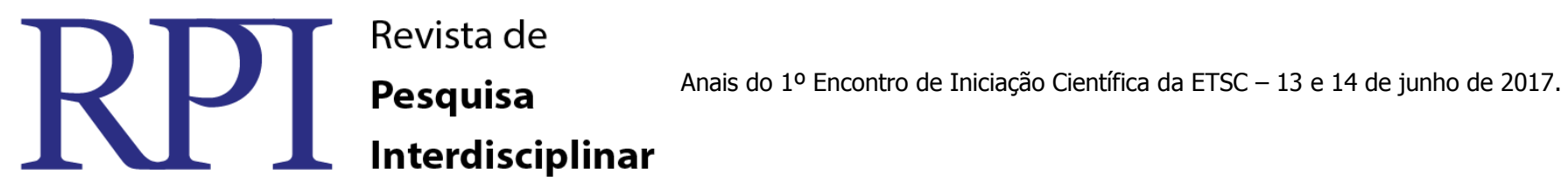

ARAÚJO, MG, LIMA, GAF, HOLANDA, CSM, CARVALHO, JBL, SALES, LKO. Opinião de profissionais sobre a efetivação da Politica Nacional de Atenção Integral à Saúde do Homem. Escola Anna Nery Revista de Enfermagem 18(4) Out-Dez 2014;

BRASIL. Ministério da Saúde. Portaria n. 2.488, de 21 de outubro de 2011. Aprova a Política Nacional de Atenção Básica, estabelecendo a revisão de diretrizes e normas para a organização da Atenção Básica, para a Estratégia Saúde da Família (ESF) e o Programa de Agentes Comunitários de Saúde (PACS). Brasília, DF; nov 28. 2011;

BRASIL. Mistério da Saúde. Política Nacional de Atenção Integral à Saúde do Homem: princípios e diretrizes. Brasília: Ministério da Saúde, 2009. Disponível em:<http://bvsms.saude.gov.br/bvs/publicacoes/politica_nacional_atencao_saude_homem.pdf >.Acesso em: 10 de novembro de 2016.

RAMALHO MNA, ALBUQUERQUE AM, MAIA JKF, PINTO MB, SANTOS NCCB. Dificuldades na implantação da política nacional de atenção integral à saúde do homem. Cienc Cuid Saude 2014.

SILVA, PLN, MACIEL, MM, CARFESAN, CS, SANTOS, S. A política de atenção à saúde do homem no Brasil e os desafios da sua implantação: uma revisão integrativa. Enferm Glob, 2013;12(32):414-43

TEIXEIRA, Daiane Cristina et al . Concepções de enfermeiros sobre a política nacional de atenção integral à saúde do homem. Trab. educ. saúde, Rio de Janeiro , v. 12, n. 3, p. 563576, Dec. 2014 . 


\title{
CASOS NOTIFICADOS DE TUBERCULOSE EM HOMENS NO ESTADO DA PARAÍBA - BRASIL
}

\author{
ÁREA TEMATICA: ENFERMAGEM NA SAÚDE COLETIVA \\ Exposição Oral
}

JOSÉ AUGUSTO DE SOUSA RODRIGUES, acadêmico do curso de enfermagem, Universidade Federal de Campina Grande-Centro de Formação de Professores. JOYCE DE SOUZA, acadêmica do curso de enfermagem, Universidade Federal de Campina Grande-Centro de Formação de Professores.

CÍCERA RENATA DINIZ VIEIRA SILVA, Mestre em saúde pública pela Universidade Estadual da Paraíba, docente da Universidade Federal de Campina Grande-Centro de

Formação de Professores. GERLANE CRISTINNE BERTINO VÉRAS, Mestranda em enfermagem pela Universidade Regional do Cariri, docente da Universidade Federal de Campina Grande-Centro de Formação de Professores.

\section{INTRODUÇÃO}

No Brasil, cerca de 70 mil novos casos de tuberculose (TB) são notificados anualmente, com aproximadamente 4,6 mil mortes em decorrência da doença (BRASIL, 2016). Este dado coloca o Brasil entre os 22 países responsáveis por $80 \%$ dos casos de TB no mundo.

De acordo com Pedruzzi et al. (2013), os homens, principalmente em idade economicamente ativa, adoecem cerca de duas vezes mais que as mulheres. A sobreposição de adoecimento masculino pode estar relacionada ao fato dos homens estarem em contato com um maior número de pessoas devido ao mercado de trabalho, ficando assim, mais vulnerável as doenças respiratórias. Esse fato também pode ser justificado pela ausência do homem nas campanhas de prevenção da doença, e, muitas vezes, pelo abandono do tratamento por motivos trabalhistas (SILVA; YAMAMURA; FIGUEIREDO, 2016).

Frente ao exposto, constata-se a importância de se realizar pesquisas que verifiquem o perfil clínico e epidemiológico dos casos novos de TB nos homens para subsidiar a elaboração de estratégias mais eficientes e eficazes para controlar esta patologia, comprovando a relevância social e acadêmica deste estudo.

\section{OBJETIVO DO TRABALHO}

Verificar o perfil clínico e epidemiológico dos casos novos de tuberculose em homens no estado da Paraíba.

\section{MATERIAIS E MÉTODOS}

Estudo epidemiológico, descritivo, de base secundária e de natureza quantitativa, realizado em novembro de 2016. Os dados foram coletados no Sistema Nacional de Agravos de Notificação do Ministério da Saúde (SINAN) entre o período de janeiro de 2012 a maio de 2016. As variáveis utilizadas para a busca foram: zona residencial, faixa etária, tipo de entrada, coinfecção com HIV, forma da doença, situação de encerramento e casos em que foi realizado o tratamento diretamente observado (TDO). Para tratamento dos dados, os mesmos 
foram tabulados no Microsoft Excel 2010 e posteriormente utilizou-se de estatística descritiva.

\section{RESULTADOS E DISCUSSÃO}

Constatou-se um total de 3.964 casos novos de TB, como mostra a Tabela 1.

Tabela 1 - Casos de tuberculose no sexo masculino no estado da Paraíba conforme zona de residência e faixa etária, 2016.

\begin{tabular}{l|c|c}
\hline \multicolumn{1}{c|}{ Variáveis } & $\boldsymbol{f}$ & $\boldsymbol{\%}$ \\
\hline Zona de residência & & 0,2 \\
\hline Peri urbana & 9.463 & 87,4 \\
\hline Urbana & 358 & 9,0 \\
\hline Rural & 134 & 3,4 \\
\hline Ing/branco & $\mathbf{3 . 9 6 4}$ & $\mathbf{1 0 0}$ \\
\hline Total & & \\
\hline & & \\
Faixa etária & 18 & 0,4 \\
\hline$<\mathbf{1}$ ano & 20 & 0,5 \\
\hline $\mathbf{1 - 9}$ anos & 22 & 0,6 \\
\hline $\mathbf{5}-\mathbf{9}$ & 52 & 1,3 \\
\hline $\mathbf{1 0}-\mathbf{1 4}$ & 184 & 4,6 \\
\hline $\mathbf{1 5}-\mathbf{1 9}$ & 1.815 & 45,8 \\
\hline $\mathbf{2 0}-\mathbf{3 9}$ & 1.334 & 33,7 \\
\hline $\mathbf{4 0}-\mathbf{5 9}$ & 191 & 4,8 \\
\hline $\mathbf{6 0}-\mathbf{6 4}$ & 119 & 3,0 \\
\hline $\mathbf{6 5}-\mathbf{6 9}$ & 142 & 3,6 \\
\hline $\mathbf{7 0}-\mathbf{7 9}$ & 67 & 1,7 \\
\hline $\mathbf{8 0} \mathbf{+}$ & $\mathbf{3 . 9 6 4}$ & $\mathbf{1 0 0}$ \\
\hline Total & & \\
\hline
\end{tabular}

Fonte: Departamento de Informática do Sistema Único de Saúde. Site 2016. Disponível em: <http://tabnet.datasus.gov.br/ >, Acesso em: 10 nov. 2016.

De acordo com a pesquisa, a zona urbana apresenta o maior número de notificações, pois é nela que se tem maior concentração de pessoas, onde podem existir condições sanitárias mais precárias. Estes dados estão de acordo com a pesquisa realizada por Cavalcante; Silva (2013), que foi desenvolvida na cidade de Natal-RN, onde foi constatado que o maior número de casos de TB foi encontrado nos bairros mais populosos da cidade.

Quanto a faixa etária, a maior prevalência se deu na população considerada economicamente ativa, corroborando com o estudo feito na cidade de Araraquara-SP, por Silva; Yamamura; Figueiredo (2016), comprovando que essa doença afeta a população de adultos-jovens, que compreendem uma parcela de pessoas mais ativas no mercado de trabalho, mostrando-se em um estado de maior vulnerabilidade.

Tabela 2 - Casos novos de TB de acordo com o perfil clínico e epidemiológico, 2016. 
Interdisciplinar

\begin{tabular}{|c|c|c|}
\hline Variáveis & $f$ & $\%$ \\
\hline \multicolumn{3}{|l|}{ Tipo de entrada } \\
\hline Caso novo & 3.063 & 77,3 \\
\hline Recidiva & 243 & 6,1 \\
\hline $\begin{array}{l}\text { Reingresso após } \\
\text { abandono }\end{array}$ & 534 & 13,5 \\
\hline Não sabe & 10 & 0,3 \\
\hline Transferência & 109 & 2,7 \\
\hline Pós-óbito & 5 & 0,1 \\
\hline Total & 3.964 & 100 \\
\hline \multicolumn{3}{|l|}{ Coinfecção com HIV } \\
\hline Negativo & 2.545 & 64,2 \\
\hline Positivo & 362 & 9,1 \\
\hline Não realizado & 847 & 21,4 \\
\hline Em andamento & 162 & 4,1 \\
\hline Ign/ branco & 48 & 1,2 \\
\hline Total & 3964 & 100 \\
\hline \multicolumn{3}{|l|}{ Forma da doença } \\
\hline $\begin{array}{l}\text { Pulmonar + } \\
\text { extrapulmonar }\end{array}$ & 44 & 1,1 \\
\hline Pulmonar & 3.395 & 85,7 \\
\hline Extrapulmonar & 476 & 12,0 \\
\hline Ign/branco & 49 & 1,2 \\
\hline Total & 3964 & 100 \\
\hline \multicolumn{3}{|c|}{ Situação de Encerramento } \\
\hline Abandono primário & 7 & 0,2 \\
\hline Cura & 1.995 & 50,3 \\
\hline Abandono & 597 & 15,1 \\
\hline Óbito por tuberculose & 156 & 3,9 \\
\hline Óbito por outra causa & 116 & 2,9 \\
\hline Transferência & 324 & 8,2 \\
\hline TB-DR & 28 & 0,7 \\
\hline Mudança de esquema & 5 & 0,1 \\
\hline Ign/branco & 736 & 18,6 \\
\hline Total & 3.964 & 100 \\
\hline \multicolumn{3}{|c|}{ Casos com TDO realizado } \\
\hline Sim & 1.445 & 36,0 \\
\hline Não & 1.361 & 34,0 \\
\hline Ign/branco & 1.188 & 30,0 \\
\hline Total & 3.964 & 100 \\
\hline
\end{tabular}

Fonte: Departamento de Informática do Sistema Único de Saúde. Site 2016. Disponível em: <http://tabnet.datasus.gov.br/ >, Acesso em: 10 nov. 2016.

Em relação ao tipo de entrada, houve um grande número de casos novos, o que pode estar relacionado à dificuldade de acesso dessa parcela da população aos serviços para promoção da saúde e prevenção primária de patologias, o que corrobora com o estudo realizado por Pedruzzi et al. (2013), onde relata que as dificuldades trabalhistas apesentam-se como um empasse no diagnóstico precoce e até no tratamento da TB em homens.

Os casos novos de TB com coinfecção pelo HIV têm um número preocupante, assim como no estudo de Silva; Yamamura; Fiqueredo (2013), onde afirmam que este fator configura-se como um dos principais agravantes, influenciando na incidência da doença e 


\section{$\int\left[\begin{array}{l}\text { Revista de } \\ \text { Pesquisa } \\ \text { Interdisciplinar }\end{array}\right.$}

favorece o surgimento das complicações, aumentando assim os desafios para o tratamento desses pacientes.

A forma mais prevalente foi a pulmonar, estando em concordância com o estudo feito por Cavalcante; Silva (2013), mostrando a necessidade do diagnóstico precoce da doença para que se consiga interromper a sua proliferação, já que a principal via de transmissão da doença é a respiratória.

Sobre a situação de encerramento da doença, podemos observar que os dados obtidos não foram satisfatórios, apresentando um baixo índice de cura e um alto índice de abandono do tratamento, assim como no estudo realizado por Silva; Yamamura; Figueiredo (2013), visto que a Organização Mundial de Saúde e o Ministério da Saúde recomendam que o ideal seja alcançar os índices de $85 \%$ de cura e menos de 5\% de abandono do tratamento.

Pode-se observar que o índice de casos que não realizaram o TDO e os casos ignorados/branco atingiu uma porcentagem de mais de $64 \%$, divergindo do que foi encontrado por Belo et al.(2013) onde se teve um maior cuidado no registro dos dados, e o percentual de pacientes que realizaram o tratamento foi maior, evidenciando-se assim a importância de fazer e registrar os dados corretamente na ficha de notificação.

\section{CONCLUSÃO}

Fazem-se necessárias estratégias mais direcionadas ao perfil dos casos novos de TB no estado da Paraíba, para promover um diagnóstico precoce e favorecer na adesão ao tratamento, pois como foi evidenciado pelo estudo o estado da Paraíba não conseguiu chegar à meta estabelecida pela OMS para a cura e ultrapassou a taxa de abandono.

A enfermagem em equipe multiprofissional pode contribuir grandemente para o controle da TB, prestando uma assistência em atenção primária interdisciplinar, holística e de qualidade.

PALAVRAS-CHAVE: Perfil de Saúde. Saúde do Homem. Tuberculose.

\section{REFERÊNCIAS}

BELO, E. $\mathrm{N}$ et al. Tuberculose nos municípios amazonenses da fronteira Brasil-ColômbiaPeru-Venezuela: situação epidemiológica e fatores associados ao abandono. Rev Panam Salud Publica, v 34, n 5, p 321-329, 2013.

BRASIL. Tuberculose: casos confirmados notificados no Sistema de Informação de Agravos de Notificação. Ministério da Saúde: 2016. Disponível em:

<http://tabnet.datasus.gov.br/cgi/tabcgi.exe?sinannet/cnv/tubercpb.def $>$, Acesso em: 10/11/2016.

CAVAlCANTE, E. F. O; SILVA, D. M. G. V. Perfil de pessoas acometidas por tuberculose. Revista da Rede de Enfermagem do Nordeste, v 14, n 4, p 720- 729, 2013.

PEDRUZZI, B.M et al. Perfil socioeconômico e sociodemográfico de pacientes com tuberculose no sudeste do brasil: uma revisão integrativa. Revista Baiana de Saúde Pública, v.37, n.3, p.618-628, jul./set. 2013.

SILVA, D. A; YAMAMURA, M; FIGUEIREDO, R. M. Tuberculose no grupo de vigilância epidemiologia (GVE) XII - Araraquara: Incidência e perfil das notificações de 2009 a 2013.

Cuidarte Enfermagem, v 10, n 1, p 15-21, janeiro-junho 2016. 


\title{
PROPORÇÃO DE CONTATOS EXAMINADOS DOS CASOS DE HANSENÍASE NAS REGIÕES DO BRASIL
}

\author{
ÁREA TEMÁTICA: Enfermagem na Saúde Coletiva \\ (Exposição Oral)
}

MARIA JOYCE TAVARES ALVES, Acadêmica do Curso de Bacharelado em Enfermagem, Universidade Federal de Campina Grande- Campus Cajazeiras.

GABRIELLE MANGUEIRA LACERDA, Acadêmica do Curso de Bacharelado em Enfermagem, Universidade Federal de Campina Grande- Campus Cajazeiras.

DAILON DE ARAÚJO ALVES, Mestrando em Enfermagem na Universidade Regional do Cariri - Docente da Universidade Regional do Cariri. GERLANE CRISTINNE BERTINO VÉRAS, Mestranda em Enfermagem na Universidade Regional do Cariri - Docente da Universidade Federal de Campina Grande - Campus

Cajazeiras.

\section{INTRODUÇÃO}

No Brasil, a hanseníase é considerada um problema de saúde pública devido à redução insuficiente da prevalência do número de casos. Um dos fatores que contribuem para essa situação está relacionado à fragilidade dos serviços de saúde em monitorar os contatos, visto serem as pessoas que encontram-se em maior vulnerabilidade para o desenvolvimento da hanseníase (PINTO NETO et al., 2013).

Sendo considerado contato domiciliar, a pessoa que reside ou residiu com o paciente de hanseníase e contato social, a pessoa que conviveu ou convive de forma próxima e prolongada, como vizinhos, colegas de trabalhos e de escola (BRASIL, 2016).

A vigilância dos contatos não doentes deve ser realizada anualmente, durante cinco anos, e após esse período devem ser orientados quanto à possibilidade de aparecimento de sinais e sintomas sugestivos da hanseníase, e tem como objetivo descobrir as possíveis fontes de infecção da patologia em domicílio ou em ambientes sociais, independente da classificação operacional estabelecida para o paciente, além de fornecer orientações pertinentes e a aplicação da vacina BCG, quando indicado (BRASIL, 2016), e em especial, possibilitar uma detecção precoce dos casos (FARIA et al., 2013). Consequentemente, avaliar a capacidade dos serviços de saúde em hanseníase.

Visto a importância dos contatos dos casos de hanseníase, constata-se a relevância social e acadêmica deste estudo.

\section{OBJETIVO DO TRABALHO}

Verificar a proporção de contatos examinados dos casos novos de hanseníase nas regiões do Brasil.

\section{MATERIAIS E MÉTODOS}

Trata-se de um estudo descritivo, exploratório, de base secundária e natureza quantitativa, realizado em novembro de 2016. Os dados foram coletados no Sistema de Informação de Agravos de Notificação - SINAN, disponíveis de forma online pelo Departamento de Informática do Sistema Único de Saúde (DATASUS). A amostra constituiuse dos contatos registrados e examinados dos casos novos de hanseníase em 2015 nas regiões do Brasil. 
Os dados foram analisados descritivamente em frequência absoluta e relativa, sendo posteriormente apresentados em tabela e discutidos a luz da literatura pertinente.

\section{RESULTADOS E DISCUSSÃO}

Verificou-se um total de 97.095 contatos registrados e 75.967 (78,2\%) examinados, distribuídos de acordo com cada região do Brasil, como mostra a Tabela 1.

Tabela 1: Valores absolutos e relativos dos contatos dos casos novos de hanseníase registrados e examinados nas Regiões do Brasil, 2015.

\begin{tabular}{l|c|c|c}
\hline \multirow{2}{*}{ REGIÕES } & $\boldsymbol{N}^{\boldsymbol{o}}$ CONTATOS & \multicolumn{2}{c}{$\boldsymbol{N}^{\boldsymbol{o}}$ CONTATOS EXAMINADOS $(\boldsymbol{f})$} \\
\cline { 3 - 4 } & REGISTRADOS & & $\boldsymbol{\%}$ \\
& $(\boldsymbol{f})$ & $\boldsymbol{f}$ & 77,8 \\
\hline Norte & 20.003 & 15.569 & 73,1 \\
\hline Nordeste & 44.440 & 32.471 & 88,4 \\
\hline Sul & 12.663 & 11.189 & 92,0 \\
\hline Sudeste & 2.944 & 2.708 & 82,5 \\
\hline Centro-Oeste & 16.067 & 13.259 & --- \\
\hline Ignorado & 978 & --- & $\mathbf{7 8 , 2}$ \\
\hline \multicolumn{1}{c}{ TOTAL } & $\mathbf{9 7 . 0 9 5}$ & $\mathbf{7 5 . 9 6 7}$ & \\
\hline
\end{tabular}

Fonte: Departamento de Informática do Sistema Único de Saúde. Site. 2016. Disponível em: <http://datasus.saude.gov.br/>. Acesso em: 10 nov. 2016.

De acordo com a tabela 1, observa-se que a região Nordeste apresenta capacidade precária $(<75 \%)$ em realizar a vigilância dos contatos de acordo com os parâmetros do Ministério da Saúde; as regiões Norte, Sul e Centro-Oeste, com capacidade regular $(\geq 75,0$ a $89,9 \%$ ); e a região Sudeste com capacidade boa ( $\geq 90,0 \%)$, o que corrobora com o estudo de Temoteo et al. (2013), que verificaram uma menor realização de exames nos contatos na região Nordeste.

O baixo índice de contatos examinados, permite constatar que há uma deficiência quanto a vigilância dos contatos que fazem parte do convívio direto e indireto do paciente com hanseníase, evidenciando que há necessidade de reforçar a vigilância desses contatos, assim como, avaliar a ação da equipe de saúde que pode estar sendo realizada de maneira ineficaz e assim comprometendo o controle e prevenção da hanseníase (LOBATO; NEVES; XAVIER, 2016).

Quanto às possíveis causas relacionadas aos contatos não realizarem o exame, encontram-se a falta de acompanhamento do paciente; ausência de sinais e sintomas representativos da doença em questão; falta de interesse; falta de informação e conhecimento quanto a hanseníase e sua transmissão; horários incompatíveis; vergonha; e até mesmo por medo do exame (TEMOTEO et al., 2013).

\section{CONCLUSÕES}

Verificou-se que a maioria das regiões brasileiras apresenta uma quantidade significativa de contatos não examinados, em especial na região Nordeste, o que reforça a necessidade de intensificar pesquisas para o reconhecimento da realidade local e o planejamento e execução de ações que possam melhorar a assistência à comunidade. 
Vale ressaltar que o enfermeiro, juntamente com a equipe multiprofissional, deve atuar interdisciplinarmente, para melhorar a vigilância, promoção, e recuperação da saúde do indivíduo/comunidade, além da participação em educação permanente.

PALAVRAS-CHAVE: Hanseníase. Serviços de saúde comunitária. Vigilância epidemiológica.

\section{REFERÊNCIAS}

BRASIL. Ministério da Saúde. Secretaria de Vigilância em Saúde. Departamento de Vigilância das Doenças Transmissíveis. Diretrizes para vigilância, atenção e eliminação da Hanseníase como problema de saúde pública: manual técnico-operacional, 2016.

BRASIL. Departamento de Informática do Sistema Único de Saúde. 2016. DATASUS. Disponível em: 〈http://datasus.saude.gov.br/ >. Acesso em: 10 nov. 2016.

FARIA, D. R. et al. Avaliação de contatos de hanseníase. Revista Panorâmica On-Line, Barra do Garças- Mato Grosso, 2013.

LOBATO, D. C.; NEVES, D. C. O.; XAVIER, M. B. Avaliação das ações da vigilância de contatos domiciliares de pacientes com hanseníase no Município de Igarapé-Açu, Estado do Pará, Brasil. Revista Pan-Amazônica de Saúde, 2016.

PINTO NETO, J. M. et al. Análise do controle dos contatos intradomiciliares de pessoas atingidas pela hanseníase no Brasil e no estado de São Paulo de 1991 a 2012. Hansenologia Internationalis, 2013.

TEMOTEO, R. C. A. et al. Hanseníase: avaliação em contatos intradomiciliares. ABCS Health Sciences, 2013. 


\title{
Interdisciplinar
}

\section{TENDÊNCIA DA MORBIDADE POR PNEUMONIA NA REGIÃO NORDESTE}

\author{
ÁREA TEMÁTICA: Enfermagem na Saúde Coletiva \\ (Exposição Oral)
}

MARIA JOYCE TAVARES ALVES, Acadêmica do Curso de Bacharelado em Enfermagem, Universidade Federal de Campina Grande- Campus Cajazeiras.

GABRIELLE MANGUEIRA LACERDA, Acadêmica do Curso de Bacharelado em Enfermagem, Universidade Federal de Campina Grande- Campus Cajazeiras. JOSÉ AUGUSTO DE SOUSA RODRIGUES, Acadêmico do Curso de Bacharelado em Enfermagem, Universidade Federal de Campina Grande- Campus Cajazeiras. JOYCE DE SOUZA, Acadêmica do Curso de Bacharelado em Enfermagem, Universidade Federal de Campina Grande- Campus Cajazeiras. FERNANDA FORMIGA FLÁVIO, Especialista em Urgência e Emergência e Unidade de Terapia Intensiva, Universidade Federal de Campina Grande- Campus Cajazeiras.

\section{INTRODUÇÃO}

O envelhecimento populacional é uma resposta à mudança de alguns indicadores de saúde, especialmente a queda da fecundidade e da mortalidade e o aumento da esperança de vida e é um dos maiores desafios da saúde pública contemporânea. Os idosos são bastante acometidos por distúrbios respiratórios que são condições que possuem alta taxa de morbidade e mortalidade e resultam em impactos sociais, econômicos e pessoais. Dentre eles, merece destaque a pneumonia, que é a quinta causa de morte no Brasil na população idosa (ANDRADA, et al., 2015; FONTOURA, et al., 2010).

Vários fatores, dentre eles idade avançada e presença de algumas doenças crônicas, como doença pulmonar obstrutiva crônica, diabetes mellitus e insuficiência cardíaca, estão associados à sua maior gravidade e mortalidade. (AVELINO, et al., 2015; SCHWARTZMANN, et al., 2010).

No Brasil, são poucos e esparsos os dados disponíveis sobre a incidência da doença, particularmente em adultos. As taxas de internação por esse agravo no Brasil são elevadas, e especula-se que a falta de adesão às recomendações de diretrizes internacionais e nacionais para o seu manejo seja um dos fatores possivelmente envolvidos (DAUFENBACK, et al. 2014).

Tendo em vista o fato de que a população idosa é frequentemente acometida pelas doenças respiratórias, principalmente pela pneumonia, e que, como supracitado, ainda são restritas as informações e pesquisas sobre tal assunto, é de extrema importância aprofundar os estudos para que se possa garantir uma melhor assistência às pessoas idosas no que diz respeito à prevenção da doença.

\section{OBJETIVO DO TRABALHO}

Quantificar o índice de internações por pneumonia em pessoas acima de 60 anos na Região Nordeste em um dado recorte histórico, através dos índices de internações disponibilizados pelo sistema de Internações Hospitalares-SIH contido na plataforma DATASUS.

\section{MATERIAIS E MÉTODOS}


A referida pesquisa foi realizada por meio do DATASUS, utilizando os dados da região Nordeste, nos períodos de 2004 a 2013, do Sistema de Informação Hospitalar (SIH).

A população estudada contemplou todos os registros de idosos que foram internados na rede hospitalar cujos dados estão disponibilizados e acessíveis no SIH, entre os anos de 2004 a 2013, na região Nordeste. Por sua vez, a amostra foi composta dos registros de internações e óbitos da população acima de 60 anos com o diagnóstico de pneumonia constante no DATASUS (BRASIL, 2015).

Os dados foram coletados mediante as informações contidas no SIH, a partir do site http//www.datasus.gov.br foram: "informação de saúde", "informações epidemiológicas e morbidade", "geral, por local de residência", "Brasil por região e unidade de federação", "sexo", "faixa etária".

Para a consolidação dos dados ano a ano, foi utilizado um instrumento de coleta semiestruturado pelos autores. Para análise dos dados foi utilizado estatística simples descritiva, com proporção, com o qual se alcançou os dados percentuais. De posse dos dados coletados no sítio do DATASUS, foi reconstruída manualmente a tabela agrupando os dados por ano. Em seguida, foi construída no Excel 2010 uma tabela com frequência e percentual, incluindo todos os dados dos dez anos conforme variáveis investigadas.

\section{RESULTADOS E DISCUSSÃO}

Os resultados desta pesquisa estão descritos e dispostos na tabela 1, para melhor visualização e compreensão.

Tabela 1: Distribuição das internações e óbitos por pneumonia ocorridas na região nordeste na população acima de 60 anos - 2004 a 2013

\begin{tabular}{|c|c|c|c|c|c|c|c|}
\hline \multirow{2}{*}{ Idade } & \multicolumn{2}{|c|}{$60-69$} & \multicolumn{2}{|c|}{$70-79$} & \multicolumn{2}{|c|}{$>80$} & \multirow[t]{2}{*}{ Total } \\
\hline & $\mathbf{N}$ & $\%$ & $\mathbf{N}$ & $\%$ & $\mathbf{N}$ & $\%$ & \\
\hline 2004 & 14.039 & 33,48 & 14.896 & 35,53 & 12.992 & 30,99 & 41.927 \\
\hline 2005 & 11.142 & 32,29 & 11.790 & 34,17 & 11.503 & 33,34 & 34.503 \\
\hline 2006 & 10.667 & 31,07 & 11.849 & 34,51 & 11.817 & 34,33 & 34.333 \\
\hline 2007 & 10.659 & 30,06 & 12.108 & 34,15 & 12.692 & 35,79 & 35.459 \\
\hline 2008 & 10.311 & 29,75 & 11.770 & 33,96 & 12.577 & 36,29 & 34.658 \\
\hline 2009 & 12.438 & 28,96 & 14.435 & 33,61 & 16.077 & 37,43 & 42.950 \\
\hline 2010 & 11.107 & 28.21 & 13.055 & 33,16 & 15.205 & 38,62 & 39.367 \\
\hline 2011 & 12.162 & 26,29 & 15.692 & 33,93 & 18.394 & 39,77 & 46.248 \\
\hline 2012 & 11.262 & 26,93 & 13.727 & 32,82 & 16.831 & 40,25 & 41.820 \\
\hline 2013 & 11.983 & 25,50 & 15.411 & 32,8 & 19.587 & 41,69 & 46.981 \\
\hline Total & --- & --- & --- & --- & --- & --- & 404.246 \\
\hline
\end{tabular}

Fonte: DATASUS, Sistema de Informação de Internação Hospitalar (SIH). (2004-2013). Disponível em:〈http://www.datasus.gov.br>. Acesso em: 15 Set. 2015. 


\section{$\int\left[\begin{array}{l}\text { Revista de } \\ \text { Pesquisa } \\ \text { Interdisciplinar }\end{array}\right.$}

Em análise da tabela 1 nos deparamos com uma oscilação no número de internações, ao longo dos anos em estudo. Observa-se uma média aritmética de 397.246 casos para internações, com um aumento percentual médio de 18,65\% nas internações ao longo dos dez anos. No que diz respeito aos grupos etários, ambos mantiveram-se oscilantes no tocante as internações durante todo o período.

Logo as hospitalizações potencialmente evitáveis, com ênfase a pneumonia, acabam por representar um conjunto de problemas de saúde que deveriam ser solucionados nos primeiros níveis da atenção. Haja vista que pacientes atendidos em um serviço organizado de acordo com os princípios da atenção básica possuem menor índice de internação quando comparados aqueles atendidos por outros serviços de atenção (GOMES, et. al. 2015; ROCHA, et. al. 2014; SOUZA, et. al. 2014).

Nota-se que o percentual de internações transcorrendo os grupos etários mantem-se com oscilações discretas, porém quando a análise da faixa etária até 79 anos passa a ser verticalmente nos deparamos com uma redução potencial entre os anos, o que já não pode ser observado no grupo acima de 80 anos que apresentou um aumento ponderal de pouco mais de $10 \%$ no período investigado.

Esse fato gera preocupação, uma vez que a internação acarreta ao idoso um risco aumentado de adquirir infecção, em função das modificações fisiológicas do envelhecimento associado a processos invasivos e a diminuição da proteção imunológica. Vale ressaltar que a faixa etária acima dos 60 anos, associado ao processo infeccioso elevam os índices de morbimortalidade desses pacientes, quando comparados com indivíduos mais jovens (ZEPKA; CAETANO, 2015).

Os dados da região nordeste retratam a urgência de ampliação dos recursos físicos, humanos e de insumos que possibilitem a intervenção precoce e assim a diminuição dos índices de morbidade e consequentemente o de mortalidade por estarem intimamente ligados. Uma vez que essa região ainda apresente uma grande porcentagem de sua população residindo em zona rural e com restrições no acesso aos serviços de saúde, educação e saneamento básico (DÓREA; PINA; SANTOS, 2015).

\section{CONCLUSÕES}

Complicações respiratórias, como a pneumonia, são relativamente frequentes em idosos contribuindo para o aumento da morbimortalidade e o tempo de permanência hospitalar.

Verificou-se que a pneumonia apresenta-se com elevados índices de morbimortalidade principalmente no grupo acima dos 80 anos. Confirmando a necessidade do controle das infecções potencialmente evitáveis pela atenção primaria fazendo com que o paciente não urgente busque o serviço especializado apenas quando realmente necessário.

Além disso, as politicas públicas assim como os serviços de medicina suplementar necessitam de melhorias para atender eficazmente essa população visto que a prevenção de doenças e dependência de tratamentos dispendiosos evita gastos futuros para o próprio governo e deveriam ser traçadas conforme a realidade regional.

PALAVRAS-CHAVE: Pneumonia. Idoso. Epidemiologia.

\section{REFÊRENCIAS}

ANDRADA, M. M. C. et al. Diagnóstico de enfermagem para idosos internados segundo a Classificação Internacional das Práticas de Enfermagem. Rev. Rene. v. 16, n. 1, p. 97- 105, 2015. Disponível em: 


\section{$\mathrm{RPP}$}

$\langle$ http://www.revistarene.ufc.br/revista/index.php/revista/article/view/1905 >. Acessado em: 28 Set. 2015.

AVELINO, C. C. V. et al. Qualidade da atenção primária à saúde: uma análise segundo as internações evitáveis em um município de minas gerais, Brasil. Rev. Ciencia \& Saúde Coletiva. v. 20, n. 4, p. 1285-1293, 2015. Disponível em:

$<$ http://www.scielosp.org/pdf/csc/v20n4/pt_1413-8123-csc-20-04-01285.pdf > . Acessado em: 27 Set. 2015.

BRASIL. Departamento de Informática do SUS. DATASUS. Home. Disponível em:<http://www.datasus.gov.br >. Acesso em: 15 Set. 2015.

DAUFENBACK, L. Z. Impacto da vacinação contra influenza na morbidade hospitalar por causas relacionadas à influenza em idosos no Brasil. Rev. Epidemiol. Serv. Saúde. v. 23, n. 1, p. 9-20, Brasilía, 2014. Disponível em: <http://scielo.iec.pa.gov.br/scielo.php?pid=S167949742014000100002\&script=sci_arttext $>$. Acessado em: 28 Set. 2015.

DÓREA, G. S; PINA, M. G. M; SANTOS, D. Aspectos nutricionais de idosos praticantes de atividade física. Rev. Demetra. v. 10, n. 2, p. 347-360, 2015. Disponível em: <http://www.epublicacoes.uerj.br/index.php/demetra/article/view/14793\#.Vglpo26PvHo >. Acessado em: 28 Set. 2015.

FONTOURA, et. al. Análise temporal das internações hospitalares e óbitos causados por doenças do aparelho respiratório em idoso. Rev. Bras. Geriatr. Gerontol. v. 13, n. 1, p. 121132, 2010. Disponível em: <http://www.scielo.br/scielo.php?pid=S180998232010000100013\&script=sci_arttext $>$. Acessado em: 08 Set. 2015.

GOMES, J. C. et al. Critério de admissão em UTI e avaliação de prognóstico de paciente idoso. Rev. Enfermag. Revista. v. 18, n. 1, p. 51-57, 2015. Disponível em: $<$ http://periodicos.pucminas.br/index.php/enfermagemrevista/article/view/9379>.

Acessado em: 28 Set. 2015.

SCHWARTZMANN, et. al. Pneumonia comunitária e pneumonia hospitalar em adultos. Rev. Faculd. Medic. Ribeir. Preto. v. 43, n. 3, p. 238-248, 2010. Disponível em: $<$ http://revista.fmrp.usp.br/2010/vol43n3/Simp3_Pneumonia\%20comunit\%E1ria\%20e\%2 0pneumonia\%20hospitalar\%20em\%20adultos.pdf >. Acessado em 08 Set. 2015.

SOUZA, I. C. P. et al. Perfil de paciente dependentes hospitalizados e cuidadores familiares: Conhecimento e preparo para as práticas do cuidado domiciliar. Rev. Min. Enfermag. v. 18, n. 1, p. 164-172, 2014. Disponível em: <http://www.reme.org.br/artigo/detalhes/916> . Acessado em: 28 Set. 2015.

ZEPKA, A. S; CAETANO, T. L. A urgência no atendimento ao idoso: Estudo de Caso. Rev. Univap. v. 21, n. 37, 2015. Disponível em: $<$ http://revista.univap.br/index.php/revistaunivap/article/view/280>. Acessado em: 28 de Set. 2015. 


\title{
ACIDENTES COM ANIMAIS PEÇONHENTOS: EPIDEMIOLOGIA DAS NOTIFICAÇÕES NA REGIÃO NORDESTE NO PERÍODO DE 2010-2015
}

\author{
LINHA DE PESQUISA: Enfermagem na Saúde Coletiva; exposição oral
}

WAGNER MACIEL SARMENTO

Acadêmico do curso de bacharelado em enfermagem do Centro de Formação de Professores da Universidade Federal de Campina Grande.

POLIANA CARLA BATISTA DE ARAÚJO

Acadêmica do curso de bacharelado em enfermagem do Centro de Formação de Professores

da Universidade Federal de Campina Grande.

BRUNO NEVES DA SILVA

Acadêmico do curso de bacharelado em enfermagem do Centro de Formação de Professores da Universidade Federal de Campina Grande.

EDER ALMEIDA FREIRE

Doutor em bioquímica. Docente do Centro de Formação de Professores da Universidade

Federal de Campina Grande.

\section{INTRODUÇÃO}

Os acidentes com animais peçonhentos representam um problema de saúde pública, principalmente por causa da gravidade e frequência com que ocorrem. Alguns grupos como idosos, gestantes crianças e adolescentes (menores que 14 anos), são considerados mais vulneráveis, pois apresentam maior risco de óbito (SILVA; BERNARDE; ABREU, 2014).

Entende-se por animal peçonhento, segundo Pinho; Pereira (2001), os animais que sintetizam e possuem um aparelho especializado para inoculação de um determinado veneno (peçonha), onde este passa através de glândulas, de forma ativa, as quais se comunicam com dentes ocos, ferrões ou aguilhões, a depender do tipo de animal.

Os acidentes por animais peçonhentos são agravos que merecem atenção, visto que acontecem cerca de 100 mil casos anualmente no Brasil. As vítimas deste tipo de acidente, principalmente nos casos de ofidismo (acidentes com serpentes), estão sujeitas a inúmeras complicações, ou até mesmo à morte (CHIPPAUX, 2015). Levando esses dados em consideração, contata-se a relevância social e acadêmica da realização deste estudo, que pode contribuir para adoção de medidas que visem à prevenção desses acidentes, a partir do conhecimento do seu perfil epidemiológico.

\section{OBJETIVO DO TRABALHO}

Descrever as características epidemiológicas dos casos notificados de acidentes com animais peçonhentos na região Nordeste no período de 2010-2015.

\section{MATERIAIS E MÉTODOS}

Realizou-se um estudo descritivo, de base secundária com abordagem quantitativa no mês de outubro de 2016 utilizando-se de dados oficias do Sistema de Informação de Agravos e Notificação (SINAN), disponíveis no Departamento de Informática do Sistema Único de Saúde de forma online. A amostra constituiu-se de casos de acidentes por animais peçonhentos na região Nordeste entre os anos de 2010 e 2015. 
A análise dos dados foi realizada por meio de tabulações e de estatística descritiva de porcentagem no software Microsoft Excel 2010®, utilizando as seguintes variáveis: sexo, faixa etária, grau de escolaridade e tipo de acidente.

\section{RESULTADOS E DISCUSSÃO}

A análise dos registros permitiu constatar um total de 271.044 notificações. A distribuição no intervalo de anos definido demonstra elevado número de casos e encontra-se na tabela abaixo:

Tabela 1 - Número de acidentes com animais peçonhentos notificados na região Nordeste no período de 2010-2015

\begin{tabular}{c|c}
\hline \multicolumn{1}{c|}{ Ano } & $\begin{array}{c}\text { Número de } \\
\text { notificações }\end{array}$ \\
\hline 2010 & 38.263 \\
\hline 2011 & 44.875 \\
\hline 2012 & 43.697 \\
\hline 2013 & 52.708 \\
\hline 2014 & 58.921 \\
\hline 2015 & 32.580 \\
\hline
\end{tabular}

Fonte: Departamento de Informática do Sistema Único de Saúde. Site. 2016. Disponível em: <http://datasus.saude.gov.br/>. Acesso em: 03 nov. 2016.

Das notificações, observa-se que 49,88\% (135.268) pertenciam ao sexo masculino e $50,09 \%$ (135.821) ao sexo feminino. Observa-se ainda que $0,02 \%$ (56) dos casos notificados obtiveram sexo ignorado no momento da notificação. Vale salientar que esses resultados, quando comparados ao da tabela acima, apresentam-se divergentes quanto ao número de casos, pois, as notificações disponíveis relacionadas ao sexo das vítimas totalizam 271.143 casos, enquanto as notificações no geral, no intervalo definido, 271.044 notificações. Esses resultados discordam de outros achados na literatura, visto que diversos estudos apontam predominância de acometimento em indivíduos do sexo masculino, devido ao homem estar geralmente mais envolvido em atividades fora do lar (D'AGOSTINI; CHAGAS; BELTRAME, 2011).

A faixa etária dos indivíduos vítimas desses acidentes variou de indivíduos menores de um ano a indivíduos com idade superior a 80 anos. A tabela 2 traz a relação.

Tabela 2 - Faixas etárias dos indivíduos vítimas de acidentes com animais peçonhentos notificados na região Nordeste no período de 2010-2015

\begin{tabular}{c|c}
\hline Faixa etária & Número de notificações \\
\hline Ignorado/em branco & 60 \\
\hline$<1$ Ano & 4.016 \\
\hline $1-4$ & 14.770 \\
\hline $5-9$ & 43.697 \\
\hline $10-14$ & 52.708 \\
\hline $15-19$ & 58.921 \\
\hline $20-39$ & 32.580 \\
\hline $40-59$ & 65.096 \\
\hline $60-64$ & 10.672 \\
\hline $65-69$ & 8.030 \\
\hline $70-79$ & 9.887 \\
\hline
\end{tabular}

RPI Revista de Pesquisa Interdisciplinar, Cajazeiras, v. 2, Edição Especial, 2017. 


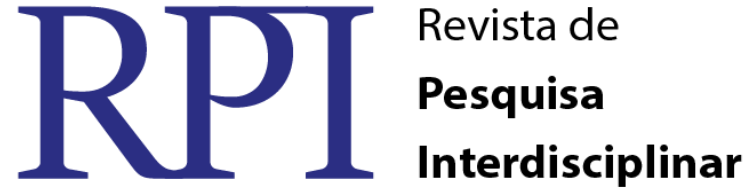

$80 \mathrm{e}+\quad 3.697$

Fonte: Departamento de Informática do Sistema Único de Saúde. Site. 2016. Disponível em: <http://datasus.saude.gov.br/ >. Acesso em: 03 nov. 2016.

Percebe-se predominância de acidentes com indivíduos entre 40 a 59 anos. Esses resultados encontram-se apoiados em outros estudos, como no de Oliveira; Leite; Costa (2011) e D'Agostini; Chagas; Beltrame (2011). Em contrapartida, outros estudos contrastam com esse resultado, apontando maior ocorrência de casos nos indivíduos entre 10 a 19 anos de idade, o que pode estar relacionado à inserção prematura desses indivíduos no trabalho agrícola, provavelmente justificada para auxiliar no aumento da renda familiar (LEMOS et al., 2009). Cabe destacar que essas faixas etárias também apresentaram alto registro de casos na presente pesquisa.

Em relação ao grau de escolaridade dos casos notificados, observa-se que na maioria das notificações esse campo não foi preenchido, constando como em branco ou ignorado em 90,34\% (244.971) das notificações. Do restante dos casos, 9,65\% (26.174) apresentaram nenhum grau de escolaridade. Ainda que o grau de escolaridade não seja uma condição determinante para a incidência dos acidentes, a ausência de conhecimentos sobre as medidas de prevenção e a exposição a ocupações menos especializadas podem propiciar a ocorrência desses eventos (SANTANA; SUCHARA, 2015).

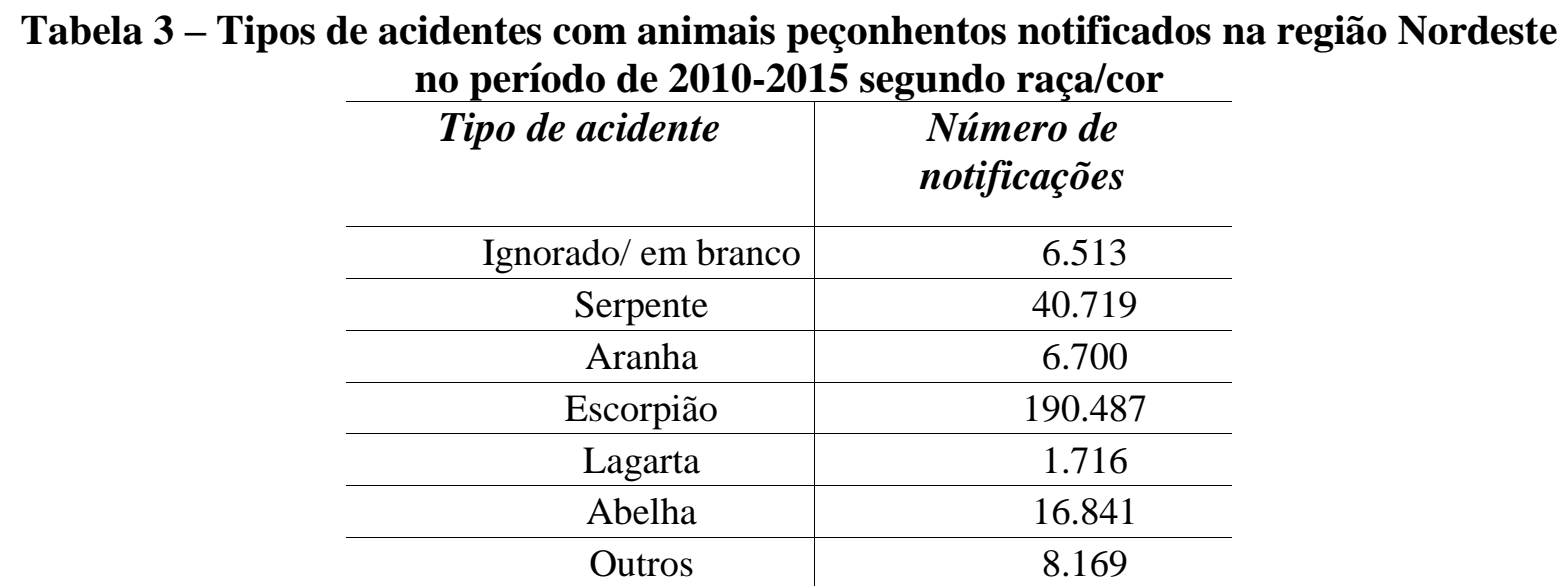

Fonte: Departamento de Informática do Sistema Único de Saúde. Site. 2016. Disponível em: <http://datasus.saude.gov.br/>. Acesso em: 03 nov. 2016.

A tabela 3 traz os tipos de acidentes com animais peçonhentos registrados. Nota-se que a maioria desses se deu através da picada de escorpiões. Desses casos, 91,71\% (174.703) evoluíram para cura, 0,12\% (247) para óbito pelo agravo notificado, 0,01\% (21) para óbito por outras causas e $8,14 \%$ (15.516) obtiveram o campo de evolução do caso ignorados ou em branco.

A alta prevalência do escorpionismo (acidentes envolvendo escorpiões) é observada em outros estudos, sendo que a região Nordeste é considerada uma área endêmica para esses acidentes. Esses elevados índices podem ser consequências das constantes ações humanas sobre o habitat desses animais, inclusive pelas expansões de construções sobre áreas naturais (SILVA, 2012).

Para os acidentes com serpentes, a maioria se deu com o gênero Bothrops com 61,56\% (25.069) dos casos; seguida por acidentes com serpentes do gênero Crotalus constituindo 10,34\% (4.214); gênero Micrurus com 1,69\% (689) e gênero Lachesis com 0,50\% (206) dos casos. O percentual de acidentes com serpentes não venenosas foi de 7,63\% (3.109) dos casos 


\section{$\int\left[\begin{array}{l}\text { Revista de } \\ \text { Pesquisa } \\ \text { Interdisciplinar }\end{array}\right.$}

registrados e 18,25\% (7.432) das notificações obtiveram esse quesito em branco ou ignorado no momento de notificação.

A predominância dos acidentes com o gênero Bothrops também foi verificada em outros estudos, associando os resultados à habilidade que esses animais possuem de adaptarse a diferentes meios e estarem presentes nos mais variados tipos de ecossistemas (LEMOS et al., 2009). Além disso, essas serpentes possuem hábitos diversos e são frequentemente mais agressivas (OLIVEIRA; COSTA, 2011). A menor incidência de casos com os demais gêneros de serpentes, bem como o percentual elevado de casos com categorias não conhecidas estão em concordância com a literatura (SARAIVA, et al., 2012).

Quanto à evolução dos casos, 83,42\% (33.970) evoluíram para cura, 0,56\% (230), obtiveram óbito como desfecho; $0,04 \%$ (18) evoluíram para óbito por outras causas e 15,96\% (6.501) tiveram esse registro ignorado ou em branco. A taxa de mortalidade por esses incidentes está relacionada à brevidade do intervalo de tempo entre o acidente e o atendimento médico, sendo que um cuidado rápido pode evitar o óbito e complicações como insuficiência renal e necrose tecidual (BONAN et al., 2010).

Os registros dos acidentes com abelhas apontaram que 89,62\% (15.093) dos casos evoluíram para cura; $0,31 \%$ (53) obtiveram óbito como desfecho, 0,04\% (7), evoluíram para óbito por outras causas e 10,02\% (1.688) dos casos obtiveram esse registro ignorado no momento da notificação. A intensidade da reação desencadeada em cada vítima desta espécie de agravo irá variar de indivíduo para indivíduo, podendo evoluir de uma simples manifestação dermatológica para uma reação histamínica e culminar em óbito (ROAT et al., 2014).

\section{CONCLUSÕES}

Inferiu-se com esse estudo que, apesar de não ser um assunto amplamente divulgado pelas políticas públicas de saúde, existe um vasto panorama de ocorrência de casos de acidentes com animais peçonhentos, especialmente na região Nordeste, ocasionando agravos que podem ser considerados uma preocupação de saúde pública.

As fragilidades encontradas relacionam-se ao sistema de informação utilizado, visto que o número de notificações divergiu quando comparados o número de casos gerais com o número de casos por sexo, por exemplo; e ao perfil das notificações, visto que algumas categorias foram subnotificadas durante o registro dos dados, como o grau de escolaridade dos indivíduos acidentados.

A importância da realização de medidas que levem aos sujeitos informações sobre a prevenção e o manejo com esses acidentes pode representar uma estratégia importante para diminuir e evitar agravos por esses incidentes. O enfermeiro, nesse contexto, visto ser o profissional que está mais diretamente ligado ao paciente, deve criar oportunidades de empoderar a população acerca desses temas e promover a saúde de seus pacientes.

PALAVRAS-CHAVE: Animais Peçonhentos. Epidemiologia. Saúde Pública.

\section{REFERÊNCIAS}

BONAN, P.R.F. et al. Perfil epidemiológico dos acidentes causados por serpentes venenosas no norte do estado de Minas Gerais, Brasil. Revista de Medicina de Minas Gerais. v. 20, n. 4, p. 503-507, 2010.

CHIPPAUX, Jean-Philippe. Epidemiologia dos envenenamentos por animais peçonhentos terrestres no Brasil com base na notificação de casos: de fatos óbvios para contingências. 


\section{$\mathrm{RPP}$}

Journal of Venomous Animals and Toxins including Tropical Diseases. v. 21, p. 1-17, 2015.

D'AGOSTINI, F.M.; CHAGAS, F.B.; BELTRAME, V. Epidemiologia dos acidentes por serpentes no município de Concórdia, SC no período de 2007 a 2010 . Evidência, Joaçaba. v. 11, n. 1, p. 51-60, 2011.

LEMOS, J.C. et al. Epidemiologia dos acidentes ofídicos notificados pelo Centro de Assistência e Informação Toxicológica de Campina Grande (Ceatox-CG), Paraíba. Revista brasileira de epidemiologia. v. 12, n. 1, 2009.

OLIVEIRA, H.F.A.; LEITE, R.S.; COSTA, L.C.F. aspectos clínico-epidemiológicos de acidentes com serpentes peçonhentas no município de Cuité, Paraíba, Brasil. Gazeta médica da Bahia. v. 81, n. 1, p. 14-19, 2011.

PINHO, F.M.O.; PEREIRA, I.D. Ofidismo. Revista da Associação Médica Brasileira. v. 47, n. $1,2001$.

ROAT, T.C. et al. Modification of the brain proteome of Africanized honeybees (Apis mellifera) exposed to a sub-lethal doses of the insecticide Fipronil. Ecotoxicology (London). v. 1, n. 1, 2014.

SANTANA, V.T.P.; SUCHARA, E.A. Epidemiologia dos acidentes com animais peçonhentos registrados em Nova Xavantina - MT. Revista de epidemiologia e controle de infecção. v. 5, n. 3, 2015.

SARAIVA, M.G. Perfil epidemiológico dos acidentes ofídicos no Estado da Paraíba, Brasil, 2005 a 2010. Epidemiolia e Serviços de Saúde. v.21, n. 3, 2012.

SILVA, J.D. Escorpianismo no Brasil. 2012. (Trabalho de conclusão de curso) Universidade Federal do Rio Grande do Sul, Porto Alegre, 2012.

SILVA, A.M.; BERNARDE, P.S.; ABREU, L.C. Acidentes Com Animais Peçonhentos No Brasil por Sexo E Idade. Revista brasileira de crescimento e desenvolvimento humano. $v$. 25, n. 1, p. 54-62p, 2015. 


\section{TRATAMENTO FARMACOLÓGICO DOS IDOSOS COM HIPERTENSÃO ARTERIAL SISTÊMICA: RELATO DE EXPERIÊNCIA} ÁREA TEMÁTICA: Enfermagem na Saúde Coletiva, exposição oral.

GABRIELLA SILVA NOGUEIRA- Acadêmica de Enfermagem da Universidade Federal de

Campina Grande (UFCG)

LUCELIA FERNANDES DINIZ- Acadêmica de Enfermagem da Universidade Federal de

Campina Grande (UFCG)

MARIA IASMIN LOPES RAMALHO- Acadêmica de Enfermagem da Universidade

Federal de Campina Grande (UFCG)

TAINÁ MARIA VIDAL DOS SANTOS- Acadêmica de Enfermagem da Universidade

Federal de Campina Grande (UFCG)

GERLANE CRISTINNE BERTINO VERÁS - Mestranda em Enfermagem pela

Universidade Regional do Cariri - Docente da Universidade Federal de Campina Grande INTRODUÇÃO

A prevalência da hipertensão arterial sistêmica (HAS) em indivíduos com mais de 60 anos é superior a $60 \%$, sendo o diagnóstico adequado e a persistência dos pacientes no acompanhamento é determinante para atingir a eficácia do tratamento e reduzir a morbimortalidade cardiovascular decorrentes da doença (BASTOS-BARBOSA et al., 2012).

A finalidade do anti-hipertensivo é promover a diminuição da pressão arterial (PA), dos eventos cardiovasculares fatais e não fatais, e se possível da taxa de mortalidade (FHEMIG, 2013).

De acordo com Tavares et al. (2016), diversos fatores influenciam na não aceitação dos idosos ao tratamento farmacológico da HAS, como os aspectos socioeconômicos, demográficos, psicossociais, culturais, regime terapêutico, relacionamento com os profissionais de saúde, baixa escolaridade, apoio social e familiar, provocando o descontrole da pressão arterial sistêmica. Dessa forma, se torna imprescindível o diagnóstico correto e o acompanhamento do tratamento clínico para a diminuição do impacto da doença e dos óbitos causados por complicações cardiovasculares que incidem na população idosa.

\section{OBJETIVO DO TRABALHO}

Relatar a experiência de discentes de enfermagem ao verificar como ocorre a adesão ao tratamento farmacológico de idosos com hipertensão arterial sistêmica.

\section{METODOLOGIA}

Trata-se de uma pesquisa descritiva, do tipo relato de experiência, decorrente das aulas práticas de discentes do $5^{\circ}$ período do curso de bacharelato em Enfermagem de uma Universidade Federal localizada no estado da Paraíba. 


\section{$\int\left[\begin{array}{l}\text { Revista de } \\ \text { Pesquisa } \\ \text { Interdisciplinar }\end{array}\right.$}

Anais do $1^{\circ}$ Encontro de Iniciação Científica da ETSC - 13 e 14 de junho de 2017.

As aulas práticas ocorreram em agosto de 2016 nos domicílios de idosos com hipertensão arterial sistêmica residentes na área de abrangência de uma estratégia saúde da família. As discentes foram divididas em duplas, sendo supervisionadas direta e indiretamente pela Agente Comunitária de Saúde da microárea, a monitora e a professora da disciplina Enfermagem Clínica I.

Foram realizadas quinze visitas domiciliares, onde as discentes desenvolveram atividades de orientações em saúde e cuidados diretos, como aferição da PA, verificação das medidas antropométricas e preenchimento da caderneta do idoso.

\section{RESULTADOS E DISCUSSÃO}

Durante os cuidados de enfermagem prestados nas visitas domiciliares, notou-se que a maioria dos pacientes eram do sexo masculino e moravam sozinhos. Dos achados, o ponto considerado mais preocupante foi relacionado ao uso das medicações, visto que muitos não seguiam a recomendação de tomá-los no horário e na dosagem prescrita ou mesmo não faziam uso destes. Esses achados nos remetem a importância de promover ações estratégicas de saúde pela equipe multiprofissional para assistir integralmente os idosos e envolvê-los efetivamente em seu processo saúde-doença, tornando-os agentes ativos. Para Aiofi et al. (2015), dentre os fatores que contribuem para a não adesão dos idosos ao tratamento farmacológico da HAS, podemos citar a presença de outras comorbidades que dificultem a leitura e o entendimento das informações presentes nas bulas dos medicamentos, compreensão do uso da posologia adequada, esquecimento do uso das medicações e déficit cognitivo.

Destaca-se que durante as visitas foram evidenciadas a carência de conhecimento dos idosos sobre o processo fisiopatológico e as principais complicações da HAS. Diante disso, as discentes de enfermagem prestaram as informações necessárias para a sensibilização da importância do tratamento farmacológico contínuo, a ingesta de alimentos hipossódicos, a prática de exercícios físicos e as visitas regulares a Unidade Básicas de Saúde de referência, ressaltando que o uso de fármacos associados a hábitos de vida saudável é primordial para evitar as complicações da HAS, que eventualmente possam surgir.

\section{CONSIDERAÇÕES FINAIS}

Constatou-se, a partir da experiência vivenciada, que a falta de informação é um fator ainda presente na população idosa em relação ao uso das medicações, implicando assim na dificuldade do idoso a aderir ao tratamento de forma correta. As discentes, 


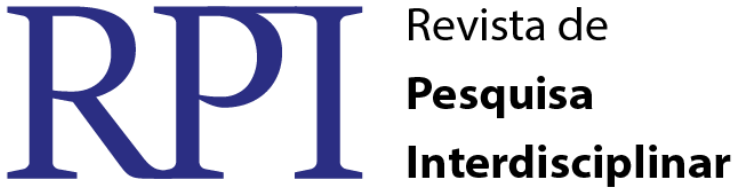

como futuras profissionais da enfermagem, devem atentar para o papel do enfermeiro da atenção primária à saúde, para planejar e organizar ações de educação em saúde que promovam a sensibilização do indivíduo e contribua para a melhoria da adesão ao tratamento da hipertensão arterial, favorecendo o controle de complicações e mortalidade com causa básica cardiovascular, em especial, pelo acompanhamento adequado dos idosos em equipe multidisciplinar.

PALAVRAS CHAVES: Adesão à medicação. Hipertensão. Idoso.

\section{REFERENCIAS}

AIOLFI, R.C. et al. Adesão ao uso de medicamentos entre idosos hipertensos. Rev.

Bras. Geriatr. Gerontol, Rio de Janeiro, 397-404, 2015.

BASTOS-BARBOSA, R.G. et al. Adesão ao tratamento e controle da pressão arterial em idosos com hipertensão. Arq.Bras.Cardio, Ribeirão Preto- SP, 2012. FHEMIG. Diretrizes clínicas e protocolos clínicos. Protocolo n ${ }^{\circ} 044$. Hipertensão Arterial Sistêmica. Minas Gerais, p.415-445, 2013.

TAVARES, D.M. et al. Quality of life and accession to the pharmacological treatment among elderly hypertensive. RevBrasEnferm [Internet], 122-9, 2015. 


\title{
$\mathrm{RPP}$
}

\section{PRÁTICAS DE TRABALHO DE AGENTE COMUNITÁRIO DE SAÚDE: ORIENTADOR DE AÇÕES, SERVIÇOS E CUIDADOS EM SAÚDE ÁREA TEMÁTICA: ENFERMAGEM NA SAÚDE COLETIVA}

\author{
(Exposição oral)
}

ARICLES MILLANE GOMES BATISTA ${ }^{1}$, Acadêmica de Enfermagem, pela Universidade Federal de Campina Grande, campus Cajazeiras - PB. (APRESENTADOR) EDILAINE CRISTINA MARTINS DA SILVA ${ }^{2}$, Enfermeira formada pela Universidade Federal de Campina Grande, campus Cajazeiras - PB. MARCELO COSTA FERNANDES ${ }^{3}$, Professor Doutor em Cuidados Clínicos em Enfermagem e Saúde, Docente da Universidade Federal de Campina Grande, Unidade Acadêmica de Enfermagem - UAENF, campus Cajazeiras - PB. (ORIENTADOR)

\section{INTRODUÇÃO}

O Agente Comunitário de Saúde (ACS), membro que compõe a equipe de profissionais da Estratégia de Saúde da Família (ESF), assume papel importante na consolidação e da melhoria da assistência prestada na Atenção Básica (AB). Por meio do processo de trabalho possibilita a construção de vínculo dos pacientes com a unidade, além de fomentar a promoção da saúde, prevenção e identificação das doenças que venham acometer a comunidade adscrita.

O processo de trabalho do ACS ocorre a partir da prática de ações que visam o cuidado. Essas atividades são realizadas por meio da relação com os usuários, espaço este em que o ACS pode usar de tecnologias de cuidado, como a escuta, o acolhimento e a fala, as quais visam sanar as necessidades de saúde da comunidade sob sua responsabilidade (FERREIRA et al., 2009).

O cotidiano de trabalho do ACS é complexo, já que adentra as residências da população, escuta os problemas, obtém informações sobre as condições de vida e buscam, junto com os demais membros da equipe, estratégias para solucionar as problemáticas identificadas (PERES et al., 2011).

Além disso, por fazer parte da comunidade em que trabalha, o ACS conhece as particularidades, tanto do território, quanto das famílias, o que lhe proporciona condições e subsídios para construir um plano de ações adequadas à realidade encontrada (GALAVOTE, 2011).

Destaca-se ainda que as atividades relacionadas ao processo de trabalho do ACS no âmbito da $\mathrm{AB}$ estão apontadas na Portaria $\mathrm{N}^{\circ}$ 2.488, de 21 de outubro de 2011, pertencente à Política Nacional de Atenção Básica (PNAB), as quais possuem como base a promoção, proteção e recuperação da saúde do sujeito, família e comunidade (BRASIL, 2011).

Porém há vários obstáculos que dificultam a efetivação das práticas do ACS como: a ausência de reconhecimento das suas funções ora pela gestão ora pela própria população atendida; a precarização do processo de trabalho; a desmotivação e o medo em decorrência da violência e criminalidade que intimidam, bem como impedem a realização de ações em áreas com grande vulnerabilidade (SANTOS, DAVID, 2011).

\section{OBJETIVO DO TRABALHO}

Analisar as práticas de trabalho de Agente Comunitário de saúde com ênfase nas orientações de ações, serviços e cuidados em saúde.

\section{MATERIAIS E MÉTODOS}




\section{$\mathrm{RPP}$}

Este estudo é de natureza descritiva com abordagem qualitativa. A pesquisa foi realizada nas Unidades Básicas de Saúde (UBS) do Município de Cajazeiras no estado Paraíba. Esta cidade faz parte da $4^{\text {a }}$ Macrorregião de Saúde e $9^{a}$ Gerência Regional de Saúde da Paraíba e apresenta atualmente 23 Equipes de Saúde da Família para atender às necessidades de saúde da população.

O encerramento da coleta de dados ocorreu a partir do momento que foi identificada a saturação teórica. Foram selecionadas aleatoriamente 11 UBS do município de Cajazeiras, sendo entrevistados dois ACS de cada unidade. Os critérios de inclusão estabelecidos para participação na pesquisa foram: atuar há pelo menos um ano como ACS no município e não estarem ausentes do trabalho por estarem de férias ou em licença de qualquer natureza, seja saúde, maternidade, entre outras, no período estabelecido para a coleta de dados.

A técnica utilizada para a coleta de dados foi a entrevista semiestruturada. Os dados obtidos nas entrevistas para esta pesquisa foram organizados por meio da técnica do Discurso do Sujeito Coletivo (DSC), uma forma de obter o discurso coletivo com base nos discursos individuais. O DSC é uma proposta de organização e tabulação de dados qualitativos de natureza verbal, obtidos de depoimentos (LEFÈVRE; LEFÈVRE, 2005).

Quanto à análise do conteúdo das entrevistas dos ACS, primeiramente, foi realizado a leitura flutuante das falas com o intuito de compreender o conjunto das transcrições. Posteriormente, foram necessárias leituras sucessivas para que fosse possível identificar os núcleos de sentido relacionados às questões norteadoras que compuseram o roteiro da entrevista. Logo após, foram identificadas as Expressões-Chaves $(\mathrm{ECH})$ em cada resposta, representadas pelas falas literais dos ACS. Destas expressões, foram elaboradas as Ideias Centrais (IC), que foram organizadas em categorias e agrupadas e divididas em temáticas para a construção dos Discursos do Sujeito Coletivo (DSC). Vale destacar que cada temática surgiu como resultado das respostas das perguntas norteadoras realizadas pelo pesquisador durante as entrevistas.

As pesquisas requerem ética em sua realização, portanto este estudo respeitou a condição humana e seguiu as recomendações da resolução 466/2012 do Conselho Nacional de Saúde. O estudo teve início após a aprovação do projeto pelo Comitê de Ética em Pesquisa (CEP) da instituição de ensino, sob número 1.347.452. A participação na pesquisa foi iniciada mediante o esclarecimento sobre os objetivos do estudo e a assinatura do Termo de Consentimento Livre e Esclarecido (TCLE).

\section{RESULTADOS E DISCUSSÕES}

Participaram do DSC desta investigação seis ACS, sendo apresentado a seguir:

DSC: $O$ meu trabalho é justamente isso, é uma troca de experiências, levar e trazer informação para aquele que não tem. Eu procuro dar o máximo de mim levando informações pra comunidade, ou seja, informar quais os serviços que temos na nossa unidade de saúde pra que eles venham conhecer o trabalho, o que temos a oferecer a cada um deles, fazer com que eles entendam que é possivel vir na unidade e conseguir o que eles estão precisando. Quando a gente sai pra comunidade, fala do cronograma do posto, quais são os atendimentos, quais são os profissionais, que horas eles estão na unidade e também quando as pessoas procuram mais a unidade, quando as mulheres fazem prevenção, levam as crianças pra fazer a puericultura, tudo isso fortalece a atenção básica. Nas nossas visitas a gente faz orientação, a gente faz a busca ativa dos usuários pra unidade básica de saúde, tiro as dúvidas das famílias, alerto quanto aos cuidados com os idosos, gestantes e acompanho como anda a saúde de todos da minha área. 


\section{$\int\left[\begin{array}{l}\text { Revista de } \\ \text { Pesquisa } \\ \text { Interdisciplinar }\end{array}\right.$}

Observa-se que os ACS's são profissionais comprometidos com a comunidade, onde através das informações procuram orientar as famílias sobre os serviços de saúde oferecidos, visando melhorar o cuidado com a saúde, bem como aumentar o acesso das pessoas às unidades de saúde. Vale salientar que o ACS não só leva os problemas da comunidade para a unidade, mas também mantém a ação no sentido contrário, socializando com a população informações sobre saúde.

O ACS tem o papel de acompanhar as famílias de sua comunidade, compartilhar orientações por meio de atos educativos, facilitar o acesso até a unidade de saúde, desenvolver ações de baixa complexidade, possibilitar a entrada dos demais membros da equipe nas residências das pessoas, entre outras ações.

Percebe-se no DSC que os ACS's consideram as orientações, a prevenção de doenças e à promoção da saúde como ações prioritárias nos serviços básicos de saúde, que tem como finalidade reduzir a carência de informações das famílias, além de colaborar para a melhoria da qualidade de vida. Para os ACS as informações e as orientações transmitidas, facilitam a vida das pessoas e com essas ações se consideram mais úteis diante das pessoas e das famílias.

Outro ponto presente nesse DSC foi a força de vontade em ajudar o próximo. Para Santos e Francolli (2010) os ACS's se revelam comprometidos em incentivar mudanças dos hábitos de vida na comunidade, através de ações concretas, de ouvir com atenção, de orientações propícias, que além de acarretar vantagem à comunidade são relevantes para fortalecer a ligação entre comunidade e unidade de saúde.

De acordo com Santana et al., (2013) as ações dos ACS's são voltadas para o compartilhamento de informações e orientações sobre saúde e sobre a rotina e o funcionamento da UBS. Ao executá-lo, realiza orientações direcionadas à alimentação saudável, prática de atividade física e prevenção de agravos e doenças.

As ações de orientação realizadas pelos ACS estão em conformidade com a portaria 2.488 de 21 de outubro de 2011, que aprova a Portaria Nacional de Atenção Básica (PNAB), onde estabelece que esse trabalhador deve orientar as famílias quanto à utilização dos serviços de saúde disponíveis, assim como desenvolver ações educativas individuais e coletivas nos domicílios e na comunidade (BRASIL, 2011).

Por fim, uma das principais atividades que o ACS realiza e que pode articular com as ações educativas é a visita domiciliar, onde podem socializar orientações sobre higiene, verificação do cartão de vacina, uso correto de medicamentos, cuidados com recém-nascidos e com idosos, alimentação saudável e importância da prática de exercício físico.

\section{CONCLUSÕES}

Ficou evidente ao longo das discussões que pelo fato do ACS atuar na área onde reside, acaba se tornando uma ponte entre a comunidade e a equipe de saúde. Ainda segundo os investigados o ACS facilita o acesso aos serviços e os cuidados com a saúde por meio das informações e orientações dadas às famílias.

É importante destacar que este estudo apresenta limitações, uma vez que foi desenvolvido na Estratégia Saúde da Família de um município, sendo difícil generalizar os resultados a nível nacional, visto que os resultados dependem da dinâmica do processo de trabalho dos ACS de cada localidade.

Espera-se que os achados desta pesquisa contribuam para despertar novas discussões e reflexões entre os diversos autores, equipes, comunidade e gestores sobre a importância da valorização e do reconhecimento do trabalho desses profissionais para o fortalecimento da Atenção Básica 


\section{$\mathrm{RPP}$}

\section{PALAVRAS-CHAVES}

atenção primária à saúde. agentes comunitários de saúde. equipe. trabalho.

\section{AGRADECIMENTOS}

Agradeço aos Agentes Comunitários de Saúde da cidade de Cajazeiras por contribuírem na construção deste estudo.

\section{REFERÊNCIAS}

BRASIL. Portaria n ${ }^{\circ} 2.488$, de 21 de outubro de 2011. Aprova a Política Nacional de Atenção Básica, estabelecendo a revisão de diretrizes e normas para a organização da Atenção Básica, para a Estratégia Saúde da Família (ESF) e o Programa de Agentes Comunitários de Saúde (PACS). Diário Oficial da União, 2011.

FERREIRA, V. S. C. et al. Processo de trabalho do agente comunitário de saúde e a reestruturação produtiva. Cad. Saúde Pública. Rio de Janeiro, v. 25, n. 4, p. 898-906, abr. 2009.

GALAVOTE, H. S. et al. Desvendando os processos de trabalho do agente comunitário de saúde nos cenários revelados na Estratégia Saúde da Família no município de Vitória (ES, Brasil). Ciênc. saúde coletiva. Rio de Janeiro, v.16, n.1, p. 231- 40, jan. 2011.

LEFÈVRE, F.; LEFÈVRE, A. M. C. O discurso do sujeito coletivo: um novo enfoque em pesquisa qualitativa (desdobramentos). Caxias do Sul: Educs, 2005.

PERES, C. R. F. B. et al. O Agente Comunitário de Saúde frente ao processo de trabalho em equipe: facilidades e dificuldades. Rev. esc. enferm. USP. São Paulo, v. 45, n.4, p. 905-11, ago. 2011.

SANTANA, F. R. et al. Ações de saúde na estratégia saúde da família à luz da integralidade: município goiano. Rev. Eletr. Enf., Goiás, v. 15, n. 2, p. 422-9, abr./jun. 2013.

SANTOS, L. F. B.; DAVID, H. M. S. L. Percepções do estresse no trabalho pelos agentes comunitários de saúde. Rev. enferm. UERJ. Rio de Janeiro, v.19, n.1, p. 52-7, jan/mar. 2011. SANTOS, L. P. G. S.; FRACOLLI, L. A. O agente comunitário e saúde: possibilidades e limites para a promoção da saúde. Rev. Esc. Enferm. USP. São Paulo v. 44, n.1, p. 76-83, mar. 2010. 


\section{$\mathrm{RPP}$}

\section{A IDENTIDADE DO IDOSO ESTAMPADA NO ENVELHECER: O QUE TRÁS A LITERATURA?}

LINHA DE PESQUISA: Enfermagem na saúde coletiva. FORMATO DE APRESENTAÇÃO DO RESUMO: Exposição Oral.

ANDRESSA PEREIRA DO CARMO, Graduanda em Enfermagem, Universidade Federal de Campina Grande. ALANA KELLY MAIA MACEDO NOBRE DE LIMA, Mestre em Odontologia, Universidade Federal de Campina Grande. MARÍLIA MOREIRA TORRES GADELHA, Graduanda em Enfermagem, Universidade Federal de Campina Grande. ANÚBES PEREIRA DE CASTRO, Doutora em Saúde Pública, Universidade Federal de

Campina Grande.

\section{INTRODUÇÃO}

Até meados do século passado, as pesquisas sobre o envelhecimento e envelhecer valorizavam e focavam nas perdas ocorridas durante esse processo, como o caso dos déficits psicológicos, de cognição e fisiológicos. E, focavam nesses déficits apenas como "perda pela elevada idade" e excluíam o porquê que estes problemas teriam acometido o idoso (tabagismo, alcoolismo, etc), então, assim surgiu o interesse de pesquisar sobre o envelhecimento usual e o bem-sucedido e fazer comparações entre estas, identificando assim suas variáveis (GONZALEZ; SEIDL, 2011).

Atualmente, discutir o crescimento da população idosa está em constante alvo dos debates que ocorrem no âmbito da saúde pública (FREITAS et al, 2012) os principais objetivos dessas discussões são conhecer o perfil desses idosos e suas características físicas, sociais e emocionais. Essas alterações que ocorrem com o sujeito no momento que ele percebe o envelhecimento podem ser positivas ampliando o sujeito ou interferindo no processo de identidade, pois tanto pode ser vista a partir do próprio ser quanto na percepção do outro (FREITAS et al, 2012).

A construção da identidade do idoso muitas vezes passa a ser construída através dos valores culturais, o que associa dependência, decadência e impossibilidades à denominação do idoso, ou seja, o idoso é incapaz (ARGIMON et al., 2011), ocultando assim essa fase do desenvolvimento humano.

Com esses pressupostos, este trabalho nomeia-se a partir da identificação e construção de publicações que envolvem o processo identitário do idoso no seu envelhecer.

\section{OBJETIVO DO TRABALHO}

Nessa perspectiva objetiva-se proporcionar a reflexão acerca da identidade do idoso estampada no envelhecer.

\section{MATERIAIS E MÉTODOS}

Este trabalho é extraído dos resultados parciais de um Projeto do Programa de Bolsas em Iniciação Científica da Universidade Federal de Campina Grande PIBIC/UFCG/CNPq, intitulado Processo Identitário/Identificatório da Pessoa que Envelhece: Revisão Integrativa em Periódicos Nacionais e Internacionais, a partir de fontes em revisão bibliográfica.

Sabe-se que uma revisão integrativa da literatura, é bastante utilizada em análises empíricas e teóricas para juntar a teoria com a prática clínica e, reunir e sintetizar resultados a partir de um tema de investigação (MENDES; SILVEIRA; GALVÃO, 2008). 


\section{$\int \begin{aligned} & \text { Revista de } \\ & \text { Pesquisa } \\ & \text { Interdisciplinar }\end{aligned}$}

Com base nisso, compilaram-se estudos encontrados na base de dados LILACS (Literatura Latino-Americana e do Caribe em Ciências da Saúde) com artigos compreendidos entre os anos de 2011 à 2015, onde se tem bastante temática representável.

A busca foi realizada a partir de terminologias cadastradas nos Descritores em Ciências da Saúde determinados pela Biblioteca Virtual em Saúde. As palavras-chave utilizadas para essa missão foram: Envelhecimento, Idosos, Velhice, Identidade e Processo; e em inglês: Aging, Elderly, Old Age, Identity e Process.

Todos os estudos encontrados se encaixavam na tríade velhice/envelhecimento/identidade e possuíam esses eixos como tema central. Artigos que se encontravam repetidos na base de dados foram excluídos, assim como os textos que não possuíam o estudo na íntegra.

\section{RESULTADOS E DISCUSSÃO}

Inicialmente na base de dados da LILACS foram encontrados 74 estudos sobre envelhecimento humano, 10. $716 \mathrm{com}$ idosos, $152 \mathrm{com}$ o tema velhice e $1.016 \mathrm{com}$ a temática identidade.

Posteriormente, esses temas foram interligados com a palavra processo. Assim obteve-se conforme tabela 1:

Tabela 1. Quantidade de artigos encontrados com os temas interligados com a palavra processo.

\begin{tabular}{lllll}
\hline TEMAS/ & ENVELHECIMENTO & IDOSOS & VELHICE & IDENTIDADE \\
BASE DE & AND & AND & AND & AND \\
DADOS & IDENTIDADE & IDENTIDADE & IDENTIDADE & PROCESSO
\end{tabular}

\begin{tabular}{lllll}
\hline LILACS & 25 & 63 & 6 & 203 \\
\hline
\end{tabular}

Fonte: Dados da Pesquisa.

Pode-se observar que há grande quantidade de artigos na literatura e, sendo assim, optamos por ler todos os artigos por resumo e mais tarde na íntegra. Então, segue a tabela 2 para melhor entendimento:

Tabela 2. Estudos selecionados após leitura criteriosa.

\begin{tabular}{lllll}
\hline TEMAS/ & ENVELHECIMENTO & IDOSOS & VELHICE & IDENTIDADE \\
BASE & AND & AND & AND & AND \\
DE & IDENTIDADE & IDENTIDADE & IDENTIDADE & PROCESSO \\
DADOS & & & & \\
\hline LILACS & 6 & 4 & 0 & 1 \\
\hline
\end{tabular}

Fonte: Dados da Pesquisa.

O que se percebe até aqui é que embora haja grande quantidade de estudos na literatura sobre envelhecimento, este resultado cai quando aborda-se o processo de identidade no idoso. Abordando assim apenas 11 estudos referentes à temática.

Corroborando com este estudo, Brasil et al., (2013) trás em seu artigo, a importância de ser estudada a identidade no idoso. Freitas et al., (2012) diz que há déficit no sistema público de saúde por não ter controle quanto das diferentes dimensões que a identidade no envelhecer aborda.

A partir disso percebe-se que o idoso possui visões distintas sobre ele, sendo assim necessário que haja um melhor entendimento para o enfrentamento de conflitos existentes na sociedade e até dele mesmo em seu contexto social (CARMO; CASTRO, 2016), pois, as pessoas constroem a sua identidade a partir de sua socialização.

\section{CONCLUSÕES}

Pode-se concluir que há escassez de estudos na tríade velhice/envelhecimento/identidade, dificultando a abordagem do conteúdo, embora haja um 


\section{$\mathrm{RPP}$}

crescente aumento nas publicações sobre velhice e envelhecer consistente nos últimos anos, o que aumenta a ânsia de incentivar os profissionais a estudarem e publicarem sobre a temática, a fim de conhecer mais a fundo o processo identitário no envelhecimento e poder ajudar a melhorar esse déficit.

PALAVRAS-CHAVE: Envelhecimento. Identidade. Processo. Velhice.

\section{AGRADECIMENTOS}

Ao Programa Institucional de Bolsas em Iniciação Científica (PIBIC/CNPqUFCG) por ajudar à fomentar essa pesquisa.

\section{REFERÊNCIAS}

ARGIMON, I. I. L., et al. Velhice e Identidade: Significações de Mulheres Idosas. Revista

Kairós Gerontologia, 2011.

BRASIL, K. T. R; BARCELOS, M. A. R.; ARRAIS, A. R.; CÁRDENAS, C. J. A clínica do envelhecimento: desafios e reflexões para prática psicológica com idosos. Aletheia v. 40, jan./abr. 2013.

CARMO, A. P.; CASTRO, A. P. Identidade de idosos no contex to brasileiro: análise em periódicos nacionais In: CONGRESSO BRASILEIRO DE CIÊNCIAS DA SAÚDE. Anais... v.1, ISSN 2525-6696. Campina Grande, 2016.

Disponível em:

http://editorarealize.com.br/revistas/conbracis/trabalhos/TRABALHO_EV055_MD1_SA4_ID 1762_02052016113642.pdf

FREITAS, C. M. S. M. et al. Identidade do idoso: representações no discurso do corpo que envelhece. Estud. interdiscipl. envelhec., Porto Alegre, 2012.

GONZALEZ, L. M. B.; SEIDL, E. M. F. O envelhecimento na perspectiva de homens idosos. Paidéia, 2011.

MENDES, K. D. S.; SILVEIRA, R. C. C. P.; GALVÃO, C. M. Revisão integrativa: método de pesquisa para a incorporação de evidências na saúde e na enfermagem. Texto Contexto Enfermagem, Florianópolis, 2008. 


\title{
$\mathrm{RPP}$
}

\section{REALIZAÇAO PRECOCE DO EXAME PAPANICOLAOU PARA DETECÇAO DO HPV}

\author{
ÁREA TEMÁTICA: Enfermagem na Saúde Coletiva \\ Exposição Oral
}

FRANCISCO ASSIS CAVALCANTE JÚNIOR, Graduado do curso de enfermagem da Universidade Federal de Campina Grande/Centro de Formação de Professores. FRANCISCA MARIA BARBOSA DE SOUZA, Graduada do curso de enfermagem da Universidade Federal de Campina Grande/Centro de Formação de Professores. MARILENA MARIA DE SOUZA, Docente da Universidade Federal de Campina Grande/Centro de Formação de Professores. CÍCERA RENATA DINIZ VIEIRA SILVA, Docente da Universidade Federal de Campina Grande/Centro de Formação de Professores. GERLANE CRISTINNE BERTINO VÉRAS, Mestranda em Enfermagem pela Universidade Regional do Cariri - Docente da Universidade Federal de Campina Grande/Centro de Formação de Professores.

\section{INTRODUÇÃO}

As infecções sexualmente transmissíveis (IST) constituem a segunda maior causa de morbidade em mulheres jovens adultas, depois das causas relacionadas ao ciclo gravídicopuerperal, nos países em desenvolvimento. Causam também prejuízo econômico para a família e para a sociedade, afetam negativamente a saúde reprodutiva, além de reduzir a produtividade do indivíduo e, não menos importante, promove o preconceito em relação ao seu portador (LIMA et al. 2013).

Quanto ao papilomavírus humano (HPV), tem a propriedade de invadir rapidamente o trato genital logo após as relações sexuais, o que poderá promover alterações celulares precursoras do câncer de colo de útero $(\mathrm{CCU})$, este sendo considerado um importante problema de saúde, uma vez que apresenta elevadas taxas de morbimortalidade, principalmente em regiões em desenvolvimento, onde a economia e os investimentos na saúde pública são relativamente baixos (ALBUQUERQUE et al., 2011).

Existem aproximadamente 118 tipos de HPV que foram completamente descritos, sendo os tipos 6, 11, 16 e 18 os mais prevalentes. Os tipos 6 e 11 são os que causam verrugas genitais, enquanto o 16 e 18 são responsáveis por cerca de $70 \%$ dos casos de CCU (NAGAKAWA, 2010).

De acordo com o Instituto Nacional de Câncer - INCA (2014), o HPV representa a principal causa de $\mathrm{CCU}$, que tem também como fatores de risco o comportamento sexual e as IST's, dentre outros. Este câncer é o terceiro tumor mais frequente na população feminina, atrás do câncer de mama e do colorretal, e a quarta causa de morte de mulheres por câncer no Brasil.

As infecções por HPV podem permanecer assintomáticas por muito tempo no indivíduo, o qual poderá transmitir o vírus sem saber, por isso são necessários exames de rotina a fim de detectar o surgimento de possíveis anormalidades. O diagnóstico precoce permite o rastreamento das lesões celulares em suas fases iniciais, por meio de um método de detecção conhecido como colpocitologia oncótica ou exame de Papanicolaou (INCA, 2014).

O exame Papanicolaou foi desenvolvido em 1939, por George Papanicolaou por meio do qual iniciou o rastreio regular de doenças que ocorrem no colo do útero. Este exame consegue detectar de forma precisa e com custos baixos até $90 \%$ dos $\mathrm{CCU}$, inclusive antes da manifestação da sintomatologia. O número de mortes devido a esse tipo de câncer diminuiu 


\section{$\int \begin{aligned} & \text { Revista de } \\ & \text { Pesquisa } \\ & \text { Interdisciplinar }\end{aligned}$}

mais de $50 \%$ desde a introdução deste exame. No entanto, uma proporção significativa de mulheres nunca o realizou ou quando realiza não o faz na periodicidade preconizada pelo Ministério da Saúde (MS) não sendo possível o diagnóstico precoce de alguma alteração celular que possa ser precursora do CCU, consequentemente não sendo tratada em tempo hábil; e às vezes quando fazem com a periodicidade preconizada chegando a um diagnóstico precoce, por vezes não são tratadas adequadamente (INCA, 2014).

O exame Papanicolaou deve ser realizado em toda Unidade Básica de Saúde por profissionais capacitados. Além da detecção das células precursoras ou não do câncer, o exame detecta as alterações como infecção ou inflamação. Sendo recomendada a sua realização a partir dos 25 anos de idade até os 64 anos em mulheres que já tenham praticado atividade sexual, e deverá ser repetido a cada três anos, após dois exames com resultados normais consecutivos realizados com intervalo de um ano entre eles (INCA 2014).

Visto as possíveis conseqüências decorrentes da infecção pelo HPV, surgiu o interesse em evidenciar os casos diagnosticados em mulheres com vida sexual ativa antes dos 25 anos de idade.

\section{OBJETIVO}

Evidenciar os casos de HPV em mulheres com idade inferior a 25 anos.

\section{MATERIAIS E MÉTODOS}

Trata-se de uma pesquisa documental e exploratória, com abordagem quantitativa, que foi realizada na Unidade Básica de Saúde São José/Posto de Assistência Primária à Saúde (PAPS), localizada na praça Irmã Fernanda, no bairro Casas Populares, município de Cajazeiras - PB.

A amostra desta pesquisa foi composta pelos registros dos resultados do exame Papanicolaou realizados no período de 2009 a 2014 na referida Unidade Básica de Saúde. Os dados foram coletados nos meses de março e abril de 2015, por meio de um instrumento de coleta de dados pré-elaborado no Microsoft Excel o que permitiu o melhor manuseio do corpus documental do estudo.

Após a realização da coleta, os dados foram tabulados quantitativamente, apresentados em gráficos e analisados de forma descritiva, recorrendo à literatura pertinente.

Do ponto de vista ético, os pesquisadores levaram em consideração as observâncias éticas preconizadas pela Resolução No 466/12 do Conselho Nacional de Saúde, principalmente em relação ao anonimato dos usuários inseridos na investigação, sigilo e confidencialidade dos dados dos mesmos (BRASIL, 2012).

Esta Pesquisa trata-se de um recorte da pesquisa "Infecções Sexualmente Transmissíveis Evidenciadas no Exame de Papanicolaou em uma Unidade Básica de Saúde", que teve projeto aprovado pelo Comitê de Ética em Pesquisa da Universidade Federal de Campina Grande, Campus Cajazeiras sob o parecer nº 998.248.

\section{RESULTADOS E DISCUSSÕES}

Foram analisados 2.634 (100\%) resultados dos exames de Papanicolaou, destes 741 $(28,13 \%)$ apresentaram algum tipo de anormalidade, sendo $43(5,80 \%)$ alterações celulares possivelmente não neoplásicas, $23(3,10 \%)$ pelo HPV e $675(91,10 \%)$ por outras IST's, o que supera a média encontrada em um estudo realizado no município de Campinas-SP, por Santos et al. (2007), que teve como amostra 1.982 resultados de exame Papanicolaou, sendo 489 $(24,7 \%)$ identificando algum tipo de alteração. 
Verificou-se ainda, que dos 23 casos de HPV, 7 (30,43\%) foram evidenciados no resultado do exame de mulheres com idade inferior a 25 anos, sendo $01(14,29 \%)$ para a idade de $17,18,19,21$ e 23 anos e $02(28,57 \%)$ para a idade de 22 anos. De acordo com este resultado, pode-se notar que uma quantidade significativa de detecção do HPV está ocorrendo antes da idade mínima preconizada pelo MS para início da realização do exame Papanicolaou.

Silva et al. (2014), relatam que alguns estudos enfatizam a necessidade da ampliação da faixa etária dos 25 aos 64 anos, já que vem se evidenciando à redução do Início da Atividade Sexual (IAS) e também maior incidência do HPV nas adolescentes, além do fato de que, apesar da evolução para CCU ser bastante lenta, mulheres com menos de 25 anos já são diagnosticadas com o câncer.

Com isto, observa-se que existe uma relação direta entre o IAS com o risco para IST's, como comprova a pesquisa "Conhecimento, atitude e práticas na prevenção do câncer de colo uterino e HPV em adolescentes", realizado por Cirino; Nichiata; Borges (2010), com amostra de 134 adolescentes entre 14 a 19 anos de idade no município de São Paulo, onde 87 (64,9\%) adolescentes relataram vida sexual ativa, tendo média de idade para IAS de 14,8 anos. Destas, $24(27,6 \%)$ referiram IST prévia, o que corrobora com Santos et al. (2007), que relatam que as mulheres que iniciam precocemente a atividade sexual são mais vulneráveis as IST's, inclusive o HPV, devido ao fato de se ter mais probabilidade de ter muitas relações sexuais durante a vida, como também maior número de parceiros o que aumenta o risco para o CCU.

Segundo Roteli-Martins et al. (2007), adolescentes ativas sexualmente representam as taxas mais altas de infecções incidentes e prevalentes por HPV, variando entre 50 e $80 \%$ de infecção com dois a três anos do IAS.

\section{CONCLUSÃO}

Frente aos resultados, pode-se comprovar a importância da realização precoce do exame Papanicolaou entre mulheres com idade inferior a 25 anos que já iniciaram a vida sexual, apesar do CCU ser de evolução lenta; contudo o IAS está acontecendo cada vez mais precoce, aumentando a vulnerabilidade de se adquirir a infecção pelo HPV, que é o principal fator de risco para o CCU.

Se faz necessário então, o envolvimento dos profissionais de saúde em comunhão com os gestores para estimularem a realização do exame Papanicolaou em todas as mulheres que iniciaram sua atividade sexual, independentemente da sua idade, com o intuito de prevenir precocemente possíveis alterações celulares que podem ser precursoras do CCU, inclusive realizando educação sexual nas instituições de ensino com campanhas para a realização do exame de Papanicolaou, destinados ao público adolescente, com enfoque adequado e linguagem apropriada.

PALAVRAS-CHAVE: Papillomaviridae. Teste de Papanicolaou. Prevenção.

\section{REFERÊNCIAS}

ALBUQUERQUE, Z. B. P.; et al. Atendimento pelo SUS na percepção de mulheres com lesões de câncer cervicouterino em Goiânia-GO. Revista Eletrônica de Enfermagem, Goiânia, v. 13, n. 2, 2011.

BARCELOS, M. R. B. et al. Infecções Genitais em Mulheres Atendidas em Unidade Básica de Saúde: prevalência e fatores de risco. Rev. Bras. Ginecol. Obstet.30(7): 349-54, 2008. 


\section{$\mathrm{RPP}$}

BRASIL. Secretaria de Vigilância em Saúde - Departamento de DST, AIDS e Hepatites Virais. Brasília 2014. Disponível em http://www.aids.gov.br/pagina/dst-no-brasilacesso em 21/12/2014.

Ministério da Saúde. Conselho Nacional de Saúde. Resolução n 466, de 12 de dezembro de 2012. Brasília (DF): Ministério da Saúde: 2012.

CIRINO F. M. S. B.; NICHIATA, L. Y. I.; BORGES, A. L. V. Conhecimento, atitude, práticas na prevenção do câncer do colo uterino e HPV em adolescentes. Esc Anna Nery Rev Enferm. jan-mar; 14 (1): 126-34, 2010

INCA. Instituto Nacional do Câncer. Câncer do colo do útero. Disponível em http://www2.inca.gov.br/wps/wcm/connect/tiposdecancer/site/home/colo_utero/definica o+. Acesso em: 26 dez. 2014

LIMA, M. C. L. et al. Prevalência e fatores de risco independentes à tricomoníase em mulheres assistidas na atenção básica. Acta Paul Enferm. 2013; 26(4): 331-7.

NAKAGAWA J.T. T, SCHIRMER, J, BARBIERI, M.Vírus HPV e câncer de colo de útero, Rev. Bras. Enferm 63(2): 307-11 Brasília 2010.

ROTELI-MARTINS, C.M. et.al. Associação entre idade ao início da atividade sexual e subsequente infecção por papilomavírus humano: resultados de um programa de rastreamento brasileiro. Rev. Bras. Ginecol. Obstet. 29(11):580-7, 2007.

SANTOS, J. DE O.; SILVA, S. R.; SANTOS, C. F. DOS; ARAÚJO, M. C. S.; BUENO, S. D. Alterações cérvico-uterinas em mulheres atendidas em uma unidade básica de saúde no município de Campinas-SP. REME- Ver. Min. Enf.; 11(4):439-445, out/dez; 2007.

SILVA, B.L. et.al. Prevenção do Câncer de Colo Uterino e a Ampliação da Faixa Etária de Risco. Rev. Enferm. UFPE on line 8(6):1482-90,Recife 2014. 


\section{PROCESSO DE TRABALHO DO AGENTE COMUNITÁRIO DE SAÚDE: CONSTRUÇÃO COLETIVA DO CUIDADO COMO ESTRATÉGIA PARA FORTALECER O VÍNCULO COM A COMUNIDADE NA ATENÇÃO BÁSICA} ÁREA TEMÁTICA: ENFERMAGEM NA SAÚDE COLETIVA (Forma de apresentação: Exposição oral)

GEÍSA BATISTA LEANDRO ${ }^{1}$, Acadêmica de Enfermagem, pela Universidade Federal de Campina Grande, campus Cajazeiras - PB. (APRESENTADOR) FABRÍCIA CRISTINA VIDAL DA SILVA², Acadêmica de Enfermagem, pela Universidade

Federal de Campina Grande, campus Cajazeiras - PB. PALOMA KAREN HOLANDA BRITO ${ }^{3}$, Acadêmica de Enfermagem, pela Universidade Federal de Campina Grande, campus Cajazeiras - PB. EDILAINE CRISTINA MARTINS DA SILVA ${ }^{4}$, Enfermeira formada pela Universidade Federal de Campina Grande, campus Cajazeiras - PB. MARCELO COSTA FERNANDES, Professor Doutor em Cuidados Clínicos em Enfermagem e Saúde, Docente da Universidade Federal de Campina Grande, Unidade Acadêmica de Enfermagem - UAENF, campus de Cajazeiras - PB. (ORIENTADOR)

\section{INTRODUÇÃO}

O Agente Comunitário de Saúde (ACS), membro que compõe a equipe de profissionais da Estratégia de Saúde da Família (ESF), assume papel importante na consolidação e da melhoria da assistência prestada na Atenção Básica (AB). Por meio do processo de trabalho possibilita a construção de vínculo dos pacientes com a unidade, além de fomentar a promoção da saúde, prevenção e identificação das doenças que venham acometer a comunidade adscrita (OLIVEIRA, et al., 2012).

As atividades desenvolvidas na comunidade pelos ACS devem ser feitas mediante a segurança e qualificação dos mesmos, onde possa ter conhecimento científico e prático, a partir do observado nos domicílios e no que possa ser trabalhado com os usuários dos serviços de saúde. São estes os profissionais que conduzem às informações e anseios da comunidade a equipe de saúde por qual é responsável em cuidar dos mesmos. Devem desempenhar ações que facilitem e aproxime a população à unidade de saúde, de modo que construa, por meio das atividades desenvolvidas diariamente, vínculos com os demais profissionais inseridos na ESF, fornecendo a assistência devida e necessária aos indivíduos (JUSTO; GOMES; SILVEIRA, 2015).

Em meio às dificuldades encontradas pelos ACS nas comunidades e na própria unidade, é preciso apresentar resultados satisfatórios e demandas dos usuários para que os problemas da comunidade sejam diminuídos ou sanados, na garantia que os serviços sejam de boa qualidade, sendo este profissional espelho ou reflexo do bem-estar da unidade. De forma que a informação em saúde seja um dos contribuintes e determinantes no processo de trabalho do ACS, como também de todos os profissionais de saúde inseridos na ESF, contribuindo no empoderamento da comunidade em detrimento do que é ofertado e dos direitos no sistema de saúde (MELO; QUINTÃO; CARMO, 2015).

Contudo deve-se intensificar, conhecer e valorizar da contribuição do trabalho dos ACS como parte integrante da construção coletiva do cuidado no âmbito da Atenção Básica, sendo estes peças importantes para a objetividade e efetividade das estratégia estipuladas para a comunidade.

\section{OBJETIVO DO TRABALHO}




\section{$\int \begin{aligned} & \text { Revista de } \\ & \text { Pesquisa } \\ & \text { Interdisciplinar }\end{aligned}$}

Analisar o processo de trabalho do agente comunitário de saúde com ênfase construção coletiva do cuidado como estratégia para fortalecer o vínculo com a comunidade na Atenção Básica.

\section{MATERIAIS E MÉTODOS}

Trata-se de estudo de natureza descritiva com abordagem qualitativa, realizado nas Unidades Básicas de Saúde (UBS), no município de Cajazeiras no estado da Paraíba. Esta cidade faz parte da $4^{a}$ Macrorregião de Saúde e $9^{a}$ Gerência Regional de Saúde da Paraíba e apresenta atualmente 23 Equipes de Saúde da Família para atender às necessidades de saúde da população. Os participantes envolvidos no estudo foram 22 Agentes Comunitários de Saúde todos estes vinculados as UBS do referido município, o encerramento da coleta de dados ocorreu a partir do momento que foi identificada a saturação teórica. Foram selecionadas aleatoriamente 11 UBS do município de Cajazeiras, sendo entrevistados dois ACS de cada unidade. Os critérios de inclusão estabelecidos para participação na pesquisa foram: atuar há pelo menos um ano como ACS no município e não estarem ausentes do trabalho por estarem de férias ou em licença de qualquer natureza, seja saúde, maternidade, entre outras, no período estabelecido para a coleta de dados.

A técnica utilizada para a coleta de dados foi a entrevista semiestruturada, uma vez que esta instiga o entrevistado(a) possibilitando ir além daquilo que está sendo diretamente perguntado. A entrevista foi realizada individualmente na própria UBS dos ACS que aceitaram participar da pesquisa e se enquadravam nos critérios estabelecidos pelo entrevistador. $\mathrm{O}$ estudo apresentava questões norteadoras sobre o assunto respeitando a livre expressão de suas representações. As entrevistas foram gravadas com a autorização dos entrevistados, sendo elas posteriormente transcritas, estudadas e interpretadas.

Os dados obtidos nas entrevistas para esta pesquisa foram organizados por meio da técnica do Discurso do Sujeito Coletivo (DSC), como uma forma de obter o discurso coletivo com base nos discursos individuais. Quanto à análise do conteúdo das entrevistas dos ACS, primeiramente, foi realizado a leitura flutuante das falas com o intuito de compreender o conjunto das transcrições. Posteriormente, foram necessárias leituras sucessivas para que fosse possível identificar os núcleos de sentido relacionados às questões norteadoras que compuseram o roteiro da entrevista.

O mesmo teve inicio após a aprovação pelo Comitê de Ética em Pesquisa da Universidade Federal de Campina Grande sob o processo de ${ }^{\circ} 1.347 .452$. A participação na pesquisa foi iniciada mediante o esclarecimento sobre os objetivos do estudo e a assinatura do Termo de Consentimento Livre e Esclarecido (TCLE), que explicou todos os detalhes da pesquisa, garantindo-lhe anonimato e o sigilo absoluto das informações, assim como a direito de participarem ou não do estudo.

Após os esclarecimentos e tendo havido concordância, foi solicitada a assinatura do participante do TCLE, contendo duas vias, uma entregue ao participante e a outra ficando com a pesquisadora.

\section{RESULTADOS E DISCUSSÕES}

Durante a coleta de dados e mediante a análise dos DSC, observou-se a devida importância dada pelo ACS ao trabalho em equipe e das boas relações que existem ou que devem existir entre os mesmos, auxiliando-os na avaliação dos dados levantados em suas áreas de atuação. Enfatizou-se a importância da realização de reuniões para as discussões dos problemas identificados, de modo que todos tomassem por conhecimento a realidade das 


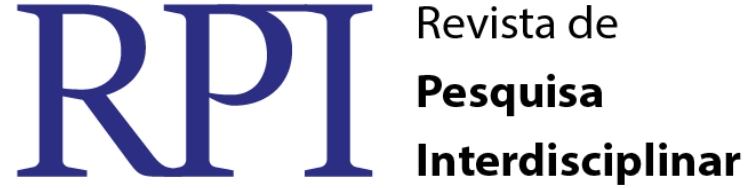

diversas áreas que formam a comunidade, viabilizando a consolidação dos problemas identificados durante a consolidação das visitas domiciliares.

Atentou-se para a credibilidade que os usuários depositam aos integrantes da unidade de saúde por meio do vínculo construído com os ACS. Identificou-se a necessidade da construção do cuidado de forma coletiva onde estes profissionais imprescindíveis compusessem o elenco dos cuidadores que prestam serviços diretos ou indiretos aos usuários.

O DSC apresentado a seguir foi construído mediante a fala de seis ACS, a qual é possível realizar reflexão acerca da essencialidade do trabalho em equipe: "A articulação é muito boa, trabalhamos realmente em equipe. A gente tem essa parceria entre ACS e unidade de saúde, porque todas as informações que a gente coleta lá fora, a gente tem que trazer pra dentro da unidade pra que se possa ter uma articulação e a agente colher bons frutos nesse trabalho, porque seria em vão eu trabalhar individualmente e não trazer os anseios da comunidade aqui pra dentro pra ser dividido com a equipe, né? (...) Tem que ter as duas partes lutando pra chegar na mesma meta, alcançar o mesmo objetivo. A gente articula, planeja o que vai ser feito durante aquele mês, a gente sempre faz o cronograma, a gente faz reuniões mensais, é discutido o problema existente em cada comunidade e a gente vê metas a cumprir e se reúne novamente, articula programas, realiza atividades na comunidade, na própria unidade pra ver se consegue realmente trazer a comunidade à unidade de saúde da família. Um bom relacionamento entre a equipe é essencial porque assim, você passa pra comunidade essa segurança. Então se o ACS tem uma boa parceria com a unidade, com toda a equipe, já vai influenciar a comunidade ter mais um pouquinho de acesso a gente $e$ confiança (vínculo), porque a gente tem que passar confiança pra eles, pra que eles possam confiar na equipe."

O trabalho desenvolvido pelos ACS requer dedicação e isso faz com que os cuidados a serem planejados e executados tenham a colaboração de todos, de forma articulada e integrada, buscando a sensibilização dos pacientes com relação às boas condutas e hábitos de saúde. Da maneira que o ACS tenha seu papel definido na comunidade e contribua ativamente nas ações de educação em saúde, pois os mesmos possuem um conhecimento que é necessário ser repassados para a população, em que muitas ocasiões passam por despercebidos e não são tão atuantes nessas atividades desenvolvidas na comunidade (KEBIAN; ACIOLI, 2014).

Tal comprometimento da equipe multiprofissional da ESF faz-se necessário para a concretização da $\mathrm{AB}$ como o serviço preferencial e porta de entrada ao Sistema Único de Saúde (SUS), instigando a população refletir e modificar atitudes e comportamentos frente à assistência centralizadora de caráter biomédico, sendo subsídio necessário para a compreensão do direito à saúde que assista o indivíduo na sua integralidade (VIDAL; MOTTA; BATISTA, 2015).

O ACS estando frente às dificuldades e obstáculos vivenciados no cotidiano e atuando como mediador da comunidade necessita desenvolver competências para que seja reconhecido como mediador dos serviços não só oferecidos pela unidade da comunidade a qual trabalha, mas dos demais setores que dão suporte e subsídios para a $\mathrm{AB}$ do município. $\mathrm{A}$ formação destes profissionais está pautada nas habilidades desenvolvidas, profissão esta que contribuiu de forma decisiva na obtenção de resultados e atividades de promoção a saúde, prevenção de doenças, tratamento e reabilitação dos enfermos.

Justo, Gomes e Silveira (2015) os ACS sofrem tensões e sobrecargas em decorrência de serem mediadores das cobranças da população e por outro lado dos seus supervisores ou gerentes da unidade de saúde no que se refere às demandas a serem atendidas e que sejam tragas até o profissional que possa intervir de forma definitiva no caso. Situações estas que por vezes venham a formar desconfortos situacionais nos encontros da equipe, tendo por entendimento que as dificuldades encontradas sejam sugestivamente sanadas pelos profissionais que compõem a equipe. 


\section{$\int \begin{aligned} & \text { Revista de } \\ & \text { Pesquisa } \\ & \text { Interdisciplinar }\end{aligned}$}

A relação com os demais profissionais é necessária para que as demandas colhidas sejam realmente atendidas, pois se acredita que o trabalho do ACS só funcione se houver o empenho de toda a equipe da ESF, por isso dar-se a importância da boa convivência em equipe. Tendo em vista que a convivência harmoniosa com os demais seja fundamental na relação com toda a comunidade adscrita aos quais são responsáveis (OLIVEIRA, et al., 2012).

$\mathrm{O}$ vinculo que é formado entre o ACS e a comunidade se dar por várias formas, como conquistas, respeito, compromisso na qual a profissão é desempenhada, carinho e gostar do que faz, não fazendo com que os problemas da equipe e pessoais possam refletir na assistência com o paciente. Embora existam casos em que a comunidade não compreenda a importância do ACS em seu meio e que reflete na forma de execução de trabalho do mesmo (OLIVEIRA, et al., 2012).

A presença do diálogo e da competência a qual desempenha a profissão talvez seja a forma mais indicada para que o ambiente de trabalho possua características e condições favoráveis em que todos se sintam acolhidos, possibilitando que as estratégias sejam realmente eficazes e funcionais, como também conduza ao objetivo que do Sistema Único de Saúde (SUS) atender a integralidade dos indivíduos.

\section{CONCLUSÕES}

Logo o ACS executa papel elementar na comunidade fortalecendo os laços de segurança e confiabilidade dos usuários aos cuidados prestados pela ESF, pois são os mesmos que estão em maior proximidade com os pacientes. Necessita que aconteçam reuniões da equipe para que haja a troca de experiências, conhecimentos e compartilhamento de saberes entre os membros.

Enfocar nas atividades de educação em saúde com maiores participações do ACS, investir na educação permanente dos mesmos para que seus conhecimentos e habilidades sejam aprimoradas constantemente para que não sejam vitimas do conformismo é preciso pensar sempre no novo, em algo que possa melhorar as condições de saúde da população, a partir da informação correta aos usuários e que entendam que necessitam e devem receber uma assistência de qualidade e igualitária.

Portanto é necessário que os agentes trabalhem de forma articulada e em conjunto com os demais membros da equipe de forma coletiva, alcançando os objetivos traçados e fortalecendo os vínculos com a comunidade.

\section{PALAVRAS-CHAVES}

Atenção primária à saúde. Agentes comunitários de saúde. Equipe. Trabalho.

\section{AGRADECIMENTOS}

Agradeço ao professor Dr. Marcelo Costa Fernandes pela oportunidade de me conduzir a Saúde Coletiva e acreditar na eficiência e importância da Atenção Básica para a população do país e poder participar do LATICS, trabalho a qual me dedico a cada dia com satisfação.

\section{REFERÊNCIAS}

JUSTO, C. M. P.; GOMES, M. H. A.; SILVEIRA, C. Limites e imposições dos instrumentos de controle do trabalho de agentes comunitários de saúde da Estratégia de Saúde de Família. Saúde e Sociedade, São Paulo, v. 24, n. 2, apr./june. 2015.

KEBIAN, L. V. A.; ACIOLI, S. A visita domiciliar de enfermeiros e agentes comunitários de saúde da Estratégia Saúde da Família. Rev. Eletr. Enf., Rio de Janeiro, v. 16, n. 1, p. 161-9, jan./mar. 2014. 


\section{$\mathrm{RPP}$}

MELO, M. B.; QUINTÃO, A. F.; CARMO, R. F. O Programa de Qualificação e Desenvolvimento do Agente Comunitário de Saúde na perspectiva dos diversos sujeitos envolvidos na atenção primária em saúde. Saúde e Sociedade, São Paulo, v. 24, n. 1, jan./mar. 2015.

OLIVEIRA, D. T.; FERREIRA, P. J.O.; MENDONÇA, L. B.A.; OLIVEIRA, H. S. Percepções do Agente Comunitário de Saúde sobre sua atuação na Estratégia de Saúde da Família. Congitare Enfermagem, Curitiba, v. 17, n 1, jan./mar. 2012.

VIDAL, S. V.; MOTTA, L. C. S.; BATISTA, R. S. Agentes comunitários de saúde: aspectos bioéticos e legais do trabalho vivo. Saúde e Sociedade, São Paulo, v. 24, n. 1, jan/mar. 2015. 


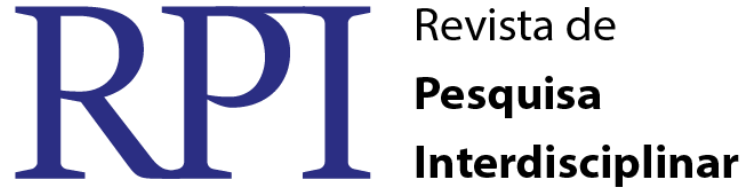

\section{CARACTERÍSTICAS EPIDEMIOLÓGICAS DE CASOS NOVOS DE HANSENÍASE EM CAJAZEIRAS, PARAÍBA}

LINHA DE PESQUISA: Enfermagem na Saúde Coletiva; exposição oral

BRUNO NEVES DA SILVA

Acadêmico do curso de bacharelado em enfermagem do Centro de Formação de Professores da Universidade Federal de Campina Grande.

FABRÍCIA CRISTINA VIDAL SILVA Acadêmica do curso de bacharelado em enfermagem do Centro de Formação de Professores da Universidade Federal de Campina Grande.

GERLANE CRISTINNE BERTINO VÉRAS

Enfermeira. Professora mestranda do Centro de Formação de Professores da Universidade Federal de Campina Grande.

\section{INTRODUÇÃO}

De acordo com Oliveira; Leão; Brito (2014), o Brasil é o segundo colocado em registro de casos de hanseníase no mundo, com alta detecção em alguns Estados das Regiões Norte, Nordeste e Centro-Oeste. Especificamente na Região Nordeste, há a necessidade de intensificação de ações que visem a eliminação da doença, visto que há um padrão de média endemicidade quando considerados os parâmetros de prevalência de cada Estado (OLIVEIRA; ASSIS; SILVA, 2013).

No Estado da Paraíba estão localizados parte dos clusters (áreas de concentração de hanseníase) identificados no país, onde a maior endemicidade se dá mais especificamente nas microrregiões de Cajazeiras, Catolé do Rocha, Itaporanga, Piancó e Serra do Teixeira (BRITO et al., 2015). O município de Cajazeiras apresenta número elevado de casos anuais, constituindo-se em um município que merece atenção das ações de saúde pública, segundo dados do Sistema de Notificação de Agravos de Notificação (SINAN). Nessa perspectiva, esse estudo se faz relevante à medida que pode contribuir para intensificar as ações de combate à doença a partir da identificação das suas características epidemiológicas.

\section{OBJETIVO}

Descrever as características epidemiológicas dos casos novos de hanseníase no município de Cajazeiras, PB.

\section{MATERIAIS E MÉTODOS}


Trata-se de um estudo descritivo, transversal e de base secundária com abordagem quantitativa. A pesquisa foi realizada no período de outubro de 2016 utilizando-se dados do SINAN disponíveis de forma online pelo Departamento de Informática do Sistema Único de Saúde (DATASUS). A amostra constituiu-se das notificações de casos novos de hanseníase registrados do ano de 2010 ao ano de 2015 no município de Cajazeiras, Paraíba.

A análise dos dados se deu por meio de tabulações no software Microsoft Excel $2010^{\circledR}$ utilizando as seguintes variáveis: coeficiente de detecção de casos novos, sexo, faixa etária, classificação operacional e clínica da doença, modo de detecção dos casos, avaliação do grau de incapacidade física e evolução do caso.

\section{RESULTADOS E DISCUSSÕES}

Constatou-se 256 casos novos de hanseníase no período investigado, como demonstra a Tabela 1.

Tabela 1 - Número de casos novos de hanseníase notificados no período de 2010-2015 em Cajazeiras, Paraíba

\begin{tabular}{c|c|c}
\hline $\boldsymbol{A n o}$ & $\boldsymbol{f}$ & $\boldsymbol{\%}$ \\
\hline 2010 & 63 & 24,6 \\
\hline 2011 & 48 & 18,7 \\
\hline 2012 & 56 & 21,9 \\
\hline 2013 & 26 & 10,2 \\
\hline 2014 & 20 & 7,8 \\
\hline 2015 & 43 & 16,8 \\
\hline Total & $\mathbf{2 5 6}$ & $\mathbf{1 0 0}$ \\
\hline
\end{tabular}

Fonte: Departamento de Informática do Sistema Único de Saúde. Site. 2016. Disponível em: <http://datasus.saude.gov.br/ > . Acesso em: 26 out. 2016.

Na tabela 2, observa-se o coeficiente de detecção dos casos novos, sendo Cajazeiras caracterizado como um município hiperendêmico de acordo com os parâmetros estabelecidos pelo Ministério da Saúde (MS), exceto no ano de 2014, quando apresentou um coeficiente abaixo de 40/100.000 habitantes (BRASIL, 2016).

Tabela 2 - Coeficiente de detecção de casos novos de hanseníase no período de 20102015 em Cajazeiras, Paraíba

\begin{tabular}{c|c}
\hline \multicolumn{1}{|c|}{ Ano } & $\begin{array}{c}\text { Coeficiente de } \\
\text { detecção de casos } \\
\text { novos }\end{array}$ \\
\hline 2010 & 107,8 \\
\hline 2011 & 81,6 \\
\hline 2012 & 94,7 \\
\hline 2013 & 42,9 \\
\hline 2014 & 32,8 \\
\hline
\end{tabular}

RPI Revista de Pesquisa Interdisciplinar, Cajazeiras, v. 2, Edição Especial, 2017. 


\section{Interdisciplinar}

\begin{tabular}{l|r}
2015 & 70,0 \\
\hline
\end{tabular}

Fonte: Departamento de Informática do Sistema Único de Saúde. Site. 2016. Disponível em: <http://datasus.saude.gov.br/ >. Acesso em: 26 out. 2016.

Ximenes et al. (2013), apontam que a elevada incidência da hanseníase está relacionada a baixos níveis de desenvolvimento socioeconômico e a condições deficientes dos serviços de saúde para o diagnóstico precoce, tratamento e acompanhamento dos casos, fatores que também interferem na busca ativa dos contatos.

Com relação ao perfil epidemiológico, identificou-se que $141(55,1 \%)$ casos notificados eram do sexo masculino e 115 (44,9\%) do sexo feminino. Estando em concordância com um estudo de Ribeiro et al. (2013). Contudo, esses resultados encontram-se em contraste com outros estudos, como o de Dias et al. (2013), que apontam uma maior prevalência do número de casos em mulheres, o que é justificado por estas apresentarem maior preocupação com a estética corporal e frequentarem com mais facilidade os serviços de saúde.

Quanto a faixa etária, $75(29,3 \%)$ casos foram entre 20 a 34 anos, 63 (24,6\%) entre 35 a 49 anos e $55(21,5 \%)$ entre 50 a 64 anos. Esses resultados demonstram uma inclinação da doença para a parcela da população economicamente ativa, como descrito por Melão et al. (2011) e Ribeiro et al. (2013).

A classificação operacional apontou 134 (52,3\%) casos paucibacilares e $122(47,6 \%)$ multibacilares; quanto à classificação clínica, verificou-se que esse campo foi ignorado ou constou em branco no ato do preenchimento das notificações. O elevado número de casos multibacilares, considerados a principal fonte de transmissão quando não tratados, pode contribuir para o quadro de endemicidade presente no município (RIBEIRO et al., 2013).

Quanto ao modo de detecção dos casos (Tabela 3), observa-se maior frequência por encaminhamento e demanda espontânea, o que sugere que a detecção está ocorrendo após um estabelecimento de um quadro clínico mais evidente.

Tabela 3 - Modo de detecção de casos novos de hanseníase notificados no período de 2010-2015 em Cajazeiras, Paraíba

\begin{tabular}{l|c|c}
\hline \multicolumn{1}{c|}{ Modo de detecção } & $\boldsymbol{f}$ & \% \\
\hline Encaminhamento & 113 & 44,1 \\
\hline Demanda espontânea & 99 & 38,7 \\
\hline Exames de coletividade & 26 & 10,2 \\
\hline Exame de contatos & 7 & 2,7 \\
\hline Outros modos & 7 & 2,7 \\
\hline Sem registro & 4 & 1,6 \\
\hline Total & $\mathbf{2 5 6}$ & $\mathbf{1 0 0}$ \\
\hline
\end{tabular}




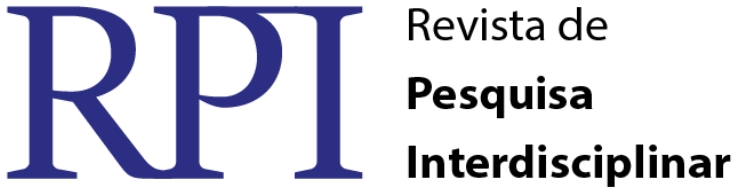

Fonte: Departamento de Informática do Sistema Único de Saúde. Site. 2016. Disponível em: <http://datasus.saude.gov.br/ >. Acesso em: 26 out. 2016.

O número elevado de pacientes diagnosticados por demanda espontânea e baixo número por exames de coletividade e de contatos foi apontado por Miranzi; Pereira; Nunes, (2010); salientando que estes dois últimos são os modos que auxiliam no diagnóstico precoce dos casos e contribuem para a diminuição da prevalência de casos ocultos e das incapacidades físicas, constituindo-se dos principais instrumentos de avaliação da hanseníase (MIRANZI; PEREIRA; NUNES, 2010).

O baixo número de exames de contatos realizados pode sugerir negligência e/ou passividade do serviço de saúde ofertado, relacionado ao investimento reduzido por parte das equipes de Saúde da Família na realização de busca ativa de casos; ou à presunção de que houve menos transmissão da hanseníase para essa população em decorrência de aspectos imunológicos que tornaram os indivíduos mais ou menos susceptíveis a adoecer (BRITO et al., 2016).

Quanto à evolução dos casos, $188(73,4 \%)$ evoluíram para cura, sendo este um indicador da qualidade do serviço de hanseníase considerado precário pelo MS (BRASIL, 2016); 39 (15,2\%) dos casos não tiveram registro quanto a este aspecto; 15 (5,8\%) dos casos foram transferidos; $12(4,7 \%)$ vieram a óbito; e $2(0,8 \%)$ receberam alta por abandono

\section{CONCLUSÕES}

Constata-se que o município de Cajazeiras ainda representa um território hiperendêmico para a hanseníase, que apresenta mais casos em homens, na faixa etária economicamente ativa e que tem seus serviços de saúde em hanseníase com várias fragilidades. Observou-se também, ausência de registros das informações pertinentes aos casos, o que interfere negativamente para se estabelecer um perfil epidemiológico dos casos e consequentemente, a elaboração de estratégias mais efetivas e eficazes no controle da hanseníase no município.

O enfermeiro, juntamente com uma equipe multiprofissional, deve realizar ações de educação e promoção da saúde, prevenção secundária eficiente e acompanhamento efetivo dos casos, além de proporcionar formação de vínculo entre os profissionais e o paciente/família para o enfrentamento da doença diante das angústias, preconceitos, medos, possíveis reações hansênicas e as adversidades experimentadas no decorrer do tratamento e pós-alta. É de extrema importância também, que haja o envolvimento da equipe de saúde em educação permanente.

RPI Revista de Pesquisa Interdisciplinar, Cajazeiras, v. 2, Edição Especial, 2017. 


\section{$\mathrm{RPP}$}

PALAVRAS-CHAVE: Epidemiologia. Hanseníase. Saúde Pública.

\section{REFERÊNCIAS}

BRASIL. Ministério da Saúde. Secretaria de Vigilância em Saúde. Departamento de Vigilância das Doenças Transmissíveis. Diretrizes para vigilância, atenção e eliminação da Hanseníase como problema de saúde pública: manual técnico-operacional, 2016.

BRITO, K.K.G et al. Caracterização dos casos de hanseníase diagnosticados através do exame de contato. Revista de enfermagem UFPE online. v. 10 n. 2, p. 435-441, 2016.

BRITO, K.K.G et al. Análise epidemiológica da hanseníase em um estado endêmico do nordeste brasileiro. Revista Gaúcha de Enfermagem. v. 36, p. 24-30, 2015.

DIAS, J.L. et al. Características determinantes entre portadores de hanseníase em uma área hiperendêmica. Revista Brasileira de Ciências da Saúde. n. 38, 2013.

MELÃO, S. et al. Perfil epidemiológico dos pacientes com hanseníase no extremo sul de Santa Catarina, no período de 2001 a 2007. Revista da Sociedade Brasileira de Medicina Tropical. v. 44, n. 1, p. 79-84, 2011.

MIRANZI, S.S.; PEREIRA, L.H.M.; NUNES, A.A. Perfil epidemiológico da hanseníase em um município brasileiro, no período de 2000 a 2006. Revista da Sociedade Brasileira de Medicina Tropical. v. 43, n. 1, p.62-67, 2010.

OLIVEIRA, V.M.; ASSIS, C.R.D.; SILVA, K.C.C. Levantamento epidemiológico da hanseníase no nordeste brasileiro durante o período de 2001-2010. Scire Salutis. v.3, n.1, 2013.

OLIVEIRA, J.C.F.; LEÃO, A.M.M.; BRITTO, F.V.S. Análise do perfil epidemiológico da hanseníase em Maricá, Rio de Janeiro: uma contribuição da enfermagem. Revista de enfermagem da UERJ. Rio de Janeiro, v. 22, n. 6, p. 815-21, 2014.

RIBEIRO, V.S. et al. Características clínicas e epidemiológicas da hanseníase no estado do maranhão, 2001 a 2009. Revista de Pesquisa em Saúde. v. 14, n. 2, p. 81-86, 2013.

XIMENES, F.R.G. et al. Epidemiologia da hanseníase no município de Cariré - ceará, 2001 a 2010. Revista Eletrônica Gestão \& Saúde. v. 4, n. 3, p. 829-842, 2013. 


\section{ROTINA DE ENFERMAGEM PARA RECEBIMENTO DE MATERIAL DE USO DOMICILIAR: RELATO DE EXPERIÊNCIA}

LINHA DE PESQUISA: Enfermagem na Saúde Coletiva; exposição oral

BRUNO NEVES DA SILVA

Acadêmico do curso de bacharelado em enfermagem do Centro de Formação de Professores da Universidade Federal de Campina Grande.

JÉSSICA ARAÚJO BEZERRA NÓBREGA Acadêmica do curso de bacharelado em enfermagem do Centro de Formação de Professores da Universidade Federal de Campina Grande.

PEDRO JULIANO DA SILVA Acadêmico do curso de bacharelado em enfermagem do Centro de Formação de Professores da Universidade Federal de Campina Grande.

INADJA SANCLEYA ROZAS DE OLIVEIRA Acadêmica do curso de bacharelado em enfermagem do Centro de Formação de Professores da Universidade Federal de Campina Grande.

FABIANA FERRAZ QUEIROGA FREITAS MESTRE EM ENFERMAGEM DOCENTE DA UNIVERSIDADE FEDERAL DE CAMPINA GRANDE

\section{INTRODUÇÃO}

Os resíduos de serviços de saúde podem ser produzidos em qualquer ambiente onde o cuidado de saúde é realizado. A classificação desses resíduos, segundo legislação brasileira, é feita em cinco grupos: A (infectantes), B (químicos), C (radioativos), D (comuns) e E (perfurocortantes); a classificação permite a separação dos resíduos para posterior descarte e tratamento final corretos, pois, as falhas decorrentes nesse processo podem gerar riscos ocupacionais, sobretudo quanto ao descarte incorreto de perfurocortantes; além de poder ocasionar danos ao meio ambiente, quando esses são desprezados sem tratamento prévio (SOUZA et al., 2015).

A exposição individual a microrganismos causadores de diversas doenças tem sido uma preocupação de saúde pública, tanto para trabalhadores de saúde, quanto para a população, visto que uma parcela desta faz uso diário de diversos materiais que podem ocasionar acidentes, sobretudo materiais perfurocortantes. A exposição a materiais biológicos, pode, segundo Marziale e Rodrigues (2002), ocorrer de duas formas: percutânea, através de objetos perfurocortantes; ou por intermédio de contato direto do material com a pele e/ou mucosas. 
Neste sentido, ocorre uma preocupação com uso de materiais contaminantes, infectantes e perfurocortantes em contexto domiciliar, uma vez que os usuários nem sempre compreendem os riscos que um descarte incorreto pode propiciar para a saúde da população, sobretudo para os profissionais que realizam a coleta destes materiais.

De acordo com o Conselho Federal de Enfermagem, as rotinas de enfermagem são elementos que especificam de forma exata a maneira de execução de uma determinada atividade e descrevem sistematicamente os passos que devem ser seguidos para realizar as ações que compõem uma atividade, na ordem da execução. Sobre organização destas rotinas, de acordo Soares et al. (2013), elas devem ser intensivamente adequadas às políticas institucionais.

Sendo assim, como é papel da enfermagem desenvolver as rotinas da instituição, de acordo com a realidade local, tomar conhecimento de como estas estão sendo executadas pode contribuir para criar estratégias para a adequação dessas rotinas e prevenir acidentes com matérias biológicos, o que torna relevante a realização desse trabalho.

\section{OBJETIVO DO TRABALHO}

Descrever o diagnóstico situacional das normas de rotina de enfermagem para recebimento de material contaminante, infectante e perfurocortante de uso domiciliar de uma Estratégia de Saúde da Família localizada em um município de pequeno porte no interior do sertão paraibano

\section{MATERIAIS E MÉTODOS}

Trata-se de um relato de experiência vivenciado por estudantes de graduação em enfermagem que retratam a realidade encontrada em uma unidade de saúde localizada em Cachoeira dos Índios, cidade integrante da $9^{a}$ Gerência de Saúde Paraibana, realizado por meio de observação da rotina de trabalho da equipe de enfermagem da unidade durante visita técnica.

\section{RESULTADOS E DISCUSSÃO}

Constatou-se que os materiais eram entregues na unidade de saúde para o paciente, como por exemplo, as seringas para os diabéticos insulinodependentes, e, após, estes eram orientados a acondicioná-los em recipiente rígido para evitar possíveis acidentes, a exemplo de uma garrafa pet, já que a unidade não dispunha de recipiente apropriado a ser dispensados junto com os insumos. Após o recebimento desses pela unidade, ocorre o recolhimento pela 


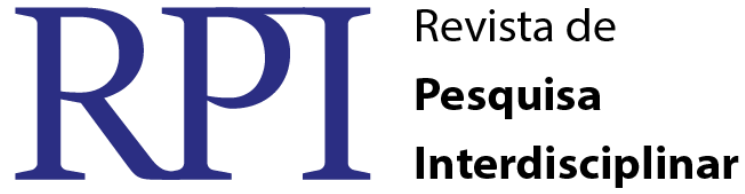

Anais do $1^{\circ}$ Encontro de Iniciação Científica da ETSC - 13 e 14 de junho de 2017.

equipe da limpeza e encaminhamento para uma sala de acondicionamento temporário para depois ser dado o destino final, desconhecido pela equipe de saúde.

Nota-se que o acondicionamento dos materiais não é realizado de acordo com o que é preconizado. Os materiais perfurocortantes, por exemplo deveriam ser desprezados em uma caixa própria para esse fim, que deveria ser entregue ao usuário pelo profissional da equipe de enfermagem, que deveria também fornecer as orientações de como mantê-la; e ao serem devolvidos à unidade de saúde, estes resíduos deveriam, conforme preconiza a RDC 306 da Agência Nacional de Vigilância Sanitária (ANVISA), serem recebidos pelo auxiliar de enfermagem e depois acondicionados em saco branco leitoso com simbologia de resíduo infectante. Posteriormente, o auxiliar de limpeza deve encaminhá-lo para o abrigo de coleta que ficaria localizado na parte externa da unidade (BRASIL, 2004).

Vale destacar ainda, que as ampolas de insulina, por exemplo, deveriam ser acondicionadas em um local separado dos perfurocortantes, o que não foi observado, pois eram também acondicionadas em garrafas pet, ao invés de em saco branco leitoso com simbologia infectante que deveria também ser dispensado para os pacientes, como é preconizado.

A incorreta forma de administração desses resíduos de insumos fornecidos traz repercussões negativas diretas ao meio ambiente e à saúde pública; nesta, os riscos estão diretamente relacionados às pessoas que posteriormente irão manipular esses materiais, seja na própria unidade, seja o pessoal ligado à assistência médica, ao setor de limpeza, ou até mesmo o próprio usuário do serviço de saúde (SOUSA et al., 2013).

Ainda de acordo com Sousa et al. (2013), não há uma definição específica para os coletores desses tipos de materiais, sendo mencionadas apenas algumas características comuns que estes coletores devem possuir; sendo assim, em uma instituição onde há limitação nos recursos financeiros, o reaproveitamento de certos recipientes pode representar economia de gastos, o que pode explicar a improvisação dos coletores acima descrita; é importante destacar, entretanto, que essa prática de improvisação pode acabar causando um problema mais preocupante: a ausência de identificação do seu conteúdo e de limite máximo de acondicionamento elas podem aumentar principalmente os riscos de acidentes ocupacionais.

Os materiais não perfurocortantes, mas infectantes e contaminantes, como material para curativo e cateteres, por exemplo, quando trocados em uso domiciliar, retornava para a unidade pelo próprio profissional de enfermagem que realiza o procedimento, sendo que, segundo relato, ao chegar nesta, são acondicionados em saco branco leitoso e recebem destino final não conhecido pela equipe. 
Neste contexto, excetuando-se o destino final desconhecido, nota-se que a postura utilizada é a correta, pois, segundo a RDC 306 da ANVISA, materiais com resíduos biológicos (risco A), devem ser armazenados temporariamente em saco branco leitoso devidamente identificado, com símbolo de risco biológico impresso (BRASIL, 2004).

\section{CONCLUSÕES}

Observou-se através deste relato que na ESF visitada não há uma rotina de enfermagem determinada para os resíduos biológicos, no entanto, a coleta é em partes compatível com o preconizado pela ANVISA. Entretanto, é válido destacar que as experiências obtidas, no que se refere às incoerências e divergências com a legislação, podem ser explicadas a partir do ponto de vista socioeconômico da unidade em questão, visto que a ausência de materiais pode ser o principal motivo das incorreções observadas.

Esses dados retratam a necessidade de revisar os métodos de descarte e dispensa de insumos pela equipe de enfermagem, visando adotar normas preconizadas pelo Ministério da Saúde, para aumentar a segurança do manejo desses materiais tanto para a população quanto para os profissionais que os recolhem, evitando o acontecimento de acidentes com material biológico a partir da adoção de medidas de biossegurança.

PALAVRAS-CHAVE: Biossegurança. Enfermagem. Diagnóstico Situacional.

\section{REFERÊNCIAS}

BRASIL. ANVISA. Agência Nacional de Vigilância Sanitária. Resolução RDC no 306, de 7 de dezembro de 2004. Dispõe sobre o Regulamento Técnico para o gerenciamento de resíduos de serviços de saúde. Disponível em <http://www.saude.mg.gov.br/images/documentos/res_306.pdf>. Acesso em 22 jul. 2016.

MARZIALE, M.H.P.; RODRIGUES, C.M. A produção científica sobre os acidentes de trabalho com material perfurocortante entre trabalhadores de enfermagem. Revista LatinoAmericana de Enfermagem. v. 10, n. 4, 2002.

SOARES, L.G.S. et al. Percepção do risco biológico em trabalhadores de enfermagem.

Cogitare Enfermagem. v. 18, n. 1, p. 36-42, 2013.

SOUSA, R.L. et al. Descarte adequado de perfurocortantes num hospital de Macapá-Brasil: um importante fator de prevenção de acidentes. Ciência Equatorial. v. 3, n. 1, 2013.

SOUZA, A.C.S. et al. Descarte de resíduos infectantes: informações demonstradas e ações praticadas por estudantes de enfermagem e medicina. Revista Eletrônica de Enfermagem. v. 17, n. 1, p. 124-130, 2015. 


\section{CARACTERÍSTICAS DA PREVALÊNCIA DA TOXOPLASMOSE GESTACIONAL: REVISÃO SISTEMATIZADA DA LITERATURA}

LINHA DE PESQUISA: Enfermagem na Saúde Coletiva; exposição oral

BRUNO NEVES DA SILVA

Acadêmico do curso de bacharelado em enfermagem do Centro de Formação de Professores da Universidade Federal de Campina Grande.

RAYRLA CRISTINA DE ABREU TEMOTEO Enfermeira, Mestre em Saúde Pública, Docente do Centro de Formação de Professores da Universidade Federal de Campina Grande

\section{INTRODUÇÃO}

A toxoplasmose é considerada a parasitose mais comum no mundo, consistindo em uma doença ocasionada pelo protozoário Toxoplasma gondii. A infecção se dá através do consumo de alimentos contendo formas do parasita, a exemplo de carnes cruas ou mal cozidas (de origem bovina, ovina e suína); de mãe para feto, por via transplacentária; e, em casos raros, através de transfusões sanguíneas, transplantes de órgãos e acidentes em laboratório (FURINI et al., 2015).

As infecções pelo T. gondii geralmente evoluem de forma benigna e com curso assintomático em pessoas imunocompetentes. Entretanto, a doença consiste em um agravo severo em neonatos, ocasionando sérios danos ao feto com manifestações clínicas que variam de acordo com o trimestre de gestação no qual a mulher se encontra (CARVALHO et al., 2014).

A gravidade da doença para o feto é inversamente proporcional ao tempo de gestação no qual a mulher adquire a infecção, ou seja, as implicações são mais severas no terceiro trimestre da gestação do que no primeiro e no segundo. As principais sequelas da infecção para os neonatos são calcificações cerebrais, hidrocefalia e coriorretinite (INAGAKI et al., 2014).

Ainda de acordo com Inagaki et al., (2014), a taxa de prevalência da toxoplasmose está situada entre 20 a $90 \%$ da população adulta global, variando entre as regiões e apresentando índices mais elevados nestas com clima quente e com alta umidade, principalmente quando estas condições estão associadas a condições precárias de saneamento e hábitos alimentares. Levando esses dados em consideração, nota-se que a infecção pelo $T$. gondii ainda se configura como um problema potencial à saúde pública, visto os agravos que a infecção pode trazer para o feto durante a gestação. Sendo assim, torna-se relevante a 
realização desta pesquisa, que poderá contribuir para a veiculação das características da toxoplasmose e, quiçá, auxiliar na busca de estratégias de controle e fortalecimento da sua prevenção a partir do conhecimento das características da sua prevalência.

\section{OBJETIVO DO TRABALHO}

Descrever a prevalência da toxoplasmose em gestantes a partir da análise da literatura pertinente.

\section{MATERIAIS E MÉTODOS}

Trata-se de uma pesquisa bibliográfica sistematizada, realizada no mês de setembro de 2016 por meio da base de dados Literatura Internacional em Ciências da Saúde (MEDLINE), por apresentar um apanhado relevante de publicações acerca do tema.

Os termos utilizados para pesquisa foram obtidos por meio de consultas aos Descritores em Ciências da Saúde (DeCS), onde foram selecionados três descritores cadastrados: toxoplasmose, prevalência e gestação. Na realização das buscas, os descritores foram associados utilizando-se do operador booleano "and".

Os critérios de inclusão considerados foram artigos científicos publicados entre os anos de 2011 a 2015, em português e disponíveis na íntegra de fora gratuita. Os critérios de exclusão foram artigos em duplicata, revisões bibliográficas e artigos que não tratassem da prevalência da toxoplasmose em gestantes.

\section{RESULTADOS E DISCUSSÃO}

Foram localizadas 940 publicações; destas, após observação do intervalo de anos estabelecido, esse número reduziu para 193 resultados. Após aplicação do filtro "disponível”, que seleciona apenas publicações disponíveis para acesso de forma livre e gratuita, o número de publicações reduziu novamente, totalizando 156 publicações. Desses, após observados os critérios de publicações em língua portuguesa e na forma de artigo científico, restaram 4 resultados. Desses quatro artigos, um foi excluído por não apresentar dados relacionados à prevalência da toxoplasmose, restando três publicações que foram analisadas na íntegra. A tabela abaixo apresenta um resumo do apanhado bibliográfico.

Tabela 1 - Dados do apanhado bibliográfico acerca da toxoplasmose gestacional no Brasil no período de 2011-2015

\begin{tabular}{l|l|l|l|c}
\hline Autor & Periódico & Ano & Título & $\begin{array}{c}\text { Tipo de } \\
\text { estudo }\end{array}$ \\
\hline
\end{tabular}




\section{Revista de
Pesquisa
Interdisciplinar}

\begin{tabular}{|c|c|c|c|c|}
\hline $\begin{array}{l}\text { SARTORI, A.L.; } \\
\text { MINAMISAVA, R.; } \\
\text { AVELINO, M.M.; } \\
\text { MARTINS, C.A. }\end{array}$ & $\begin{array}{l}\text { Revista Brasileira } \\
\text { de Ginecologia e } \\
\text { Obstetrícia }\end{array}$ & 2011 & $\begin{array}{l}\text { Triagem pré-natal para } \\
\text { toxoplasmose e fatores associados à } \\
\text { soropositividade } \\
\text { de gestantes em Goiânia, Goiás }\end{array}$ & $\begin{array}{l}\text { Corte } \\
\text { transversal, } \\
\text { retrospectivo }\end{array}$ \\
\hline $\begin{array}{lr}\text { BITTENCOURT, } \\
\text { L.H.F.B.; } \quad \text { LOPES- } \\
\text { MORI, } & \text { F.M.R.; } \\
\text { MITSUKA- } & \\
\text { BRÁGANO, } & \text { R.N.; } \\
\text { VALLENTIM- } & \\
\text { ZABBOT, } & \text { M.; } \\
\text { FREIRE, } & \text { R.L.; } \\
\text { PINTO, } & \text { S.B.; } \\
\text { NAVARRO, I.T. }\end{array}$ & $\begin{array}{l}\text { Revista Brasileira } \\
\text { de Ginecologia e } \\
\text { Obstetrícia }\end{array}$ & 201 & $\begin{array}{l}\text { Soroepidemiologia da toxoplasmose } \\
\text { em gestantes } \\
\text { a partir da implantação do Programa } \\
\text { de Vigilância da Toxoplasmose } \\
\text { Adquirida e Congênita em } \\
\text { municípios da região oeste do } \\
\text { Paraná }\end{array}$ & $\begin{array}{l}\text { Observacional } \\
\text {, Transversal }\end{array}$ \\
\hline $\begin{array}{l}\text { FERENZI, } \quad \text { R.I.; } \\
\text { BERTOLINE, D.A.; } \\
\text { DERMARCHI, I.G. }\end{array}$ & $\begin{array}{l}\text { Revista Brasileira } \\
\text { de Ginecologia e } \\
\text { Obstetrícia }\end{array}$ & 2013 & $\begin{array}{l}\text { Prevalência de sorologia positiva } \\
\text { para HIV, hepatite } \mathrm{B} \text {, toxoplasmose } \\
\text { e rubéola em } \\
\text { gestantes do noroeste paranaense }\end{array}$ & Retrospectivo \\
\hline
\end{tabular}

Fonte: Dados da pesquisa, 2016.

Com relação à prevalência, as pesquisas abordaram os títulos sorológicos de anticorpos IgG e IgM para toxoplasmose nas gestantes, que permitem identificar se a infecção pelo parasita é recente ou prévia à gestação, em diferentes contextos, onde a positividade de IgG anti-Toxoplasma gondii foi a que apresentou maiores índices, chegando a resultados superiores a $50 \%$ em todos os estudos que compuseram a amostra, demonstrando que a maioria das gestantes abordadas haviam sido expostas em algum momento da vida ao parasita, o que não acarretava risco para a gestação atual. Outras pesquisas apontam essa elevada sororreatividade IgG em mulheres, como por exemplo, estudos realizados por Câmara; Silva; Castro (2015) e Pavan et al. (2016).

No tocante ao perfil epidemiológico dos casos, Sartori et al. (2011), observaram maior soropositividade de anticorpos IgG em gestantes entre 20 a 30 anos de idade, com baixa escolaridade e de cores parda e preta. Bittencourt et al. (2012) corroboram com os maiores índices de IgG em gestantes com baixa escolaridade, sem, entretanto, apontar nenhum dos outros fatores anteriormente citados como relacionados à maior prevalência dos títulos de anticorpos; contudo, os autores apontam que mulheres com mais de um parto apresentaram maiores índices de sorologia $\operatorname{IgG}$ positiva.

Essa associação entre baixos níveis de escolaridade e infecção pelo Toxoplasma gondii foi verificada em outros estudos, como o de Dias et al. (2011), que apontam maior vulnerabilidade para as mulheres com menos de oito anos de estudo. 


\section{$\int\left[\begin{array}{l}\text { Revista de } \\ \text { Pesquisa } \\ \text { Interdisciplinar }\end{array}\right.$}

Anais do $1^{\circ}$ Encontro de Iniciação Científica da ETSC - 13 e 14 de junho de 2017.

Ainda no tocante à idade, Ferenzi et al. (2013) identificaram maior prevalência de anticorpos IgG anti-Toxoplasma gondii em gestantes que estavam situadas entre a faixa etária de 30 a 40 anos.

Quanto à sorologia IgM (associada à presença de infecção ativa ou recente), das mulheres testadas, a prevalência de resultados positivos não chegou a $2 \%$ em nenhum dos estudos analisados, tendo seu valor mais alto no estudo de Sartori et al. (2011), que identificaram, a partir de seu estudo retrospectivo com dados de 12.846 gestantes, um percentual de $0,7 \%$ de mulheres com valores de IgM positivo associado a valores IgG também positivos.

Destaca-as ainda um elevado percentual de mulheres soronegativas para ambos os tipos de anticorpos anti-Toxoplasma gondii nos estudos feitos por Bittencourt et al. (2012) e por Sartori et al. (2011), que verificaram percentuais de gestantes vulneráveis à infecção durante a gestação de $40 \%$ e $32,3 \%$, respectivamente, em suas amostras, o que demonstra elevado percentual de grávidas que chegam à gestação suscetíveis à infecção e a consequente transmissão vertical, podendo gerar sequelas ou a morte do feto. Furini et al. (2015), também encontraram percentual elevado de gestantes suscetíveis à toxoplasmose e chamam atenção para a necessidade de conscientização acerca dos fatores de risco relacionados à doença, bem como a necessidade de realização de exames diagnósticos para a infecção durante o pré-natal.

O elevado percentual de soropositividade para o Toxoplasma gondii demonstra que o parasita é de fácil disseminação e não apresenta complicações sérias à saúde da gestante, representando um problema sério ao recém-nascido. $\mathrm{O}$ grande número de mulheres susceptíveis à infecção sugere que medidas de prevenção e promoção à saúde devem ser intensificadas para evitar que estas venham a adoecer durante a gestação e comprometer a saúde do binômio mãe-filho.

\section{CONCLUSÕES}

Conclui-se que ações profiláticas de saúde púbica devem ser elaboradas e estimuladas, visto os índices elevados de mulheres suscetíveis a contrair a infecção na gravidez, fazendo-se necessária a implantação de programas de controle da toxoplasmose.

A assistência pré-natal constitui-se em um excelente momento de abordar os fatores de risco e as formas de prevenção contra o Toxoplasma gondii, podendo o enfermeiro, nesse contexto, aparecer como um ator importante, visto o seu potencial de estabelecer vínculo com a pessoa, a família e a comunidade.

PALAVRAS-CHAVE: Gestação. Prevalência. Toxoplasmose. 


\section{$\int \begin{aligned} & \text { Revista de } \\ & \text { Pesquisa } \\ & \text { Interdisciplinar }\end{aligned}$}

\section{REFERÊNCIAS}

BITTENCOURT, L.H.F.B. et al. Soroepidemiologia da toxoplasmose em gestantes a partir da implantação do Programa de Vigilância da Toxoplasmose Adquirida e congênita em municípios da região oeste do Paraná. Revista Brasileira de Ginecologia e Obstetrícia. v. 34, n. 2, p. 63-68, 2012.

CARVALHO, A.G.M.A et al. Diagnóstico laboratorial da toxoplasmose congênita. Revista de Ciências da Saúde Nova Esperança. v. 12, n. 1, p. 88-95, 2014.

CÂMARA, J.T.; SILVA, M.G.; CASTRO, A.M. Prevalência de toxoplasmose em gestantes atendidas em dois centros de referência em uma cidade do Nordeste, Brasil. Revista

Brasileira de Ginecologia e Obstetrícia. v. 37, n. 2, p. 64-70, 2015.

DIAS, R.C.F. et al. Factors associated to infection by Toxoplasma gondii in pregnant women attended in Basic Health Units in the city of Rolândia, Paraná, Brazil. Revista do Instituto de Medicina Tropical de São Paulo. São Paulo, v. 53, n. 4, 2011.

FERENZI, R.I. Prevalência de sorologia positiva para HIV, hepatite B, toxoplasmose e rubéola em gestantes do noroeste paranaense. Revista Brasileira de Ginecologia e Obstetrícia. v. 35, n. 2, p. 66-70, 2013.

FURINI, A.A.C. et al. Soroprevalência de Anticorpos anti-Toxoplasma gondii em Amostras de Gestantes no Pré-Natal. Revista Brasileira de Ciências da Saúde. v. 19, n. 3, p. 199-204, 2015.

INAGAKI, A.D.M. Análise espacial da prevalência de toxoplasmose em gestantes de Aracaju, Sergipe, Brasil. Revista Brasileira de Ginecologia e Obstetrícia. v. 36, n. 12, 2014. PAVAN, A.A. et al. Soroepidemiologia da toxoplasmose em gestantes do município de Medianeira, Paraná, Brasil. Arquivos de Ciências da Saúde da UNIPAR. v. 20, n. 2, p. 131$135,2016$.

SARTORI, A. L. Triagem pré-natal para toxoplasmose e fatores associados à soropositividade de gestantes em Goiânia, Goiás. Revista Brasileira de Ginecologia e Obstetrícia. v. 33, n. 2, p. 93-98, 2011 


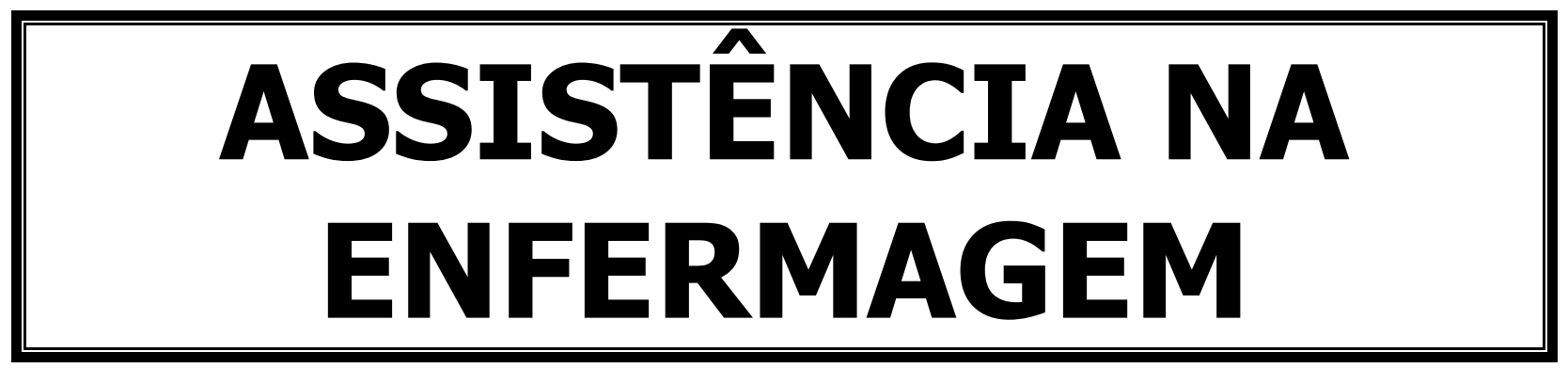




\section{PRÁTICAS INTEGRATIVAS E COMPLEMENTARES NA ASSISTÊNCIA DE ENFERMAGEM: ESTUDO REFLEXIVO}

LINHA DE PESQUISA: Assistência de enfermagem; banner.

MAÍSA GALDINO PEREIRA Acadêmica do curso bacharelado em enfermagem do Centro de Formação de Professores da Universidade Federal d Campina Grande.

LUANA RÉGIA FERREIRA VIEIRA Acadêmica do curso bacharelado em enfermagem do Centro de Formação de Professores da Universidade Federal d Campina Grande

SARA SAMIRYS SANTANA Acadêmica do curso bacharelado em enfermagem do Centro de Formação de Professores da Universidade Federal d Campina Grande.

MARCELO FERNANDES COSTA Enfermeiro. Doutor em Cuidados Clínicos em enfermagem. Docente da Universidade Federal de Campina Grande/UFCG

\section{INTRODUÇÃO}

Às Práticas Integrativas e Complementares (PICs) são ações que visam promover um atendimento integral, possibilitando que o profissional atue de forma humanizada, ampliada e centrada no indivíduo, avaliando o sujeito como um ser único, dotado de particularidades e complexidades. A partir das PICs, o profissional busca ultrapassar os limites do modelo assistencial biomédico, bastante priorizado nas práticas da medicina convencional. A aceitação de que o corpo pode sofrer influências positiva ou negativa, a partir dos meios que não podem ser observados com uma medicina convencional/biomédica, o profissional passa a garantir abordagens essenciais para uma atuação a fim de promover ações de prevenção e recuperação da saúde (BRASIL, 2006). 
Práticas essas que são conhecidas como medicina alternativa sendo dividida em grupos que atuam de diferentes formas, a fim de promover uma maior interação entre profissionais e usuários: Medicina antroposófica; crenoterapia; medicina tradicional chinesa; fitoterapia; homeopatia. Esses tipos de prática não substituem ou alteram a atuação da medicina convencional, ao contrário, deve ser utilizada para agregar saberes e potencializar os resultados de melhora. Somando os conhecimentos e habilidades e atuando promovendo uma melhor manutenção da saúde. Buscando sempre a autonomia do paciente e estimulando a construção de uma prática centrada na saúde e não mais na doença (SANTOS; TESSER, 2012).

Faz-se necessário estudos e discussões acerca da implementação das PICs, já que o modelo atual predominante ainda é o tradicionalista médico-centrado e as PICs buscam promover essa mudança de paradigma onde enxergar o indivíduo como o todo é de fundamental importância para a sua eficácia, buscando a transição do modelo biomédico para o modelo mais holístico e humanitário.

\section{OBJETIVO}

Refletir sobre as práticas integrativas e complementares no cotidiano de práticas do enfermeiro.

\section{METODOLOGIA}

Estudo reflexivo elaborado a partir da Política Pública de Práticas Integrativas e Complementares em Saúde, bem como no cotidiano de práticas na rede de atenção à saúde.

\section{RESULTADOS E DISCUSSÕES}

Os métodos alternativos por muitos anos foram algo utilizado pela humanidade, porém com o avanço da ciência e da tecnologia o modelo curativista foi ganhando espaço, sendo superior às práticas culturais e alternativas. O modelo biomédico utilizado ainda hoje visa apenas à doença e os meios externos que a ocasionam, esquecendo que o ser humano é um ser holístico e vários fatores interferem no seu processo de adoecimento, por isso se faz necessário levar em conta também as dimensões sociais e culturais que o indivíduo está inserido. 


\section{$\int\left[\begin{array}{l}\text { Revista de } \\ \text { Pesquisa } \\ \text { Interdisciplinar }\end{array}\right.$}

Anais do $1^{\circ}$ Encontro de Iniciação Científica da ETSC - 13 e 14 de junho de 2017.

O intuito da PICs é oferecer à população opções terapêuticas respeitando e utilizando os princípios culturais, saberes locais, garantindo o acesso integral ao paciente. Sendo essas práticas em caráter multiprofissional concomitantemente com o nível básico de atenção (PENNAFORTE et al, 2012).

Segundo a Resolução do Cofen de $n^{\circ}$ 197/97, reconhece as terapias alternativas como especialidade e/ou qualificação do profissional de enfermagem, desde que este seja aprovado em um curso com carga mínima de 360 horas. O que permite ao enfermeiro, desde que qualificado prestar a assistência necessária, deixando de lado o agir mecanicista, visando à autonomia e o bem-estar do indivíduo.

As práticas integrativas têm-se mostrado um cenário bastante promissor na área da saúde, sendo importante a participação do enfermeiro do que diz respeito ao gerenciamento, na divulgação e discussão com todos os envolvidos (PENNAFORTE; et al, 2012).

Ainda de acordo com o autor supracitado, a enfermagem como grande atuante na promoção e resolutividade das condições de saúde, permanece imersa nos saberes teóricos científicos, valorizando condições mecanicistas de atendimento doutrinado no conhecimento hospitalar e centrado na doença. Diante do crescimento da utilização de práticas que universalize à assistência e garanta um atendimento integral e humanizado, a utilização de formas não convencionais de tratamentos oferece uma melhor expansão de uma assistência e a enfermagem como principal precursora dos cuidados ao indivíduo, ganha uma maior possiblidade de visibilidade referente ao cuidar.

A utilização das práticas integrativas e complementares estimulam os mecanismos naturais, valorizando os conhecimentos de vivências e culturas. Promovendo uma maior interação entre indivíduos e meio ambiente, estando diretamente ligado ao processo de prevenção e recuperação de agravos no processo de saúde-doença. Promovendo as práticas humanitárias e de valorização do sujeito. (MAGALHÃES; ALVIM, 2013)

\section{CONCLUSÃO:}

Diante do constante cenário de mudanças da saúde para melhor promover uma atenção integral, às práticas integrativas e complementares voltam a ganhar espaço como saber de extrema relevância para a atuação multiprofissional. As principais dificuldades encontradas para uma maior eficácia dessas práticas é justamente o despreparo profissional em ampliar seu 


\section{$\mathrm{RPP}$}

campo de atuação, despreparo esses que se inicia ainda no período de graduação, onde ainda é valorizado modelo de assistência a saúde de forma mecanicista.

As Práticas Integrativas e Complementares compreendem a medicina complexa e condutas terapêuticas, favorecem a criação de vínculos sociais e com o meio ambiente, a autonomia por parte do paciente, buscam a prevenção e recuperação de agravos à saúde através de tecnologias leves, auxiliando ao profissional uma visão mais abrangente do processo saúde-doença, contribui especialmente para o paciente processo do autocuidado, o tornando menos dependente dos cuidados médicos. A integração da PIC no SUS caracteriza a qualificação e expansão dos serviços, na busca de incorporar uma assistência integral e eficaz à saúde.

Descritores: Práticas integrativas e complementares; Assistência a Saúde; Enfermagem.

\section{REFERÊNCIAS}

BRASIL. Ministério da Saúde. Secretaria de Atenção à Saúde. Departamento de Atenção Básica. Política Nacional de Práticas Integrativas e Complementares no SUS - PNPIC-SUS Brasília: Ministério da Saúde, 2006. 92 p. - (Série B. Textos Básicos de Saúde).

(COFEN. Conselho Federal de Enfermagem. Resolução COFEN-197/97. Estabelece e reconhece as terapias alternativas como especialidade e/ou qualificação do profissional de enfermagem. Brasília (DF); 1997.

CORDEIRO, C. A. Usuárias do centro de práticas integrativas e complementares: despertando para o cuidar de si. Dissertação (Mestrado). Universidade Federal da Paraíba, João Pessoa. Área de Concentração: Enfermagem na Atenção à Saúde. 2015, pág. 117.

MAGAlhãES, M. G. M; ALVIM, N. A. T. Práticas integrativas e complementares no cuidado de enfermagem: um enfoque ético. Rev. Esc. Anna Nery (impr.), 2013, vol. 17, n. 4, pág. 646 - 653.

SANTOS, M. C., TESSER, C. D. : Um método para a implantação e promoção de acesso às Práticas Integrativas e Complementares na Atenção Primária à Saúde. Ciência \& Saúde Coletiva, 2012, vol.17, n. 11, pág. 3011-3024. 
SACRAMENTO, H.T. A implementação da política nacional de práticas integrativas e complementares no município de Vitória-ES: percepção dos médicos e gestores. Dissertação (mestrado) em Políticas Públicas e Desenvolvimento Local - Escola Superior de Ciências da Santa Casa de Misericórdia de Vitória - 2015. 121f.

PENNAFORTE; et al. Práticas integrativas e o empoderamento da enfermagem. Rev. Min. Enferm. 2012, vol. 16, n. 2, pág. 289-295. 


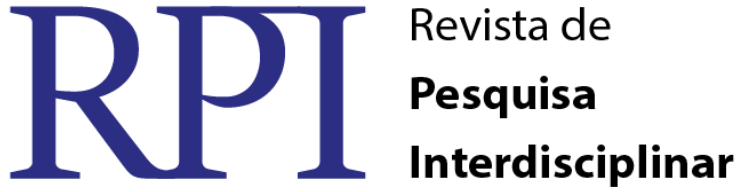

\section{FATORES ASSOCIADOS AO DESENVOLVIMENTO DE ESTRESSE EM ENFERMEIROS \\ LINHA DE PESQUISA: ASSISTÊNCIA DE ENFERMAGEM. EXPOSIÇÃO ORAL}

\author{
Jovelina Fernandes dos Santos, Acadêmica de Enfermagem, UFCG. \\ Manuella Andrade, Acadêmica de Enfermagem, UFCG. \\ Thaynara Maria de Oliveira Alburquerque, Acadêmica de Enfermagem, UFCG. \\ Prof. Especialista orientadora:Flaviana Dávilade Sousa Soares \\ Prof. Enf. Mestranda do CFP da UFCG:GerlaneCristinneBertinoVéras
}

\section{INTRODUÇÃO}

O estresse provoca desequilíbrio nos mecanismos fisiológicos do individuo, em que cada organismo é um sistema vivo que troca informações e matéria entre seu ambiente interno e externo (SMELTZER, 2012).

A vida moderna apresenta vários episódios de estresse, isso é um fato marcante e presente tanto na vida profissional como na vida pessoal. No que tange ao profissional da enfermagem sabe-se que este presta assistência ao paciente e família, convivendo com aspectos conflitantes como o nascimento e a morte. (BIANCHI, 2009)

O processo de trabalho do enfermeiro, incluindo a estrutura e a organização funcional, mostra-se altamente complexo. Existem momentos de muita tensão emocional, desgaste físico e psíquico que podem contribuir como fator desencadeante do estresse. Isso requer do profissional enfermeiro uma adaptação em relação a esses agentes estressores para manter o seu equilíbrio homeostático. (ALVES, 2011)

Tendo como base a problemática apresentada, é de grande relevância analisar como as questões que dizem respeito à qualidade de vida dos profissionais de enfermagem podem influenciar diretamente nos resultados e na qualidade da assistência prestada pela enfermagem aos seus pacientes e no seu bem-estar.

\section{OBJETIVO}

Identificar quais os principais elementos desencadeadores do estresse no trabalho do enfermeiro que podem resultar em déficit na qualidade da assistência e bem-estar pessoal. 


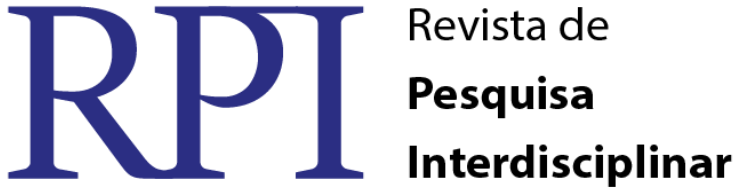

\section{METODOLOGIA}

Trata-se de uma revisão integrativa da literatura, a qual tem como objetivo buscar produções científicas sobre os principais fatores associados ao desenvolvimento de estresse nos profissionais da saúde

A coleta de dados foi realizada nas seguintes bases de dados eletrônicas: Literatura Latino-Americana e do Caribe em Ciências da Saúde (LILACS), ScientificElectronic Library Online (SciELO), Base de Dados de Enfermagem (BDENF), Medical LiteratureAnalysisandRetrieval System Online (MEDLINE), via Biblioteca Virtual de Saúde (BVS). A busca foi realizada no mês de novembro de 2016, empregando a combinação dos seguintes descritores: "Estresse profissional", "Saúde mental", "Saúde do trabalhador" e "Enfermeiros", conforme a classificação dos Descritores em Ciências da Saúde (DeCS).

A questão norteadora da pesquisa foi: Quais os principais fatores associados ao desenvolvimento do estresse em enfermeiros?

Os critérios de inclusão definidos para a seleção foram: artigos completos on-line e gratuitos que abordassem a temática referente à revisão integrativa; disponíveis em bases de dados nacionais e internacionais; publicados no idioma português ou inglês; no período compreendido entre 2010 a 2015.

\section{RESULTADOS E DISCUSSÃO}

A coleta dos dados foi realizada após a análise dos 49 artigos encontrados, buscando atender aos objetivos da temática evidenciada, após a aplicação dos critérios de inclusão, exclusão e a leitura na íntegra destes. Foram utilizados 11 artigos para o desenvolvimento da pesquisa dos quais 3 se apresentavam no idioma inglês e 3 em português e com os dados coletados pode-se analisar os fatores associados ao estresse dos enfermeiros. Os periódicos de publicação foram: Revista da Escola de Enfermagem da USP; Aquichan, Escola Anna Nery; Revista Brasileira de Terapia Intensiva; Revista Latino-Americana de Enfermagem; Revista eletrônica saúde mental álcool e drogas; Ojin: The Journal Online de Assuntos em Enfermagem; Revista de Enfermagem da UERJ; The Online JournalofIssues in Nursing, Com base na análise da literatura científica foi possível perceber que muitos fatores podem desencadear o estresse em enfermeiros, dentre eles o alto grau de comprometimento na saúde física e psicológica e o desgaste emocional que 


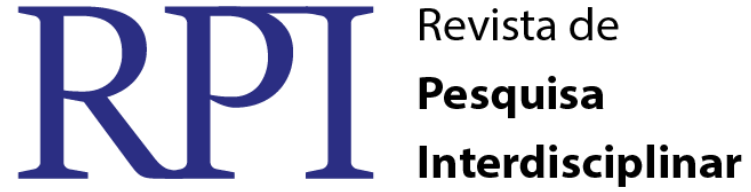

foi apresentado em 3 artigos. Campos et al., (2014), apresenta os sentimento de injustiça, frustração, insegurança, inutilidade como elementos que repercutem diretamente na qualidade de vida do enfermeiro. Fatores que interferem no físico foram mencionados por Lombardo et al., (2014), pois mostra que à alta sobrecarga de tarefas e esforços físicos refletem como dores de cabeça, distúrbios do sono, sintomas cardíacos.

A estrutura física deficiente dos ambientes de trabalho, a falta de recursos materiais e condições precárias aparecem em 2 artigos, tais elementos comprometem a segurança do trabalhador e a assistência prestada ao paciente. Segundo Hanzelmannet al.,(2010), a falta desses recursos associados aos profissionais não treinados, excesso de carga horária e salários indignos podem potencializar o estresse nesses profissionais em seu cotidiano de trabalho. Sabe-se que os profissionais permanecem por longos períodos de tempo em seus locais de trabalho e esses ambientes deveriam proporcionar melhores condições para desempenhar suas atividades com segurança e tranquilidade, pois a falta de recursos materiais pode causar prejuízos à saúde dos enfermeiros. De forma geral, o processo de trabalho da enfermagem envolve atividades estressantes e desgastantes, nos artigos analisados podemos perceber que o esgotamento profissional, falta de reconhecimento, de motivação e de valorização são referidos em 2 artigos, de acordo com Lorenzet al.,(2010) são fatores pouco explicitados em palavras, porém, evidenciado pelo próprio enfermeiro.

A falta de autonomia do profissional quanto às dificuldades de integração com outros profissionais tanto da própria equipe de trabalho estão indiretamente ligados, esses aspectos estão inseridos em 2 artigos, de acordo com Paula et al., (2010), os enfermeiros apontam o autoritarismo da chefia como um problema nas relações interpessoais no ambiente de trabalho, esses elementos estão presente em sua rotina e interferem diretamente na sua qualidade de vida, podendo desencadear elevados níveis de estresse tanto na sua vida pessoal quanto profissional.

Outro fator estressor identificado em 2 artigos é a despersonalização que segundo Carlotto e Palazzo, (2006) refere-se ao sentido de desumanização, tem-se a percepção de deterioração da competência para resolver problemas e da satisfação com as realizações no trabalho, e repercute como insensibilidade emocional que faz com que o profissional trate os seus pacientes e os colegas de maneira desumanizada.

\section{CONCLUSÃO}

A presente revisão integrativa permitiu identificar os fatores que mais desencadeiam o estresse nos enfermeiros. Desse modo, com o conhecimento dos principais elementos 
estressores, o enfermeiro deve buscar mecanismos que visem minimizar as fontes geradoras de estresse, com a finalidade de melhorar a sua qualidade de vida e prestar melhor assistência aos pacientes, famílias e comunidade.

Destarte, é fundamental que a instituição de saúde na qual o enfermeiro trabalha, prepare esses trabalhadores fisicamente e psiquicamente e se empenhe em minimizar os fatores que comprometem o seu bem-estar. O local de trabalho é a representação da continuidade do lar, e uma boa qualidade de vida irá influenciar diretamente no desempenho profissional, elevando a autoestima, tornando este profissional produtivo e gerando uma atenção única e de qualidade ao paciente.

PALAVRAS-CHAVE: Enfermeiros; Estresse profissional, Saúde mental, Saúde do trabalhador.

\section{REFERÊNCIAS}

ALVES, Ana Carolina Guerra Corrêa. Estresse e o trabalho do enfermeiro: uma revisão bibliográfica. 2011.

BIANCHI, Estela Regina Ferraz et al. Escala Bianchi de stress. Revista da Escola de Enfermagem da USP, v. 43, n. spe, p. 1055-1062, 2009.

CAMPOS, Juliana Faria; DAVID, Helena Maria Scherlowski Leal; SOUZA, Norma Valeria Dantas de Oliveira. Pleasure and suffering: assessment of intensivist nurses in the perspective of work psychodynamics. Escola Anna Nery, v. 18, n. 1, p. 90-95, 2014.

CARLOTTO MS, Palazzo LS. Síndrome de burnout e fatores associados: um estudo epidemiológico com professores. Cad Saúde Pública. 2006; 22(5):1017-26.

HANZELMANN, Renata Silva; Passos, Joanir Pereira. Imagens e representações da enfermagem acerca do stress e sua influência na atividade laboral. Revista da Escola de Enfermagem da USP, v. 44, n. 3, p. 694-701, 2010.

LORENZ, Vera Regina; Benatti, Maria Cecília Cardoso; Sabino, Marcos Oliveira. Burnout e estresse em enfermeiros de um hospital universitário de alta complexidade. Rev. Latino-Am.

Enfermagem, v. 18, n. 6, p. 1084-91, 2010.

LOMBARDO, Barbara; EYRE, Caryl. A fadiga da compaixão: o iniciador A enfermeira. Ojin: The Journal Online de Assuntos em Enfermagem , v 16, n. 1, 2011.

PAULA, Glaudston Silva et al. O sofrimento psíquico do profissional de enfermagem da unidade hospitalar. Aquichan, v. 10, n. 3, p. 267-279, 2010. 
SMELTZER, Suzane C. et al. Brunner\&Suddarth Tratado de Enfermagem Médico Cirúrgica. 12. ed., v. 1, Rio de Janeiro: Guanabara; 2012, p. 77-85. 


\section{REFLEXÕES ACERCA DA NECESSIDADE DE UMA ASSISTÊNCIA HUMANIZADA A PACIENTES E FAMILIARES NA UNIDADE DE TERAPIA INTENSIVA INFANTIL}

\section{ASSISTÊNCIA DE ENFERMAGEM (Exposição oral)}

IRISLÂNDIA DE OLIVEIRA BATISTA 1, Graduanda em Enfermagem, UFCG. THACIANE MARIA F. DE SOUZA 2, Graduanda em Enfermagem, UFCG. MARIA KARULINE ANDRADE E SILVA 3, Graduanda em Enfermagem, UFCG. GILIARA CAROL DINIZ DE LUNA GURGEL, Docente, UFCG.

\section{INTRODUÇÃO}

As Unidades de Terapia Intensiva (UTI) são locais diferenciados no qual se tem uma concentração de tecnologias e rotinas minuciosas a depender do estado de saúde do paciente. A hospitalização infantil inclui a criança, a família e o profissional, onde essa convivência pode durar de dias até meses, sendo esta internação considerada como mais complexa que a do adulto tendo em vista que a morte de uma criança é tida como mais trágica, já que a capacidade de recuperação é alta nesses pacientes (MENIN, 2015).

Além disso, se torna mais complexo pelo envolvimento dos pais, que desde a gestação aguardam a chegada de um filho saudável e quando este nasce com algum problema de saúde ou prematuro, necessitando de internação na Unidade de Terapia Intensiva Neonatal (UTIN), o sentimento de alegria dos pais cede espaço para insegurança e medo, desse modo torna-se necessária uma abordagem mais humanizada da equipe de saúde, não só para com o recém-nascido, mas também com os familiares.(OLIVEIRA,2013).

Durante a assistência os profissionais também enfrentam diversos desafios, dentre estes a constante realidade de lidar com a consumação da vida de crianças, necessitando de diversos subsídios para enfrentarem problemas e conseguirem prestar uma assistência integral e humanizada aos pacientes e seus familiares (MENIN, 2015).

A humanização na UTI está relacionada ao cuidado e acolhimento dos envolvidos, onde não se considera apenas a doença ou problema que acomete o neonato em si, mas que valoriza a integralidade e subjetividade do sujeito e de sua família (PINHEIRO, 2011).

\section{OBJETIVO}




\section{$\int\left[\begin{array}{l}\text { Revista de } \\ \text { Pesquisa } \\ \text { Interdisciplinar }\end{array}\right.$}

Anais do $1^{\circ}$ Encontro de Iniciação Científica da ETSC - 13 e 14 de junho de 2017.

Sendo assim, neste estudo têm-se o intuito de analisar e compreender alguns pontos imprescindíveis para uma assistência de qualidade, visando o bem-estar dos pacientes, familiares e também dos profissionais, tendo em vista as fragilidades que cercam este ambiente.

\section{MATERIAIS E MÉTODOS}

Trata-se de uma revisão narrativa da literatura, na qual foram definidas a escolha do tema, a questão norteadora da pesquisa relacionada à fragilidade presente no âmbito hospitalar, principalmente na Unidade de Terapia Intensiva Infantil, levando em conta a necessidade de um atendimento humanizado. A busca foi realizada no mês de novembro de 2016 nas seguintes bases de dados: Biblioteca Virtual de Saúde (BVS) e Scientific Electronic Library Online (SciELO). Os termos usados nesta revisão foram obtidos por meio de consulta ao DeCS. Utilizou-se na busca das publicações os descritores "enfermagem", "uti", "humanização" e "infantil".

Como critérios de inclusão definiram-se: artigos em português disponíveis na íntegra nas referidas bases de dados, de acesso livre, determinando o intervalo de tempo da busca como início e fim nos anos de 2009 e 2015, respectivamente. Foram excluídos os trabalhos não disponíveis na íntegra, material não convencional, bem como, artigos que não abordavam a temática proposta. A busca foi realizada individualmente por dois pesquisadores, de forma independente, e para a pré-seleção dos artigos encontrados, foi realizada uma análise coletiva todos os resumos disponíveis para categorização dos estudos. Posteriormente, os artigos foram organizados segundo a base de dados de obtenção, resultando em um total de 6 documentos, e procedendo-se a eliminação de publicações duplicadas.

\section{RESULTADOS E DISCUSSÃO}

Nas últimas décadas tem-se discutido bastante sobre a humanização e sua importância. A partir desses debates que com o passar dos anos tem ganhado mais enfoque, o Brasil no ano de 2004 lança a Política Nacional de Humanização (PNH) pelo ministério da saúde, com o objetivo de favorecer e qualificar a assistência (SOUZA, 2010). A partir dessa qualificação iniciou-se o combate às altas taxas de morbimortalidade neonatal, pois de acordo com Silva (2009) em torno de 20 milhões de bebês nasciam com peso inferior a $2.500 \mathrm{~g}$, tendo como principais fatores de entrada na UTI o nascimento prematuro e o baixo crescimento intrauterino, na maioria em países desenvolvidos.

É perceptível a necessidade de uma equipe multidisciplinar as quais devem atentar-se às fragilidades, devendo contemplar vários aspectos, entre sociais, emocionais e psicológicos os quais sofrem alterações durante a internação de um familiar (MENIN, 2015). Segundo 


\section{$\int\left[\begin{array}{l}\text { Revista de } \\ \text { Pesquisa } \\ \text { Interdisciplinar }\end{array}\right.$}

Anais do $1^{\circ}$ Encontro de Iniciação Científica da ETSC - 13 e 14 de junho de 2017.

Pinheiro (2011) quando esta internação ocorre com um neonato na UTI, outros fatores também devem ser considerados como o ruído e a iluminação do ambiente, que podem interferir de maneira negativa no processo de recuperação do bebê, podendo por exemplo causar uma desorganização no seu estado fisiológico, comprometendo sua recuperação.

O tempo que a criança passa na UTI pode gerar na equipe de profissionais de saúde maior vínculo e afetividade, estabelecendo assim segurança na realização de suas atividades, mas tudo isso se rompe no momento da morte em que os profissionais se deparam com a perda e o sofrimento, levando ao luto (MENIN, 2015).

Segundo Silva (2009), a Enfermagem em suas diversas atribuições, desempenha um papel de suma importância diante de um processo de trabalho baseado no emprego de tecnologias leves, buscando assim um atendimento de forma mais solidária, ética e que proporciona aos pais um momento diferenciado onde os mesmos sentem-se seguros com os cuidados prestados.

Diante de todo o enfrentamento por parte da família na internação de seus filhos, existem outras dificuldades tais como a falta de recursos financeiros para o deslocamento de sua residência até o hospital, a mudança de rotinas, e neste contexto, o suporte da equipe de saúde se faz imprescindível, sendo reportado como relevante inclusive os componentes religiosos e a estrutura familiar adjacente (OLIVEIRA, 2013).

Sendo assim, o cuidado humanizado está intimamente relacionado à integralidade, onde os procedimentos e a maquinaria não são vistos isoladamente, porém é importante lembrar que é fundamental a qualidade de vida dos profissionais ali atuantes, pois Freire (2015) relata que esse fator pode melhorar o cuidado realizado por parte do profissional uma vez que estes demonstram menos cansaço e melhor nível cognitivo, podendo assim desempenhar melhor suas atribuições na UTI, já que se trata de um ambiente onde se lida diariamente com vida e morte.

\section{CONCLUSÕES}

É perceptível a necessidade de uma equipe habilitada, para assim termos um serviço de qualidade e principalmente atendendo as necessidades dos pacientes e seus familiares, de forma holística, visando sua integralidade e também entendendo o contexto e as alterações que acontecem com familiares após a internação de crianças em uma UTI, que é um momento muito difícil.

O ambiente hospitalar já proporciona diversas incertezas e medos para pacientes e acompanhantes os quais necessitam também de informações e assistência, uma vez que o psicológico destas se abala em determinados momentos. 


\section{Interdisciplinar}

Embora a equipe também enfrente dificuldades e limitações, muitas vezes também criam vínculos com os pacientes, e em alguns casos presencia um desfecho que não pode ser adiado, a morte. Sendo assim todos necessitam de apoio, de uma atenção humanizada, fazendo com que os momentos ali vividos, não fiquem marcados apenas como momentos difíceis, mas que possam servir de aprendizado e força para enfrentar os desafios profissionais da área, garantindo o vínculo e a dimensão relacional da assistência.

PALAVRAS-CHAVE: Assistência. Enfermagem. Familiares. Humanização.

\section{REFERÊNCIAS}

OLIVEIRA, Kézia; VERONEZ, Maely, et al. Vivências de familiares no processo de nascimento e internação de seus filhos em UTI neonatal. Esc Anna Nery, v. 17, n. 1, p. 4653, jan-mar, 2013.

FREIRE, Cícero Beto; DIAS, Ricardo Freitas; et al. Qualidade de vida e atividade física em profissionais de terapia intensiva do sub médio São Francisco. Rev Bras Enferm, v. 68, n. 1, p. 26-31, jan-fev, 2015.

MENIN, Gisele Elise; PETTENON, Marinez Koller. Terminalidade da vida infantil:percepções e sentimentos de enfermeiros. Rev. bioét, v. 23, n. 3, p.608-614, 2015.

SILVA, Laura Johanson da; SILVA, Rangel Leila; et al. Tecnologia e humanização na Unidade de Terapia Intensiva neonatal: reflexões no contexto do processo saúde-doença. Rev Esc Enferm USP, v. 43, n. 3, p. 684-689, 2009.

SOUZA, Kátia Maria Oliveira; FERREIRA, Suely Deslandes. Assistência humanizada em UTI neonatal: os sentidos e as limitações identificadas pelos profissionais de saúde. Ciência \& Saúde Coletiva, v. 15, n. 2, p. 471-480, 2010.

PINHEIRO, Eliana Moreira; GUINSBURG Ruth; et al. Ruído na Unidade de Terapia Intensiva Neonatal e no interior da incubadora. Rev. Latino-Am. Enfermagem, vol. 19, n.5, p.1-8, 2011. 


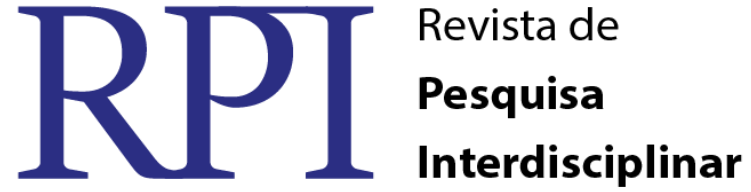

\section{ATUAÇÃO DOS PROFISSIONAIS DE ENFERMAGEM NA HUMANIZAÇÃO DO PARTO}

\author{
ASSISTÊNCIA DE ENFERMAGEM (Exposição oral) \\ THACIANE MARIA F. DE SOUZA 1, Graduanda em Enfermagem, UFCG. \\ IRISLÂNDIA DE OLIVEIRA BATISTA 2, Graduanda em Enfermagem, UFCG. \\ MARIA KARULINE ANDRADE E SILVA 3, Graduanda em Enfermagem, UFCG. \\ GILIARA CAROL DINIZ DE LUNA GURGEL, Docente, UFCG.
}

\section{INTRODUÇÃO}

A humanização pode ser definida como estratégias que melhoram o atendimento, no ouvir da gestante levando em consideração a família, respeitando as questões psicológicas, espirituais e biológicas da mesma. Essa humanização se faz necessária no ambiente hospitalar, devido ao número crescente de tecnologias e procedimentos mecanicistas, diminuindo assim a autonomia do paciente. A assistência humanizada deve seguir princípios que são essenciais como o respeito, a dignidade, e sensibilidade, criando assim um ambiente acolhedor diferente do tradicional imposto sobre a mulher (VERSIANI, 2015).

Neste contexto, humanizar é garantir à mulher que ela seja protagonista desse momento que é tão especial na sua vida. Assim, o profissional de enfermagem tem um papel muito importante que é a criação do vínculo com a gestante ou parturiente, promovendo um maior conforto para mesma, estimulando e garantindo que a mulher seja vista na sua individualidade e integralidade (OLIVEIRA,2011).

A implementação de uma assistência humanizada de qualidade e segura é dificultada pela falta de leitos, de trabalhadores da saúde, estrutura física, falta de recursos financeiros e materiais nas unidade (BUSANELLO, 2011). Segundo Cassiano et. al (2015) o modelo de assistência à mulher durante a gravidez e o puerpério no Brasil, ainda é um modelo biomédico de fragmentação do ser humano, e isso contribui de certa forma para o aumento de procedimentos invasivos e intervencionistas durante este período, percebendo-se também que na maioria das vezes estes são realizados de forma desnecessária e sem o consentimento da paciente e da família.

Durante o atendimento da parturiente, os profissionais de saúde devem atentar-se não só para sinais clínicos, pois neste momento deve-se prestar uma assistência atendendo todas as necessidades da paciente, e respeitando seus costumes e crenças, buscando assim amenizar 


\section{$\int\left[\begin{array}{l}\text { Revista de } \\ \text { Pesquisa } \\ \text { Interdisciplinar }\end{array}\right.$}

Anais do $1^{\circ}$ Encontro de Iniciação Científica da ETSC - 13 e 14 de junho de 2017.

a tensão e os medos que o ambiente hospitalar pode causar nesse momento (VERSIANI, 2015).

\section{OBJETIVO}

Identificar a atuação dos profissionais de Enfermagem na humanização do parto, como também o atendimento durante o trabalho de parto, este trabalho se propõe ainda a verificar onde é necessário atentar para instigar este ponto de vista desde a formação destes profissionais.

\section{MATERIAIS E MÉTODOS}

Trata-se de uma revisão narrativa, na qual foram definidas a escolha do tema, a questão norteadora da pesquisa relacionada à necessidade presente no âmbito hospitalar, de uma humanização na assistência ao trabalho de parto. A busca foi realizada no mês de novembro de 2016 nas seguintes bases de dados: Biblioteca Virtual de Saúde (BVS) e Scientific Electronic Library Online (SciELO). Os termos usados nesta revisão foram obtidos por meio de consulta ao DeCS. Utilizou-se na busca das publicações os descritores “enfermagem", "humanização" e "parto".

Como critérios de inclusão definiram-se: artigos em português disponíveis na íntegra nas referidas bases de dados, de acesso livre, determinando o intervalo de tempo da busca como início e fim nos anos de 2011 e 2015, respectivamente. Foram excluídos os trabalhos não disponíveis na íntegra, material não convencional, bem como, artigos que não abordavam a temática proposta. A busca foi realizada individualmente por dois pesquisadores, de forma independente, e para a pré-seleção dos artigos encontrados, foi realizada uma análise coletiva todos os resumos disponíveis para categorização dos estudos. Posteriormente, os artigos foram organizados segundo a base de dados de obtenção, resultando em um total de 07 documentos.

\section{RESULTADOS E DISCUSSÃO}

São diversos os meios para proporcionar à mulher um parto humanizado, tendo a mesma como protagonista de toda atividade. Apesar do avanço, ainda há no Brasil uma grande dificuldade em implantar definitivamente uma assistência humanizada, por vários motivos como falta de qualificação dos profissionais, e até mesmo a falta de informação, que contribuem para o agravamento do quadro, pois ainda há gestantes que são submetidas a cesarianas sem necessidade, o que aumenta as taxas de mortalidade de forma incompatível com as tecnologias disponíveis, ou por não receberem o cuidado adequado (GOMES, 2012).

Para termos assistência de forma humanizada, depende-se também de diversos fatores como o modo que o profissional respeita o ambiente de trabalho e o quanto o mesmo tem 


\section{$\int\left[\begin{array}{l}\text { Revista de } \\ \text { Pesquisa } \\ \text { Interdisciplinar }\end{array}\right.$}

Anais do $1^{\circ}$ Encontro de Iniciação Científica da ETSC - 13 e 14 de junho de 2017.

compromisso com o serviço, respeito a todos que ali se encontram, sem discriminação alguma no atendimento, atuando com visão multidisciplinar, e articulando todas as instâncias do Sistema Único de Saúde para garantir a integralidade (CASSIANO, 2015). Outra forma de humanizar o momento do parto segundo Brüggemann (2013) é garantir que a parturiente possa ser acompanhada por uma pessoa de sua confiança como o companheiro, mãe ou irmã, pois dessa maneira a mulher se sente melhor acolhida e mais confiante nesse momento cercado de grandes sentimentos como alegria e medo por exemplo.

Durante o período gravídico e puerperal a mulher necessita de um acompanhamento intenso e adequado, a fim de permitir que todas as suas necessidades sejam atendidas e que a gravidez não seja vista como um momento negativo, sendo imprescindível um serviço que preze pelo bem estar da mãe e da criança (FERREIRA et. al 2013).

O acompanhamento desde a unidade hospitalar até a sua residência é necessário, pois identifica e trata precocemente qualquer complicação que venha a aparecer no puerpério, possibilitando assim maior conforto e segurança às mulheres diminuindo as altas taxas de morbimortalidade perinatal e puerperal, bem como as reinternações. A Política Nacional de Humanização $(\mathrm{PNH})$ enfatiza que se deve considerar o direito à autonomia pelos sujeitos e o estabelecimento de vínculos (CASSIANO, 2015).

Por outro lado, os profissionais precisam de condições favoráveis para realizar suas atividades, como estímulo, qualificação e aperfeiçoamento constante para oferecer uma melhor qualidade na assistência, atendendo assim as demandas do paciente. Diante das eventuais dificuldades nas condições de trabalho, a Enfermagem tende a se adequar às dificuldades enfrentadas para a otimização da prestação da assistência (CASSIANO, 2015), corroborando a importância deste profissional, no que diz respeito à obtenção do bem-estar da mãe, criança e toda a família (OLIVEIRA, 2011).

São diversos os desafios nos relacionamentos interpessoais presente no âmbito hospitalar, desde a formação dos profissionais de saúde, onde é perceptível a necessidade das unidades formadoras terem um olhar diferenciado nesta área procurando buscando assim fortalecer a formação de vínculos entre futuros profissionais e pacientes (VERSIANI, 2015).

\section{CONCLUSÃO}

Em virtude do que foi mencionado faz-se necessário capacitação, e sensibilização dos profissionais, além de melhores condições dos serviços de saúde e políticas que efetivem o cuidado humanizado. 
A formação destes profissionais deve ter também um embasamento que ofereça a estes um olhar integral em relação aos seus pacientes, uma vez que deve-se procurar manter e fortalecer os vínculos entre todos os que prestam e necessitam desta assistência.

O trabalho de parto já é um momento bastante apreensivo, cheio de medo e incertezas, para a mãe e seus familiares, e se os mesmos não forem atendidos de forma humanizada, pode transformar um momento único como o do parto, em um momento constrangedor, cabendo assim a todos os profissionais de saúde buscarem, prestar uma assistência de qualidade.

PALAVRAS-CHAVE: Enfermagem. Humanização. Parto.

\section{REFERÊNCIAS}

VERSIANI, Clara de Cássia; BARBIERI, Márcia; et al. Significado de parto humanizado para gestantes. Revista de Pesquisa Cuidado é Fundamental online. v. 7, n. 1, p. 1927 1935, jan-mar, 2015.

CASSIANO, Alexandra do Nascimento, ARAÚJO, Mércio Gabriel; et al. Percepção de enfermeiros sobre a humanização na assistência de enfermagem no puerpério imediato.

Revista de Pesquisa Cuidado é Fundamental online. v. 7, n. 1, p. 2051-2060, jan-mar, 2015.

BUSANELlO, Josefine; KERBER, Nalú Pereira da Costa; et al. Parto Humanizado de adolescentes: concepção dos trabalhadores de saúde. Rev. Enferm. UERJ v. 19, n. 2, p. 218 223, abr-jun, 2011.

OLIVEIRA, Andressa Suelly Saturnino de; RODRIGUES, Dafne Paiva; et al. Percepção de puérperas acerca do cuidado de enfermagem durante o trabalho de parto e parto. Rev. Enferm. UERJ. v. 19, n. 2, p. 249-254, abr-jun, 2011.

GOMES, Maysa Luduvice; Vasconcelos MOURA, Maria Aparecida. Modelo humanizado de atenção ao parto no brasil:evidências na produção científica. Rev. Enferm. UERJ, v.20 , n.2, p. 248-53, 2012.

BRÜGGEMANN, Odaléa Maria; OLIVEIRA, Maria Emilia de; et al. A inserção do acompanhante de parto nos serviços públicos de saúde de Santa Catarina, Brasil. Esc Anna Nery, v.17, n.3, p.432 - 438, 2013.

FERREIRA, Lúcia Aparecida; SILVA, Jaciara Aparecida de Jesus; et al. Expectativa das gestantes em relação ao parto. Rev. pesqui. cuid. fundam. (Online), v.5, n.2, abr.-jun, 2013. 


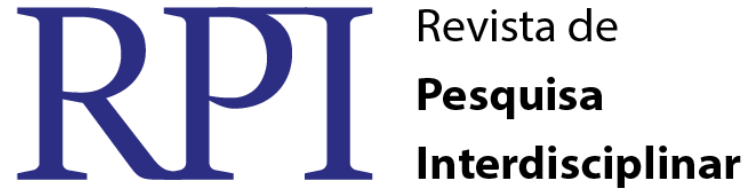

Anais do $1^{\circ}$ Encontro de Iniciação Científica da ETSC - 13 e 14 de junho de 2017.

\section{HERPES ZOSTER NA INFÂNCIA UMA HERANÇA MATERNA}

LINHA DE PESQUISA: Assistência de enfermagem; Exposição Oral.

MAÍSA GALDINO PEREIRA

Acadêmica do curso bacharelado em enfermagem do Centro de Formação de Professores da Universidade Federal d Campina Grande. LUANA RÉGIA FERREIRA VIEIRA

Acadêmica do curso bacharelado em enfermagem do Centro de Formação de Professores da Universidade Federal d Campina Grande

SARA SAMIRYS SANTANA

Acadêmica do curso bacharelado em enfermagem do Centro de Formação de Professores da Universidade Federal d Campina Grande.

MARIANA DE ABREU BRITO

Acadêmica do curso bacharelado em enfermagem do Centro de Formação de Professores da Universidade Federal d Campina Grande. RAYRLA CRISTINA DE ABREU TEMOTEO Enfermeira. Mestre em enfermagem. Docente da Universidade Federal de Campina Grande/UFCG

\section{INTRODUÇÃO:}

O vírus da Varicela Zoster (VVZ), da família Herpesviridae, desenvolve-se preferencialmente no sistema nervoso, sendo altamente contagioso. Em sua manifestação primária é popularmente conhecida como catapora e tem capacidade de manter-se, mesmo após a cura, alojada nos gânglios do sistema nervoso central. Sendo a principal manifestação clínica o aparecimento de pústulas que provocam intenso prurido (PORTELLA; SOUZA; GOMES, 2013). 


\section{$\int\left[\begin{array}{l}\text { Revista de } \\ \text { Pesquisa } \\ \text { Interdisciplinar }\end{array}\right.$}

Anais do $1^{\circ}$ Encontro de Iniciação Científica da ETSC - 13 e 14 de junho de 2017.

Indivíduos após a infecção primária retém o vírus em forma latente, podendo persistir por toda vida. A manifestação secundária é ocasionada pela infecção do vírus Varicela Zoster (VVZ), quando sua reativação é ocasionada por situações que promovam à baixa da imunidade desencadeiam o Herpes zoster (HZ). (LOBO, et al, 2015).

A infecção primária é muito comum acometer o indivíduo durante a infância, sem que o mesmo desenvolva qualquer complicação. Porém é uma doença considerada grave quando acomete mulheres na gestação, podendo trazer risco tanto para a mulher como para o feto que poderá desenvolver a herpes zoster no primeiro ano de vida, catapora após o parto, nascer com baixo peso, atraso no desenvolvimento, entre outras complicações.

É necessário promover uma desmistificação da simplicidade do adoecimento de gestantes pelo Vírus Varicela Zoster (VVZ), sendo que, o vírus pode ser transmitido de forma vertical ocasionando complicações ao recém-nascido ou o desenvolvimento do Herpes zoster (HZ) ainda na infância. É de grande relevância explanar sobre as principais complicações da não profilaxia dessas gestantes e sobre as complicações do herpes zoster infantil.

\section{OBJETIVO:}

Identificar as manifestações clínicas do herpes zoster em crianças ocasionado pela infecção da mãe pelo vírus Varicela Zoster na gestação, bem como, as principais complicações desenvolvidas pelo Herpes zoster quando apresentada na infância.

\section{METODOLOGIA:}

Revisão sistematizada da literatura, de caráter exploratório e abordagem qualitativa. Realizouse as buscas no período de setembro de 2016, por artigos publicados, no ano de 2012 até os dias atuais, na base de dados Scientific Electronic Library Online (SciELO), utilizando como descritores: gestação, herpes zoster, varicela. Foram incluídos na análise apenas artigos originais de acesso livre, em português e que abordassem os temas dos descritores citados acima. Foram localizados 204 artigos, após cruzar os descritores, restaram 38 artigos e ao final foram selecionados de acordo com os critérios de inclusão estabelecidos, sete artigos que se enquadram no objetivo do estudo.

\section{RESULTADOS:}




\section{$\int\left[\begin{array}{l}\text { Revista de } \\ \text { Pesquisa } \\ \text { Interdisciplinar }\end{array}\right.$}

Anais do $1^{\circ}$ Encontro de Iniciação Científica da ETSC - 13 e 14 de junho de 2017.

A infecção pelo herpes zoster no primeiro ano de vida é bastante rara de, porém existem alguns casos em que podem surgir, como é no caso de crianças imunocompetentes; saudáveis, mas que foram expostas ao VVZ ainda no útero ou no pós-parto (CARRUSCA, et al, 2016).

Ainda de acordo com o autor supracitado, é bastante comum complicações oriundas da infecção da varicela zoster. Onde em alguns casos ocorre o aparecimento de infecções oportunistas, complicações relacionadas à nervos e complicações respiratórias. O desenvolvimento do vírus do Herpes Zoster durante a infância está relacionado ao contato com o vírus da varicela principalmente durantes o período gestacional, alguns estudos apontam para que o maior grau de contaminação fetal ocorra entre a oitava e vigésima semana de gestação.

A manifestação do Herpes Zoster infantil está diretamente ligada ao sistema de resposta imunológica que essa criança apresenta. Geralmente para o desenvolvimento do HZ em crianças consideradas saudáveis, mas que a mãe apresentou um quadro de VVZ durante a gestação, é necessário uma investigação de como anda a resposta imunológica celular e humoral dessa criança. No geral, crianças diferentemente de adultos, apresentam uma melhor recuperação dos quadros de HZ, tendo uma evolução clínica bem autolimitada e benigna. Quadro de infecções são riscos constantes, porém, dificilmente apresentam complicações pósmanifestação aguda do HZ, como por exemplo, o desenvolvimento de Nevralgias pósherpética (PEREIRA; SOUSA; VALLE, 2015).

A varicela materna durante a gestação é um fator de risco para o desenvolvimento do HZ nos primeiros anos de vida, que pode levar a morbimortalidade do recém-nascido. As manifestações podem ser mucocutâneas, neurológica ou disseminada. Sendo a disseminada a mais frequente acometendo metade dos casos e apresentando altos índices de mortalidade. Quando acomete o sistema nervoso, podem desencadear sequelas neurológicas ou anormalidades em cerca de $70 \%$ das crianças. (CARVALHO; ANCHIETA; ROMANELLI, 2014).

Sendo frequentemente benigno em crianças, quando a reativação do VVZ acontece no gânglio sensorial do dermátomo, ocorre a disseminação do vírus pelo nervo sensitivo indo até a região cutânea, causando dor. Após, começam a aparecer pequenas pápulas, que vão aumentando de tamanho e formando as vesículas que por sua vez tornam-se úlceras, que após sete dias desenvolvem-se para crostas. O exantema regride depois de 15 dias, que pode ser acompanhado de febre, irritabilidade, hipersensibilidade, sensação de queimadura e prurido. O HZ oftálmico pode ocasionar dor, complicação e lesão do nervo trigémio, inflamação 


\section{$\mathrm{RPP}$}

Anais do $1^{\circ}$ Encontro de Iniciação Científica da ETSC - 13 e 14 de junho de 2017.

crônica ou infecção viral direta, sendo necessário o tratamento hospitalar. A sobreinfecção bacteriana e a hipopigmentação cicatricial, são as complicações mais comuns. (PEREIRA; SOUSA; VALLE, 2015).

O Tratamento indicado para as crianças com a infecção congênita por Herpes Zosters é o antiviral aciclovir que pode ser oral ou endovenoso, devendo ser administrado de 5 - 10 dias ou em até dois dias sem aparecimento de novas lesões. Crianças onde a Herpes Zoster é autolimitada ou benigna o uso de antivirais não é recomendado. (MALVEIRO, D; et al, 2015).

Existem dificuldades em realizar um estudo mais abrangente sobre o tema por conta da escassez de literaturas que relatem sobre a transmissibilidade e manifestação do Vírus Varicela zoster infantil.

\section{CONCLUSÃO:}

Dado o exposto, os cuidados e orientações prestados em uma assistência de pré-natal, deve-se preocupar visando não somente doenças de alta complexidade, mas também aquelas que possuem um carácter muitas vezes considerado mais simples e sem muitos prejuízos momentaneamente. A consideração e sensibilidade de que a Herpes Zoster sendo uma infecção que pode transcender o complexo mãe e feto, pode gerar complicações. Complicações essas que quando não tratadas corretamente podem comprometer a funcionalidade fisiológica de algumas áreas, gerando complicações mais sérias e prejuízos futuros.

É de extrema importância o preparo do profissional para diagnosticar e tratar precocemente pacientes em período gravídico-puerperal e orientar sobre possíveis complicações geradas por algo popularmente considerado simples, como é o caso da Varicela Zoster. O conhecimento da transmissibilidade de forma vertical auxilia o profissional na sistematização de uma assistência que possibilite os cuidados necessários a mãe que apresenta a manifestação aguda da Varicela Zoster e posteriormente a profilaxia para com o recémnascido, evitando assim uma possível manifestação na forma de Herpes zoster.

PALAVRAS-CHAVE: Gestação. Herpes Zoster. Varicela. 


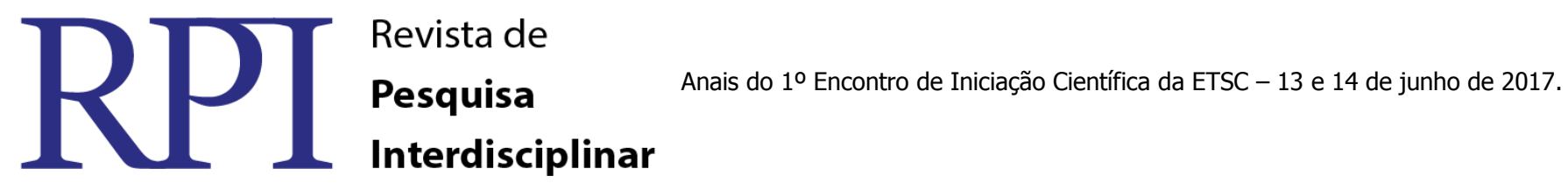

\section{REFERÊNCIAS}

CARRUSCA, C, et al. Herpes zoster como primeira manifestação de infeção por vírus varicela-zoster numa criança saudável-Nascer e crescer revista de pediatria do centro hospitalar do porto, 2016, vol. 25, n. 1, pág. 38 - 41.

LOBO, I. M.; SANTOS, A.N. C; SANTOS JÚNIOR, J.A; PASSOS, R.O; PEREIRA, C.U. Vírus varicela zoster- Revista brasileira de medicina, 2015, vol.72, n.6.

PORTELLA, A.V. T; SOUZA, L.C. B; GOMES, J. M. A.: Herpes-zóster e neuralgia pósherpética. Revista dor [online], 2013, vol.14, n.3, pág. 210 - 215.

PEREIRA, T; SOUSA, L; VALLE, T. Herpes Zosters em crianças saudáveis: o rosto inocente da controvérsia. Rev. Port. Med. Geral. Fam. 2015, vol. 31, pág. 34 - 37.

MALVEIRO, D; et al. Herpes Zosters num lactente de três meses de idade. Nascer e Crescer Revista de Pediatria do Centro Hospitalar do Porto. 2015, vol. 24, n. 4, pág. 179-182.

CARVAlHO, A. L; ANCHIETA, L. M; ROMANELLI, R. M. C. Infecção Congênita por Herpes-Vírus. Rev. Médica de Minas Gerais. 2014, vol. 24, n. 2, p. 223 - 232.

GARRIDO, A; FERREIRA, C. P. Vacina da Varicela na Infância. Rev. Port Med Geral Fam 2012, vol. 28, p.116-124. 


\section{APLICAÇÃO DO PROCESSO DE ENFERMAGEM EM CLÍNICA MÉDICA: RELATO DE EXPERIÊNCIA}

LINHA DE PESQUISA: Assistência de enfermagem; exposição oral

BRUNO NEVES DA SILVA

Acadêmico do curso de bacharelado em enfermagem do Centro de Formação de Professores da Universidade Federal de Campina Grande.

LETÍCIA DE SOUSA EDUARDO

Acadêmica do curso de bacharelado em enfermagem do Centro de Formação de Professores da Universidade Federal de Campina Grande.

INADJA SANCLEYA ROZAS DE OLIVEIRA Acadêmica do curso de bacharelado em enfermagem do Centro de Formação de Professores da Universidade Federal de Campina Grande.

PEDRO JULIANO DA SILVA

Acadêmica do curso de bacharelado em enfermagem do Centro de Formação de Professores da Universidade Federal de Campina Grande.

GERLANE CRISTINNE BERTINO VÉRAS

Enfermeira. Professora mestranda do Centro de Formação de Professores da Universidade

Federal de Campina Grande.

\section{INTRODUÇÃO}

O Processo de Enfermagem (PE) é utilizado como instrumento do profissional de enfermagem para sistematizar sua assistência, por possibilitar a identificação das necessidades do cliente e o planejamento dos cuidados de forma articulada, na perspectiva de gerar maior eficácia, conforto físico e mental (ALVIM, 2013).

De acordo com Avim (2013), o PE é desenvolvido em cinco fases: histórico de enfermagem, diagnóstico de enfermagem (DE), planejamento da assistência de enfermagem, implementação e avaliação.

A resolução 358/2009 do Conselho Federal de Enfermagem refere-se à Sistematização da Assistência de Enfermagem e a implementação do PE em ambientes, públicos ou privados, em que ocorre o cuidado profissional de Enfermagem, e dá outras providências, contudo, observa-se que na prática, há uma fragilidade nas instituições em implantar e implementar este processo.

Frente ao exposto, constata-se a relevância deste estudo para a comunidade acadêmica, profissional e sociedade em geral. 


\section{$\mathrm{RPP}$}

Anais do $1^{\circ}$ Encontro de Iniciação Científica da ETSC - 13 e 14 de junho de 2017.

\section{OBJETIVO DO TRABALHO}

Descrever a experiência da aplicação do Processo de Enfermagem a uma paciente com hipertensão arterial e infecção do trato urinário.

\section{MATERIAIS E MÉTODOS}

Trata-se de um relato de experiência e baseia-se nas aulas práticas da disciplina Enfermagem Clínica I realizadas em campo de estágio hospitalar de um município de médio porte no Estado da Paraíba por estudantes do quinto período de bacharelado em enfermagem. O presente estudo explora a aplicação do PE para uma paciente de 79 anos de idade, que até o momento da coleta de dados, se encontrava hospitalizada com diagnóstico de hipertensão arterial sistêmica e infecção do trato urinário.

As atividades em campo hospitalar foram desenvolvidas em maio de 2016, por cinco alunos, acompanhados por uma monitora e uma professora onde obteve-se compreensão do quadro clínico geral e as necessidades prioritárias da paciente. Após colhido o histórico, foram traçados diagnósticos, resultados e intervenções de enfermagem, posteriormente implementadas e avaliadas.

\section{RESULTADOS E DISCUSSÕES:}

Na realização do histórico de enfermagem, coletou-se que a paciente foi admitida na clínica médica proveniente da urgência com hipótese diagnóstica de infecção do trato urinário e hipertensão arterial sistêmica, apresentando como motivo de internação o risco de complicações. Quanto aos DE, foram construídos utilizando-se da taxonomia da Associação Norte-Americana de Diagnósticos de Enfermagem (NANDA), conforme descritos na Tabela 1 .

Tabela 1 - Diagnósticos de Enfermagem Reais e Potenciais Estabelecidos, 2016. Problema 01:mobilidade física prejudicada

Mobilidade física prejudicada relacionada a prejuízos neuromusculares evidenciados por hemiplegia à esquerda

Risco de síndrome do desuso relacionado à imobilidade no leito prejudicada

Risco de integridade da pele prejudicada relacionado à imobilidade física

Risco de aspiração relacionado à mobilidade no leito prejudicada

Problema 02: Sono e repouso insatisfatório

Padrão de sono prejudicado relacionado à imobilidade física evidenciada por relato verbal

Problema 03: Eliminação vesical disfuncional 


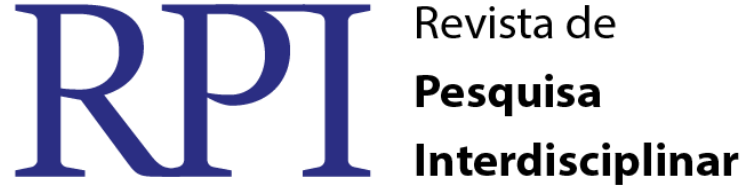

Eliminação urinária prejudicada relacionada à infecção do trato urinário evidenciado por polaciúria

\section{Problema 04: Nutrição descompensada}

Nutrição desequilibrada: menos que as necessidades corporais relacionado à capacidade prejudicada de digerir os alimentos, evidenciado por abdome distendido e relato verbal

A partir da definição dos DE, foi realizado o planejamento de enfermagem, que envolveu traçar resultados esperados e intervenções de enfermagem, que posteriormente foram efetivadas e avaliadas.

Os resultados esperados envolveram: manutenção da mobilidade física, função articular e pele íntegra; ausência de broncoaspiração; sono e repouso satisfatório; reestabelecimento do padrão urinário e nutrição equilibrada.

Tabela 2 - Intervenções de Enfermagem Planejadas e Realizadas, 2016.

$\checkmark$ Interagir com o setor de fisioterapeuta e de nutrição;

$\checkmark$ Promover massagem de conforto, hidratar a pele da cliente e proteger proeminências ósseas;

$\checkmark$ Realizar mudança de decúbito a cada duas horas;

$\checkmark$ Atentar para higiene e integridade da pele;

$\checkmark$ Realizar exercícios passivos/ativos, quando possível

$\checkmark$ Manter a cliente em posição de Fowler durante as refeições e após uma hora;

$\checkmark$ Administrar dieta de forma lenta;

$\checkmark$ Inspecionar sinais de infecção broncoaspirativa;

$\checkmark$ Auxiliar a cliente no controle do sono diurno;

$\checkmark$ Identificar e solucionar situações estressantes antes do horário de dormir;

$\checkmark$ Ensinar o paciente técnicas de relaxamento;

$\checkmark$ Proporcionar um ambiente calmo e seguro;

$\checkmark$ Atentar para eliminação vesical e registrar;

$\checkmark$ Oferecer líquidos e uma dieta adequada;

$\checkmark$ Atentar para sinais de hipertermia e manter dentro da normalidade;

$\checkmark \quad$ Manter técnica asséptica durante o cateterismo vesical, caso este seja necessário.

$\checkmark \quad$ Orientar sobre a importância da dieta alimentar adequada para sua recuperação;

$\checkmark \quad$ Avaliar distensão abdominal e verificar presença de dor.

As intervenções prescritas para os diagnósticos relacionados ao problema de mobilidade física prejudicada estão em concordância com Andrade; Chianca (2013), no estudo que objetivou validar intervenções de enfermagem para pacientes com mobilidade física prejudicada, trazem que supervisão da pele e controle de pressão sobre áreas do corpo são ações consideradas essenciais para esse DE; promoção do exercício como ação considerada complementar e massagem simples considerada como intervenção não essencial. Para ao DE risco de síndrome do desuso, os resultados encontrados na literatura envolveram outros aspectos, como encontrado em um estudo de Bertoncello et al., (2013), que trazem 


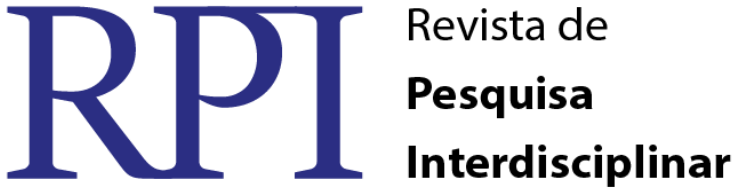

como intervenções para esse diagnóstico: controle do ambiente e estimulação cognitiva; administração de medicamentos conforme prescrição; promoção de suporte emocional; prevenção de quedas; controle da dor e orientar para realidade.

Quanto aos diagnósticos risco de aspiração e risco de integridade da pele prejudicada, as intervenções propostas também são também descritas em um estudo realizado em um hospital localizado em Fortaleza, Ceará, apontando controle das vias aéreas, monitorização respiratória e precauções contra aspiração como principais intervenções para evitar broncoaspiração e cuidados com pele e mucosas e mudança de decúbito como principais ações de enfermagem para manutenção da integridade da pele (OLIVEIRA; FREITAS, 2009).

Quanto as intervenções propostas para o problema sono e repouso insatisfatório, os autores Nóbrega; Nóbrega; Silva (2010), discutem a importância de observar as circunstâncias físicas que o paciente possa apresentar, tais como: apneia do sono, via aérea obstruída, dor/desconforto, uma vez que esses fatores podem atuar interferindo a integridade do sono. $\mathrm{O}$ estabelecimento de intervenções adequadas para minimizar o desconforto e melhorar a qualidade do sono pode ser efetivado pela utilização de intervenções como controle do ambiente, por exemplo. (AGUIAR et al, 2010)

Quanto ao problema eliminação vesical disfuncional, nota-se que devido à infecção urinária, esses cuidados são importantes para a preservação do estado de saúde da paciente e evitar infecções e complicações.

As intervenções prescritas para o problema nutrição descompensada, estão em concordância com um estudo realizado pelos autores Santiago et al (2011), com sete enfermeiras assistenciais em Fortaleza/Brasil, apresentando correspondência com atividades de intervenções propostas pela Classificação das Intervenções de Enfermagem (NIC) para o diagnóstico prescrito no presente estudo, tais como: assistência para aumentar o peso; controle da nutrição; aconselhamento nutricional e planejamento da dieta.

\section{CONCLUSÕES}

A aplicação do PE se fez importante à medida que permitiu a implementação de cuidados que favoreceram um cuidado integral e mais efetivo, contribuindo para uma melhor recuperação do estado geral de saúde da cliente.

É de extrema relevância a aplicação do $\mathrm{PE}$ em aulas práticas por permitir o desenvolvimento e aprimoramento por parte dos acadêmicos em melhorar sua assistência, fazendo-a mais direcionada, eficaz e efetiva para solucionar os problemas dos clientes. 
Constatou-se que a ausência de fichas apropriadas na instituição para o PE, dificulta o seu registro adequado, porém não inviabiliza a sua execução.

Um dos entraves identificados com a realização desse trabalho, foi a impossibilidade de acompanhamento do caso para a identificação dos resultados alcançados a médio prazo.

PALAVRAS-CHAVE: Cuidado de Enfermagem. Processo de Enfermagem. Sistematização da Assistência de Enfermagem.

\section{REFERÊNCIAS}

AGUIAR, M.I.F. et al. Sistematização da assistência de enfermagem a paciente com síndrome hipertensiva específica da gestação. Revista Rene Fortaleza, v. 11, n. 4, p. 66-75, 2010.

ANDRADE, L.T.; CHIANCA, T.C.M. Validação de intervenções de enfermagem para pacientes com lesão medular e mobilidade física prejudicada. Revista Brasileira de Enfermagem. v. 66, n. 5, p. 688-693, 2013.

BERTONCELLO, K.C.G. et al. Diagnósticos de risco epropostas de intervenções deEnfermagem aos pacientesvítimas de múltiplos traumas. Revista Brasileira de Pesquisa em Saúde. v. 15. n. 2, p. 23-31, 2013.

OLIVEIRA, M.F.; FREITAS, M.C. Diagnósticos e intervenções de enfermagem frequentes em mulheres internadas em uma unidade de terapia intensiva. Revista brasileira de enfermagem. v. 62, n. 3, 2009.

SANTOS, C.M. S.; PRADO, P.R. Sistematização da assistência de enfermagem em paciente portador da doença de Wilson. Seringal de Idéias. n. 3, 2010.

ALVIM, A. L. S. O Processo de Enfermagem e suas Cinco Etapas. Enfermagem em Foco v. 4, n. 2, p. 140-141, 2013. 


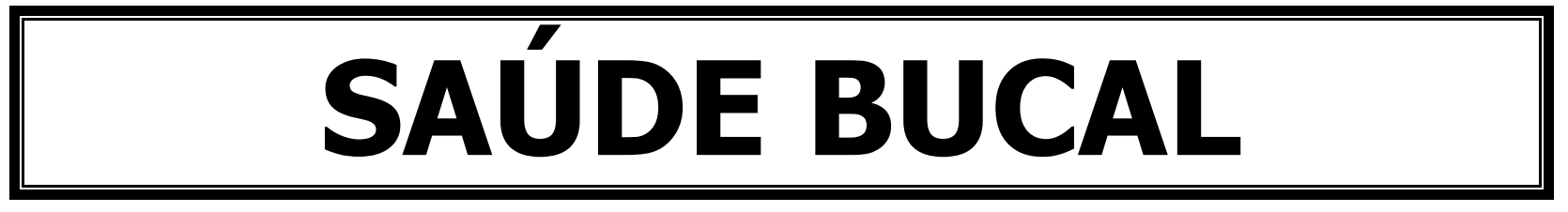

RPI Revista de Pesquisa Interdisciplinar, Cajazeiras, v. 2, Edição Especial, 2017. 


\title{
Interdisciplinar
}

\section{PROMOÇÃO DE SAÚDE BUCAL EM BEBÊS}

\author{
LINHA DE PESQUISA: Saúde Bucal Coletiva (Banner)
}

LUANA RAQUEL ARAÚJO SIFRÔNIO, aluna do Curso Técnico em Saúde Bucal, UFCG. MARIA LUIZA RAQUEL DA SILVA, aluna do Curso Técnico em Saúde Bucal, UFCG. NICÁCIA MACLAINE BATISTA DE BRITO, aluna do Curso Técnico em Saúde Bucal,

UFCG.

ROCHELLI ALVES FERREIRA, aluna do Curso Técnico em Saúde Bucal, UFCG. ILANA SANAMAIKA QUEIROGA BEZERRA, Doutora em Odontologia, UFCG.

\section{INTRODUÇÃO}

A odontologia vem se voltando atualmente para o atendimento de bebês, tentando instituir precocemente medidas educativas e preventivas. Esta tendência tem se fortalecido baseada nos dados existentes na literatura que mostram que a cárie dental em crianças pode se iniciar muito cedo e que a sua prevalência tende a aumentar com a idade (SOUZA, BATISTA, PESSOA; 2013). É sabido que tudo que se aprende nos primeiros anos de vida, tanto em relação à saúde geral quanto à saúde bucal, fornece bases para uma boa saúde nas idades subsequentes, especialmente se o exemplo se encontra dentro de casa. Junta-se a isto o fato de que a prevenção primária é o ideal tanto pelo lado biológico como pelo econômico (OLIVEIRA, BOTTA, ROSELLI; 2010).

Em bebês e crianças, observa-se que a dentição decídua, por possuir como característica principal a transitoriedade, tem seu valor subestimado e o tratamento negligenciado, e que pouca importância é dada aos aspectos preventivos da doença-cárie. $\mathrm{O}$ papel dos dentistas dentro do contexto de saúde bucal da população infantil é de extrema importância, uma vez que esses profissionais detêm amplo conhecimento a respeito dos fatores etiológicos, meios de prevenção e controle das doenças bucais (RAMOS, MAIA; 1999).

A Odontologia para Bebês consiste no atendimento odontológico realizado em crianças a partir do nascimento, com a finalidade de manter a saúde bucal, dentro de uma filosofia e tratamento educativo preventivo. A disseminação de conhecimentos objetivando a promoção de saúde dessa população específica, portanto, representa o principal objetivo educacional a ser alcançado, cujo início deve ser precoce, através da orientação às gestantes e às mães de recém-nascidos, já que estas passam a ser as principais responsáveis pelo desenvolvimento de hábitos em seus filhos (SOUZA, BATISTA, PESSOA; 2013).

\section{OBJETIVO}

O objetivo desse trabalho é fazer uma revisão da literatura a respeito da promoção de saúde bucal em bebês, ressaltando a relevância do atendimento preventivo precoce.

\section{MATERIAIS E MÉTODOS}

Para responder ao objetivo supracitado, utilizou-se de uma revisão de literatura, como anteriormente citado. Para Mancine e Sampaio (2006), revisões da literatura são caracterizadas pela análise e pela síntese da informação disponibilizada por estudos relevantes publicados sobre um determinado tema. Dessa forma, busca-se resumir o corpo de conhecimento existente e propõem-se conclusões sobre o assunto de interesse. Existem diversos tipos de estudos de revisão e cada um deles segue uma metodologia específica. 


\section{$12 \begin{aligned} & \text { Revista de } \\ & \text { Pesquisa } \\ & \text { Interdisciplinar }\end{aligned}$}

Neste estudo, optou-se pela revisão narrativa, que não utiliza critérios sofisticados para a busca de informações na literatura. Adicionalmente, apesar da seleção dos estudos e a interpretação das informações estarem sujeitas à subjetividade dos autores, é proposta a construção de uma contextualização do problema apresentado e realização de uma análise crítica do mesmo.

\section{RESULTADOS E DISCUSSÃO}

A saúde de uma população, em especial a saúde bucal, é expressa claramente pelas condições do meio no qual ela está inserida e, principalmente, pela forma com que são estabelecidos os relacionamentos interpessoais e familiares. A melhor maneira de motivar crianças sobre saúde bucal é através dos pais, pois estes desempenham um papel psicossocial muito importante para os filhos (SCHALKA, RODRIGUES;1996). Com isso, o exemplo estabelecido pela família tem grande impacto no desenvolvimento de hábitos de saúde bucal da criança.

A atenção à saúde bucal nos primeiros anos de vida é de fundamental importância, podendo significar a diferença entre manter uma condição favorável, ou a necessidade de um tratamento invasivo, o qual muitas vezes pode levar a perda precoce de elementos dentários. A odontologia para bebês está fundamentada na educação e na prevenção, sendo a conscientização dos pais a chave principal para educar e motivar, devendo ela ser realizada através de orientações sobre a importância da boca, da dentadura decídua, da amamentação natural, do conceito de cárie dentária como doença e da existência de medidas preventivas e eficazes. A partir do princípio de que a educação gera hábitos de vida saudáveis, novos conceitos foram desenvolvidos, surgindo, então, a necessidade de uma atuação precoce, com a finalidade de manter a saúde, antes mesmo de prevenir a doença (RAMOS, MAIA; 1999).

$\mathrm{O}$ atendimento ao bebê e, consequentemente, a educação e motivação dos pais em relação à saúde bucal são as formas mais práticas, simples, eficazes e econômicas para se realizarem programas de saúde pública.

A partir do exposto, pode-se compreender que a principal medida na promoção de saúde bucal em relação à cárie dentária é que esta comece precocemente, de preferência na gravidez, com a orientação da mãe fazendo parte do pré-natal, onde ela poderia receber informações simples como, por exemplo, quando começar a limpar os dentes de seu bebê e com que idade levá-lo ao dentista pela primeira vez (FAUSTINO-SILVA et al.; 2008). Desta forma, poderiam ser evitadas a transmissão dos patógenos pela mãe, já que se trata de uma doença infecto-contagiosa e, como tal, transmissível. Entretanto, é comum pais de crianças pequenas não levarem seus filhos ao dentista antes dos três anos de idade e desconhecerem a gravidade dos problemas dentários até que estes atinjam graus de severidade acentuado e sintomático, desconforto doloroso ou a aparência estética desagradável, pois estes parecem ser os primeiros indicadores para os pais quanto à necessidade de cuidados (SOUZA, BATISTA, PESSOA; 2013).

A alta prevalência de cárie em bebês implica na necessidade de programas voltados para a promoção de saúde na primeira infância, que visem manter a saúde bucal dessas crianças. A informação ou conhecimento materno prévio sobre hábitos adequados, bem como o envolvimento materno com medidas educativas e preventivas, refletem em atitudes saudáveis em relação à saúde bucal de seus filhos. A educação é um instrumento de transformação social, não só a educação formal, mas toda a ação educativa que propicie a reformulação de hábitos, aceitação de novos valores e que estimule a criatividade. A educação para a saúde deve ser pensada como um processo capaz de desenvolver nos indivíduos a consciência crítica das causas reais dos seus problemas e, ao mesmo tempo, criar uma prontidão para atuar no sentido de mudança (OLIVEIRA, BOTTA, ROSELLI; 2010). 


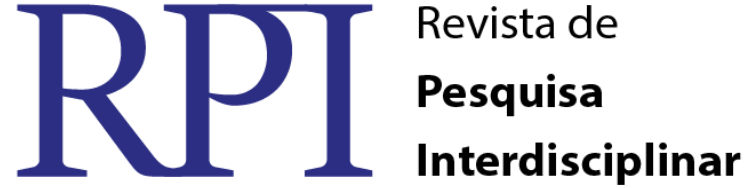

\section{CONCLUSÕES}

Dessa forma, é possível concluir que A atenção precoce visa reduzir as chances de desenvolvimento de cárie em bebês e proporcionar sua ambientação ao consultório odontológico, além da criação de hábitos de higiene bucal, tanto nas crianças de pouca idade quanto nos pais, principais responsáveis pela educação dos filhos. A prevenção e atenção precoce com a finalidade de preservação da saúde são de extrema importância para a educação e formação de crianças saudáveis. A Odontologia do Futuro baseia-se nesse princípio e não somente em novas tecnologias e avanços científicos. Dessa maneira, os resultados dos esforços atuais serão vistos em adultos conscientes e saudáveis, os quais serão verdadeiros instrumentos educadores para as novas gerações.

PALAVRAS-CHAVE:

Saúde bucal. Odontologia preventiva. Cárie dentária. Promoção de saúde.

\section{REFERÊNCIAS}

FAUSTINO-SILVA, D. D.; RITTER, F.; NASCIMENTO, I. M.; FONTANIVE, P. V. N.; PERSICI, S.; ROSSONI, E.; Cuidados em saúde bucal na primeira infância: percepções e conhecimentos dos pais ou responsáveis de crianças em um centro de saúde de Porto Alegre, RS. Rev. Odonto ciênc., São Paulo, v. 23, n. 4, p. 375-9, 2008.

MANCINI, M. C.; SAMPAIO, R. F. Quando o objeto de estudo é a literatura: estudos de revisão. Rev. Bras. Fisioter. São Carlos, v. 10, n. 4, dez. 2006. Disponível em: http://www.scielo.br/scielo.php?script=sci_arttext\&pid=S1413-

35552006000400001\&lng=en\&nrm=iso Acesso em 18 de outubro de 2016. http://dx.doi.org/10.1590/S1413-35552006000400001.

OLIVEIRA, A. L. B. M.; BOTTA, A. C. ROSELL, F. L. Promoção de saúde bucal em bebês. Revista de Odontologia da Universidade Cidade de São Paulo, São Paulo, v. 22, n. 3, p. 247-53, set./dez. 2010.

RAMOS, B. C.; MAIA, L. C. Cárie tipo mamadeira e a importância da promoção de saúde bucal em crianças de 0 a 4 anos. Rev Odontol Univ São Paulo, São Paulo, v. 13, n. 3, p. 303311, jul./set. 1999.

SCHALKA, M. M. S. RODRIGUES, C. R. M. D. A importância do médico pediatra na promoção da saúde bucal. Rev. Saúde Pública. São Paulo, v. 30, n. 2, p. 179-86, Abr. 1996.

SOUZA, R. M. R.; BATISTA, T. N. L.; PESSOA, T. R. R. F. Promoção da saúde bucal para mães e bebês na USF Nova Conquista - João Pessoa/ PB - relato de experiência de um grupo tutorial PETSaúde da Família e redes. Rev. ABENO. São Paulo, v. 13, n. 2, p. 50-7, 2013. 


\title{
$\mathrm{RPP}$
}

\section{CONHECIMENTO DE GESTANTES SOBRE SAÚDE BUCAL: UMA REVISÃO DA LITERATURA}

\author{
LINHA DE PESQUISA: Saúde Bucal Coletiva (Banner)
}

DAYSE KELLY FEITOZA ROLIM, aluna do Curso Técnico em Saúde Bucal, UFCG FRANCISCO CANUTO MARTINS, aluno do Curso Técnico em Saúde Bucal, UFCG MIKAELLE PAULINO DA SILVA, aluna do Curso Técnico em Saúde Bucal, UFCG MANUELLA UILMANN SILVA COSTA SOARES, Doutora em Odontologia, UFCG ILANA SANAMAIKA QUEIROGA BEZERRA, Doutora em Odontologia, UFCG

\section{INTRODUÇÃO}

A Odontopediatria vem estabelecendo medidas de prevenção para a Saúde bucal das gestantes. Foi através de trabalhos realizados com crianças que se esclareceu como é importante a promoção de saúde e o início de um tratamento durante o pré-natal para evitar doenças bucais. Dessa forma, toda mulher, ao engravidar, deve ter o acompanhamento de um cirurgião-dentista durante a sua gestação - pré-natal odontológico (BATISTELA et al., 2006; REIS et al., 2010).

O profissional da saúde, por sua vez, tem de responsabilizar, conscientizar e educar a futura mãe para que ela possa cuidar melhor dos seus bebês, introduzindo hábitos saudáveis de higiene bucal desde a infância. É importante enfatizar desde cedo que o cuidado com a própria saúde bucal e a dos bebês reflete-se em ausência de doenças bucais durante toda a vida (VIEIRA \& ZOCCRATTO, 2007, SCAVUZZI et al., 2008).

A manutenção da saúde bucal durante a gestação é extremamente importante. No entanto grande parte da população não tem acesso a informações relacionadas às alterações bucais características deste período. Durante anos, foram criados mitos relacionando a gravidez à perda dos dentes. Atualmente, sabe-se que as condições biológicas, psicossociais e os limitados conhecimentos sobre as técnicas de higiene bucal pelas gestantes são os responsáveis pelas doenças bucais mais frequentes na gravidez: a cárie dentária e a doença periodontal (REIS et al., 2010). A mulher tem o papel-chave dentro da família, zelando pela sua saúde e de seus entes, tornando-se multiplicadora de informações e ações que possam levar ao bem-estar do núcleo familiar e consequentemente à melhora da qualidade de vida. A aquisição de hábitos e escolhas saudáveis implica diretamente a mudança de comportamento, levando à promoção e manutenção de saúde do indivíduo (GRANVILLE-GARCIA et al., 2007).

\section{OBJETIVO}

O objetivo desse trabalho é fazer uma revisão da literatura acerca do conhecimento de gestantes sobre saúde bucal, sua importância para o momento da gestação e como esse autocuidado pode se refletir em benefícios para o bebê.

\section{MATERIAIS E MÉTODOS}

Para responder ao objetivo supracitado, utilizou-se de uma revisão de literatura, como anteriormente citado. Para Mancine e Sampaio (2006), revisões da literatura são caracterizadas pela análise e pela síntese da informação disponibilizada por estudos relevantes publicados sobre um determinado tema. Dessa forma, busca-se resumir o corpo de conhecimento existente e propõem-se conclusões sobre o assunto de interesse. Existem diversos tipos de estudos de revisão e cada um deles segue uma metodologia específica.

Neste estudo, optou-se pela revisão narrativa, que não utiliza critérios sofisticados para a busca de informações na literatura. Adicionalmente, apesar da seleção dos estudos e a 


\section{$\mathrm{RPP}$}

interpretação das informações estarem sujeitas à subjetividade dos autores, é proposta a construção de uma contextualização do problema apresentado e realização de uma análise crítica do mesmo.

\section{RESULTADOS E DISCUSSÃO}

Orientações sobre a saúde bucal durante o período da gravidez são de extrema importância, sendo neste período que as mulheres estão abertas a novos conhecimentos para manter a saúde do bebê, conscientizando-as sobre as possíveis alterações bucais que podem ocorrer durante a gestação e como preveni-las. Como foi dito anteriormente, várias são as manifestações de alterações bucais que podem ocorrer na gestação, sendo as mais comuns a cárie dentária e a doença periodontal; porém, a gravidez não é determinante para o seu aparecimento; o que acontece é que processos bucais já iniciados tendem a se agravar (REIS et al., 2010).

A gestante por muitas vezes tem receio a consultas odontológicas por acreditarem que tal procedimento possa trazer algum tipo de risco ao bebê. No entanto elas também reconhecem que a gestação pode implicar em alguns problemas bucais, já que podem diminuir a frequência da escovação, principalmente no período da manhã devido a enjoos matutinos e as que mantem a mesma frequência, geralmente escovam mais rápidos e com menos eficiência.

A educação em saúde bucal é o método mais empregado nos programas preventivos de saúde bucal, juntamente com as iniciativas para a fluoretação das águas de abastecimento, a indicação do uso de dentifrícios, a escovação supervisionada e o uso do fio dental, bochechos com solução fluoretada e aplicação tópica de fluoretos (GRANVILLE-GARCIA et al., 2007; VIEIRA \& ZOCRATTO, 2007). Bastiani et al., (2010), constataram que a maioria das gestantes não tem conhecimento acerca dos prejuízos que podem causar para a criança o tempo de amamentação prolongada, uso indevido de mamadeira e o hábito do consumo de açúcar para o preparo dos alimentos do bebê; além dos conhecimentos com relação à higiene bucal pessoal e da criança. Esses mesmos autores avaliaram longitudinalmente a efetividade da educação durante o pré-natal e concluíram que houve uma conscientização e retenção das informações por parte dos pais em relação às orientações sobre saúde bucal para com o bebê. Assim, sugeriram programas de promoção da saúde bucal continuados após o nascimento do bebê para reforço e motivação com vistas a permanecer a mudança de hábitos frente à saúde (BATISTELA et al., 2006; SCAVUZZI et al., 2008).

Dessa forma, medidas de educação em saúde, medidas preventivas e tratamentos com gestantes que possuem poucos conhecimentos devem ser estimulados, para que as mesmas não negligenciem próprias alterações bucais que podem ser tratadas e na saúde de seus bebês. Por falta de tais conhecimentos as mesmas acreditam ser normais os problemas bucais durante a gestação, não possuindo conscientização de que seus problemas bucais podem também afetar a saúde de bebê. Isto acontece muitas vezes por falta de um Cirurgião-dentista nos programas de pré-natal no acompanhamento as gestantes (BASTIANI et al., 2010).

\section{CONCLUSÕES}

Em suma, nota-se que devem ser desenvolvidas ações de promoção da saúde e programas educativos e preventivos visando a prevenção de doenças nesta população tão especial. É indispensável que as gestantes tenham acesso a informações que contemplem a melhoria de sua qualidade de vida. Nessa perspectiva ressalta-se a necessidade de os cirurgiões-dentistas estarem inseridos em programas de pré-natal e, desta forma, vivenciarem seu papel de educadores.

\section{PALAVRAS-CHAVE:}




\section{RPT Rensisa de

Autocuidado. Educação em Saúde. Gestantes. Saúde Bucal.

\section{AGRADECIMENTOS}

Os autores agradecem ao Conselho Nacional de Desenvolvimento Científico e Tecnológico $(\mathrm{CNPq})$ por fomentar a pesquisa, visto que esse trabalho trata-se de uma parte de pesquisa de Iniciação Científica, e pela possibilidade de capacitação de profissionais.

\section{REFERÊNCIAS}

BASTIANI, C.; COTA, A. L. S.; PROVENZANO, M. G. A.; FRACASSO, M. L. C.; HONÓRIO, H. M.; RIOS, D. Conhecimento das gestantes sobre alterações bucais e tratamento odontológico durante a gravidez. Odontol Clín-Cient, Recife, v. 9, n. 2, p. 15560, abr./jun., 2010.

BATISTELLA, F. I. D.; IMPARATO, J. C. P.; RAGGIO, D. P.; CARVALHO, A. S. Conhecimento das gestantes sobre saúde bucal. RGO, Porto Alegre, v. 54, n. 1, p. 67-73, jan./mar. 2006.

GRANVILLE-GARCIA, A. F.; LEITE, A. F.; SMITH, L. E. A.; CAMPOS, R. V. S.; MENEZES, V. A. Conhecimento de gestantes sobre saúde bucal no município de Caruaru PE. Revista de Odontologia da UNESP, São Paulo, v. 36, n. 3, p. 243-9, 2007.

MANCINI, M. C.; SAMPAIO, R. F. Quando o objeto de estudo é a literatura: estudos de revisão. Rev. Bras. Fisioter. São Carlos, v. 10, n. 4, dez. 2006. Disponível em: http://www.scielo.br/scielo.php?script=sci_arttext\&pid=S1413-

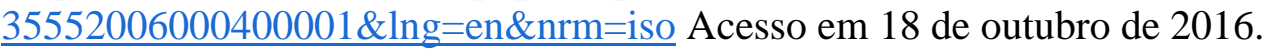
http://dx.doi.org/10.1590/S1413-35552006000400001.

REIS, D. M.; PITTA, D. R.; FERREIRA, H. M. B.; JESUS, M. C. P.; MORAES, M. E. L.; SOARES, M. G. Educação em saúde como estratégia de promoção de saúde bucal em gestantes. Ciência \& Saúde Coletiva, São Paulo, v. 15, n. 1, p. 269-76, 2010.

SCAVUZZI, A. I. F.; NOGUEIRA, P. M.; LAPORTE, M. E.; ALVES, A. C. Avaliação dos Conhecimentos e Práticas em Saúde Bucal de Gestantes Atendidas no Setor Público e Privado, em Feira de Santana, Bahia, Brasil. Pesq Bras Odontoped Clin Integr, João Pessoa, v. 8, n.1, p. 39-45, jan./abr. 2008.

VIEIRA, G. F.; ZOCCRATTO, K. B. F. Percepção das gestantes quanto a sua saúde bucal. RFO, Passo Fundo, v. 12, n. 2, p. 27-31, mai/ago., 2007. 


\section{$\mathrm{RPP}$}

\section{TRANSTORNOS ALIMENTARES: MANIFESTAÇÕES ORAIS NA ANOREXIA NERVOSA E BULIMIA NERVOSA}

LINHA DE PESQUISA: Clínica Odontológica; exposição oral

Antonia Bezerra de Sousa, discente do CTSB, UFCG; Fernanda Raquel Rolim Gomes, discente do CTSB/UFCG Tatiana da Silva Gomes, discente do CTSB/UFCG; Francisca Janaina de Sousa Franca Izidro, discente do CTSB/UFCG; Alana Kelly Maia Macedo Nobre de Lima, Mestre em Odontologia, docente CTSB/UFCG.

\section{INTRODUÇÃO}

A alimentação tem grande importância no desenvolvimento adequado dos adolescentes. A manutenção de um padrão alimentar adequado reflete-se na saúde física e mental do jovem, proporcionando subsídios para o total aproveitamento de sua potencialidade. $\mathrm{O}$ padrão alimentar correto nem sempre é do conhecimento dos adolescentes ou dos adultos com que eles convivem (CORDÁS, 2010)

A bulimia é representada por pacientes com dieta normal, no entanto, em momento de descontrole, comem compulsivamente. Segue-se a culpa pelo ato cometido, valendo-se de vômitos, exercícios, jejuns, dentre outras formas para evitar o ganho de peso (POPOFF et. al., 2010).

A anorexia é caracterizada pelo desejo patológico de emagrecer. Por isso, o paciente reduz drasticamente a alimentação, no entanto, quando se alimenta, pode sentir culpa e se valer de mecanismos compensatórios como autoindução ao vômito, laxantes e diuréticos (NAVARRO et. al., 2011).

Pode haver predisposição genética, no entanto, o culto ao corpo perfeito e a valorização da magreza têm sido fatores desencadeadores (LIMA, et. al., 2012).

A idade média de ocorrência desses transtornos é entre 17 e 25 anos, em pacientes jovens, do sexo feminino, em uma proporção 10:1 quando comparada ao sexo oposto. A incidência de desordens de alimentação, exceto a obesidade, aumenta com a melhoria da condição socioeconômica. O curso de desenvolvimento das doenças é caracterizado pela contínua perda de peso. Com frequência, há distorção de imagem corporal e a pessoa percebe-se gorda, mesmo apresentando estágios acentuados de desnutrição. Os hábitos alimentares tornam-se secretos e ritualizados, seguidos de indução de vômito, uso de laxantes e diuréticos ou prática excessiva de exercícios, sempre objetivando alcançar a magreza desejada (TRAEBERT; MOREIRA, 2012).

\section{OBJETIVO DO TRABALHO}

Apresentar uma revisão de literatura sobre as manifestações orais na anorexia nervosa e na bulimia nervosa.

\section{MATERIAIS E MÉTODOS}

Para responder ao objetivo supracitado, utilizou-se de uma revisão de literatura. Para Mancine e Sampaio (2006), revisões da literatura são caracterizadas pela análise e pela síntese da informação disponibilizada por todos os estudos relevantes publicados sobre um determinado tema, de forma a resumir o corpo de conhecimento existente e levar a concluir 


\section{Interdisciplinar}

sobre o assunto de interesse. Existem diversos tipos de estudos de revisão e cada um deles segue uma metodologia específica.

Neste estudo, optou-se pela revisão narrativa, que não utiliza critérios sofisticados para a busca de informações na da literatura. Adicionalmente, apesar da seleção dos estudos e a interpretação das informações estarem sujeitas à subjetividade dos autores, é proposta a construção de uma contextualização do problema apresentado e realização de uma análise crítica do mesmo.

\section{RESULTADOS E DISCUSSÃO}

O Cirurgião-Dentista pode ser um dos primeiros profissionais a identificar sinais de anorexia e bulimia nervosa por meio das alterações que ocorrem na cavidade bucal (LIMA, et. al., 2012). Sabe-se que o principal agravante entre todos os efeitos dos distúrbios alimentares relacionados à cavidade bucal é a erosão dos tecidos duros dentais, a característica clínica mais comum da lesão por erosão é a perda de brilho do esmalte, resultado da ação do ácido gástrico que entra em contato com os dentes causando a desmineralização e dissolução do esmalte (BARATIERI et AL, 2004.). A superfície com erosão dentária apresenta-se lisa em forma de "U" ou pires. A lesão mostra-se larga, roxa e sem ângulos nítidos. Quando atinge a dentina, provoca sensibilidade ao frio, calor e pressão osmótica. Quando acomete dentes restaurados, as restaurações tornam-se proeminentes, projetando-se acima da superfície dental (SCHEUTZEL 2013).

Para Burke et al (2012), a queilite actínica também pode manifestar-se em pacientes bulímicos devido à debilidade do sistema imune provocada pela carência nutricional. A queilite actínica ocorre no vermelhão dos lábios, apresentando-se como áreas eritematosas, erosadas, ulceradas e crostosas, nas quais pode ser observado sangramento.

Em razão do uso de antidepressivos, os pacientes bulímicos estão sujeitos aos efeitos colaterais decorrentes, e apesar de sua grande utilização, os antidepressivos apresentam efeitos colaterais importantes, como a xerostomia. A sensação da boca seca pode ser explicada, em grande parte, pela diminuição da produção salivar decorrente da ação anticolinérgica observada nestes grupos farmocológicos (Junior.,et. AL, 2012).

Popoff,et al (2012) relatam que nem todos os bulímicos apresentam erosão dental, e que os fatores associados com a ocorrência e a severidade da condição são o tempo de duração da doença e a frequência dos episódios de vômito e a quantidade de saliva.

As complicações clínicas da anorexia relacionadas à cavidade oral se enquadram, na anorexia do tipo purgativa, apresenta episódios de alimentação compulsiva e uso de laxantes e diuréticos, porém é necessário ressaltar que os seguintes aspectos corroboram o diagnóstico, mas não são elementos essenciais e primários da doença, tais como: regurgitação autoinduzida, purgação autoinduzida, exercícios excessivos e uso de anorexígenos e/ou diuréticos (CORDÁS, 2010).

O eritema do palato, faringe e gengiva, além das alterações dentárias como erosão dental, são comuns em pacientes com características de anorexia purgativa. $O$ aumento das glândulas parótidas é perceptível, pois há uma intensa estimulação das glândulas e, assim, uma consequente hipertrofia. A frequência e a gravidade da hipertrofia se correlacionam com a frequência dos vômitos. Geralmente, o comprometimento é bilateral, indolor e raramente acomete as glândulas submandibulares (ASSUMPÇÃ O; CABRAL, 2014). 
A saliva reduz a acidez do vômito e, consequentemente, em pacientes anoréxicos e bulímicos, nota-se o aumento das glândulas salivares, pois elas produzem maiores níveis de fluído e, assim, neutralizam o ácido presente na cavidade oral. Em pacientes com fluxo salivar baixo, a acidez permanece principalmente no dorso da língua, comprovando que as faces palatinas dos dentes anteriores são as mais afetadas (BURKE et al., 2012).

\section{CONCLUSÕES}

A partir do conhecimento das complicações é de extrema importância uma abordagem relacionada tanto para a educação alimentar quanto á saúde bucal, principalmente em pacientes com hábitos de higiene oral deficitária e ataques cariogênicos frequentes; sendo necessário que o profissional esteja apto a diferenciar os distúrbios alimentares e conhecer quais doenças geram mais efeitos à cavidade bucal, além de possibilitar uma abordagem ampla, multidisciplinar, que possa estimular a procura de assistência profissional especializada, contribuindo assim para redução das consequências desse transtorno a fim de que outros profissionais da área da saúde se tornem engajados na cura e resolução das complicações referentes a doenças como a anorexia e a bulimia nervosa.

PALAVRAS-CHAVE: anorexia nervosa. bulimia nervosa, saúde bucal

\section{REFERÊNCIAS}

ASSUMPÇÃO, C. L.; CABRAL, M. D.; Complicações clínicas da anorexia nervosa e bulimia nervosa. Rev Bras Psiquiatr, v. 24, Supl. III, p. 29 - 33, 2014.

BARBOZA, C.A.G., et. al. Participação do cirurgião-dentista no diagnóstico e tratamento interdisciplinar dos transtornos alimentares. Int. J Dent, Recife, v.10, n.1, p. 32-37, jan./mar., 2011

BARATIERI, L. N. et al. Odontologia Restauradora: fundamentos e possibilidades. São Paulo: Santos, 2004

BURKE, F. J. T. et al. Bulimia: implications of the practicing dentist. Brit Dent J, v. 180, n. 11, p. 421-426, jun., 2012.

CORDÁS, T. A. Transtornos alimentares: classificação e diagnóstico. Rev Psiquiat clin, v. 31, n. 4, p. 154, 2010.

POPOFF, D. N. A., et. al. Bulimia: manifestações bucais e atenção odontológica. RGO - Rev Gaúcha Odontol., Porto Alegre, v. 58, n. 3, p. 381-385, jul./set. 2012.

NAVARRO, V. P. et. al. Desordens alimentares: aspectos de interesse na odontologia. RGO Rev Gaúcha Odontol., Porto Alegre, v.59, suplemento 0, p. 15-18, jan./jun., 2011

LIMA, D. S. M. et. al. A saúde oral e os transtornos alimentares entre adolescentes. Rev. bras. odontol., Rio de Janeiro, v. 69, n. 2, p. 190-3, jul./dez. 2012

JUNIOR, R. M., et. al. Manifestações Orais e Maxilofaciais Secundárias à Bulimia Nervosa: Uma Revisão Sistemática. Pesq Bras Odontoped Clin Integr., João Pessoa, v.12,n.2,p.27984, abr.jun., 2012.

SCHEUTZEL, P. Etiology of dental erosion-intrinsic factors. European Journal of Oral Sciences, v. 104, p. 178-190, 2013.

TRAEBERT, J.; MOREIRA, E. A. M. Transtornos alimentares de ordem comportamental e seus efeitos sobre a saúde bucal na adolescência. Pesqui Odontol Bras, v. 15, n. 4, p. 359-363, out./dez., 2012. 


\title{
$\mathrm{RPP}$
}

\section{TRAUMATISMOS NA DENTÇÃO DECÍDUA: EPIDEMIOLOGIA E CONSEQUENCIAS}

\author{
LINHA DE PESQUISA: Clínica Odontológica; exposição oral
}

Ana Joice da Silva Alves, discente CTSB/UFCG; Ana Beatriz Bandeira dos Santos, discente CTSB/UFCG; Juliana Guedes Gomes, discente CTSB/UFCG; Natalia Silva Pereira, discente CTSB/ UFCG; Alana Kelly Maia Macedo Nobre de Lima, Mestre em Odontologia, docente CTSB/UFCG.

\section{INTRODUÇÃO}

Lesões traumáticas ocorrem a partir de uma transmissão aguda de energia ao elemento dentário e estruturas de suporte podendo resultar em fraturas e deslocamento do dente. A análise dos fatores que determinam sua frequência e distribuição revela uma interdependência entre crescimento, desenvolvimento e comportamento do indivíduo (KRAMER e FELDENS, 2013).

O traumatismo facial que resulta em dentes fraturados, deslocados ou perdidos, pode apresentar efeitos negativos consideráveis sobre os aspectos funcional, estético e psicológico da criança. A maior incidência de traumatismo sobre a dentição decídua ocorre entre dois e três anos de idade, nos primeiros movimentos independentes, quando a coordenação motora da criança está em desenvolvimento. As lesões mais comuns na dentição permanente ocorrem após quedas, seguidas por acidentes de trânsito, violência, e esportes (PERCINOTO et al., 2015).

Além da relevância epidemiológica, é imprescindível o conhecimento das consequências que podem resultar de traumatismos dentários, ou seja, assequelas que ocorrem nos dentes decíduos e também em seus sucessores permanentes (LEVINE, 2012).

\section{OBJETIVO DO TRABALHO}

Revisar estudos da literatura referentes aos fatores epidemiológicos e as sequelas em dentes decíduos traumatizados

\section{MATERIAIS E MÉTODOS}

Para responder ao objetivo supracitado, utilizou-se de uma revisão de literatura. Para Mancine e Sampaio (2006), revisões da literatura são caracterizadas pela análise e pela síntese da informação disponibilizada por todos os estudos relevantes publicados sobre um determinado tema, de forma a resumir o corpo de conhecimento existente e levar a concluir sobre o assunto de interesse. Existem diversos tipos de estudos de revisão e cada um deles segue uma metodologia específica.

Neste estudo, optou-se pela revisão narrativa, que não utiliza critérios sofisticados para a busca de informações na da literatura. Adicionalmente, apesar da seleção dos estudos e a interpretação das informações estarem sujeitas à subjetividade dos autores, é proposta a construção de uma contextualização do problema apresentado e realização de uma análise crítica do mesmo. 


\section{RESULTADOS E DISCUSSÃO}

A prevalência de lesões traumáticas na dentição decídua em crianças brasileiras é alta, variando de 6 a 36\%. Essa variação reflete um grande número de fatores que incluem desde aspectos sócio-culturais e localização geográfica, até diferentes critérios na coleta de dados e no registro das lesões em cada estudo (ROBSON, et all, 2010; KRAMER e FELDENS, 2013).

As lesões traumáticas são pouco comuns no primeiro ano de vida, em função da época de erupção dos dentes decíduos e da limitação de movimentos da criança nesta fase. Porém a partir do momento em que a criança adquire autonomia e começa a explorar o ambiente, é natural que aumente a incidência de injúrias traumáticas. A idade de maior ocorrência é bastante controversa, possivelmente em função dos diferentes delineamentos. É importante destacar, contudo, que no primeiro ano de vida observou-se uma prevalência de $6,5 \%$, enquanto queentre 1 e 2 anos de idade a prevalência foi de $21,1 \%$, confirmando evidências que indicam maior risco de injúrias traumáticas a partir dos 12 meses de idade. A queda da própria altura, por sua vez, consiste no fator etiológico maisobservado, principalmente dentro da própria casa onde vive a criança (GODOI, et all, 2015).

As sequelas provenientes destas injúrias aos tecido pulpar são: reabsorções internas da câmara pulpar e conduto radicular, reabsorções radiculares externas, calcificações pulpares, reabsorção da tábua óssea, necrose pulpar e interferência no processo eruptivo do dente permanente. Para os dentes permanentes as sequelas são hipoplasias, hipocal cificações, dilacerações, odontomas, alterações na erupção e formação incompleta da raiz (NOGUEIRA et al., 2014).

Um trauma bucal, principalmente aqueles envolvendo dentes anteriores, tem efeito desfavorável na função, sintomatologia e atratividade física do indivíduo, além de afetá-lo psico-emocionalmente (Nogueira et al., 2014). Esta é uma afirmação válida pelo fato de um trauma poder fraturar um dente e escurecê-lo por ocorrer hiperemia ou hemorragia pulpar; além disso, pode-se perdê-lo no momento do acidente ou não conseguir mantê-lo em seu alvéolo pela reabsorção da câmara pulpar e conduto radicular. Entre outras sequelas, podem-se citar alterações eruptivas e a formação incompleta da raiz (HOLAN.e RAM, 2012).

No estudo de Croll, Pascon e Langeland (1987), em 51 dentes examinados com alteração clínica da cor coronária para o cinza ou preto, 18 apresentavam condições histológicas de calcificação pulpar, enquanto que, dos 59 dentes examinados que possuíam coloração coronária para o amarelo, 17 apresentavam necrose pulpar na análise histológica. De modo similar, estudo clínico de Holan e Ram (2012) constataram que, somente a alteração da cor cinza, não necessariamente indique a degeneração pulpar. Em contrapartida, Zaze, et all (2014) observou sinais de inflamação em $83 \%$ dos dentes que apresentaram coloração escura permanente da coroa.

A perda da vitalidade pulpar é uma complicação comum subseqüiente a traumatismos dentários, especialmente após luxações severas, sendo observada uma freqüência menor entre os pacientes com menos de 3 anos (Zaze, et all 2014). Sendo assim, o tipo de trauma também pode influenciar no desenvolvimento da degeneração da polpa. O estudo de Keowood e Seow (2010) relatou maior prevalência da perda da vitalidade pulpar em traumatismos do tipo deslocamento. Entretanto, trabalhos como os de Soporowski, Alreed e Needleman (2013) e Cunha (2014)foi constatada uma 


\section{Interdisciplinar}

grande porcentagem de dentes com traumas de luxações que permaneceram com vitalidade pulpar.

O estabelecimento da condição pulpar constitui, em alguns casos, uma difícil tarefa, e somente umacompanhamento em longo prazo poderá auxiliar na escolha de uma conduta apropriada (CUNHA, 2014). As associações de parâmetros clínicos tais como o aparecimento de fístulas e das alterações radiográficas, principalmente as rarefações periapicais, têm sido utilizadas para o diagnóstico mais preciso dos casos com degeneração pulpar (PUGLIESI et al., 2013).

\section{CONCLUSÕES}

1. Os traumatismos na dentição decídua são frequentes, principalmente quando as crianças começam a ter maior autonomia;

2.Um trauma bucal tem efeito desfavorável na função, sintomatologia e atratividade física do indivíduo;

3. As sequelas mais encontradas são a descoloração coronária, necrose pulpar, obliteração do canal pulpar e reabsorção radicular.

PALAVRAS-CHAVE: traumatismo dentário. epidemiologia. sequelas

\section{REFERÊNCIAS}

CUNHA, R. F.; PUGLIESI, D. M. C.; VIEIRA, A. E. M. Oraltrauma in Brazilian patients aged 0-3 years. Dental Tramatol, Copenhagen, v. 17, n. 5, p. 210-212, Oct. 2014

GODOI, P.F.S, ZARZAR, P.M.P.A, VIEGAS CMS, JORGE, K.O, RAMOS-JORGE ML, FERREIRA, E.H. Prevalência e fatores associados ao traumatismo dentário em bebês na cidade de Belo Horizonte: um estudo representativo. In: Sociedade Brasileira de Pesquisa Odontológica, Atibaia. Brazilian Oral Research. São Paulo: Universidade de São Paulo v. 21, p. 54, Mar. 2015

HOLAN, G.; RAM, D. Sequelae and prognosis of intruded primary incisors: a retrospective study. Pediatr Dent, Chicago, v. 21, n. 4, p. 242-247, Jul./Aug. 2012.

KENWOOD, M.; SEOW, W. K. Sequalae of trauma to the primary dentition. J Pedod, Birmingham, v. 13, n. 3, p. 230-238, 2010

KRAMER PF, FELDENS CA. Traumatismo na dentição decídua: prevenção, diagnóstico e tratamento. In: Sociedade Brasileira de Pesquisa Odontológica, Atibaia. Brazilian Oral Research. São Paulo: Universidade de SãoPaulo v. 18,n. 3 p. 12-17, D e z, 2013

LEVINE, N. Injury to primary dentition. Dent Clin North Am, Philadelphia, v. 26, n. 3, p. 461-480, Jul. 2012

MANCINI, M. C; SAMPAIO, R. F. Quando o objeto de estudo é a literatura: estudos de revisão. Rev. bras. fisioter. São Carlos, v.10, n.4, Dec. 2006.

NOGUEIRA, A.J, NOGUEIRA R; GILLET A. Aspectos clínicos dos traumas dentais na primeira infância. J Bras Odontopediatr Odontol Bebê ,v 11,n 2. Fev 2014

PUGLIESI, D. M. C.; CUNHA, R. F.; DELBEM, A. C. B.;SUNDEFELD, M. L. M. M. Influence of the type of dental trauma on the pulp vitality and the time elapsed until treatment: a study in patients aged 0-3 years. Dent Traumatol, Copenhagen, v. 20, n. 3, p. 139-142, Jun. 2013

ROBSON, F.C.O, PORDEUS, I.A, VALE, M.P.P, PAIVA, S.M. Epidemiologia do traumatismo na dentição decídua. J Bras Odontoped Odontol Bebe, v. 8, n 10, p. 82-89, Jan 2010 


\section{RPI Rensisade

SOPOROWSKI, N. J.; ALLRED, E. N.; NEEDLEMAN, H. L. Luxation injuries of primary anterior teeth- prognosis and related correlates. Pediatr Dent, Chicago, v. 16, n. 2, p. 96101, Mar./Apr. 2013.

ZAZE, A. S. F.; ASSUNÇÃO, L. R. S.; PROVENZANO, M. G. A.; FRANZIN, L. C. S.; FERELLE, A.; CUNHA, R. F. Avaliação de traumatismos dentários em crianças assistidas em um pronto-atendimento odontológico. Pesqui Odontol Bras, São Paulo, v.18, sup., p. 221, set. 2014. 


\title{
$\mathrm{RPP}$
}

\section{PROMOÇÃO DA SAÚDE BUCAL EM PACIENTES COM NECESSIDADES ESPECIAIS}

\author{
LINHA DE PESQUISA: Saúde Bucal Coletiva; exposição oral
}

Maria Quitéria Tavares de Araújo, discente do CTSB, UFCG; Josefa Jaina Guedes da Silva, discente do CTSB/UFCG Maria Heloisa Marculino Duarte, discente do CTSB/UFCG; Renata Pereira da Silva, discente do CTSB/UFCG; Alana Kelly Maia Macedo Nobre de Lima, Mestre em Odontologia, docente CTSB/UFCG.

\section{INTRODUÇÃO}

Paciente especial é todo indivíduo que apresenta determinados desvios dos padrões de normalidade, identificáveis ou não, e que por isto, necessitam de atenção e abordagem especiais por um período de sua vida e ou indefinidamente (MUGAYAR 2010).

A prevenção odontológica em pacientes portadores de necessidades especiais é relevante, influindo na informação e integração nos cuidados da criança Schmidt (2010). Segundo Sampaio et al.(2013) a qualidade da higiene bucal está relacionada ao quadro clínico do paciente, sendo que indivíduos com problemas de motricidade e inteligência apresentam higiene bucal comprometida. Estudos epidemiológicos avaliando a prevalência da condição de cárie e doenças gengivais em pacientes com necessidades especiais demonstraram índices mais elevados em crianças com retardo mental, seguidos respectivamente de crianças com paralisia cerebral, cegueira, epilepsia, deficientes físicos, Síndrome de Down e surdos-mudos (GUPTA; CHOWDHURY e SARKAR, 2014)

Para realizar o tratamento dentário dos pacientes especiais existem dificuldades específicas e inespecíficas ligadas às deficiências e aos próprios pacientes, que devem ser superadas. Citam como dificuldades específicas: as dificuldades motoras; dificuldades devido à falta de comunicação; hiper ou hipomotricidade muscular; a sialorréia; macroglossia; microdontia; microtomia; o apinhamento dental; as necessidades odontológicas acumuladas; graus de limitação física; graus de riscos anestésicos e a idade da criança; e como dificuldades inespecíficas: a falta de profissionais habilitados; barreiras arquitetônicas; discriminação para com os pacientes especiais; rompimento da rotina de tratamento odontológico; alta de compreensão da família dos pacientes em relação à importância do tratamento odontológico; situação sócio- econômica do paciente; superproteção da criança especial; rejeição da criança especial e falta de compreensão quanto à importância da remoção diária da placa dental ( LANNES e MORAES, 2012)

\section{OBJETIVO DO TRABALHO}

Desenvolver uma revisão da literatura a respeito da abordagem precoce ao tratamento odontológico em pacientes com necessidades especiais.

\section{MATERIAIS E MÉTODOS}




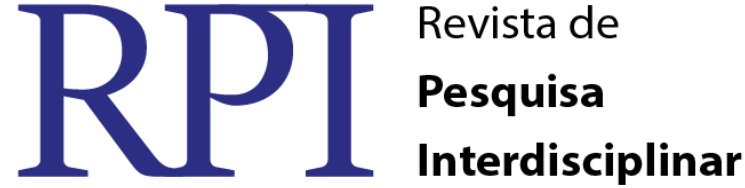

Para responder ao objetivo supracitado, utilizou-se de uma revisão de literatura. Para Mancine e Sampaio (2006), revisões da literatura são caracterizadas pela análise e pela síntese da informação disponibilizada por todos os estudos relevantes publicados sobre um determinado tema, de forma a resumir o corpo de conhecimento existente e levar a concluir sobre o assunto de interesse. Existem diversos tipos de estudos de revisão e cada um deles segue uma metodologia específica.

Neste estudo, optou-se pela revisão narrativa, que não utiliza critérios sofisticados para a busca de informações na da literatura. Adicionalmente, apesar da seleção dos estudos e a interpretação das informações estarem sujeitas à subjetividade dos autores, é proposta a construção de uma contextualização do problema apresentado e realização de uma análise crítica do mesmo.

\section{RESULTADOS E DISCUSSÃO}

Muitos pacientes especiais apresentam dificuldade em manter boa saúde bucal ou ter acesso ao serviço odontológico devido a uma incapacidade ou condição médica; diversos estudos relatam que não apenas no Brasil, mas também em outros países, onde não se dá a devida atenção aos pacientes com déficit neuro-motor, que o índice de dentes cariados, perdidos e obturados e a quantidade de placa bacteriana são mais elevados que na média da população (GUPTA; CHOWDHURY e SARKAR, 2014).

De acordo com Abreu et al (2012) ressaltam a importância de assistência odontológica para pacientes com necessidades especiais, na qual seja incluído um programa de escovação supervisionada e educação para a saúde, voltado aos pais, cuidadores, e também aos alunos do curso de graduação em odontologia, professores e equipe de atenção multidisciplinar. No caso de pacientes que necessitam de atendimento ambulatorial, a orientação dietética, escovação supervisionada e aplicação tópica de flúor, devem ser medidas complementares adotadas. De acordo com os dados levantados pelos autores, observa-se que a maioria dos procedimentos executados durante o tratamento odontológico desses pacientes, está relacionada com a promoção da saúde, mais do que procedimentos restauradores, indicando a viabilidade dessa abordagem em pacientes com necessidades especiais.

Amaral et al. (2013) observaram que por meio de programas que visam a promoção de saúde bucal de pacientes com necessidades especiais, as noções de higiene transmitidas, além de propiciarem a manutenção da saúde, também possibilitam o estreitamento do vínculo família-paciente-equipe profissional. Por meio da pesquisa realizada por Marchioni (2009), alunos de odontologia que prestavam atendimento a pacientes especiais, consideraram o condicionamento como um importante facilitador para a colaboração do paciente no atendimento odontológico, principalmente no que se refere a pacientes com deficiência mental.

Segundo Magalhães et al. (2013) em seu estudo com pacientes portadores de paralisia cerebral atendidos no Centro de Atendimento a Pacientes Especiais (CAPE) os quais foram submetidos a um programa de prevenção de cáries e doença periodontal, baseado na conscientização, estimulação e busca de novas alternativas que promovessem o controle da placa bacteriana. Os autores constataram que por meio da aplicação do programa, a placa bacteriana teve uma redução estatisticamente significante.

Estas pessoas têm uma necessidade aumentada para o cuidado preventivo odontológica; para prevenção de cárie e doenças periodontais. A maioria destes pacientes não apresenta plena capacidade de realizar seus cuidados bucais necessitando da ajuda de demais pessoas. A participação de familiares ou responsáveis nestes cuidados é fundamental para o sucesso do tratamento odontológico e para promoção da saúde bucal do paciente. Quanto 
maior o grau de dependência do paciente, mais atenção o cuidador deve ter à higienização e aos cuidados preventivos Abreu et al (2012). A primeira abordagem odontológica deve ser composta de uma aproximação com os pacientes e familiares assim como o conhecimento das condições médicas preexistentes. Salienta-se que muitos destes pacientes apresentam complicações orgânicas (LANNES e MORAES, 2012).

\section{CONCLUSÕES}

1. Estes pacientes têm dificuldade em ter acesso ao serviço odontológico e consequentemente manter a saúde bucal;

2. É importante manter os pacientes com necessidades especiais em um programa de promoção de saúde bucal, pois demonstram uma redução significante do biofilme bacteriano, e, além disto, também possibilitam o estreitamento do vínculo famíliapaciente-equipe profissional;

3. A grande maioria destes pacientes necessita de pessoas para ajudá-los com os cuidados bucais.

PALAVRAS-CHAVE: pacientes especiais. prevenção. saúde bucal

\section{REFERÊNCIAS}

ABREU, M.H.N.G, CASTILHO, L.S, RESENDE, V.L. Assistência odontológica a indivíduos portadores de deficiências: o caso da Associação Mineira de Reabilitação e Escola Estadual João Moreira Salles. Arq Odontol,v. 37, n.2, p. 153-61, Fev 2012

AMARAL, A.M; SILVA, A.M; ARAÚJO, E.S; SENIUK, F; SANTOS, I.R, MACIEL I.C. Trabalhando com a família do amigo especial. Divulg Saúde Debate, v. 19, n. 4, p. 64-6, Oct 2013

GUPTA, D.P; CHOWDHURY, R; SARKAR S. Prevalence of dental caries in handicapped childrens of Calcutta. J Indian Soc Pedod Prev Dent, v. 11, n.1, p. 23-7, Jan 2014

LANNES C, MORAES S.A.V. Pacientes Especiais. In: Guedes-Pinto AC. Odontopediatria. São Paulo: Editora Santos, p.1061-68, 2012.

MAGALHÃES, M.H.C.G; BECKER, M.M, RAMOS M.S. Aplicação de um programa de higienização supervisionada em pacientes portadores de paralisia cerebral. RPG, v. 4, n. 2, p. 109-13, Nov 2013.

MANCINI, M. C; SAMPAIO, R. F. Quando o objeto de estudo é a literatura: estudos de revisão. Rev. bras. fisioter., v.10, n.4, Dec. 2006.

MARCHIONI, S.A.E. Investigação sobre o uso do condicionamento pelos alunos de odontologia no atendimento a deficientes mentais. Rev Neuropsiquiatria, v. 3, n,2, p.127-33, Nov. 2009.

MUGAYAR L.R.F. Pacientes portadores de necessidades especiais: manual de odontologia e saúde oral. São Paulo: Pancast; 2010.

SAMPAIO, E.F; CÉSAR, F.N; MARTINS, M.G.A. Perfil odontológico dos pacientes portadores de necessidades especiais atendidos no Instituto de Previdência do Estado do Ceará. Rev Bras Prom Saúde, v. 17, n. 3, p. 127-34, 2013.

SCHMIDT, M.G. Pacientes especiais: portadores de deficiências neuropsicomotoras. In: Corrêa MSNP. Odontopediatria na primeira infância. 1. ed. São Paulo: Santos; p. 645-63, 2010. 


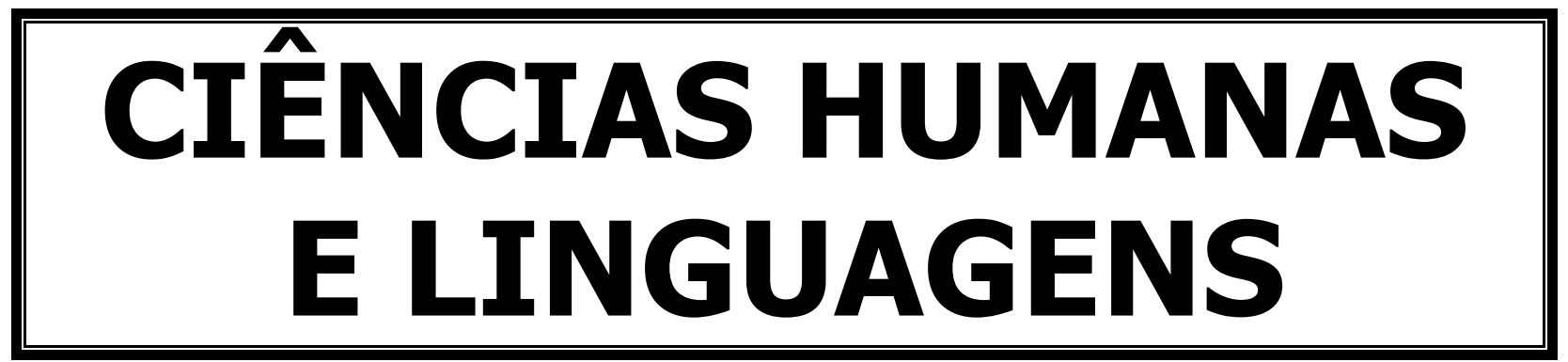

RPI Revista de Pesquisa Interdisciplinar, Cajazeiras, v. 2, Edição Especial, 2017. 


\title{
$\mathrm{RPP}$
}

\section{PROMOÇÃO DA SAÚDE BUCAL EM PACIENTES COM NECESSIDADES ESPECIAIS}

\author{
LINHA DE PESQUISA: Saúde Bucal Coletiva; exposição oral
}

Maria Quitéria Tavares de Araújo, discente do CTSB, UFCG; Josefa Jaina Guedes da Silva, discente do CTSB/UFCG Maria Heloisa Marculino Duarte, discente do CTSB/UFCG; Renata Pereira da Silva, discente do CTSB/UFCG; Alana Kelly Maia Macedo Nobre de Lima, Mestre em Odontologia, docente CTSB/UFCG.

\section{INTRODUÇÃO}

Paciente especial é todo indivíduo que apresenta determinados desvios dos padrões de normalidade, identificáveis ou não, e que por isto, necessitam de atenção e abordagem especiais por um período de sua vida e ou indefinidamente (MUGAYAR 2010).

A prevenção odontológica em pacientes portadores de necessidades especiais é relevante, influindo na informação e integração nos cuidados da criança Schmidt (2010). Segundo Sampaio et al.(2013) a qualidade da higiene bucal está relacionada ao quadro clínico do paciente, sendo que indivíduos com problemas de motricidade e inteligência apresentam higiene bucal comprometida. Estudos epidemiológicos avaliando a prevalência da condição de cárie e doenças gengivais em pacientes com necessidades especiais demonstraram índices mais elevados em crianças com retardo mental, seguidos respectivamente de crianças com paralisia cerebral, cegueira, epilepsia, deficientes físicos, Síndrome de Down e surdos-mudos (GUPTA; CHOWDHURY e SARKAR, 2014)

Para realizar o tratamento dentário dos pacientes especiais existem dificuldades específicas e inespecíficas ligadas às deficiências e aos próprios pacientes, que devem ser superadas. Citam como dificuldades específicas: as dificuldades motoras; dificuldades devido à falta de comunicação; hiper ou hipomotricidade muscular; a sialorréia; macroglossia; microdontia; microtomia; o apinhamento dental; as necessidades odontológicas acumuladas; graus de limitação física; graus de riscos anestésicos e a idade da criança; e como dificuldades inespecíficas: a falta de profissionais habilitados; barreiras arquitetônicas; discriminação para com os pacientes especiais; rompimento da rotina de tratamento odontológico; alta de compreensão da família dos pacientes em relação à importância do tratamento odontológico; situação sócio- econômica do paciente; superproteção da criança especial; rejeição da criança especial e falta de compreensão quanto à importância da remoção diária da placa dental ( LANNES e MORAES, 2012)

\section{OBJETIVO DO TRABALHO}

Desenvolver uma revisão da literatura a respeito da abordagem precoce ao tratamento odontológico em pacientes com necessidades especiais.

\section{MATERIAIS E MÉTODOS}




\section{$\mathrm{RPP}$}

Para responder ao objetivo supracitado, utilizou-se de uma revisão de literatura. Para Mancine e Sampaio (2006), revisões da literatura são caracterizadas pela análise e pela síntese da informação disponibilizada por todos os estudos relevantes publicados sobre um determinado tema, de forma a resumir o corpo de conhecimento existente e levar a concluir sobre o assunto de interesse. Existem diversos tipos de estudos de revisão e cada um deles segue uma metodologia específica.

Neste estudo, optou-se pela revisão narrativa, que não utiliza critérios sofisticados para a busca de informações na da literatura. Adicionalmente, apesar da seleção dos estudos e a interpretação das informações estarem sujeitas à subjetividade dos autores, é proposta a construção de uma contextualização do problema apresentado e realização de uma análise crítica do mesmo.

\section{RESULTADOS E DISCUSSÃO}

Muitos pacientes especiais apresentam dificuldade em manter boa saúde bucal ou ter acesso ao serviço odontológico devido a uma incapacidade ou condição médica; diversos estudos relatam que não apenas no Brasil, mas também em outros países, onde não se dá a devida atenção aos pacientes com déficit neuro-motor, que o índice de dentes cariados, perdidos e obturados e a quantidade de placa bacteriana são mais elevados que na média da população (GUPTA; CHOWDHURY e SARKAR, 2014).

De acordo com Abreu et al (2012) ressaltam a importância de assistência odontológica para pacientes com necessidades especiais, na qual seja incluído um programa de escovação supervisionada e educação para a saúde, voltado aos pais, cuidadores, e também aos alunos do curso de graduação em odontologia, professores e equipe de atenção multidisciplinar. No caso de pacientes que necessitam de atendimento ambulatorial, a orientação dietética, escovação supervisionada e aplicação tópica de flúor, devem ser medidas complementares adotadas. De acordo com os dados levantados pelos autores, observa-se que a maioria dos procedimentos executados durante o tratamento odontológico desses pacientes, está relacionada com a promoção da saúde, mais do que procedimentos restauradores, indicando a viabilidade dessa abordagem em pacientes com necessidades especiais.

Amaral et al. (2013) observaram que por meio de programas que visam a promoção de saúde bucal de pacientes com necessidades especiais, as noções de higiene transmitidas, além de propiciarem a manutenção da saúde, também possibilitam o estreitamento do vínculo família-paciente-equipe profissional. Por meio da pesquisa realizada por Marchioni (2009), alunos de odontologia que prestavam atendimento a pacientes especiais, consideraram o condicionamento como um importante facilitador para a colaboração do paciente no atendimento odontológico, principalmente no que se refere a pacientes com deficiência mental.

Segundo Magalhães et al. (2013) em seu estudo com pacientes portadores de paralisia cerebral atendidos no Centro de Atendimento a Pacientes Especiais (CAPE) os quais foram submetidos a um programa de prevenção de cáries e doença periodontal, baseado na conscientização, estimulação e busca de novas alternativas que promovessem o controle da placa bacteriana. Os autores constataram que por meio da aplicação do programa, a placa bacteriana teve uma redução estatisticamente significante.

Estas pessoas têm uma necessidade aumentada para o cuidado preventivo odontológica; para prevenção de cárie e doenças periodontais. A maioria destes pacientes não apresenta plena capacidade de realizar seus cuidados bucais necessitando da ajuda de demais pessoas. A participação de familiares ou responsáveis nestes cuidados é fundamental para o sucesso do tratamento odontológico e para promoção da saúde bucal do paciente. Quanto 
maior o grau de dependência do paciente, mais atenção o cuidador deve ter à higienização e aos cuidados preventivos Abreu et al (2012). A primeira abordagem odontológica deve ser composta de uma aproximação com os pacientes e familiares assim como o conhecimento das condições médicas preexistentes. Salienta-se que muitos destes pacientes apresentam complicações orgânicas (LANNES e MORAES, 2012).

\section{CONCLUSÕES}

1. Estes pacientes têm dificuldade em ter acesso ao serviço odontológico e consequentemente manter a saúde bucal;

2. É importante manter os pacientes com necessidades especiais em um programa de promoção de saúde bucal, pois demonstram uma redução significante do biofilme bacteriano, e, além disto, também possibilitam o estreitamento do vínculo famíliapaciente-equipe profissional;

3. A grande maioria destes pacientes necessita de pessoas para ajudá-los com os cuidados bucais.

PALAVRAS-CHAVE: pacientes especiais. prevenção. saúde bucal

\section{REFERÊNCIAS}

ABREU, M.H.N.G, CASTILHO, L.S, RESENDE, V.L. Assistência odontológica a indivíduos portadores de deficiências: o caso da Associação Mineira de Reabilitação e Escola Estadual João Moreira Salles. Arq Odontol,v. 37, n.2, p. 153-61, Fev 2012

AMARAL, A.M; SILVA, A.M; ARAÚJO, E.S; SENIUK, F; SANTOS, I.R, MACIEL I.C. Trabalhando com a família do amigo especial. Divulg Saúde Debate, v. 19, n. 4, p. 64-6, Oct 2013

GUPTA, D.P; CHOWDHURY, R; SARKAR S. Prevalence of dental caries in handicapped childrens of Calcutta. J Indian Soc Pedod Prev Dent, v. 11, n.1, p. 23-7, Jan 2014

LANNES C, MORAES S.A.V. Pacientes Especiais. In: Guedes-Pinto AC. Odontopediatria. São Paulo: Editora Santos, p.1061-68, 2012.

MAGALHÃES, M.H.C.G; BECKER, M.M, RAMOS M.S. Aplicação de um programa de higienização supervisionada em pacientes portadores de paralisia cerebral. RPG, v. 4, n. 2, p. 109-13, Nov 2013.

MANCINI, M. C; SAMPAIO, R. F. Quando o objeto de estudo é a literatura: estudos de revisão. Rev. bras. fisioter., v.10, n.4, Dec. 2006.

MARCHIONI, S.A.E. Investigação sobre o uso do condicionamento pelos alunos de odontologia no atendimento a deficientes mentais. Rev Neuropsiquiatria, v. 3, n,2, p.127-33, Nov. 2009.

MUGAYAR L.R.F. Pacientes portadores de necessidades especiais: manual de odontologia e saúde oral. São Paulo: Pancast; 2010.

SAMPAIO, E.F; CÉSAR, F.N; MARTINS, M.G.A. Perfil odontológico dos pacientes portadores de necessidades especiais atendidos no Instituto de Previdência do Estado do Ceará. Rev Bras Prom Saúde, v. 17, n. 3, p. 127-34, 2013.

SCHMIDT, M.G. Pacientes especiais: portadores de deficiências neuropsicomotoras. In: Corrêa MSNP. Odontopediatria na primeira infância. 1. ed. São Paulo: Santos; p. 645-63, 2010.

\section{SOBRE FILOSOFIA CLÍNICA $1^{\circ}$ EIC/ETSC 2016}


ÁREA TEMÁTICA: Ciências humanas e linguagens Banner

FRANCISCA ANA LÍVIA RODOLFO DA SILVA, Aluna, $3^{\circ}$ Ano ETSC-UFCG-Cajazeiras. HILLARY FERREIRA PARNAIBA, Aluna, $3^{\circ}$ Ano ETSC-UFCG-Cajazeiras. ANTUNES FERREIRA SILVA, Mestre, ETSC-UFCG-Cajazeiras

\section{INTRODUÇÃO}

A filosofia clínica é uma metodologia filosófica que se aplica no indivíduo e, junto ao ponto de vista filosófico, procura amenizar as dores da alma. Chegou no brasil através de Lúcio Packter, em 1994, com a sua própria versão. Esse filósofo é graduado em Filosofia pela Pontifícia Universidade Católica - Fafimc, de Porto Alegre, Pós-Graduado em Filosofia e Psicanálise pela Universidade Tuiuti, de Curitiba e Pós-Graduado em Psicologia pela Universidade Metropolitana Unida, de São Paulo. Na década de 80, Lúcio, insatisfeito com algumas abordagens terapêuticas, se dispôs a viajar pelo mundo em busca de novas técnicas e métodos para conhecer e cuidar do ser humano integralmente. Com isso, a partir de conhecimentos adquiridos, iniciou suas pesquisas e criou uma abordagem terapêutica que batizou com o nome de Filosofia Clinica. Consequentemente, é considerado o precursor do movimento no país. Com essa nova terapia surge então a necessidade de diferenciar a filosofia clínica de psicologia, onde há associações, já que ambas pretendem ser aplicadas ao todo do ser humano, aquele que procura a terapia, na intenção de um cuidado terapêutico.

\section{OBJETIVO DO TRABALHO}

Compreender o método da filosofia de Lúcio Packter, procurando analisar seus objetivos e motivos a serem usados. Além disso fazer a distinção da associação criada pela semelhança existente entre psicologia e filosofia clínica.

\section{MATERIAIS E MÉTODOS}

O trabalho foi conduzido através de pesquisas online e a partir do conhecimento adquirido nas aulas didáticas sobre o assunto.

\section{DISCUSSÃO}

Visando trabalhar as questões existenciais do paciente, em filosofia clínica é chamado de partilhante, porque na dinâmica desse método o que há é uma construção partilhada que acontece em virtude da interseção de ambas as partes em busca de um conforto existencial, essa abordagem terapêutica é filosofia pois se inicia a partir da inspiração de seu método em decorrência das pesquisas dos filósofos ao longo da história e dos pensamentos ocidentais. É clinica pois pretende aplicar-se ao todo do ser humano, do partilhante que busca ajuda, intencionando um cuidado terapêutico. O objetivo da Filosofia Clínica, diferentemente da psicologia, é garantir uma autonomia de pensamento do partilhante. Dividindo-se em três etapas, esse método localiza o partilhante existencialmente, identifica a Estrutura de Pensamento (EP) e aplica os submodos, os meios pelos quais o partilhante viabiliza e a efetivação de sua estrutura de pensamento. Em outras palavras, a Filosofia Clinica identifica não o problema em si mas suas causas e permite que o partilhante viabilize e a partir daí decida como resolve-lo e extingui-lo de vez. Seus métodos de resolução são individuais e 


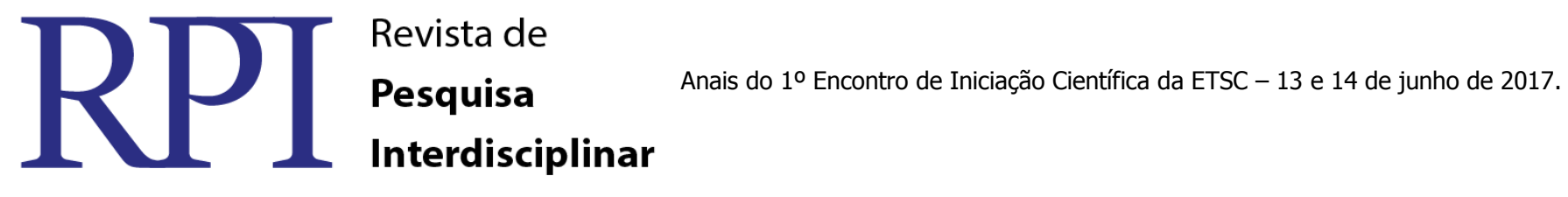

específicos para cada partilhante e problema singularmente. Por outro lado, a psicologia de certa forma cria uma relação de dependência do paciente com o tratamento. Nomeia os problemas como patologias e procura "atacar" a questão que levou o paciente até o psicólogo.

\section{CONCLUSÕES}

Torna-se explícito, portanto, que a Filosofia Clínica não promove curas, pois não classifica a questão como uma patologia, mas auxilia na tentativa resolver problemas emocionais que podem chegar ou chegam a causar crise existencial.

\section{PALAVRAS-CHAVE:}

Lúcio Packter, Filosofia Clínica, Psicologia, Terapia.

\section{REFERÊNCIAS}

CARUZO, Miguel Angelo. O que é Filosofia Clínica? Disponível em: <http://www.psicologiamsn.com/2012/03/o-que-e-filosofia-clinica.html>. Acesso em: 15 nov. 2016.

PACKTER, Instituto. Prof. Lúcio Packter. Disponível em: <http://www.filosofiaadistancia.com.br/professores/Lúcio Packter/LP.html>. Acesso em: 15 nov. 2016.

MOURA, Matheus. Filosofia no divã: Conheça a Filosofia Clínica e de que forma ela pode influenciar seu comportamento no cotidiano. Disponível em: <http://filosofia.uol.com.br/filosofia/ideologia-sabedoria/22/artigo163498-1.asp>. Acesso em: 15 nov. 2016.

WIKIPÉDIA. Filosofia clínica. $2016 . \quad$ Disponível em: <https://pt.wikipedia.org/wiki/Filosofia_clínica>. Acesso em: 11 Não é um mês valido! 2016. 


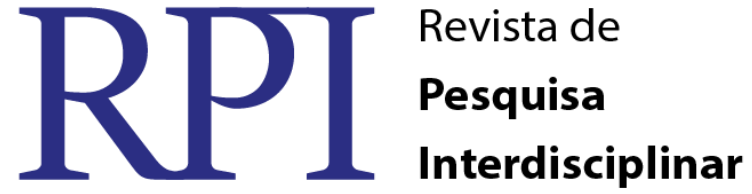

\section{ALMEJADA POR TODOS : A FELICIDADE \\ ÁREA TEMÁTICA: Ciências humanas e linguagens. Exposição em banner}

ATILYO LIMA BARROSO, ensino médio, ETSC-UFCG. ANTUNES FERREIRA SILVA, mestre em filosofia, ETSC-UFCG.

\section{INTRODUÇÃO}

A palavra ethos é de etimologia grega e significa comportamento, ação, atividade. É dela que deriva a palavra ética. A ética é, portanto, o estudo do comportamento, das ações, das escolhas e dos valores humanos. Mas no nosso cotidiano ocorre de percebermos que há uma série de modelos de "éticas" diferentes que postulam modos de vida e de ação, por vezes excludentes. Qual é o melhor tipo de vida (se é que há um)? O que é a felicidade? É melhor ser feliz ou fazer o bem ou o que é certo?

Perguntas como essas são feitas em todas as épocas da história humana. E desde a antiguidade clássica dos gregos, já havia muitos modelos de respostas para elas. Uma delas é a fornecida pelo filósofo Aristóteles, famoso por sua Metafísica. Vamos nos aprofundar um pouquinho mais no que ele tem a nos dizer.

Em seu livro "Ética a Nicômaco", Aristóteles consagrou a tão famosa ética do meiotermo. Em meio a um período de efervescência cultural, o prazer e o estudo se confrontam para disputar o lugar de melhor meio de vida. No entanto, a sobriedade de nosso filósofo o fez optar por um caminho que condene ambos os extremos, sendo, pois, os causadores dos excessos e dos vícios.

A metrética (medida) que usa o estagirita (Aristóteles era chamado assim por ter nascido em Estagira) procurava o caminho do meio entre vícios e virtudes, a fim de equilibrar a conduta do homem com o seu desenvolvimento material e espiritual. Assim, entendido que a especificidade do homem é a de ser um animal racional, a felicidade só poderia se relacionar com o total desenvolvimento dessa capacidade. A felicidade é o estado de espírito a que aspira o homem e para isso é necessário tanto bens materiais como espirituais.

Aristóteles herda o conceito de virtude ou excelência de seus antecessores, Sócrates e Platão, para os quais um homem deve ser senhor de si, isto é, ter autocontrole (autarquia). Trata-se do modo de pensar que promove o homem como senhor e mestre dos seus desejos e não escravos destes. $\mathrm{O}$ homem bom e virtuoso é aquele que alia inteligência e força, que utiliza adequadamente sua riqueza para aperfeiçoar seu intelecto. Não é dado às pessoas simples nem inocentes, tampouco aos bravos, porém tolos. A excelência é obtida através da repetição do comportamento, isto é, do exercício habitual do caráter que se forma desde a infância.

Segundo Aristóteles, as qualidades do caráter podem ser dispostas de modo que identifiquemos os extremos e a justa medida. Por exemplo, entre a covardia e a audácia está a coragem; entre a belicosidade e a bajulação está a amizade; entre a indolência e a ganância está a ambição e etc. É interessante notar a consciência do filósofo ao elaborar a teoria do meio-termo. Conforme ele, aquele que for inconsciente de um dos extremos, sempre acusará o outro de vício. Por exemplo, na política, o liberal é chamado de conservador e radical por aqueles que são radicais e conservadores. Isso porque os extremistas não enxergam o meiotermo.

Portanto, seguindo o famoso lema grego "Nada em excesso", Aristóteles formula a ética da virtude baseada na busca pela felicidade, mas felicidade humana, feita de bens materiais, riquezas que ajudam o homem a se desenvolver e não se tornar mesquinho, bem como bens espirituais, como a ação (política) e a contemplação (a filosofia e a metafísica). 


\section{$\mathrm{RPP}$}

\section{OBJETIVO DO TRABALHO}

O projeto tem por objetivo buscar uma melhor abordagem sobre a felicidade segundo os pensamentos aristotélicos visando uma melhor compreensão e uma interpretação mais ampla.

\section{MATERIAIS E MÉTODOS}

O trabalho foi realizado a partir de discursões e palestras, de cunho filosófico, realizadas na sala de aula. Além de fazer uso de textos e pensamentos do filósofo citado. Vale ressaltar a utilização de livros e anexos bibliográficos no meio virtual.

\section{RESULTADOS E DISCUSSÃO}

A filosofia aristotélica é teleológica, ou seja, está orientada por uma finalidade (telos, em grego, significa "fim"). Na "Ética a Nicômaco", a finalidade é identificada como o "bem", ou seja, dizer que todas as ações tendem a um fim é o mesmo que dizer que todas as coisas tendem a um bem.

É importante considerar que há diferenças entre os fins. Há, por exemplo, atividade cujo fim está em si mesma e atividades cujos fins são diferentes delas. O pensamento filosófico nos esclarece: a arte médica é um meio para alcançar a saúde; a construção naval é um meio para obter um navio; a economia é um meio para obter a riqueza. São, portanto, bens instrumentais. Aqueles bens que são bens em si mesmos são denominados de bens intrínsecos.

Podemos observar, portanto, uma hierarquia entre bens, e os intrínsecos figurando ao topo. Ambos, bens instrumentais e bens intrínsecos, tendem a um fim.

Aristóteles percebeu que não poderia haver apenas bens secundários, um bem desejado em função de outro. Era necessário que existisse um fim último para a ação humana. A esse fim último, Aristóteles refere-se como Sumo Bem, "o melhor dos bens".

Como é o "melhor que existe", o Sumo Bem deve ser objeto de um saber supremo, uma ciência que seja superior às outras ciências. Para ele, essa ciência era a Política. Dessa forma, podemos compreender que o bem para os seres humanos não deve ser alcançado individualmente e, sim, em coletivo, por toda a cidade.

Já entendemos que toda ação tem um fim e deve haver um fim que seja um fim último. Entendemos também que deve haver um fim último para a ação humana e que será objeto da Política: "Ninguém duvidará de que o seu estudo pertença à arte mais prestigiosa e que mais verdadeiramente se pode chamar a arte mestra" (Aristóteles, 1973, p. 249).

Ainda nos falta entender qual é a finalidade à qual o ser humano se dirige, esse fim que é o Sumo Bem, o mais alto de todos os bens que se pode alcançar pela ação.

Aristóteles diz que tanto as pessoas mais sábias quanto as pessoas menos doutas concordam que toda a ação humana tem como objetivo alcançar a felicidade. Se faz parte da natureza humana o desejo de ser feliz, o fim mais elevado não poderia ser outro e, por isso, há esse consenso.

No entanto, não há um consenso a respeito do sentido que a "felicidade" tem para todas as pessoas. $\mathrm{O}$ sentido que as pessoas atribuem à felicidade varia muito e é como se, de fato, não soubessem ou não fosse possível saber o que vem a ser a felicidade. Enquanto as pessoas sábias entendem que a felicidade é um fim em si mesma, as demais pessoas definem-na como 


\section{$\int\left[\begin{array}{l}\text { Revista de } \\ \text { Pesquisa } \\ \text { Interdisciplinar }\end{array}\right.$}

se fosse "alguma coisa simples e óbvia, como o prazer, a riqueza ou as honras" (Aristóteles, 1973, p. 251).

Parece mesmo que a felicidade esteja associada a uma noção de "falta". Por exemplo, se perguntarmos para uma pessoa doente o que é a felicidade, ela responderá que é a saúde; para uma pessoa endividada, a resposta que teremos será que o dinheiro é a felicidade; para uma pessoa que está passando frio, uma resposta possível é que um cobertor é a felicidade, da mesma forma que, para uma pessoa faminta, a felicidade é um prato de comida. O que podemos pensar, com Aristóteles, é que não há uma mudança no que é a felicidade, e sim na percepção que temos dela.

Aristóteles, ao observar que não existe um consenso a respeito do conceito de felicidade, identificou três modos de vida. Cada modo de vida tem uma percepção distinta a respeito do que é a felicidade.

O primeiro modo de vida é a vida guiada pelo prazer. As pessoas que vivem assim, e que são a maior parte das pessoas, pensam que o bem e a felicidade são sinônimos de satisfação de impulsos, assim como são para os outros animais. Por isso, Aristóteles identifica esse tipo de modo de vida com a escravidão.

O segundo modo de vida é a vida política. Nesse caso, as pessoas buscam honrarias e grandes feitos para que sejam reconhecidas pelas demais pessoas, como se a felicidade dependesse do olhar do outro - pois, a ação humana não é suficiente para conduzir à felicidade; depende de uma interpretação, de alguém que a valide.

Disse Aristóteles que as pessoas que pensam assim parecem querer provar para si mesmas que são, de fato, boas. Do mesmo modo, são as pessoas que buscam não honra, e sim riquezas. As riquezas não trazem felicidade, são apenas úteis e instrumentos para se alcançar alguma outra coisa.

A terceira e mais elevada forma de vida é a vida contemplativa. Esse modo de vida aproximase mais da real finalidade humana, pois as pessoas que vivem assim, como os sábios e filósofos, buscam o bem por ser um bem e não por quererem outra coisa a partir dele, orientadas pelo exercício da razão.

A vida contemplativa é a vida puramente racional e, por meio dela, o ser humano age de acordo com sua mais elevada faculdade e em busca de um bem que é a própria finalidade e, por isso, é o Sumo Bem. Como a razão é a mais elevada faculdade humana, a vida contemplativa é o modo de vida mais feliz para o ser humano e, portanto, sua felicidade.

\section{CONCLUSÕES}

Com a conclusão do projetos pode-se notar que a razão é a faculdade que analisa, pondera, julga, discerne. Ela nos permite distinguir o que é bom ou mau, a distinguir os vícios das virtudes. Ela nos permite fazer escolhas pertinentes para nossa felicidade. Por exemplo, a temeridade é um vício por excesso, a covardia é um vício por falta; o meio termo é a coragem, que é uma virtude. O orgulho é um vício por excesso, a humildade um vício por falta; o meio termo é a veracidade, que também é uma virtude. A inveja é um vício por excesso, a malevolência é um vício por falta; o meio termo é a justa indignação. Para Aristóteles toda escolha exige uma mediania, um equilíbrio entre o excesso e a falta. Na vida não podemos ser imprudentes e impulsivos se arriscando em situações perigosas. Por outro lado, também não podemos ser covardes e ter medo de tudo deixando que o medo nos domine. É necessário o meio termo entre esses dois sentimentos, devemos enfrentar os medos e perigos sabendo agir com bom senso. O mesmo raciocínio serve para alimentação, não podemos comer muito para passar mal do estômago, assim como não podemos evitar comer, pois também vamos adoecer. Devemos comer com moderação. Por esta ótica, também podemos pensar os sentimentos. Na vida não podemos ser vaidosos preocupando-nos apenas com nossas qualidades, satisfazendo sempre o nosso ego. Por outro lado, também não podemos ser muito 


\section{RPT Reustade

modestos, achando que somos inferiores. É necessário auto-estima, sabendo reconhecer através da razão nossos defeitos e nossas qualidades. Para Aristóteles, portanto, devemos sempre escolher o meio termo, sendo moderados em tudo o que fazemos na vida. Somente assim atingiremos o bem e a felicidade.

PALAVRAS-CHAVE: Distinguir. Felicidade. Razão.

\section{REFERÊNCIAS}

ARISTÓTELES. Tópicos. Dos argumentos sofísticos. Metafísica: livro I e livro II. Ética a Nicômaco. Poética. São Paulo: Abril Cultural, 1973. (Os pensadores, 4).

Aristóteles. Ética a Nicômaco. Edipro, São Paulo, 2007

Costa, José S. Tomás de Aquino: a razão a serviço da fé. São Paulo: Moderna, 1993

Stratheer, Paul. Aristóteles em 90 minutos. Rio de janeiro: Jorge Zahar, 1997. 


\title{
$\mathrm{RPP}$
}

\author{
DE OLHO NO TEMPO \\ ÁREA TEMÁTICA: Ciências Humanas e Linguagens \\ Exposição em banner
}

\begin{abstract}
EDIGLEY CARDOSO FERREIRA JÚNIOR, Est. Ensino Médio, ETSC-UFCG. RICH ELTON CARVALHO RAMALHO, Est. Ensino Médio, ETSC-UFCG. ANTUNES FERREIRA DA SILVA, Mestre em Filosofia, ETSC-UFCG.
\end{abstract}

\section{INTRODUÇÃO}

O conceito de tempo é tratado desde a antiguidade como se fosse algo adquirido através dos dias em que são vividos e que seria uma utopia decifrarem esta definição. Porém, esse conceito ele vem sendo discutido há vários séculos e alguns filósofos deram a sua contribuição a respectiva ideia. Por exemplo, nas filosofias de Platão, Aristóteles, Santo Agostinho, Santo Tomás de Aquino e Newton a partir de quando eles resolvem especular a origem cosmológica, uma maneira possível de fazer a medição temporal e qual a relação entre o tempo, o movimento e a divindade. Pretendemos mostrar a opinião dos filósofos antigos Platão e Aristóteles, seu discípulo que foi influenciado possivelmente por mestre, que definiram esse conceito baseando-se no movimento dos corpos e na existência da alma, uma vez que acreditava que ela seria o único ser inteligível capaz de numerar o tempo. Ademais, que na filosofia medieval, Agostinho definiu o tempo como psicológico com respeito à percepção do homem que é diferente de Deus e em relação à medição como uma distensão e que teve início com a criação de Deus, assim como Tomás de Aquino definiu em "sua teologia".

O tempo é considerado uma das propriedades gerais da exterioridade relativamente ao pensamento e então, para o indivíduo pode ser dividido em três partes: o passado, o presente e o futuro. O passado ensina o que já ficou para trás, então não vale a pena se apegar ao mesmo, pois todas as lembranças você querendo ou não elas irão sair em forma de lágrimas, já o presente é o que deve ser vivido, sem levar em consideração o passado, é o tempo que se deve ser plantado o recomeço ou o tempo que se deve fazer tudo novamente, e o futuro é algo que não nos pertence, pois quando o mesmo chegar ele não mais será futuro e sim presente.

\section{OBJETIVO DO TRABALHO}

Pretendemos frisar na nossa exposição como o conceito de tempo foi definido pelos filósofos desde a antiguidade, e também por filósofos modernos. É de sua importância ressaltar que os conceitos de tais filósofos não serão estudados para discutir qual é o correto, mas para expor o pensamento de cada um.

Primeiro mostraremos que filosofias antigas posteriores as dos pré-socráticos e a de Sócrates (470- 399 a.C.), como a de Platão e a de Aristóteles definiram o tempo como algo que depende do movimento dos corpos para existir, isto é, como se o movimento determinasse a mudança das horas, dias, meses e anos. Ademais, as duas filosofias acreditam que a alma precisa existir, já que para eles ela é a única capaz de compreender a numeração dos movimentos.

Em segundo lugar buscaremos expor como o tempo foi conceituado na Idade Média, por filósofos cristãos da Igreja Católica, como Santo Agostinho e Santo Tomás de Aquino, que usaram a sua fé em Deus na sua filosofia; aceitando de forma crítica o que está escrito nas Sagradas Escritura e especulando-a em busca do pleno entendimento da Criação e de tudo que foi criado por a divindade.

E por último e não menos importante, traremos a filosofia contemporânea de Newton, que também definiu o assunto já mencionado. Tentaremos, sobretudo, mostrar quais as críticas desse filósofo com respeito aos medievais e aos antigos que conceituaram o respectivo 


\section{$\int\left[\begin{array}{l}\text { Revista de } \\ \text { Pesquisa } \\ \text { Interdisciplinar }\end{array}\right.$}

assunto de formas semelhantes ou diferentes. Mas também pretendemos apresentar qual a definição de Newton, uma vez que em Princípios Matemáticos ele deixa claro o seu conceito.

\section{MATERIAIS E MÉTODOS}

Fizemos diversas pesquisas sobre o tema, pesquisando o que cada filósofo pensava sobre o mesmo, e tentamos dividi-los entre os realistas e os antirrealistas.

Utilizamos alguns recursos como: a internet, revistas e livros de alguns dos filósofos citados aqui, como Platão, Aristóteles, Santo Agostinho, Santo Tomás de Aquino e Newton.

\section{DISCUSSÃO}

\section{Platão e Aristóteles: tempo e movimento dos corpos.}

Em Timeu Platão (428- 347 a.C.) define a sua cosmologia. Nesta o tempo tem um a origem cosmológica, sendo uma cópia imperfeita do modelo perfeito que é a eternidade divina e nascendo a partir de quando a divindade ordenou o caos. Por isso que nessa mesma obra, Platão, defende que o tempo pode ser medido segundo o movimento dos astros, Sol, Lua e as estrelas. E, deste modo, pode ser medido conforme o movimento dos corpos. Essa filosofia será criticada pela medieval de Santo Agostinho de Hipona (354-430), que no livro XXI das Confissões diz que o tempo não pode ser medido dessa forma.

A filosofia de Aristóteles defendia que o tempo se mede quando se numera o movimento. Mas para numerar algo, é preciso que exista a alma. Por isso que no livro IV da Física conceitua o tempo com certa relação com a alma, existindo se ela também existir, porquanto se o tempo é numerável, necessita de alguém para numerar. Mas essa percepção é descartada por Newton que em Princípios Matemáticos defende o tempo absoluto independente de qualquer coisa externa.

Ora, uma vez Platão tenha sido mestre de Aristóteles, certamente este leu Timeu. Por isso que no livro IV da Física conceitua o tempo como número do movimento, segundo o antes e o depois, isto é, mesmo Aristóteles não acreditando que o tempo não é o próprio movimento, define-o como algo que tenha dependência deste. Desta forma, parece que o Discípulo teve uma influência do Mestre nesse ponto, uma vez que Platão afirma em sua obra Timeu: E por ser esse modelo um animal eterno, cuidou de fazer também eterno o universo, na medida do possível. Mas a natureza eterna desse ser vivo não podia ser atribuída em toda a sua plenitude ao que é engendrado. Então, pensou em compor uma imagem móbil da eternidade, e, ao mesmo tempo em que organizou o céu, fez da eternidade que perdura na unidade essa imagem eterna que se movimenta de acordo com o número e a que chamamos tempo. E como antes do nascimento do céu não havia dias nem noites nem meses nem anos, foi durante aquele trabalho que ele cuidou do seu aparecimento. Todos eles são partes do tempo, e o que foi ou será, simples espécies criadas pelo tempo, que indevidamente e por ignorância, transferimos a essência eterna. (...) Seja como for, o tempo nasceu com o céu, para que, havendo sido criados concomitantemente, se dissolvessem juntos, caso venham algum dia a acabar; foi feito segundo modelo da natureza eterna, para que se lhe assemelhasse o mais possível. Porque o modelo existe desde toda a eternidade, enquanto o céu foi, é e será perpetuamente na duração do tempo. O nascimento do tempo decorre da sabedoria e desse plano da divindade, e para que o tempo nascesse também nasceram a lua e outros cinco astros denominados errantes ou planetas, para definir e conservar os números do tempo.

Cabe salientar que quando Aristóteles define a alma como a única capaz de contemplar o mundo inteligível, assemelha-se ao seu mestre Platão; porque quando aquele defende na Física que o tempo necessita da alma para existir, devido esta ser a responsável 


\section{$\int \begin{aligned} & \text { Revista de } \\ & \text { Pesquisa } \\ & \text { Interdisciplinar }\end{aligned}$}

por numerá-lo de acordo com o movimento, parece com a cosmologia de Platão definida no Timeu.

Ademais, parece que, segundo Platão, se o movimento dos corpos não estiver em ação, não há tempo , assim como, consoante Aristóteles, se não existir movimento, consequentemente o tempo não existirá, uma vez que a ausência do número do movimento nele significará a sua inexistência. E que a filosofia do Mestre influenciou a do Discípulo no conceito de tempo, movimento, mas também na cosmologia.

\section{O tempo para Santo Agostinho}

O conceito de tempo do filósofo medieval Santo Agostinho é muito diferente do que foi definido por Platão e seu discípulo Aristóteles, uma vez que não se baseava no movimento dos corpos, com respeito à medida. Logo, Agostinho definiu o conceito de tempo como uma certa distensão.

"Ninguém me diga, portanto, que o tempo é o movimento dos corpos celestes. Quando, com a oração de Josué, o Sol parou, a fim de ele concluir vitoriosamente o combate, o Sol estava parado, mas o tempo caminhava. Este espaço de tempo foi suficiente para executar e para pôr termo ao combate. [..] Vejo portanto que o tempo é uma certa distensão [...] Portanto, o tempo não é o movimento dos corpos."

No livro XXI de Confissões, Agostinho problematiza a forma de se medir o tempo, já que como o tempo passado e o futuro não existem, devido este existir futuramente, aquele já ter existido e o tempo presente não possuir extensão para medi-lo, a medição se torna complexa de ser compreendida. Deste modo, na filosofia agostiniana não existe tempo passado nem futuro, mas fatos. Além disso, nela o tempo é medido pela impressão ou percepção das coisas que acontecem no presente, visto que se não for isso, não se pode, assim, medir o tempo. Isto é, parece que foi esta maneira proposta por Agostinho para a medição do tempo, visto que no livro XXI de sua obra Confissões fala da atenção do presente como o único meio possível.

Desta forma, observa-se que o tempo para Agostinho é psicológico, isto é, parece ser uma impressão da mente [espírito]. Uma vez o tempo é psicológico, o filósofo submete a existência de três motivos essenciais para o tempo esse aspecto. Tais motivos fazem com que Agostinho divida o tempo em "lembrança presente das coisas passadas, visão presente das coisas presentes e esperança presente das coisas futuras".

\section{O tempo para São Tomás de Aquino}

Na concepção de São Tomás de Aquino o tempo é a medida do movimento ou de uma mudança qualquer. O mesmo defende que o tempo é a enumeração, é a contabilização, a cronometragem, é um número desta coisa que tem um antes e um depois. Ou seja, o tempo para São Tomás de Aquino é a medida das coisas que mudam ou se movimentam, um exemplo a ser citado é uma disputa de uma corrida qualquer, no qual você terá um tempo antes da corrida, o tempo em que se inicia a corrida e por ultimo o tempo depois da corrida, então para o respectivo filósofo o número que indica o movimento do antes e do depois, é tempo.

São Tomás e Aristóteles definiram o movimento, na qual a definição diz: "movimento só não aquele chamado local, mas é também o movimento da geração da corrupção, de envelhecimento, das mudanças, o cabelo que fica branco é um movimento; toda e qualquer mudança corpórea, toda e qualquer mudança mental, é sempre um movimento é um motu, é uma mudança.". 


\section{$\mathrm{RPP}$}

\section{Isaac Newton: Tempo absoluto e Matemático}

Segundo Newton o tempo é absoluto, verdadeiro e matemático e não tem relação alguma com algo externo. Sendo absoluto, o tempo é imutável e diferente do relativo e que vulgarmente é usado no lugar do verdadeiro. Porque, todo o fluxo do tempo absoluto não se pode mudar, isto é, ser alterado, ainda que os movimentos sejam rápidos ou nulos, ou até nulos, a ordem das partes do tempo é imutável.

Além disso, Newton não concorda com São Tomás de Aquino que trata do tempo e das coisas criadas no tempo com surgimento a partir da vontade de Deus. Segundo o mesmo, o tempo absoluto não pode ser vinculado com as coisas externas, mas também porque sempre existiu e seu fluxo nunca pode ser alterado. Ou seja, quando Tomaz de Aquino trata de Deus como Criador das coisas e do início da existência do tempo é possível perceber que sua filosofia é contraditória com a de Newton, segundo frisa Compêndio de Teologia. Também não pode ser criado pelo criador, pois o tempo para Newton é absoluto, verdadeiro, matemático e também é imutável e eterno. Nesse ponto parece que Newton critica Platão, Santo Agostinho e São Tomás de Aquino, que defendem que o tempo nasceu com a criação da divindade quando se refere á imutabilidade do tempo.

Mas com respeito ao movimento, Newton distingue o tempo absoluto do relativo da astronomia de Platão porque, segundo aquele, as mudanças dos corpos são vulgarmente consideradas com medidas iguais. Com efeito, frisa que o movimento dos corpos pode ser mais acelerado ou retardado, no entanto o fluxo do tempo absoluto permanece inalterável. Desta maneira, parece que Newton critica a filosofia de Platão e do discípulo deste que basicamente defendem o movimento dos corpos como agente principal para se medir o tempo. Além disso, parece que Newton nessa parte de sua filosofia se assemelha a Santo Agostinho que definia o tempo como certa distensão e percebido através de medidas sensíveis da mente, e não através das longas ou curtas mudanças das coisas existentes no Cosmos.

\section{O tempo em Husserl}

O tempo em Husserl, diz respeito á percepção que temos das coisas em nossa consciência, não precisando que este tempo corresponda aquele do mundo externo a nossa mente. Um exemplo a ser dado a essa teoria seria quando percebemos que alguns momentos passam rápidos e outros demoram a passar, aí se perguntamos - o tempo não é o mesmo? Pois bem, para Husserl o tempo é apenas questão de percepção, ou seja, uma questão de consciência. Então o tempo é definido de acordo com a consciência e não de acordo com o relógio. Ademais, o tempo da física serviria então apenas para questões práticas, como não chegar atrasado e medir velocidade.

\section{RESULTADOS}

O tempo não tem um conceito definido como já foi exposto aqui, porém preocupados com o que os indivíduos acham sobre o respectivo assunto, inovamos e criamos uma pequena pesquisa, na qual traz três perguntas: "Pra você, o que é o tempo?"; "Em relação ao tempo você acredita que o mesmo é eterno ou tem fim?"; "Se você soubesse que o seu tempo (sua vida) acabaria hoje, o que você faria?". Essas três perguntas e não diferentemente dos filósofos trouxeram opiniões distintas e a partir delas, analisamos de acordo com a primeira resposta se essa pessoa comungaria com o conceito dos realistas ou dos antirrealistas. Vejamos o gráfico abaixo que é relacionado á primeira pergunta: 
Interdisciplinar

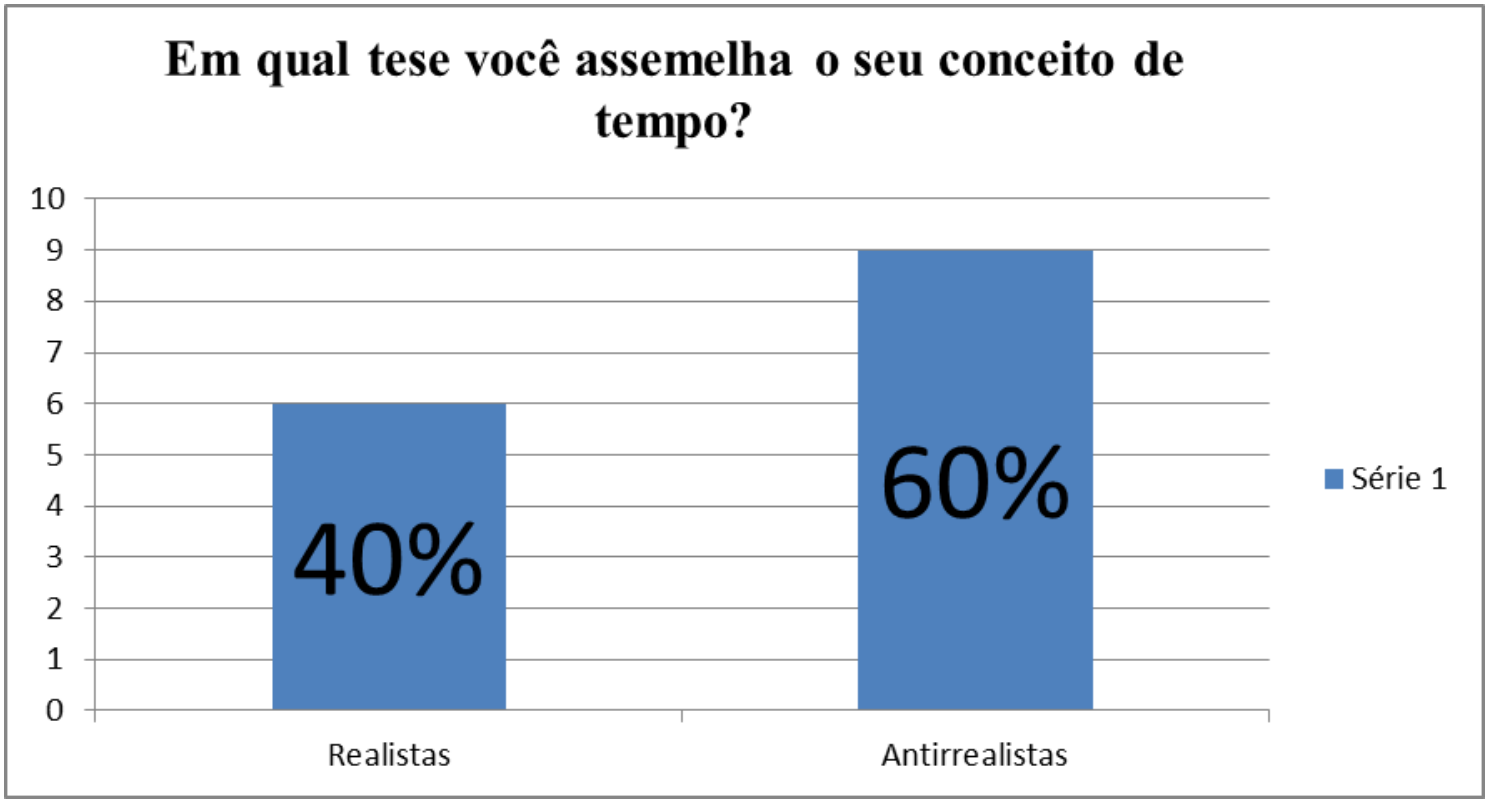

A segunda pergunta como já foi citada, tivemos os seguintes resultados:

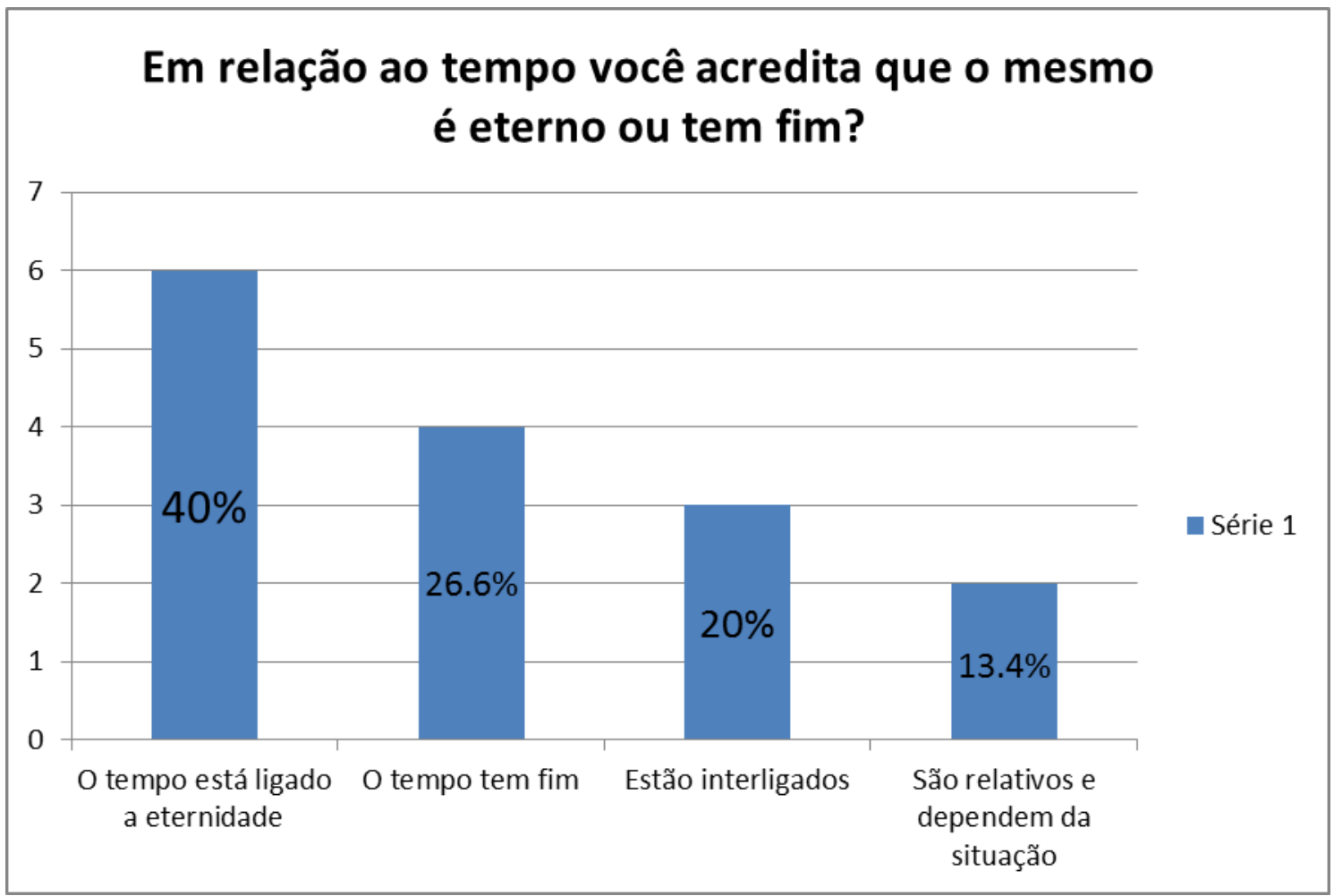

Na terceira pergunta, obtivemos os seguintes resultados: 


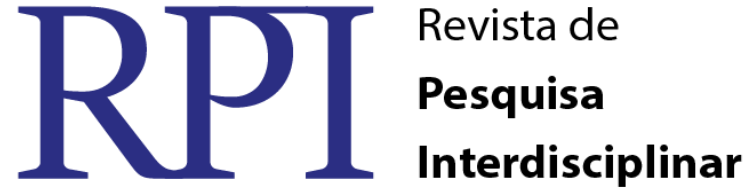

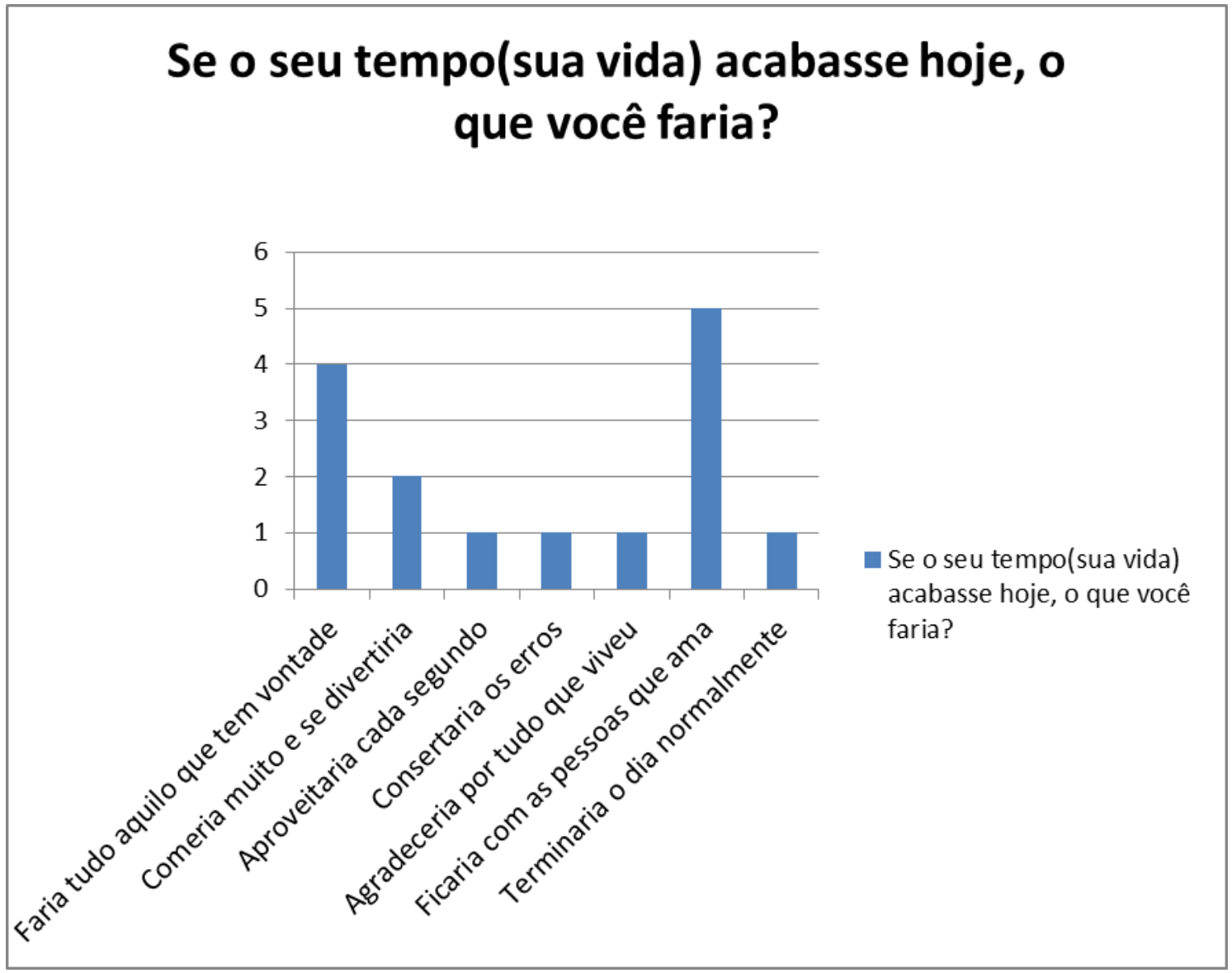

Tendo em vista os resultados obtidos nesta pequena pesquisa que contou com quinze entrevistados, é notório que na primeira pergunta a maioria concordou com os antirrealistas que dizem na sua tese que o tempo está ligado ao exterior. Na segunda pergunta a maioria concorda que o tempo está ligado a eternidade, então ambos concordam com Newton, e na terceira e última pergunta é perceptível as diferentes respostas, no qual todos os entrevistados demonstraram uma certa aflição ao responderem, pois mesmo sabendo que um dia seu tempo (sua vida) chegará ao fim, ainda não estão preparados para esse tal dia.

\section{CONCLUSÕES}

Portanto, considerando o que explanamos, ficou dito que a definição de tempo foi conceituada de formas diversas ao longo do tempo. Na filosofia antiga, posterior a dos présocráticos, foi tratado de Platão e Aristóteles, respectivamente explanando ambas as opiniões que se baseavam no movimento dos corpos e na existência do único ser inteligível capaz de compreender a numeração do tempo, que é a alma. Na filosofia Medieval foram que enfatizados os pensamentos de Santo Agostinho e de São Tomás de Aquino, eram baseados na criação de Deus e que até o tempo fora obra desta. Cabe salientar ainda, que mostremos que Santo Agostinho em sua filosofia defendia, sobretudo, o aspecto psicológico. Além disso, foi exposta a opinião de Isaac Newton com respeito ao assunto, isto é, suas críticas e assimilações das filosofias anteriores as suas. Também foi debatida a concepção do filósofo Husserl, que diz que o tempo é questão de consciência. Chegamos ao final do resumo expandido com a convicção que ainda nos dias atuais não se tem uma definição concreta e objetiva sobre o tempo e que assim como a teoria do gosto lá na estética, o tempo também depende de cada indivíduo e que ambos os assuntos são relativos e subjetivos. 


\section{$\mathrm{RPP}$}

\section{PALAVRAS-CHAVE:}

divindade. filosofias. mudança. relógio. tempo.

\section{REFERÊNCIAS}

AGOSTINHO, Santo bispo de Hipona. Confissões. Trad. J. Oliveira Santos et. al. São Paulo: Abril Cultural, 1987

ARISTÓTELES. Física. Trad. Guillermo R. de Echandía. Madrid: Editorial Gredos, 1995.

Blogger causos e filosofia, $\mathrm{O}$ que é tempo? Disponível em: <http://andersonfilos.blogspot.com.br/2010/05/o-que-e-o-tempo.html> acesso em 12 de novembro de 2016.

Blogger entre números e pensamentos, Realismo, Tomás de Aquino. Disponível em: <http:http://entrenumerosefundamentos.blogspot.com.br/2011/04/realismo-tomas-deaquino.html> Acesso em 11 de Novembro de 2016.

BORNHEIM, Gerd A. Os filósofos pré-socráticos. São Paulo: Cultrise, 1998.

CERVO, Amado Luiz; BERVAN, Pedro Alcino; SILVA, Roberto da. Metodologia Científica. São Paulo: Pearson Prentice Hall, 2007.

. Comentário ao Tratado da Trindade de Boécio. Tradução de Carlos Arthur do Nascimento. São Paulo, 1995.

EINSTEIN, Albert. Escritos de maturidade. Trad. Maria Luíza X. de A. Borges. Rio de Janeiro: Nova Fronteira, 1994.

GIL, Antonio Carlos. Como elaborar um projeto de pesquisa. São Paulo: Atlas, 2010. pp. 4363.

HAWKING, Stephen. Uma breve história no tempo. Trad. Maria Helena Torres. Rio de Janeiro: Rocco, 1996.

LAÊRTIOS, Diôgenes. Vidas e doutrinas de filósofos ilustres. Trad. Mário da Gama Kury. Brasília: UNB, 1997. pp. 283-321

LUCRÉCIO, Tito Caro. Da Natureza. Trad. Agostinho da Silva. São Paulo: Abril Cultural, 1973, pp. 31-53 (Os Pensadores).

NEWTON, Isaac ? Princípios matemáticos, Óptica e o peso e o equilíbrio dos fluidos. Trad. Carlos Lopes de Mattos e Pablo Ruben Mariconda. São PAULO: Abril Cultural.(coleção Os Pensadores)

O Ente e a Essência. Tradução de Carlos Arthur do Nascimento. Editora Vozes: Petrópolis, 1995.

PLATÃO. Timeu. Trad. Carlos Alberto. Belém: EDUFPA, 2001.

PRIGOGINE, Ylya. O fim das certezas: tempo, caos e a lei da natureza. Trad. Roberto Leal Ferreira. São Paulo: Ed. Universidade Estadual Paulista, 1996.

Questões Discutidas Sobre a Verdade. Trad. Luiz João Baraúna. São Paulo: Editora Abril, Cultural, 1979(coleção Os Pensadores). Suma Teológica. Tradução Alexandre Correia. São Paulo: Ed. Fac. de Filosofia Sedes Sapientiae, 1947.

Súmula contra os gentios. Trad. Luiz João Baraúna. São Paulo: Editora Abril, Cultural, 1979(coleção Os Pensadores).

- Teoria da relatividade. Trad. Carlos Almeida Pereira. Rio de Janeiro: Nova Fronteira, 1994.

TOMÁS DE AQUINO. Compêndio de Teologia. Trad. Luiz João Baraúna. São Paulo: Editora Abril, Cultural, 1979(coleção Os Pensadores). 


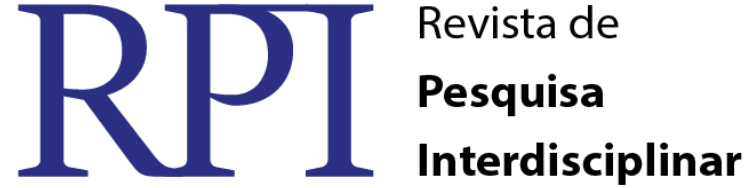

\section{A FELICIDADE E O SOFRIMENTO EM ARTHUR SCHOPENHAUER}

\author{
ÁREA TEMÁTICA: Ciências humanas e linguagens \\ Formato de apresentação do resumo: banner \\ MARIA EDUARDA OLIVEIRA RANGEL, estudante, ETSC-UFCG. \\ RICHÉLITA CHRISTIANE DUARTE DE SOUZA, estudante, ETSC-UFCG. \\ ANTUNES FERREIRA DA SILVA, mestre, ETSC-UFCG.
}

\section{INTRODUÇÃO}

"O sentido mais próximo e imediato da nossa vida é o sofrimento, e se não fosse assim, nossa existência seria o maior dos contrassensos, pois é um absurdo imaginar que a dor infinita, que nasce da necessidade essencial à vida, da qual o mundo está pleno, é meramente acidental e sem sentido. Nossa receptividade para a dor é quase infinita, mas o mesmo não ocorre com nossa receptividade para o prazer, que tem limites estreitos. É a infelicidade em geral que é a regra, embora a infelicidade individual apareça como exceção. "

A felicidade é inexistente. Apenas o sofrimento é sentido. A oposição à vontade é desagradável. Arthur Schopenhauer declara que o ser humano nunca está satisfeito com o que é ou com o que tem e é esse sentimento falho que traz toda a dor e sofrimento.

\section{OBJETIVO DO TRABALHO}

Reconhecer a quebra de paradigma entre o que é o bem e o mal em relação a felicidade e entender a necessidade do sofrimento na construção da mesma, cujas bases fazem alusão especialmente ao pessimismo schopenhaueriano.

\section{MÉTODOS}

A pesquisa aponta uma análise orientada por um estudo bibliográfico, utilizando os textos do filósofo Arthur Schopenhauer, sobretudo Da mortel Metafísica do amor/ Do sofrimento do mundo, assim como alguns comentadores referentes à temática. Deste modo, foi realizada uma sondagem do conteúdo visando formular as interpretações e fixar a autenticidade dos pensamentos propostos.

\section{RESULTADOS E DISCUSSÃO}

O sofrimento é o mal mais necessário para a existência humana e, portanto, o mal é algo positivo e o bem constitui o negativo - sendo o inverso do que a maioria das pessoas pensam -, porque a felicidade (o bem) nunca supera as expectativas, mas a dor (o mal) está sempre acima das mesmas. O fato observado é explicado pelo desejo e o tédio causarem o sofrimento. $\mathrm{O}$ desejo de possuir algo e a ansiedade adquirida geram desgaste emocional e após a realização do desejo unido ao tempo, o objeto irá se tornar entediante. A única felicidade existente é a do momento em que a vontade é saciada "a vontade é a essência íntima do mundo". De uma forma simplificada, é possível dizer que o tempo da felicidade é tão ínfimo que pode ser considerado como o período de ausência da infelicidade.

Trabalho, aflição, esforço e necessidade são pilares importantes na filosofia de Schopenhauer porque, esses sentimentos considerados angustiantes para a humanidade, fazem parte do curso da vida já que é preciso se fortalecer e lutar para possuir uma vida significante e não, apenas, miserável. Se os desejos fossem facilmente realizados, não existiria razão para 


\section{$\mathrm{RPP}$}

o indivíduo gastar seu tempo. Consequentemente, a vida tornar-se-ia entediante, podendo levar uma parte da população ao suicídio e a outra a provocar guerras, massacres e assassinatos, trazendo agonia e dor ao mundo mais do que já é presente.

É possível perceber que o sofrimento provém de o homem pensar excessivamente em tudo, seja no futuro ou, principalmente, no passado. Essas ações geram uma carga de aflição, preocupação e esperança intensas criando, assim, uma complexidade que é perceptiva quando se compara as emoções do homem as dos animais, que apresentam uma invejável despreocupação e placidez, pois esses não têm a autoconsciência de refletir sobre todas as suas ações.

"Ninguém é muito invejável, mas muito são os muito deploráveis", o ser humano, para não se sentir tão infeliz por ser infeliz, compara sua vida com a de outros seres cujas vidas são piores e, isso, os fazem se sentir mais aprazidos com a sua própria funcionalidade no meio.

\section{CONCLUSÕES}

Arthur Schopenhauer ratifica, então, a sua teoria no contraste entre a negatividade do bem-estar e a positividade da dor. Consequentemente, a vida não deve ser apreciada com base nos prazeres e sim na ausência do sofrimento, pois a força motriz da busca ou fuga da felicidade ou infelicidade são o deleite e a angústia humana.

PALAVRAS-CHAVE: Felicidade. Necessário. Schopenhauer. Sofrimento.

\section{REFERÊNCIAS}

SCHOPENHAUER, Arthur. Da morte/ Metafísica do amor/ Do sofrimento do mundo. 1 . ed. São Paulo, 2002. 


\title{
COMO ENTENDER A FILOSOFIA CLÍNICA
}

\author{
ÁREA TEMÁTICA: Ciências humanas e linguagens \\ Exposição com banner
}

BEATRIZ SOARES SILVA, estudante do ensino médio, ETSC-UFCG ANTUNES FERREIRA SILVA, Mestre em filosofia, ETSC-UFCG

\section{INTRODUÇÃO}

A Filosofia Clínica é a parte da filosofia que irá ser utilizada como metodologia para ser aplicado por filósofos especializados para tratar as dores da alma humana. Entretanto, a filosofia desde seu nascimento é uma forma de pensamento organizada, que exige profundidade, buscando origens, em que se faz a partir da compreensão dos contextos nos quais insere. Nesse momento se ver que a filosofia clínica nasceu em busca de respostas que não são mais objetivas como dizia Packter, mas sim como entender os problemas do outro ser e buscar uma solução para que seja então amenizado. Ao mesmo tempo podemos dizer que ela surge do encontro entre diferentes perspectivas, diferentes maneiras de entender o mundo. $\mathrm{E}$ assim permanece em toda a sua história tendendo a um movimento pendular entre diferentes abordagens para as questões humanas.

\section{OBJETIVO DO TRABALHO}

Reconhecer os conflitos que uma pessoa ou partilhante traz consigo e trabalhar a partir de mecanismos do pensamento humano através do recurso à psicoterapia individualista para amenizá-los.

\section{MATERIAIS E MÉTODOS}

A pesquisa apresentada norteou um estudo bibliográfico, em sites, utilizando textos como Filosofia no divã e Como ler a filosofia clínica: prática da autonomia do pensamento. Assim, foi efetuado um estudo para entender como se deu a proposta de Lúcio Packter e mostrar a metodologia filosófica para tratar questões cotidianas e então refletir sobre nossas formas de vida.

\section{RESULTADOS E DISCUSSÃO}

Desde a Grécia Antiga, os filósofos eram especialistas em amenizar males da alma. Por exemplo, Sócrates, costumava ir às praças e conversar com as pessoas, em busca de um aconselhamento para os problemas pessoais. Ou seja, mostrava interesse na problemática do homem, no qual, levava ao interlocutor, por meio de perguntas resolverem tal situação de sua vida. Esse uso prático da filosofia como terapia foi resgatado por Lúcio Packter em 1980, quando ele não gostava das respostas objetivas, então buscou por meio de experiências que estavam acontecendo na Europa entender o que era a filosofia clínica. Retornando ao Brasil fundou o Instituto Packter. Assim, em seu livro Filosofia clínica Lúcio Packter afirmou: “A primeira lição fundamental na filosofia clínica é aquilo que uma pessoa sente, vive, afirma, imagina, faz, independente de ser compartilhada com outras pessoas, de ser aceito, criticado, ironizado ou proibido". Neste tipo de terapia trabalha-se somente com a mente aonde o partilhante irá relatar seus problemas, suas histórias depois disso o profissional juntamente 


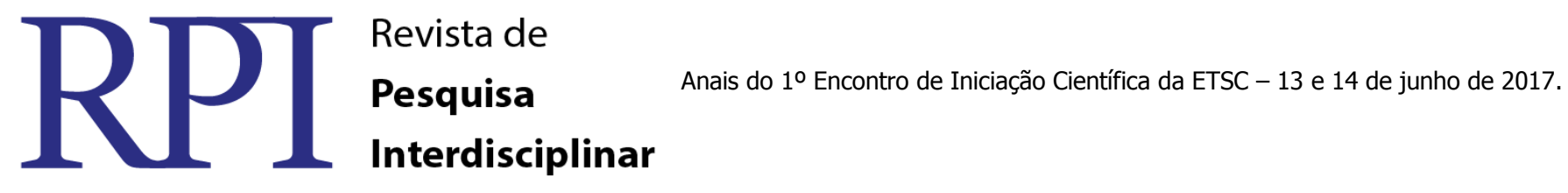

com a pessoa buscarão soluções para então resolver o problema seja este, com o tempo, com o seu dia a dia, as dificuldades.

\section{CONCLUSÕES}

O devido projeto teve o objetivo de frisar como nasceu a Filosofia clínica por meio de experimentos de pesquisas em textos como já mencionados. Desta forma, esta aborda assuntos como a lógica formal (conceitos, juízos, raciocínios, leis do pensamento e a teoria do conhecimento). Contudo, a Filosofia Clínica trabalha com as pessoas e o problema a ser resolvido.

PALAVRAS-CHAVE: Clínica. Pensamento. Soluções.

\section{REFERÊNCIAS}

AIUB, Monica. Como ler a filosofia clínica. Editora Paulus.

Disponível em: <http://filosofia.uol.com.br/filosofia/ideologia-sabedoria/22/artigo1634981.asp> Acesso em 14/11/2016.

RAINHO, João Marcos. Filósofos no Divã. Revista eletrônica de filosofia. 


\title{
Interdisciplinar
}

\section{FILOSOFIA DE ARTHUR SHOPENHAUER E BERTRAND RUSSELL SOBRE O CONCEITO DE FELICIDADE PARA O $1^{\circ}$ EIC/ETSC 2016}

\author{
ÁREA TEMÁTICA: O conceito de felicidade (exposição em banner)
}

MAELY MOREIRA DE ABRANTES, aluna do ensino médio, ETSC-UFCG. ANTUNES FERREIRA DA SILVA, Professor Mestre em Filosofia, ETSC-UFCG.

\section{INTRODUÇÃO}

Arthur Schopenhauer foi um brilhante filósofo alemão, profundamente engenhoso e com grande influência durante a segunda metade do século XIX e começo do $X X$. Ele se caracterizou por uma posição nitidamente pessimista perante o mundo e a vida. Schopenhauer desenvolveu um conceito de felicidade que tinha por fundamento a prudência e a ética. Dentro do seu pensamento a felicidade tem mais a ver com a paz interior do que com a alegria.

Bertrand Arthur Millian Russell (1872-1970), filósofo e matemático inglês, para ele a felicidade usualmente é entendida de duas formas: na primeira a felicidade é compreendida como acessível a todos; enquanto na segunda é acessível somente àqueles que sabem ler e escrever. A tentativa do filósofo é investigar o fundamento da felicidade para construir algo que seja aplicável a todos os homens. Então, verifica que os entendimentos acerca da felicidade, que usualmente são considerados, são proposições contraditórias. Na primeira, há a defesa de que todos podem ser felizes; na segunda, há a defesa que nem todos podem ser felizes, apenas os letrados. Então, o filósofo busca o fundamento da felicidade que possa ser justificável e aplicável em todos.

\section{OBJETIVO DO TRABALHO}

Compreender as distinções instituídas no que concerne o conceito de felicidade, através das considerações feitas pelos filósofos, Arthur Schopenhauer Bertrand Russell.

\section{MATERIAIS E MÉTODOS}

A presente pesquisa designa uma análise norteada por um estudo bibliográfico, utilizando os textos dos filósofos mencionados, e o uso de sites que possuem fragmentos importantes do conteúdo em questão. Deste modo, foi realizada a prospecção do conteúdo visando fomentar as interpretações e efetivar a autenticidade dos pensamentos levantados.

\section{RESULTADOS E DISCUSSÃO}

O que pode - se dizer e entender sobre a filosofia de Schopenhauer sobre o tema felicidade. Ele afirma que a essência do mundo esta nele, mas naquilo que condiciona seu aspecto exterior, na coisa em si do mundo, a qual denomina 'vontade'. Por desejar sempre, mais, passaria a ser motivo de insatisfações constantes o que resulta em sofrimento.

A vontade é o principio fundamental da natureza, o resultado de todas as forças representadas nos fenômenos, no instinto sexual, no crescimento das plantas, nas pedras, enfim, no perpétuo movimento de vida e de morte. Da vontade da vida provém todo sofrimento, que é intrínseco à existência. Somente se aspira àquilo que não se tem: da falta do 


\section{$1 \begin{aligned} & \text { Revista de } \\ & \text { Pesquisa } \\ & \text { Interdisciplinar }\end{aligned}$}

objeto desejado segue-se o sofrimento. Contudo o prazer obtido pela satisfação do desejo momentâneo, pois este abrirá caminho para novos desejos, sempre obstados, sempre em luta para obter sua satisfação. Que Schopenhauer cita: 'A felicidade não é se senão o momento fugaz da ausência da felicidade'.

Esse pensamento pessimista vem da experiência que ele teve com sua família, principalmente por causa do mau relacionamento com a sua mãe. Schopenhauer afirma que o sentido mais próximo e imediato da nossa vida é o sofrimento, porque se não fosse assim nossa existência seria o maior dos contra sensos, pois é um absurdo imaginar que a dor infinita, que nasce da necessidade essencial à vida, da qual o mundo está pleno, é meramente acidental e sem sentido. Nossa receptividade para a dor é quase infinita, mas o mesmo não ocorre com nossa receptividade para o prazer, que tem limites estreitos. É a infelicidade em geral que é a regra, embora a infelicidade individual apareça como exceção.

Então junto com o sofrimento encontra-se o tédio, o qual os animais não conhecem, por mais inteligentes e domesticados que sejam. Já no que se diz respeito aos homens, esse sentimento é um verdadeiro tormento, pois sem dúvida, a necessidade e o tédio constituem os dois polos da vida humana. Com isso para fechar o estudo nas ideias de Schopenhauer podese dizer que: 'A infelicidade é a norma, é a regra geral'.

Para Bertrand Russell existem dois tipos de felicidade, embora, naturalmente, haja graus intermediários. Os dois tipos de felicidade são: normal ou fantasia, animal ou espiritual, do coração ou da cabeça. A diferença entre esses dois tipos é que um deles se acha ao alcance de qualquer ser humano e que o outro só pode ser atingido por aqueles que sabem ler e escrever.

Contudo a diferença marcada pela educação só é percebida nas atividades que permitem obter tais prazeres. O prazer de conseguir algo implica a necessidade de existirem no início dificuldades que nos levem a duvidar da vitória, embora no final quase sempre a alcancemos. O homem que se subestima é sempre surpreendido por seus êxitos, ao passo que o homem que se superestima não chega a entender muito bem seus fracassos. O primeiro tipo de surpresa é agradável, o segundo, desagradável. Com isso entende-se que se a pessoa acreditar e gostar do que faz irá se sentir capaz e também feliz.

Na sua obra Russell fala acerca do cinismo que com tanta frequência observa-se nos jovens com estudo superior é resultado da combinação do comodismo com a impotência. A impotência traz à pessoa a sensação de que nada vale a pena, e o comodismo torna suportável a dor desse sentimento. A felicidade do cínico ou do revolucionário depende do curso que tomem os assuntos públicos, mas o mais plausível é que, enquanto estão atuando, gozam de mais felicidade do que aquele que, além de cínico, é acomodado.

Retomando o assunto em relação ao trabalho pode-se dizer que o trabalho está ao alcance de qualquer pessoa que possa desenvolver uma habilidade especializada, sempre que obtenha satisfação do exercício de sua habilidade sem exigir o aplauso do mundo. A camaradagem e a cooperação são elementos imprescindíveis à felicidade do homem normal e bem mais fáceis de encontrar nas indústrias do que na agricultura. Para um grande número de pessoas, acreditar numa causa é uma fonte de felicidade. É fácil se encontrar uma causa que não seja tão fantástica, e aqueles que sentem um interesse por essa causa terão encontrado uma ocupação pra seu tempo livre e um antídoto infalível contra a sensação de vida vazia. Não muito diferente da devoção às causas menores é nos deixarmos absorver por um hobby.

Uma fonte de felicidade básica, mas antes um meio de escapar à realidade, de esquecer por instantes alguma dor muito difícil de enfrentar. A felicidade básica depende sobretudo do que poderíamos chamar de interesse amistoso pelas pessoas e pelas coisas. $\mathrm{O}$ interesse amistoso pelas pessoas é uma modalidade de afeto, mas não de tipo possesivo, que sempre busca uma resposta empática. Esta modalidade é, não raro, causa da infelicidade. 
Uma pessoa pode sentir por certas coisas um interesse que não é amisto, mas sim hostil. O mundo é enorme e nossas faculdades são limitadas. Se toda a felicidade depende exclusivamente de nossas circunstâncias pessoais, o mais plausível é que estejamos pedindo à vida mais do que ela pode dar. O segredo da felicidade é este: que seus interesses sejam os mais amplos possíveis e que suas reações às coisas e às pessoas que lhe interessam tornam-se, na medida do possível, amistosas e não hostis.

\section{CONCLUSÕES}

A partir do que foi estudado do conceito de felicidade tendo em vista a visão de Schopenhauer, por mais que seja pessimista se vê uma verdade através do que foi citado durante o estudo. Podendo concluir que todos os seres sofrem para alcançar um objetivo, quem a partir do momento que conseguem, elas têm como recompensa um pequeno intervalo de tempo, ou seja, de felicidade. Após isso surge uma nova inquietação pra que se tenha uma nova busca alcançar novamente a felicidade.

No que diz respeito ao pensamento de Russell, ele afirma que sem a renuncia não há felicidade, a partir do momento que ocorre a renuncia encontra-se a felicidade. Mas pode existir casos que não ocorram à privação, e que se consiga obter a felicidade. Também relata que tudo que é adquirido com facilidade, após isso a pessoa só alcança o desejo moderado, não se sente totalmente realizado. Pois sem isso, o ser poderia ter tudo, mas ainda se sentiria infeliz, não seria totalmente realizado, sempre irá faltar alguma coisa, para ser feliz.

PALAVRAS-CHAVE: Busca, felicidade, infelicidade, Schopenhauer, Russell.

\section{REFERÊNCIAS}

Centro Educacional Frei Seráfico (CEFS), 15,2009, da cidade de São João del-Rei, MG. Disponível em: 〈http://www.sintrafesc.org.br/pag/view_artigo.php?id=2143/>. Acesso em: 14 nov. 2016.

RUSSELL, Bertrand. A Conquista da Felicidade. Tradução José Antônio Machado. Lisboa: Guimarães, s/d.

Parerga e Paralipomena ("Contribuições à Doutrina do Sofrimento do mundo"), in Vol. Schopenhauer, Col. Os Pensadores. Trad. de Wolgfgang Leo Maar. São Paulo: Nova Cultural, 1999. 


\title{
Registros rupestres em comunidade rural do alto sertão paraibano
}

\author{
Roberto Ramon Queiroz de Assis ${ }^{1}$
}

\section{INTRODUÇÃO}

O nordeste brasileiro é uma região privilegiada em questões arqueológicas, constituída por enumero sítios, que se tornam verdadeiros patrimônios históricos que norteiam grandes estudos sobre a povoação e cultura do homem na América, os sítios arqueológicos mais ricos em gravuras e pinturas que temos atualmente no mundo se encontram no parque nacional da serra da capivara no Piauí. (NEGREIROS, 2011)

O registro rupestre ocorre em todo o nordeste brasileiro, uma parcela dos seus sítios arqueológicos encontra-se inexploráveis por pesquisadores; na sua grande maioria como o caso dos sítios que iremos estudar, são predominantemente de pinturas e gravuras rupestres, segundo Negreiros(2011) caracteriza como:

As pinturas e gravuras rupestres compõem um testemunho gráfico da presença humana pré-histórica no continente americano. Representam fonte de dados antropológicos, por serem apresentações gráficas das representações sociais dos grupos étnicos que as realizaram. Podem ser explicadas como símbolos de ideias externadas pelos grupos responsáveis pela sua elaboração. (NEGREIROS, 2011. P, 13).

Os testemunhos deixados pelos grupos humanos pré-históricos em forma de pintura ou gravura remontam características das sociedades que ali passou, nessas representações muitas vezes expressa senas do cotidiano, ligado as suas atividades diárias e elementos da natureza que o cerca. Com essas pinturas ou gravuras podemos afirmar que em perdidos remotos nosso continente foi abitado por humanos.

Os estudos que são voltados para a pintura rupestre são mais comuns, pela facilidade de encontrar esses registros, como foi falado, é menos comum encontrar gravuras e as pinturas por conter elementos de reconhecimento torna seus estudos mais avançados (NEGREIROS 2011).

\section{MATERIAIS E MÉTODOS}

Trata-se de um estudo piloto de caráter exploratório com abordagem descritiva observacional onde foram estudados os sítios arqueológicos da Pedra do Sino e Pedra da Canoa, atentando aos registros rupestres e meio em que se encontram; de forma oral foram coletadas informações através de marcadores subjetivos.

\section{RESULTADOS E DISCUSSÃO}

\footnotetext{
${ }^{1}$ Graduando em licenciatura plena em historia pela Universidade Federal de Campina Grande, Cajazeiras PB. roberto.ramon9@gmail.com
}

RPI Revista de Pesquisa Interdisciplinar, Cajazeiras, v. 2, Edição Especial, 2017. 


\section{$\mathrm{RPP}$}

Os sitos arqueológicos estão localizados na zona rural da cidade São José de Piranhas no interior paraibano na comunidade Braga velho, o acesso se dá pela cidade de Monte Horebe-Pb em torno de 10 km; a distância existente entra a Pedra do Sino e a Pedra da Canoa

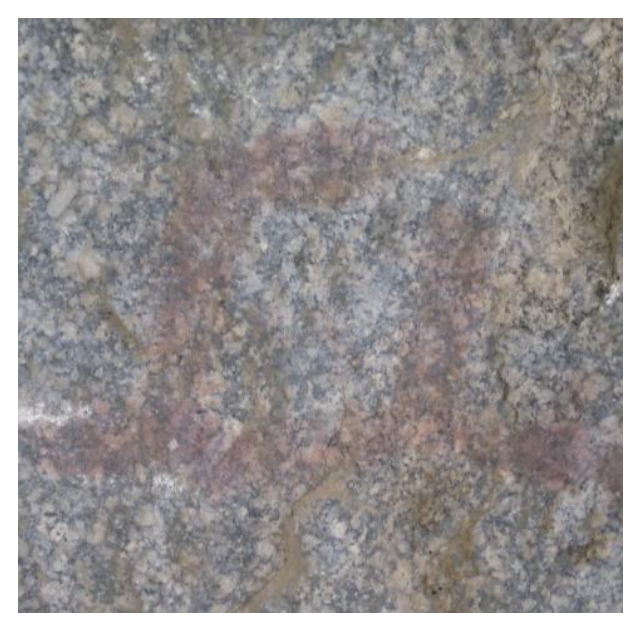
é de aproximadamente 400 metros em linha reta.

estudos pilotos como esse que iremos trabalhar, por tanto os sítios não se encontram catalogados na base de dados da Sociedade Paraibana de Arqueologia (SPA). A não catalogação de sítios dificulta o interesse de pesquisadores em estudá-los pela falta de informações ou por puro desconhecimento do local.

Um complexo arqueológico pode ser notado nessa região, já que em comunidades próximas também existe tais registros. Durante as obras da transposição do Rio são Francisco foram identificados novos registros rupestres. (sitar a matéria sítios morros)

O sitio arqueológico tem características que formam a tradição agreste, com a presença de grafismos de grandes tamanhos, isolados e que não formam cenas, com imagens semelhantes a antropomorfos e zoomorfos. Localizado em uma região serrana que se caracteriza por muitos afloramentos rochosos de grande extensão, que poderiam ser locais de acampamento para os povos pré-históricos, pois formam abrigos que podem servir de habitação. Entre as características do sitio está à vegetação em seu entorno. Predominantemente, a vegetação nos arredores do sitio é correspondente ao bioma Caatinga, que é característica da região nordeste brasileira.

Os registros rupestres não são preservados e não há uma preocupação da população em manter estes registros conservados. Devido ao tempo e a exposição aos efeitos da natureza os grafismos estão perdendo a tonalidade e há uma degradação das figuras, pois uma parte das rochas do paredão caiu e os registros rupestres ficaram embaixo das pedras. Com o passar do tempo mais pedras podem vir a cair e as figuras vão se apagando aos poucos. A Pedra da Canoa é afastada das residências da comunidade e é de difícil acesso e para chegar ao local é necessário percorrer certa distância dentro da mata e escalar algumas pedras para poder chegar ao local; já a pedra do sino é de fácil acesso.

Os registros rupestres encontrados nos sítios arqueológicos estão dispostos em paredão de rocha granítica, a cor predominante e a única observada e a cor vermelha, que possivelmente foi feita com oxido de ferro pela capacidade de tingimento em rochas de grandes cristais, outro material não proporcionaria o mesmo resultado.

Os registros rupestres encontrados são vazados, cheios, emblemáticos e geométricos, representam cenas estáticas, em especial na Pedra da Canoa os registros possuem elementos de reconhecimento Antropomorfo e Zoomorfos, sendo os Antropomorfos de menor tamanho.Imagem: Grafismo Antropomorfo, estático com preenchimento cheio. Pedra da Canoa. 


\section{$\mathrm{RPP}$}

Imagem: Grafismo Zoomorfos, estático com preenchimento cheio. Pedra da Canoa.

Os registros na Pedra do Sino não possuem elementos de reconhecimento (Zoomorfos, Antropomorfos ou Fitomorfos) são puros, apenas dois grafismos com tendência ao geometrismo. De forma geral os grafismos são de grande tamanho, representados por linhas sinuosas, alguns grafismos se estendem por todo o paredão de forma contínua, algumas se unem.

Imagem: Grafismos geométricos, vazado, Imagem: Grafismos emblemáticos, com traçado por linha sinuosa. Pedra do Sino. linhas sinuosas e vazadas e preenchidas. Pedra do Sino.

Imagem: Grafismo grosseiro, formado linhas paralelas. Pedra do Sino.
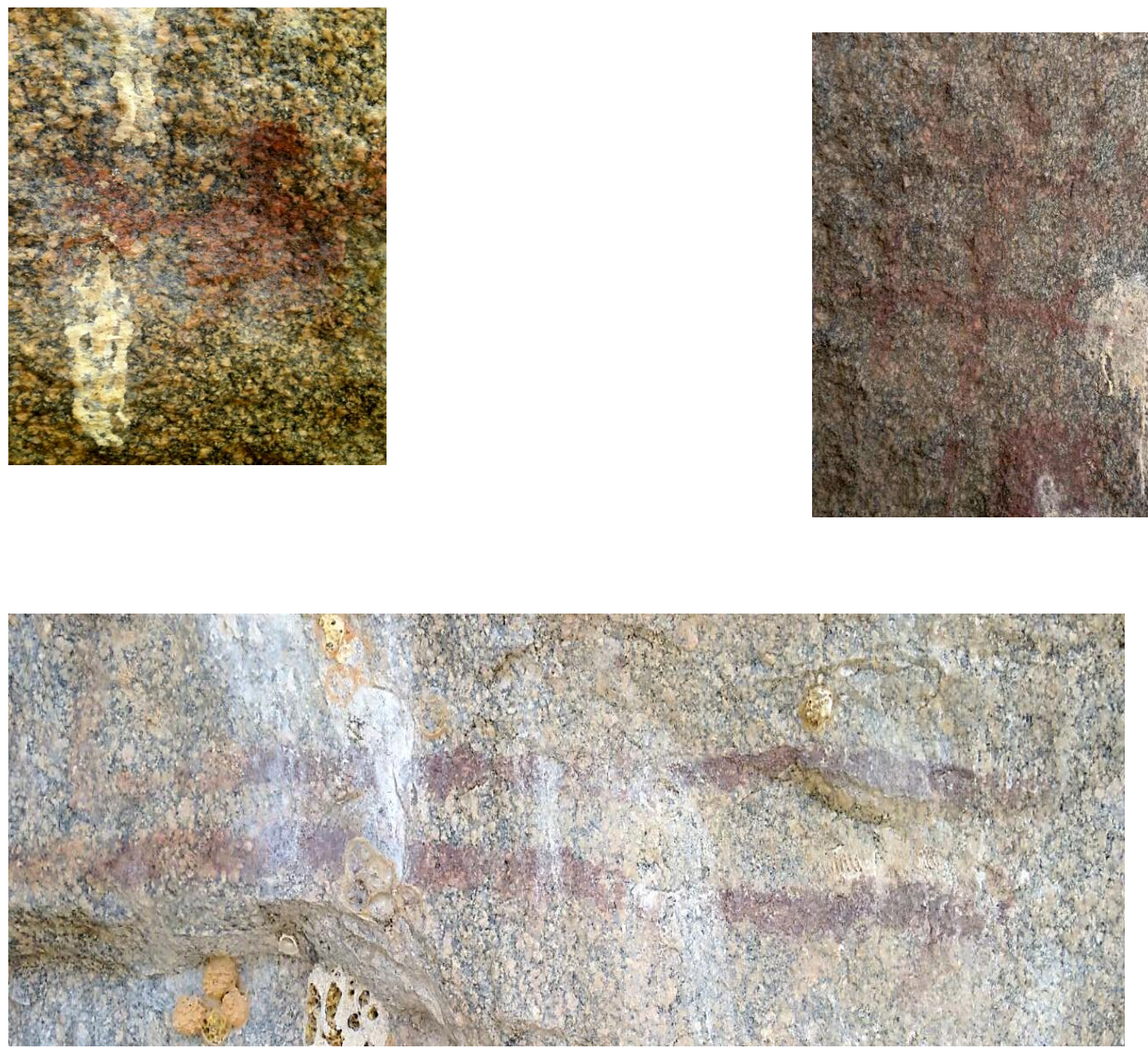


\section{$\int \begin{aligned} & \text { Revista de } \\ & \text { Pesquisa } \\ & \text { Interdisciplinar }\end{aligned}$}

É notório no Cenário nacional um descaso com os sítios arqueológicos onde, não existem políticas públicas voltadas para preservação patrimonial arqueológica; a ausência de tais políticas implica a depredação dos sítios, ação da própria sociedade que por desconhecimento da sua importância faz uso inadequado; um dos reflexos do não cuidado segundo Joachim Hermann (1989) e que a depredação pode gerar falhas na transmissão e compreensão desses conhecimentos das sociedades passadas, por tais monumentos arqueológicos serem fontes de transmissão do conhecimento pré-histórico, sua depredação pode implicar em perdas históricas bem como material e cultural da sociedade.

Os sítios arqueológicos visitados o que mais sofreu depredação foi a Pedra do Sino, podemos atribuir como causa-efeito uma ação humana ligada a práticas da agricultura local como as queimadas que aceleram a ação do intemperismo, ocasionado uma queda dos painéis que servem de suporte para os registros, na pedra do sino foram encontrados lajedos caídos e por baixo deles existem registros; outros fatores como o fácil acesso e ser menos povoado o local trouxe ponto de encontro entre jovens que passam por ali e deixam marcas nas pedras e lixo. Durante a nossa pesquisa de campo foi notado o desconhecimento da população sobre a importância da preservação das rochas que contém os registros e da mata que cerca os locais; como também ficou evidente que para a população os registros não exercem importância. Uma boa parte da população sabe da existência das pedras, mas devido a falta de informação não tem consciência de sua importância histórica, não entendem o contexto histórico que representa um registro rupestre e acham que o motivo de ir visitantes ao local é porque as pedras são bonitas e a vista é boa para tirar fotografias.

\section{CONCLUSÕES}

O desconhecimento da importância histórica e cultural dos sítios arqueológicos como fonte para compreensão antropológica da nossa sociedade deixa esse patrimônio ao descaso, os sítios arqueológicos são fontes riquíssimas por conter registros que remontam a cultura étnica de povos pré-históricos que habitaram nessas regiões e possibilita à compreensão da nossa sociedade atual, compreender nossa origem é uma necessidade dos historiadores, deter mão de estudos arqueológicos tornasse uma fonte rica, e a preservação é determinante para estudos.

De acordo com o estudo de campo realizado pela equipe no sitio Braga velho, município de são José de piranhas interior do estado paraibano, os resultados obtidos por nossa equipe foi de que o sítio arqueológico daquela região pertence à tradição agreste, pois trazem consigo as características que a descrevem.

\section{REFERÊNCIAS}

1. NEGREIROS, Caroline Siqueira de. Identificação da Técnica de Execução das Gravuras Rupestres do Sítio Toca dos Oitenta - Parque Nacional Serra da Capivara/PI/ Caroline Siqueira de Negreiros-São Raimundo Nonato, 2010.

2. Hermann, J. 1989. World Archaeology - The world's cultural heritage. In Archaeological Heritage Management in the Modern World, H.F. Cleere (ed.), 30-37. London: Unwin Hyman. 


\title{
Interdisciplinar
}

\section{IDENTIDADE PESSOAL NA FILOSOFIA CLÍNICA}

\author{
ÁREA TEMÁTICA: Filosofia Clínica \\ VIRNA MENEZES ROLIM, estudante, ETSC.UFCG. \\ ANTUNES FERREIRA DA SILVA, mestre, ETSC.UFCG.
}

\section{INTRODUÇÃO}

O debate sobre a identidade pessoal ao longo do tempo, ou seja, explicar como uma pessoa permanece a mesma em tempos diferentes de sua vida, se estende a outros campos do saber, como na neurologia, biotecnologia e na neurociência. Várias foram às condições necessárias e suficientes que serviriam de critérios para a construção de uma 'identidade pessoal' que auxiliaria o filósofo clínico ao encontro da mesma no partilhante. John Locke propôs a memória como fundamento de existência desse sentimento de unidade pessoal; Theodore Skider considera a identidade numérica como a questão da identidade pessoal; Costa diz que "os critérios para essa identificação são físicos, mentais e mistos."; Paul Ricoeur aborda a proposta da unidade da pessa através da mediação da narrativa. Veremos como esses conceitos foram importantes na construção do processo terapêutico da Filosofia Clínica.

\section{OBJETIVO DO TRABALHO}

Nesse projeto veremos como a filosofia clínica se insere no mundo existencial do partilhante, mostrar a Estrutura de Pensamento como uma identidade pessoal, da maneira de Lúcio Packter, idealizador da Filosofia Clínica.

\section{MATERIAIS E MÉTODOS}

O projeto de pesquisa constituiu uma observação embasada por um estudo bibliográfico, utilizando os textos sobre os assuntos abordados, sobretudo na revista Ciência e Vida: Filosofia Especial, assim como alguns filósofos relacionados à temática. Deste modo, foi realizada a análise do conteúdo visando acrescentar as interpretações e garantir a autenticidade dos pensamentos abordados.

\section{RESULTADOS E DISCUSSÃO}

A procura humana pela identidade pessoal tem levado a instigar o pensamento filosófico e outros campos da ciência. Este é, sem dúvida, um tema da modernidade, mas já foi, de certo modo, ainda que insuficientemente, abordado, tanto por Platão tanto por Boécio. Foi com John Locke que esse tema ganhou devida notoriedade, colocou em pauta que não basta sabermos que temos uma identidade pessoal, mas também levantar o tema e questionar as pertinências que são obstáculos a sua definição. O único questionamento que Locke faz é saber o que é que faz com que uma pessoa, posto que as suas mudanças físicas e psicológicas constantes, continue sendo a mesma pessoa ao longo da passagem do tempo e das alterações dos seus predicados? O que permanece de modo a preservar a nossa identidade pessoal? Quais são os critérios que definem a identidade de um indivíduo? Segundo Locke, algumas 


\section{$\int\left[\begin{array}{l}\text { Revista de } \\ \text { Pesquisa } \\ \text { Interdisciplinar }\end{array}\right.$}

das dificuldades com a definição de uma identidade individual surgiram por causa de uma confusão entre os vários termos usados na abordagem deste tema, em particular o uso da palavra 'identidade'. O filósofo inglês começa a sua investigação ao abordar o critério corporal. "a sua identidade não depende de uma massa das mesmas partículas, mas de outra coisa qualquer, visto que nelas a variação de grandes quantidades de massa não modifica a sua identidade", assim ele concluiu que o critério corporal não é suficiente, manifestamos alterações exteriores e interiores. A identidade pessoal foi então definida por Locke, como algo que está dependente da consciência, pois é preciso que uma pessoa se identifique com o seu corpo e com os seus estados mentais de modo a reconhecer que são seus. Não podemos basear-nos apenas na continuidade das nossas partes corporais, como já foi mencionado, porque tal não garante que estejamos em face da mesma pessoa. Mas a consciência de si próprio está intrinsecamente dependente do elemento da memória. Ora, a memória destaca-se porque só ela pode permitir o reconhecimento contínuo de uma pessoa que se identifica com ações passadas e que pode ser considerada responsável pelas ações que praticou. Esta dependência da consciência em relação à memória levanta inúmeras dificuldades porque não temos uma recordação total, absoluta de todas as nossas experiências vividas.

A tese de Locke suscita várias dúvidas, como por exemplo, Thomas Reid critica o critério mnésico, "nos confrontaríamos com o absurdo de existirem múltiplas pessoas no mesmo individuo, visto ser impossível a um ser humano preservar as mesmas recordações em todos os momentos da vida.", ou seja, ele mostra que a memória, supõe a identidade pessoal.

Theodore Skider fala que a identidade numérica, saber o que torna as pessoas numericamente idênticas ao longo do tempo, é considerada como a questão da identidade pessoal.

Costa propõe que os critérios são físicos, como a continuidade de um corpo, porém um cadáver n seria uma pessoa, defende a ideia de quem "alguma espécie de permanência física é condição necessária para a identidade pessoal, embora não seja a condição suficiente"; mentais, como eventos "autobiograficamente experienciados", como diz Locke, porém o critério da memória seria mais um sintoma que uma condição; mistos, juntando os mentais mais os físicos com alguns componentes similares.

Paul Ricoeur, fundamentando-se nos registros da narrativa de ficção e de literatura, propôs abordar o problema da unidade da pessoa através da mediação da narrativa, como a vida das pessoas está submetida ao tempo, que promove a mudança dos predicados físicos e mentais, fica impossível identificar como uma pessoa pode se conhecer em momentos distintos. O que está em causa na identidade da pessoa não é tanto a mesmidade, mas também a ipseidade, seria aquilo que caracteriza o indivíduo como ser único, singular, como nenhum outro é. Para isso é necessário às narrativas e as promessas. As narrativas seriam a história de vida contada pelo indivíduo e que o distinguia de todos os demais, enquanto as promessas seriam a junção entre a fala e a atividade correspondente. Nesta última teríamos como conhecer o indivíduo pela maneira como fala, sobre o que fala, sobre a relevância dessa e o cumprimento.

O filósofo e professor Lúcio Packter idealizou a Estrutura de Pensamento (o jeito existencial da pessoa), como identidade narrativa, como critério mental e enquanto critério físico, a qual é exigida a narrativa da historicidade da pessoa para a metodologia utilizada na Filosofia Clínica. A partir da Colheita Categorial dessa narrativa, os quais leva o filósofo clínico ao acesso ao mundo existencial do partilhante, repõe a privacidade dessa pessoa e o espaço sócio-histórico, cultural, corporal e vivencial nos seus endereços existenciais, objetivos e subjetivos. Essa Estrutura de Pensamento pode ser uma resposta e uma proposta ao problema da identidade pessoal a partir de Locke. Assim, o Filósofo Clínico considera cada pessoa única, com uma Estrutura de Pensamento individual e, portanto, aplicará 
procedimentos clínicos exclusivos conforme as características daquela Estrutura de Pensamento.

\section{CONCLUSÕES}

A filosofia clínica considera cada pessoa singular, com uma Estrutura de Pensamento diferente, e, portanto aplica procedimentos clínicos individuais conforme a sua Colheita Categorial. A importância desse projeto se deve a uma resposta pela nossa busca humana por uma identidade social, a quem nos referimos quando usamos a palavra "eu", a resposta para o que possibilita dizer que "eu sou eu", e como a filosofia clínica se insere nesse contexto. $\mathrm{O}$ ponto em comum entre o desenvolvimento da identidade pessoal e as possibilidades clínicas de acesso ao mundo existencial da pessoa.

PALAVRAS-CHAVE: Critério. Estrutura de Pensamento. Locke. Lúcio Packter.

\section{REFERÊNCIAS}

SOARES, Sebastião. O dito ser. Revista Ciência\&Vida; Filosofia Especial; Filosofia Clínica.

CORREIA, Carlos João. A identidade narrativa e o problema da identidade pessoal. Tradução comentada de "L'identité Narrative" de Paul Ricoeur. Disponível na internet via

$<$ http://www.porta33.com/eventos/content_eventos/Identidade(s)/_pdf/Paul_Ricoeur_A\%20I DENTIDADE_NARRATIVA.pdf> Arquivo capturado em 15 de nov. 2016

LIMA, Fábio de. Mesmidade e Ipseidade. Disponível na internet via <http://universodesofos.blogspot.com.br/2009/11/mesmidade-e-ipseidade.html > Arquivo capturado em 15 de nov. 2016

SACRAMENTO, Carlos. John Locke e a problemática da identidade pessoal. Do impacto na Modernidade até à sua atualidade na Contemporaneidade. Disponível na internet via $<$ http://www.adelinotorres.info/filosofia/Carlos\%20Sacramento-

john_locke_e_a_problematica_da_identidade_pessoal.pdf $>$ Arquivo capturado em 15 de nov. 2016

VIANA, Cristina Amaro. Identidade pessoal e continuidade. Disponível na internet via $<$ http://www.marilia.unesp.br/Home/RevistasEletronicas/Kinesis/19_CristinaAmaroViana.pdf $>$ Arquivo capturado em 15 de nov. 2016 


\title{
FILOSOFIA CLÍNICA PARA O $1^{\circ}$ EIC/ETSC 2016
}

\author{
ÁREA TEMÁTICA: origem da filosofia clínica \\ VICTOR RHUAN MAXIMINO SILVA VIEIRA, ensino médio, ETSC-UFCG. \\ VINICIUS de SOUZA FONSECA EVANGEGISTA, ensino médio, ETSC-UFCG. \\ ANTUNES FERREIRA SILVA, Mestre, ETSC-UFCG.
}

\section{INTRODUÇÃO}

Desde de sua origem, a filosofia tem como objetivo proporcionar o benefício humano. Com isso no decorrer de nossa história, as questões filosóficas recebem um tratamento específico, ou seja recebem um olhar investigativo como por exemplo um olhar dirigido as nossas crenças, justificar nossa existência.

Já a filosofia clínica consiste em analisar as questões que nos incomodam. O que necessita o uso do diálogo, algo ausente na nossa sociedade contemporânea, então, com esse diálogo é possível encontrar maneiras para resolver determinados problemas.

Como o objetivo da filosofia clínica é o bem estar do partilhante, o filosofo clínico não parte de abordagens ou respostas prévias ele parte de uma pesquisa dos modos de ser do seu paciente, então quando ele obtiver o resultado desta pesquisa, ele poderá auxiliar o partilhante.

As pessoas buscam a filosofia clínica para encontrar sua autonomia, e assim conseguir organizar suas ideias avaliando as situações por si mesmas, e, a partir disso orientar suas decisões, escolhas, posicionamentos e ações. As pessoas procuram um filosofo clínico com abertura suficiente para não julgar, e sim, provocar o pensar sem aconselhar.

\section{OBJETIVO DO TRABALHO}

Compreender o objetivo da filosofia clínica, como surgiu e por quem foi introduzida aqui no Brasil, assim como mostrar o que fazer para trabalhar como um filosofo clínico e a metodologia utilizada por estes profissionais.

\section{MATERIAIS E MÉTODOS}

A presente pesquisa foi feita a partir de uma análise norteada por um estudo bibliográfico, utilizando alguns sites e menções feitas por alguns filósofos. Deste modo, foi realizado estudos para a formação de interpretações e efetivar a autenticidade dos pensamentos levantados.

\section{RESULTADOS E DISCUSSÃO}

Na década de 80 o filosofo alemão Hilarion Petzold cunhou o nome filosofia clínica. Essa ideia é nada mais nada menos do que o resgate do papel terapêutico que a filosofia já possuía em suas origens. Na década de 80 a filosofia prática inicia este resgate com o objetivo de criar uma atividade para ajudar o próximo. Seu ponto de partida é o seguinte questionamento: se um psicólogo utiliza a filosofia em seus métodos, por que um filosofo não pode usar a metodologia da filosofia para ajudar as pessoas em seus problemas cotidianos.

A filosofia clínica foi introduzida no Brasil pelo filosofo Lúcio Packter, ele inspirado na filosofia prática propôs a filosofia clínica, adequada a realidade brasileira e diferente dos 


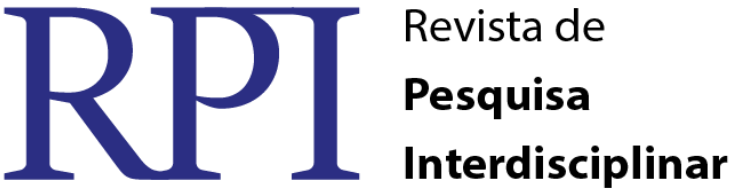

trabalhos realizados pela filosofia prática. Então Packter seleciona os conhecimentos necessários para realizar os trabalhos da filosofia clínica de uma maneira flexível de modo que permite a construção de um trabalho para cada pessoa em especial.

A pessoa que procura ajuda da filosofia clínica é chamada de partilhante e é ela que diz a forma que quer ser auxiliada. Então, com isso, o filosofo clínico acolherá o partilhante e seus problemas e com isso o profissional partilhará seus conhecimentos filosóficos com o paciente, o que faz com que o partilhante reflita sobre suas atitudes e busque as medidas cabíveis.

Para atuar como um filosofo clínico é necessário ter o curso de graduação em filosofia e a especialização em filosofia clínica, depois disso, é preciso fazer alguns estágios e consultas, pois fazendo apenas a especialização só será possível trabalhar com pesquisas e divulgação de resultados.

\section{CONCLUSÕES}

Quando Lúcio Packter introduziu a filosofia clínica no Brasil, ele tinha o objetivo de ajudar a população, o que realmente aconteceu com as pessoas que procuraram a filosofia clínica, pois percebe-se que as pessoas que procuraram ajuda na filosofia clínica levam hoje uma vida mais calma conseguindo tomar decisões de forma mais simples, pois, o filosofo clínico incita as pessoas a tomarem as decisões sem que haja o conselho do filosofo clínico. Com isso fica claro a importância da filosofia clínica na vida das pessoas que a buscam.

PALAVRAS-CHAVE: Ajuda. Procedimentos clínicos. Ouvinte

\section{REFERÊNCIAS}

SANTANA, Ana Lúcia. Filosofia clínica. Disponível em: <http://www.infoescola.com/filosofia/filosofia-clinica/>. Acesso em: 12 nov. 2016.

INSTITUTO INTERSECAO. O que é filosofia clínica? Disponível em:<http://www.institutointersecao.com.br/index.php?option=com_content\&view=arti cle\&id=56\&Itemid=53>. Acesso em: 12 nov. 2016. 


\title{
? $2 \begin{aligned} & \text { Revista de } \\ & \text { Pesquisa } \\ & \text { Interdisciplinar }\end{aligned}$
}

\section{A PERCEPÇÃO DA FILOSOFIA CIENTÍFICA SEGUNDO ARISTÓTELES}

\author{
CIÊNCIAS HUMANAS E SUAS TECNOLOGIAS. FORMATO DE APRESENTAÇÃO DO \\ RESUMO: EXPOSIÇÃO ORAL.
}

CARLOS HENRIQUE FRANÇA DE MACÊDO GOMES, aluno do $3^{\circ}$ ano do ensino médio, da Escola Técnica de Saúde de Cajazeiras. MARIA ISRAELLY DUARTE DE OLIVEIRA, aluna do $3^{\circ}$ ano do ensino médio, da Escola Técnica de Saúde de Cajazeiras. ANTUNES FERREIRA DA SILVA, professor mestre, da Escola Técnica de Saúde de Cajazeiras.

\section{INTRODUÇÃO}

A filosofia científica, campo filosófico que questiona sobre a ciência, é de grande significado para a humanidade. A figura aristotélica, discípulo de Platão, que por sua vez foi seguidor de Sócrates, foi um dos grandes responsáveis para o maior desenvolvimento deste ramo da filosofia.

Iniciada no século XX, Aristóteles agregou bastante valor a filosofia científica, sendo um dos grandes notáveis daquela época. Foi responsável pelo "descobrimento" da lógica, como também da observação metódica.

É notório que, sua história filosófica não foi marcada apenas de êxito. Vale lembrar-se das suas propostas quanto ao que diz respeito à geração dos seres vivos, com a teoria da abiogênese, e da organização do cosmo, com modelo cosmológico geocêntrico. Seus erros não descaracterizaram os seus acertos. Daí é fácil reconhecer o quão significativo foi o seu legado para a filosofia e a importância de estudar seus ensinamentos relacionados à filosofia científica.

\section{OBJETIVO DO TRABALHO}

Compreender, por meio deste, a importância de Aristóteles para a filosofia científica. Abordando seus inúmeros feitos, como também as suas falhas teóricas, e a partir daí entender as várias contribuições da sua filosofia para o desenvolvimento e progresso científico.

\section{MATERIAIS E MÉTODOS}

Para obter-se esta pesquisa, se valemos na busca por artigos e informações relevantes e verídicas em sites filosóficos, em sua maioria escritos por entendedores e praticantes da filosofia científica, bem como em algumas passagens literárias, de um livro rico em características do pensamento aristotélico, o associando ao campo da filosofia científica, com suas contribuições para esta área.

\section{RESULTADOS E DISCUSSÃO}

A ciência é definida como sendo "explicações testadas sobre as coisas e fatos que nos interessam, obtidas através da observação e do estudo". A história da ciência é de espetacular 


\section{$\mathrm{RPP}$}

grandeza, uma aventura magistral levada a cabo por grandes homens decididos a descobrir o que até então todos desconheciam e compreender o que os homens de sua época tinham como mistérios.

$\mathrm{Na}$ Grécia antiga, mais exatamente no século 4 a.C., surge Aristóteles, um médico na cidade da Macedônia, que dividia seu tempo entre a prática profissional e a dedicação plena à busca do conhecimento. Ele foi discípulo de Platão, que por sua vez foi discípulo de Sócrates. Todos filósofos, palavra que significava: "amigos da sabedoria". A importância desses três homens é tanta que muito do modo como pensamos hoje, principalmente no mundo Ocidental, vem das ideias que eles desenvolveram há mais de dois mil anos.

O papel de Aristóteles na história da filosofia científica surge diante do ambiente intelectual em que ele viveu e que ajudou a construir. Se hoje o conhecimento humano é um conjunto de muitas disciplinas, estudadas cada uma por um tipo de especialista, nos tempos de Aristóteles os filósofos se esforçavam para dominar todas as formas de conhecimento. Ser filósofo na Grécia Clássica podia significar ser ao mesmo tempo escritor, poeta, músico, matemático, geômetra, político, teólogo e, claro, cientista. Mas, antes de Aristóteles, a ciência - pelo menos a ciência natural - não tinha muito prestígio entre alguns dos mais importantes filósofos. Platão, o mestre de Aristóteles, considerava o mundo natural inferior ao mundo das idéias, onde residia a verdadeira perfeição, da qual este nosso mundo seria apenas um conjunto de sombras imperfeitas.

Aristóteles sabia a importância da observação para encontrar a melhor resposta de um problema. Só que a observação científica tem um caráter particular, que a diferencia do olhar apenas curioso com que os homens sempre contemplaram o mundo. A observação científica é metódica, ou seja, segue um método, que define o que, como e quando observar de modo a obter o máximo de informação e aprendizado sobre o que se observa.

Só por valorizar a observação metódica da natureza, Aristóteles já teria feito uma contribuição enorme ao progresso científico. Porém, ele foi um grande contribuidor para a história da ciência, e seus feitos não pararam apenas no método da observação. Como sabemos, a ciência é essencialmente lógica, e Aristóteles foi o inventor da lógica. Pelo menos, daquilo que chamamos assim, os modos de pensar pelos quais apuramos um pensamento até lapidar nele sua máxima coerência. Outro ponto importante é que Aristóteles dedicou muito de sua filosofia a entender as causas de tudo que observava. Entender as causas dos diversos fenômenos é a razão de ser da maioria dos experimentos da ciência moderna.

Mesmo sendo um filósofo notável e com teorias extraordinárias para o seu período, Aristóteles também errava, e os seus erros mais lembrados são seu modelo cosmológico geocêntrico, que propunha que o Sol e as estrelas giravam em torno da Terra, que seria o centro do universo. A teoria está errada, claro, já que é a Terra que gira em torno do sol. O filósofo também errou quando defendeu sua versão da teoria da abiogênese, que dizia que os seres vivos podiam ser gerados pela matéria bruta, como uma pedra deixada na água se transformar em um peixe. Outro furo, mas esta crença só foi abolida definitivamente por Louis Pasteur, no século XIX. E, se a biologia de Aristóteles, mesmo com algumas falhas graves, manteve-se respeitável e respeitada por milênios, suas ideias na área da ciência física não foram muito longe, a maioria suplantada por teorias mais elaboradas nos séculos que se seguiram. Só que a contribuição inestimável de Aristóteles ao método científico suplanta em muito seus erros como pesquisador e teórico. Seu legado de conhecimento obtido pela observação, método e lógica seguem desde a antiga Grécia como fundamentos indispensáveis da boa ciência.

\section{CONCLUSÕES}


Conclui-se, portanto, que a filosofia científica está intrinsecamente ligada às teorias aristotélicas, uma vez que, Aristóteles é considerado "o pai da lógica", e tal teoria é de suma importância no campo filosófico. Vale salientar, que tal filósofo foi o responsável pela revolução científica do seu período, com sua tese da observação metódica. Neste sentido, se torna impossível estudar o campo da filosofia científica sem citar Aristóteles, pois ele é considerado o notável na idade antiga, por elaborar teses extraordinárias sem qualquer auxílio tecnológico, inclusive muitas destas são consideradas verdadeiras até os dias atuais. Deste modo, Aristóteles se mostra como um homem à frete do seu tempo, por não se restringir ao básico e buscar explicações para toda e qualquer dúvida que o aparecesse.

PALAVRAS-CHAVE: intelectual. magistral. metódica. notável. suplantada.

\section{REFERÊNCIAS}

SILVA, Carolina Machado Cyrillo da "Chaim perelman - da argumentação à justiça um retorno a Aristóteles". (Dissertação apresentada como requisito parcial à obtenção do título de mestre em Direito pelo Curso de Pós-graduação em Direito da Universidade Federal de Santa Catarina, área de concentração Filosofia e Teoria do Direito. Orientador: Profa Dra. Jeanine Nicolazzi Philippi). Florianópolis - SC, 2005.

SLANA, Carlos Robertos de. História da ciência (1): A contribuição de Aristóteles à ciência. Disponível em http://educacao.uol.com.br/disciplinas/ciencias/historia-da-ciencia-1a-contribuicao-de-aristoteles-aciencia.htm. Acesso em 14 de novembro de 2016.

Aristóteles - filosofia, O PENSAMENTO: A GNOSIOLOGIA. Disponível em: http://www.pucsp.br/pos/cesima/schenberg/alunos/paulosergio/filosofia.html. Acesso em 15 novembro de 2016. 


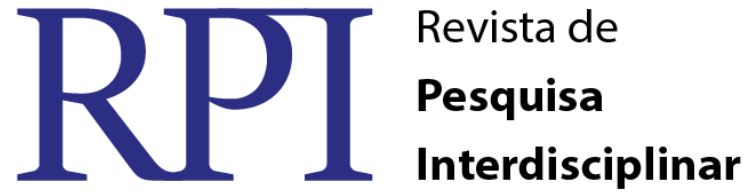

\section{A VONTADE COMO ELEMENTO DEFINITIVO DOS SENTIDOS SEGUNDO ARTHUR SCHOPENHAUER - $1^{\circ}$ EIC/ETSC 2016}

\author{
ÁREA TEMÁTICA: Filosofia da mente (exposição oral) \\ ANNA CLARA LIRA DE MOURA, aluna, ETSC-UFCG. \\ ANTUNES FERREIRA DA SILVA, mestre, ETSC-UFCG.
}

\section{INTRODUÇÃO}

Arthur Schopenhauer (1788-1860) foi um filósofo responsável por um dos pensamentos mais instigantes durante toda a linha histórica da Filosofia. Sendo considerado excessivamente cético, Schopenhauer é nomeado por muitos como pai do pessimismo. Acaba assim ganhando destaque em sua época por, sobretudo, sua principal obra: $O$ mundo como vontade e representação, a qual valoriza a noção de corpo, e juntamente com os sentimentos, elaborando assim o conceito de vontade perante os homens. Contudo, devemos aprofundar o saber com base nos conceitos de Schopenhauer a fim de conhecermos melhor suas ideias acerca da percepção dos sentidos.

\section{OBJETIVO DO TRABALHO}

Compreender o entendimento acerca da representação do mundo e seus mecanismos de percepção segundo Arthur Schopenhauer.

\section{MATERIAIS E MÉTODOS}

A pesquisa apresenta análise por meio de estudo bibliográfico, utilizando os textos do filósofo mencionado, sobretudo $O$ mundo como vontade e representação, assim como alguns comentadores da temática abordada.

\section{RESULTADOS E DISCUSSÃO}

Segundo Schopenhauer, afirmar que conhecemos as coisas em si é errado, pois na verdade, o que nós achamos conhecer é nossa percepção acerca de determinado objeto. Consequentemente, tudo o que julgamos conhecer é na verdade a nossa forma de representálas em consonância com a nossa vontade, sendo essa vontade elaborada a partir da relação entre o corpo e os sentimentos humanos. Schopenhauer então declara que o corpo é, diretamente, elemento fundamental para o conhecimento do ser; uma vez que reconhece que nosso âmbito racional tem, na verdade, como premissa as sensações corporais. Sendo assim, não há como afirmar a existência do objeto sem a percepção do ser.

\section{CONCLUSÕES}

Por conseguinte, o ser é, conforme Schopenhauer, o mecanismo que mantém o mundo como representação, uma vez que esse mundo só existe à partir da concepção elaborada pelos sentidos do próprio ser.

PALAVRAS-CHAVE: representação. Schopenhauer. sentidos. ser. vontade. 


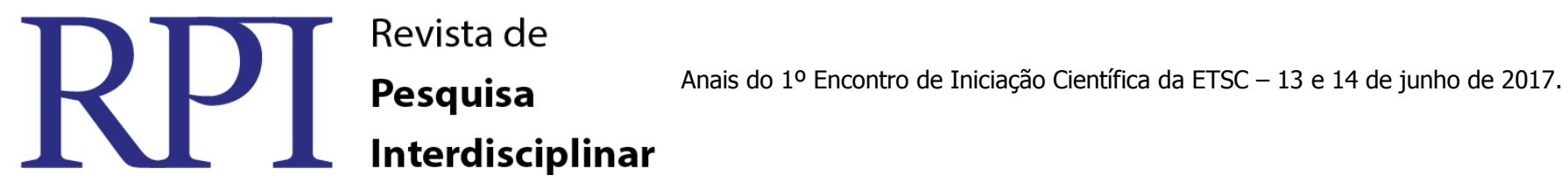

\section{REFERÊNCIAS}

Portal Ciência\&Vida, O Pensamento Instigante de Arthur Schopenhauer. Disponível em: 〈http://filosofiacienciaevida.uol.com.br/ESFI/Edicoes/19/artigo72819-1.asp〉.

Acesso em 14 de novembro de 2016.

Revista Filosofia, Schopenhauer. Disponível em:

〈http://filosofia.uol.com.br/filosofia/ideologia-sabedoria/17/artigo133464-1.asp >. 


\title{
A CONCEPÇÃO DE MORTE E O INTRÍNSECO ELO COM O SER SEGUNDO OS PRINCÍPIOS DA FILOSOFIA SCHOPENHAUERIANA
}

\author{
ÁREA TEMÁTICA: Ciências humanas e linguagens; exposição oral.
}

MARIA LAURA DANTAS NÓBREGA, aluna do ensino médio, ETSC-UFCG. REBECA KAROLLYNE ROLIM RIBEIRO, aluna do ensino médio, ETSC-UFCG. ANTUNES FERREIRA DA SILVA, Professor Mestre em Filosofia, ETSC-UFCG.

\section{INTRODUÇÃO}

Tradicionalmente ligada a questões espirituais, a morte encerra tanto uma certeza inabalável quanto um dos maiores enigmas da humanidade. Ocupando um lugar privilegiado em cultos, narrativas e dogmas de religiões das mais diversas etnias e culturas, sua fatalidade permanece envolta em temores, mistérios e tabus ancestrais. De Platão (428-347 a.C.) a Heidegger (18891976), a tradição filosófica é repleta de teorias e ensinamentos sobre este tema, tão amedrontador quanto instigante. Schopenhauer, um dos mais ilustres pensadores alemães do século XIX, apresentando-a como pedra-chave para o saber filosófico chega ao ponto de afirmar: "A morte é a musa da filosofia, e por isso Sócrates a definiu como preparação para a morte. Sem a morte, seria mesmo difícil que se tivesse filosofado". Ele ainda ressalta que, enquanto tal tema permanece desconhecido, o homem vive de forma tranquila, mas é o conhecimento de sua existência e a percepção de que se é finito que torna o sujeito temente ao evento. É possível acrescentar que as ideias metafísicas acalentam essa perspectiva de que um dia a matéria terá fim. Em sua obra, a morte vem a ser a correção da vontade de vida e o egoísmo - que lhe é essencial - é visto no fato de que o homem limita a realidade na sua pessoa pelo pensamento de que só existe esta vida. "O morrer é o momento de libertação da unilateralidade de uma individualidade que não constitui o núcleo mais íntimo do nosso ser". (Schopenhauer, 1788-1860, p. 139).

\section{OBJETIVO DO TRABALHO}

Levando em consideração a concepção de morte segundo o alemão Arthur Schopenhauer, ao afirmar que esta deve ser encarada como algo banal, é de onde se tem o alicerce para realização do trabalho, que almeja a promoção de uma discussão a cerca da temática a partir de uma visão majoritariamente pessimista, característica do filósofo. Ademais, analisando a fundo tal perspectiva, é notória a sua compreensão de que apesar de estar em constante preocupação com a finitude, e de por muitas vezes a efemeridade de seu caráter tornar tal preocupação tola, o homem não é só temor pela morte. Para Schopenhauer, o ser também possui um aspecto importante que é a "Vontade de vida" e é a mesma que lhe explicará em meio às dificuldades, a inconstância temporal e o abraço ao desconhecido, o apego à existência de maneira exacerbada. Sendo assim, o texto terá por objetivo evidenciar que, para o autor, o conhecimento tem papel fundamental nesse processo, pois ele possibilitará quando presente no indivíduo um distanciamento do apego pela vida, assim aliviando o temor pela morte, sem, contudo, negar que a "Vontade de vida" está intrínseca à essência do ser.

\section{MATERIAIS E MÉTODOS}

A presente pesquisa designa uma análise norteada por um estudo bibliográfico, utilizando os 


\section{$\int\left[\begin{array}{l}\text { Revista de } \\ \text { Pesquisa } \\ \text { Interdisciplinar }\end{array}\right.$}

textos do filósofo mencionado, sobretudo O Mundo Como Vontade e Representação e Metafísica do Amor, Metafísica da Morte, assim como alguns comentadores concernentes à temática. Deste modo, foi realizada a prospecção do conteúdo visando fomentar as interpretações e efetivar a autenticidade dos pensamentos levantados.

\section{RESULTADOS E DISCUSSÃO}

A morte é, para o homem, uma forma de pensar a própria existência. No entanto, as concepções sobre esta foram se alterando ao longo da trajetória da humanidade. Inicialmente, os antigos entediam a Filosofia como uma meditação sobre a morte. Na antiguidade grecoromana, por sua vez, era habitual entender a vida e a morte como intimamente ligadas. Porém, é somente nos tempos modernos que se passa a pensar vida e morte como nitidamente opostas. E assim, passou-se a expulsar a morte da vida cotidiana. Hoje, por exemplo, concebese a vida como o bem jurídico mais valioso; é o direito primeiro da pessoa humana e, portanto, deve ser protegido acima de todos os demais. Em contrapartida, o homem foi obrigado a se deparar com a própria fragilidade, coagindo confrontar-se com a finitude. Então, não é da morte que temos medo, mas de pensar nela.

Nesse contexto, pode-se discutir este tema na filosofia schopenhaueriana a partir de alguns pontos principais, a saber: a supervalorização da morte; a noção de morte como aniquilação absoluta e a crença de que somos imortais; e o respaldo quanto à consciência, sendo esta associada às explicações religiosas.

Em primeiro plano, a supervalorização da morte evidencia essencialmente que o temor inerente ao ser é sinal de não conhecê-la, uma vez que o poderoso afinco à vida é desprovido de conhecimento. É a incumbência do saber revelar o pouco valor da vida e combater o medo da limitação. Logo, apenas as cabeças pequenas e restritas temem a destruição total do ser na morte. De um modo geral, o instante de passagem da vida para a morte é comparável ao acordar de um sono pesado, cheio de visões e pesadelos; portanto não poderia ser um mal. Deste modo, para tal filósofo, a morte tem de ser encarada como algo banal. É também um acontecimento tão natural quanto o nascimento, pois somos meras matéria.

Nesse sentido, Schopenhauer ressalta que são concepções falhas a noção de morte como aniquilação absoluta e a crença de que somos imortais. $\mathrm{O}$ ser já nasce com o medo de tal subversão, mas se isso remete à idéia do não ser, então deveríamos ter o mesmo temor diante do tempo em que ainda não éramos. Se depois de uma existência efêmera uma segunda infinidade se seguisse, entretanto, seria uma condição dura e até mesmo intolerável. Ainda assim, a esperança de imortalidade da alma está ligada à de um mundo melhor, então o presente parece não valer muita coisa. Por outro lado, são os povos que permanecem como indivíduos eternos. Sua conduta, suas ações e seu sofrimento são sempre os mesmos. O nascimento e a morte não afetam em nada a existência das coisas; cada espécie persiste intocada pela sucessão contínua dos indivíduos que ela encerra. Por toda parte, o símbolo da natureza é o círculo - o esquema de retorno -, então para quem considera o nascimento do homem como o seu começo absoluto, a morte tem de ser o fim absoluto; e se do nada, nada vem, então nada pode ser revertido ao nada. A alma, pois, não seria eterna se fosse criada. Por fim, o pessimismo schopenhaueriano justifica que desejar a imortalidade da individualidade é querer perpetuar um erro ao infinito, pois os homens são feitos de tal modo que não podem ser felizes. O destino do individuo humano, desta forma, parece ser a morte; o do gênero humano, a permanência e a vida finita.

As reflexões sobre a permanência da consciência após a morte nos leva às percepções metafísicas consoladoras. É em torno deste fim que se dirigem todos os sistemas religiosos e filosóficos, os quais agem como o antídoto que a razão fornece contra a certeza da morte. É 


\section{$\mathrm{RPP}$}

válido sobrelevar, portanto, que a desaparição da consciência não comporta mal algum. A morte consiste apenas quando esta desaparece. Logo, a morte concerne, pois, somente à consciência. Com efeito, com a morte perde-se tal entendimento, mas não aquele que o produziu e o manteve: a vida se extingue, mas não se extingue juntamente o princípio de vida que nela se manifestou. A ideia cristã, por exemplo, defende o mantimento da consciência. A espírita, por seu turno, argumenta que a cada vida se assume uma consciência, caso seja uma continuidade da matéria. É estabelecido, desse modo, um panorama em que não há uma explicação ou verdade absoluta capaz de contentar a todos os indivíduos.

Em face desse raciocínio, Arthur Schopenhauer conclui, dentre outros questionamentos sobre a vida e a morte e os problemas psicológicos humanos, que a individualidade do homem tem tão pouco valor que a morte não implicaria em dano algum. A importância se detém, sobretudo, nas características da humanidade, que perpetuam e são indestrutíveis. O filósofo efetiva, ainda, que se concedessem ao homem uma vida eterna, seria tanta repugnância por ela ao ponto de a morte ser mais contemplativa, destacando o farto da imutabilidade do caráter imanente ao ser e de seu entendimento ilimitado.

\section{CONCLUSÕES}

O estudo descreve uma série de princípios que permitem reafirmar uma situação paradoxal pertinente à metafísica da morte e a sua relação com o ser: ora se testemunha a banalização deste fenômeno, ora encaram-no como um mistério, com caráter vertiginoso e desconcertante. Por vezes, sobressai a assimilação de que o instante mortal é um acontecimento incomparável que não permite qualquer conceitualização. Para os viventes, a morte é ao mesmo tempo seu destino como seres finitos e sua origem como seres humanos; é o fim e o começo. Mas ainda assim pode ser concebida como uma punição para a nossa existência. Todavia, ela propõe ao homem, num instante, o desafio de pensar a sua própria condição.

PALAVRAS-CHAVE: consciência. morte. Schopenhauer.

\section{REFERÊNCIAS}

SCHOPENHAUER, Arthur. Metafísica do amor, metafísica da morte. Tradução Jair Barboza. São Paulo: Martins Fontes, 2000.

O mundo como vontade e representação. Tradução Jair Barboza. São Paulo, Editora da Unesp, 2005.

Portal Ciência\&Vida, A Morte Como Instante de Vida. Disponível em: <http://portalcienciaevida.uol.com.br/esfi/Edicoes/32/artigo129564-3.asp>.

Acesso em 02 de novembro de 2016. 


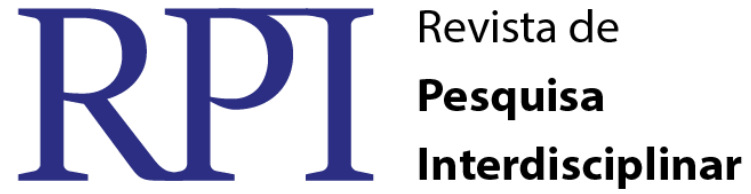

\section{Filosofia Clínica, uma reflexão importante sobre o ser humano}

ÁREA TEMÁTICA: Ciências humanas e suas tecnologias/Filosofia.

KARINA ESTRELA EGÍDIO, Ensino médio, ETSC-UFCG. MARIA HELENA EGÍDIO ANDRADE DE SOUSA, Ensino médio, ETSC-UFCG. ANTUNES FERREIRA DA SILVA, Mestre, ETSC-UFCG.

\section{INTRODUÇÃO}

A Filosofia possui várias horizontes e investigações. Muitas deles se interessam pelo homem, como ele vive e se relaciona com o mundo. É nessa linha que surge no final do século XX a Filosofia Clínica. Ela nasce não como reflexão apenas, mas tem também como característica o fato de considerar prática. A Filosofia Clínica tem como pai fundador Lúcio Packter. Ela trata de problemas ligados à flexibilidade e singularidade de cada ser. Para a Filosofia Clínica, o ser humano deve ser visto tanto por sua capacidade de pensar, razão, quanto pela ligação desta esfera com o corpo. O corpo adoece por fatores físicos quanto por fatores não-físicos. Podemos ir as origens para compreender a questões. Segundo o filósofo Hipócrates em seu livro Das Epidemias, "O esforço físico é alimento para os membros, o sono o é para as entranhas. Pensar é para o Homem o passeio da alma". A citação refere-se ao surgimento da medicina gradualmente com a filosofia, na qual, ambas remetem-se ao cuidado com o ser. A primeira refere-se ao corpo e a segunda à alma. Isso faz parte da Filosofia Clínica. Em suma, ela surge como um novo modelo de partilhar valores e formas de ver o mundo e especificamente o ser humano. Mas a Filosofia Clínica chama atenção porque ela auxilia o homem a compreender muitos problemas, a exemplo de angustias, medos, ansiedade. Porque muitas pessoas procuram o filósofo clínico para resolver tais questões? A filosofia clínica teria uma resposta? Como a filosofia clínica atua?

\section{OBJETIVO DO TRABALHO}

Compreender como a Filosofia Clínica ver o humano e de que modo ela ajuda o homem a resolver problemas como angustia, medo, ansiedade, problemas frequentes da contemporaneidade.

\section{MATERIAIS E MÉTODOS}

A presente pesquisa constitui uma análise guiada por um estudo bibliográfico, utilizando o texto Filosofia Clínica: Propedêutica de Lúcio Packter, o livro Paidéia: a Formação do homem grego de Werner Jaeger, o livro Conhecer, cuidar, amar: o Julgamento e outros Textos. Desta forma, foi construída uma síntese através dos conteúdos estudados, visando adquirir um maior discernimento acerca do tema.

\section{RESULTADOS E DISCUSSÃO}

Muitas pessoas quando enfrentam problemas como ansiedade, medo, angustia, depressão até, procuram ajuda na Filosofia Clínica. O que a Filosofia Clínica faz, de que modo ela contribui com essas questões, foi isso que analisamos. Em primeiro lugar, 


\section{$\int \begin{aligned} & \text { Revista de } \\ & \text { Pesquisa } \\ & \text { Interdisciplinar }\end{aligned}$}

precisamos levar em conta que o filósofo clínico, diferente de outros profissionais que lidam com esses tipos de problemas, compreendem cada ser humano como um ser único. Ou seja, não buscam resolver o que esta ou aquela pessoa sofre por um mesmo caminho. Se somos diferentes, também diferentes são os caminhos. A filosofia clínica procura assim respeitar cada pessoa por seu modo de ser e suas escolhas.

De que modo a filosofia clínica atua? A filosofia clínica é filosofia, pois parte de reflexões sobre os problemas enfrentados, mas também é clinica porque através das reflexões levanta caminhos para que a pessoa possa encontrar saída para seus problemas. Questões existenciais que geram frustrações, angústias, sofrimentos, medos incontroláveis, ausência da capacidade de articulação de ideias e a rejeição ou indiferença por parte do outro fazem com que haja necessidade de procurar "caminhos" que nos acolham. Há quem recorra aos amigos ou familiares, no entanto, são pessoas que compartilham das mesmas inquietações e muitas vezes ignoram, considerando superficiais as referidas apreensões. Há quem procure também terapias com psicólogos, profissionais que atuam no comportamento e nas relações humanas diagnosticando e tratando por meio de métodos coletivos doenças de origem psicológica.

A Filosofia Clínica destaca-se, portanto, por não trabalhar com teorias prévias, tipologias, estereótipos e dogmas de cada cidadão e sim pelo desenvolvimento da atividade de ajudar ao outro. O filósofo Clínico busca sentir a pessoa, o modo como fala, movimenta-se, olha e principalmente como relaciona com si mesma e com o meio ambiente. Dessa forma, auxilia-o a refletir sobre suas questões e dificuldades, a levantar e estudar possibilidades, a definir e construir novas opções.

Em geral, o trabalho com a pessoa não ultrapassa seis meses, participando esta de três etapas clínicas. Os Exames Categoriais, nos quais o filósofo localiza a existência do seu partilhante, a identificação da Estrutura de Pensamento, consistindo no modo como a pessoa enxerga o mundo e por último a Aplicação dos Submodos que são meios pelo qual o participante encontra a intersecção das questões apresentadas por ele mesmo e pelo Clínico e as põe em prática. Para possibilitar a abertura ao outro da clínica, durante o processo de formação, o filósofo Clínico submete-se a um procedimento denominado Pré-Estágio ou Clínica didática. Esse procedimento traduz-se em passar por todo um preparo especializado como um partilhante, ou seja, conhecendo a si mesmo a partir do instrumental filosóficoclínico. Após a formação, a manutenção da clínica se torna necessária, não apenas como atualização da consciência desses referenciais, mas como prevenção para o profissional.

\section{CONCLUSÕES}

Partindo-se do postulado de que a Filosofia Clínica tem origem no Século XX, momento de crise de paradigmas existenciais e da razão, questiona-se paulatinamente a crise da filosofia, o seu papel no mundo contemporâneo. Em consequência disso, surge uma nova forma de vê o mundo e entender as peculiaridades de cada indivíduo. Portanto, torna-se evidente que a chamada Filosofia Clínica não parte da concepção de normalidade, doença ou cura, mas o pensar junto com o outro é a verdadeira temática dessa, norteada pelo respeito aos seus modos de ser, a suas escolhas.

\section{PALAVRAS-CHAVE:}

Filosofia Clínica. Homem. Partilhante. Singularidade.

\section{REFERÊNCIAS}

HIPÓCRATES. Conhecer, cuidar, amar: o Julgamento e outros textos. São Paulo: 


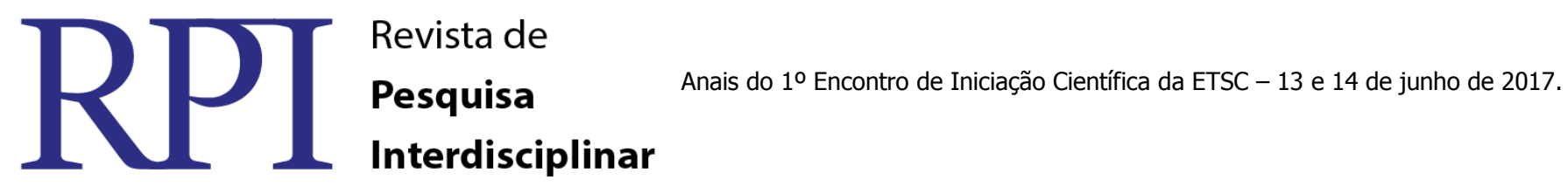

Landy, 2002.

JAEGER, W. Paidéia: a formação do homem grego. São Paulo: Martins Fontes/UNB, 1989.

PACKTER, L. Filosofia Clínica: Propedêutica. Porto Alegre, AGE, 1997.

http://www.institutointersecao.com.br/artigos/Monica/O\%20consult\%C3\%B3rio\%20de\%20F ilosofia\%20Cl\%C3\%ADnica.pdf 


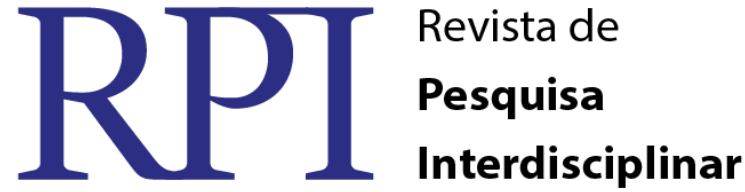

\section{TRANSVALORAÇÃO E AMOR FATI DE FRIEDRICH NIETZSCHE}

\author{
ÁREA TEMÁTICA: Ciências humanas e linguagens; exposição oral
}

FRANCISCO FILIPY FERNANDES ROCHA, aluno do ensino médio, ETSC-UFCG. TAINARA DA SILVA ANDRADE, aluna do ensino médio, ETSC-UFCG. ANTUNES FERREIRA SILVA, Professor Mestre em filosofia, ETSC-UFCG.

\section{INTRODUÇÃO}

É inquestionável a preocupação dos seres humanos com a busca de sentido da vida. Heráclito, por exemplo, (535 - 475 a.C.) preocupou-se em enfatizar a transitoriedade mundana, pretendendo, com isso, enfatizar que tudo é efêmero e o sentido das coisas podem não ter concreticidade. Já Friedrich Nietzsche, filósofo do século XIX, explicita o niilismo: as transições e o caos estão interligados entre si e, também, aos desejos interpessoais de cada indivíduo. Demasiadas vezes, esses desejos interligam-se às idealizações, surgindo uma celeuma que busca substituir o real pelo ideal. O Amor Fati (do latim, amor ao destino), citado nos livros A Gaia Ciência (1882) e em Ecce Homo (1908), ambas as obras de Nietzsche, é a ideia de amar e aceitar, sem ser, todavia, de forma meramente passiva, o que vier, como se as coisas acontecessem porque tinham de acontecer. Uma importante e fundamental alusão, ainda, é possível quanto ao Eterno Retorno deste filósofo, o qual se atrela à pergunta: "Você quer isso mais uma vez e por incontáveis vezes?". Ou seja, consiste na ideia de viver a vida da melhor forma, pensando que ela poderia ser vivida diversas outras vezes, com o mesmo molde. O ser humano deve questionar-se, então: minha vida, tal como a tenho vivido até agora, é resultado de uma mera idealização, do medo e da fraqueza de aceitála? Nietzsche, portanto, fomenta questionamentos acerca da aceitação das coisas, e como isso seria possível.

\section{OBJETIVO DO TRABALHO}

Entender o conceito de Amor Fati, intimamente ligado ao de Eterno Retorno, e avaliar suas implicações na vida do homem moderno, compreendendo o caminho apontado por Nietzsche para fugir do niilismo decorrente da morte de Deus.

\section{MATERIAIS E MÉTODOS}

Esta pesquisa consiste em uma análise guiada pela bibliografia do filósofo mencionado, utilizando seus textos, principalmente dos livros Ecce Homo e A Gaia Ciência, assim como alguns comentadores sobre a temática. Dessa forma foi possível ganhar propriedade ao falar do assunto, o que conduziu a uma interpretação e discussão relacionada ao tema.

\section{RESULTADOS E DISCUSSÃO}

O niilismo de Nietzsche começou com críticas às crenças cristãs e aos valores os quais atribuímos às coisas, que partem sempre da moralidade, das questões culturais, que são concebidas por determinado grupo. Atribuir valor às coisas, para Nietzsche, é efeito do intermédio que os humanos têm com divindades, situação fortalecida na Era Platônica e vigora até a contemporaneidade, regendo as relações da sociedade moderna. Há, também, a distinção de niilismo passivo e niilismo ativo. Aquele é mais adequado às ideias 


\section{$\int\left[\begin{array}{l}\text { Revista de } \\ \text { Pesquisa } \\ \text { Interdisciplinar }\end{array}\right.$}

schopenhauerianas, pois a vida é a uma batalha sofrida e pode ser vista como uma evolução, apesar de não haver mudança de valores. Este é o de Friedrich, o qual enaltece que o ser é mais forte sabendo que o mundo não tem sentido e, após destruir completamente toda a moral, ele tem poder de atribuir-lhe um.

Com a morte de Deus, o indivíduo perde todos os parâmetros transcendentes aos quais se exortava. A distinção das coisas a partir de juízos de valor revela-se impotente, portanto. $\mathrm{O}$ ser passa a perceber que a vida depende intrinsecamente das escolhas que ele fizer, sendo necessária uma intelectualidade elevada para fazer as mais benevolentes a si. Tudo, agora, é uma destruição contínua, e para fugir dela Nietzsche preconiza, então, a ideia de Eterno Retorno como possibilidade de aproveitar e afirmar a realidade.

O Eterno Retorno, por conseguinte, fomenta o questionamento, muito famoso, feito por Nietzsche aos seus leitores: "Viveria isso eternamente?". A ideia que essa frase traz é a de aterrorizar o ser que não usufrui da vida, que ojeriza metamorfoses e espera um sentido externo, de um Deus. Com sua morte, o Retorno coage o indivíduo a dar sentido por si mesmo. E, consequentemente, a buscar uma transvaloração. Há a escolha entre pensar em ser um demônio atormentado ou uma ser abençoado por ter que viver tudo de novo.

Desse modo, reafirma-se que a essência mundana é a transitoriedade. Os dias passam, ocorre o degelo, as flores morrem. Com o outono vem o sofrimento e a primavera traz a resiliência. O ser humano conhece, então, a real grandeza do homem, o Amor Fati, que consiste em não evitar, tampouco dissimular ou distorcer o real, concretizando o amor à vida e aceitando as metamorfoses. Assim, busca-se realizar o que ainda não é e aceitar com equanimidade o advindo. Amor ao destino é a afirmação do acaso e da necessidade, juntos.

\section{CONCLUSÕES}

A proposta de Nietzsche é aceitar que o bem e o mal, a alegria e a tristeza, a dor e o prazer, assim como outros aspectos da vida humana, são inerentes à realidade. Ele propõe que o ser supere o próprio ser ao se desapegar dos seus ídolos metafísicos, pois não há uma moral transcendental que justifique o mundo. A partir de agora ele passa a dar sentido à sua existência pela afirmação do que é, pelo amor ao que já passou. O indivíduo torna-se, então, independente de deuses e capaz de criar e destruir seus próprios valores.

Amor Fati não é simplesmente se conformar e se tornar inerte à vida, é fazer o que está ao seu alcance e, mesmo não conseguindo chegar ao seu objetivo, ainda ser capaz de amar o seu destino e apreciar a vida.

PALAVRAS-CHAVE: amor fati. eterno retorno. Nietzsche. niilismo.

\section{REFERÊNCIAS}

MARTON, Scarlett. Nietzsche, uma filosofia a marteladas. 5. ed. São Paulo: brasiliense, 1999.

NIETZSCHE, Friedrich Wilhelm. Ecce homo. Covilhã: LusoSofia, 2008.

A gaia ciência. 1. ed. São Paulo: Companhia das Letras, 2012. 


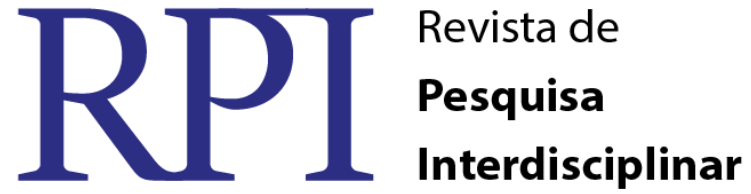

\section{LINHAS DE PENSAMENTOS DO BEHAVIORISMO PARA O $1^{\circ}$ EIC/ETSC 2016}

ÁREA TEMÁTICA: Filosofia da Mente; exposição oral.

ANA BEATRIZ DA SILVA BATISTA, aluna do ensino médio, ETSC-UFCG. MYLENA PINHEIRO ALVES, aluna do ensino médio, ETSC-UFCG. ANTUNES FERREIRA SILVA, Professor Mestre em Filosofia, ETSC-UFCG.

\section{INTRODUÇÃO}

A Filosofia da Mente pode ser vista como um ramo que estuda as relações entre mente e corpo. Sempre presente, a conduta humana deixa incógnitas, principalmente, se ocorre relação entre o corpo e a mente, e se sofre influências de estímulos exteriores ou interiores. $\mathrm{O}$ Behaviorismo, teoria inserida na Filosofia da Mente, aborda tais questões e tenta compreender o comportamento humano. Tal linha de pensamento bifurca-se em principais tipos, o Behaviorismo Metodológico e o Behaviorismo Radical, e cada qual irá formular princípios distintos para caracterizar e compreender o modo como o ser humano se comporta. É pertinente perceber que essa teoria sofre críticas, auxiliando na diminuição do espeço que estas ocupam entre as principais teorias psicológicas.

\section{OBJETIVO DO TRABALHO}

Compreender e esclarecer as distinções das linhas de pensamento do Behaviorismo enquadrado no campo de estudo da Filosofia da Mente -, seus principais defensores, suas ideias e teorias.

\section{MATERIAIS E MÉTODOS}

A pesquisa apresenta um conteúdo guiado por análises baseadas em sites da internet, principalmente os que continham informações sobre as teorias de John B. Waston e Skinner, principais nomes encontrados nas teorias do Behaviorismo Metodológico e Behaviorismo Radical, respectivamente. Tais informações foram buscadas para efetivar o conhecimento sobre as linhas de pensamento existentes na Filosofia da Mente, auxiliando a compreensão do projeto.

\section{RESULTADOS E DISCUSSÃO}

O Behaviorismo é uma linha de pensamento que está inserida no campo da Filosofia da Mente. Tal termo, do inglês, behavior, significa comportamento. Os principais campos dessa teoria são o Behaviorismo Metodológico e o Behaviorismo Radical. Essa corrente surgiu para se opor ao funcionalismo e ao estruturalismo. Um manifesto criado por John B. Waston chamado "A psicologia como um comportamentista a vê" deu início a essa teoria, em 1913. O autor defende, então, que a psicologia deveria estudar o comportamento, pois esse é passível de uma observação por uma ciência positivista. Ele é conhecido como pai do Bahaviorismo Metodológico, e acredita na possibilidade de prever e controlar a conduta humana, e as manifestações do comportamento podem resultar de um estímulo do meio ambiente que gera modificações orgânicas. Já o Neobehaviorismo Mediacional é proposto por Edward C. Tolman quando publica sua obra "Purposive behavior in animal and men" em 


\section{$\int\left[\begin{array}{l}\text { Revista de } \\ \text { Pesquisa } \\ \text { Interdisciplinar }\end{array}\right.$}

1932. De acordo com ele, o indivíduo é um mediador entre o estímulo e a resposta, atravessando etapas consideradas ações internas, conhecidas como Gestalt-sinais. Dessa forma, cada comportamento distinto é formado por um grupo de estímulos produzidos pelo indivíduo. Para ele, o comportamento tem uma intencionalidade e um objetivo a ser alcançado, sendo persistente. Tolman é considerado um percursor da Psicologia Cognitiva. $\mathrm{O}$ Behaviorismo Radical foi criado por Skinner na década de 40. Ele se opôs à concepção de Waston, pois era contra as causas internas, acreditando que o ser humano não é um todo constituído de corpo e mente, ele é único. O Behaviorismo também é analisado no campo da educação, promovendo uma alteração no comportamento dos indivíduos que participam do processo de aprendizagem. Para Waston, era possível ocorrer uma transformação no comportamento de uma criança, e ela seria apta a exercer a profissão que desejasse. Entretanto, o Behaviorismo perde espaço entre as teorias psicológicas dominantes, pela existência do desenvolvimento da neurociência - ajudando a compreender o que ocorre na mente humana e seus processos internos -, do desprestígio dos estímulos como causas para a conduta humana, e das críticas de grandes estudiosos como Noam Chomsky, que afirma que essa teoria não é o bastante pra explicar fenômenos da aprendizagem e da linguagem.

\section{CONCLUSÕES}

Waston, a princípio, defende a ideia de que o comportamento pode ser previsto e controlado, enquadrando-se no Behaviorismo Metodológico. Skinner, por sua vez, opôs seu pensamento ao de Waston, e afirmou que o ser humano é homogêneo, e não dividido em corpo e mente, sendo assim, se posiciona contra as causas internas. Correntes como o Neobehaviorismo Mediacional também existiram, tendo como seu principal defensor, Edward C. Tolman, afirmando que o organismo estava entre o estímulo e a resposta, como um mediador. O Behaviorismo também atua na educação, modificando o comportamento de indivíduos envolvidos no processo de aprendizagem, possibilitando a escolha de qualquer profissão. Conclui-se, então, que mesmo com diversas correntes do Behaviorismo, todas estão unidas em um ponto chave: a conduta do indivíduo. Todavia, essas linhas de pensamentos são derrubadas por pensadores como Noam Chomsky, pelo desenvolvimento da neurociência e pela falta de prestígio dos estímulos como causas para o comportamento humano.

PALAVRAS-CHAVE: Comportamento. Estímulo. Mente

\section{REFERÊNCIAS}

SANTANA. Ana Lucia. "Behaviorismo"; InfoEscola. Disponível em <http://www.infoescola.com/psicologia/behaviorismo/>. Acesso em 14 de novembro de 2016. MACIEL. Willyans. "Filosofia da mente"; InfoEscola. Disponível em $<$ http://www.infoescola.com/filosofia/filosofia-da-mente/>. Acesso em 14 de novembro de 2016. 


\title{
ALIANÇA ENTRE SENSIBILIDADE E RAZÃO: NOVO PARADIGMA DA PROGRAMAÇÃO
}

\author{
ÁREA TEMÁTICA: Ciências humanas e linguagens. \\ Exposição oral.
}

MARCELA EDUARDA GOMES GRANDE, estudante do ensino médio, ETSC-UFCG.
SAMIRA CARLA VIEIRA DE OLIVEIRA, estudante do ensino médio, ETSC-UFCG.
ANTUNES FERREIRA DA SILVA, mestre em filosofia, ETSC-UFCG.

\section{INTRODUÇÃO}

Desde a Antiguidade Clássica, é citado por Homero em suas obras, que o deus Hefesto criava aparelhos mecânicos capazes de realizarem movimentos sozinhos, os chamados autômatos. Partindo disso, surge a ideia de vida artificial, e junto a ela, o termo Inteligência Artificial (IA), referente ao campo de pesquisa focado em estudar a possibilidade de criação de seres artificiais.

Tendo como base os conhecimentos sobre consciência e o pensamento, será que poderemos dizer algum dia, que uma máquina pensa ou sente? Partindo- se do pressuposto de que robôs não conseguem lidar com problemas do cotidiano, já que não possuem emoções, tentaremos abordar a disparidade existente entre o homem e as máquinas, quando postos ao aspecto sentimental, e também pensando sobre a Ropopsicologia e suas tentativas de criar guias para as ações comportamentais dos robôs, fabricando sentimentos.

\section{OBJETIVO DO TRABALHO}

Compreender sobre a distinção entre homem e robô, pautando-se na busca pelo entendimento em relação à carga emocional que pode ser atribuída às máquinas. Além disso, buscar compreender o funcionamento de uma futura sociedade em que seres humanos e seres artificiais conviverão juntos, bem como os benefícios trazidos por essa nova criação.

\section{MÉTODOS}

O presente trabalho foi realizado com base em pesquisas bibliográficas, através de revistas disponibilizadas pelo Orientador, e livros que possuíam conteúdos relacionados com o tema da pesquisa, em especial Formiga Elétrica, do escritor Philip K. Dick. Desse modo, foi realizada a prospecção do conteúdo, visando o estímulo de interpretações, e confirmando a autenticidade dos pensamentos levantados.

\section{DISCUSSÃO}

O pensar ainda é inerente aos homens, possuidores de uma capacidade intelectual altamente complexa, resultado de uma intangível evolução de bilhões de anos, enquanto que as máquinas são programadas pelo homem com a finalidade de solucionar problemas, e assim fazê-los, pelos conhecimentos previamente gravados em sua memória.

As respostas que os homens dão aos vários problemas que lhes são apresentados estão intimamente ligadas ao conjunto de sua vivencia social, e, envolvidos racionalmente e, principalmente, emocionalmente suas reações podem vir a ser ineficazes para aquele 


\section{$1 \begin{aligned} & \text { Revista de } \\ & \text { Pesquisa } \\ & \text { Interdisciplinar }\end{aligned}$}

momento e aquela situação, enquanto que, por outro lado os robôs com sua Inteligência Artificial poderão apresentar decisões muito mais rápidas e exatas devido a sua função primordial seguindo uma série de regras, codificadas em sua memória, a fim de não gerar erros.

Afirmar que um dia uma máquina poderá ser equiparada ao ser humano - pesando e sentindo - parece um pouco surreal, mas levando-se em consideração adventos tecnológicos do passado que na época pareciam utopia e hoje se concretizaram, não podemos duvidar do poder de evolução da tecnologia. É difícil pensarmos como seria para nós um robô dotado de capacidade cognitiva, quando somos a espécie mais evoluída de todo o planeta. Mas, de acordo as leis da robótica de Asimov, é inegável que o mundo se tornaria um espaço muito mais harmônico.

O que diferencia os seres humanos das máquinas, em grande parte, são as emoções, as maneiras como eles aprendem a lidar com certas situações.

Segundo a pesquisadora do MIT (Massachusetts Institute of Technology) Rosalind Picard, as máquinas não conseguiriam resolver nem lidar com problemas do nosso cotidiano, justamente por não terem emoções. Isso é explicado pela grande quantidade de possibilidades lógicas de se resolver um problema, que acabariam consumindo muito tempo e capacidade de processamento, mantendo uma lógica em círculos, e por fim, dando "tilt" ${ }^{2}$. Ou seja, travando.

Nossos sentimentos não podem ser submetidos a um conjunto de regras, como se fossem um manual de instruções de um computador. Eles vão bem mais além. São intuitivos, envolvem conceitos e crenças a partir da forma como concebemos e respondemos ao mundo. Talvez um simples sistema de algoritmos não conseguisse reagir às determinadas situações.

Partindo desse pressuposto, tomamos conhecimento de termos com "Computação Afetiva", "Robopsicologia" ${ }^{3}$ e "Androideologia" ${ }^{4}$. Ambos relacionados com a tentativa de fabricar sentimentos.

Robosicologia e Androideologia são termos que estão intrinsecamente ligados, tendo em vista que o primeiro só se desenvolve a partir dos avanços do segundo. São ciências que guiariam o comportamento das máquinas.

Muitos pesquisadores já tomam a frente de experimentos relacionados à criação de personalidades virtuais, dentro do campo da computação afetiva. Essa se configura como uma área da informática na qual são consideradas as emoções e os "estados de espírito" para a criação de hardwares ${ }^{5}$ e softwares ${ }^{6}$, sendo esses facilmente comparados com nossa mente e nosso cérebro.

Sendo assim, as máquinas, robôs e computadores deixarão de fornecer respostas lógicas, criando ações originais para lidar com os desafios do nosso dia-a-dia.

Por fim, com o franco crescimento dessa área, poderemos ter o nosso computador pessoal como melhor amigo, dialogando e atribuindo-lhe características que antes eram apenas humanas.

\section{CONCLUSÕES}

\footnotetext{
${ }^{2}$ Expressão utilizada quando máquinas de jogos bloqueavam, travavam.

${ }^{3}$ Termo criado por Isaac Asimov, para denominar a ciência que estuda os processos emocionais de seres artificiais.

${ }^{4}$ Termo criado pelo matemático e filósofo Michael Scriven para nomear a ciência responsável por criar um organismo artificial inteligente capaz de aprender e reagir de maneira eficaz.

${ }^{5}$ Termo aplicado à unidade central de processamento, à memória e aos dispositivos de entrada e saída de informações de uma máquina.

${ }^{6}$ É a parte lógica, o conjunto de instruções e dados processados pelos circuitos eletrônicos.
} 
Acredita-se que hoje, os homens já são, em partes, máquinas, pois têm uma relação de dependência com computadores, celulares, televisão, videogame. Mas o que será da sociedade se a criação desses robôs humanoides for concretizada?

Seguindo as famosas leis da robótica criadas por Asimov, a convivência das futuras espécies será muito harmônica, livre de violência, desentendimentos, e outros males. As leis são as seguintes:

* $1^{a}$ lei: um robô não pode fazer mal a um ser humano e nem, por inação, permitir que algum mal lhe aconteça.

*2 $2^{\text {a }}$ lei: um robô deve obedecer às ordens dos seres humanos, exceto quando estas contrariarem a primeira lei.

*3 $3^{\text {a }}$ lei: um robô deve proteger a sua integridade física, desde que com isto não contrarie as duas primeiras leis.

Outra problemática surge a partir da leitura do conto Formiga Elétrica. Como viveriam no nosso mundo, em aspectos legislativos, esses seres artificiais? A solução seria uma nova adaptação por parte de todos, a fim de que a harmonia seja garantida.

Por fim, são avanços tecnológicos que podem trazer uma infinidade de benefícios para o nosso meio. Além de ser uma prova de que razão e sentimento andam lado a lado, bem como Filosofia e Ciência.

PALAVRAS-CHAVE: Homem. Máquina. Robopsicologia. Sentimentos.

\section{REFERÊNCIAS}

VAZ, Rafael de Oliveira. Sentimentos Fabricados. Filosofia, Ciência \& Vida Especial, São Paulo, a.1, n.3, p. 38-45.

DICK, Phillip K.. A Formiga Elétrica. 1969, 20p. 


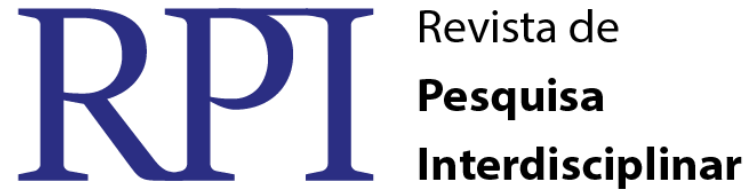

\section{O AMOR EM SCHOPENHAUER PARA O $1^{\circ}$ EIC/ETSC 2016}

\author{
ÁREA TEMÁTICA: [abrange a área da metafísica] \\ (Exposição oral)
}

IOHANNA MÉLO DE ARAÚJO, aluna do ensino médio, ETSC-UFCG. ANTUNES FERREIRA DA SILVA, Professor Mestre em filosofia, ETSC-UFCG.

\section{INTRODUÇÃO}

Arthur Schopenhauer (1778-1860) é um filósofo alemão do século XIX. É criador de diversas obras, onde a sua principal foi "O mundo como vontade e representação" (1818). Schopenhauer acreditava que o amor era um mal necessário e fundamentou teorias sobre o tema, levantando questionamentos até hoje. Em um dos seus livros perguntou-se: "Como um sentimento que coloca de lado todas as considerações, move o indivíduo para enfrentar todos os obstáculos, mesmo se à custa da própria vida, seria uma quimera?" e esse questionamento sucedeu investigações do próprio sobre o amor, chegando a conclusões. Para ele, o amor era temível, mutável, mas fundamental.

\section{OBJETIVO DO TRABALHO}

Compreender o ponto de vista do significado da palavra "amor" pelo filósofo Arthur Schopenhauer desde a sua época, e analisá-lo na contemporaneidade.

\section{MATERIAIS E MÉTODOS}

A pesquisa apresentada utiliza fragmentos da revista Filosofia, Ciência \& Vida e do livro Metafísica do Amor, destacando a matéria Não sabemos mais amar? e o capítulo A verdade do amor, respectivamente. Deste modo, foi realizada a análise e a interpretação dos dados presentes em prol da formação do texto.

\section{RESULTADOS E DISCUSSÃO}

Existem diversos significados que definam o que é o amor. Ele pode ser uma afeição, grande amizade, sentimento para algo belo ou até mesmo desejo sexual. Filósofos antigos e contemporâneos buscam a sua definição por meio de pesquisas, mas não entram em acordo. No começo de tudo, o amor foi relativamente criado pela religião, onde predominava o cristianismo. A ideia de que duas pessoas necessitariam de um casamento para a procriação era forte na época. Eram mal vistos pela sociedade quem tivesse filhos antes da oficialização da relação.

Schopenhauer, filósofo alemão do século XIX, escreveu diversos livros e um deles aborda a metafísica do amor. Viveu em uma época em que o casamento servia para procriação, e concluiu que o sentimento não passava de uma mera ilusão. Descreve em seu livro a seguinte afirmação: "O amor é uma verdade. Engana-se quem pensa o contrário." e concluiu as suas investigações afirmando que o amor se resume em desejo sexual.

As suas teses instigam a todos, pois quando o parceiro(a) fica indisposto(a) de ter relações sexuais o casamento acaba, ou simplesmente o amor acaba. Isso prova que sua tese está certa, que o amor, para Schopenhauer, não passa de desejo sexual e procriação. As pessoas pensam 


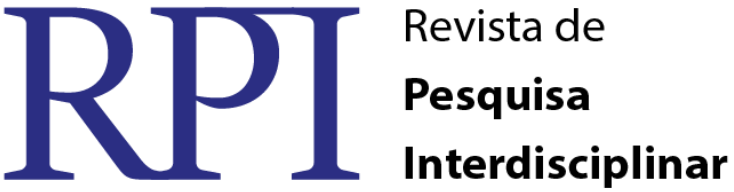

no futuro quando estão apaixonados, idealizam como vão ser os filhos e o quanto vão ser felizes, mas quando o futuro chega é tudo diferente do que foi imaginado e o "amor" vai se acabando aos poucos até estarmos com aquela pessoa só por consideração.

A sua ideia foi bastante confrontada e surgiram vários argumentos diferentes dos seus atualmente. Talíta Cícero, jornalista de Revista Filosófica, se opõe aos argumentos de Schopenhauer e afirma "Amar não é precisar do outro simplesmente porque aprecia a companhia. Amar é necessitar da presença do outro, pois as almas se completam e o sozinho o mundo não tem sentido".

\section{CONCLUSÕES}

Schopenhauer descreve o amor a partir de suas investigações, chegando a conclusão que o sentimento é uma mera ilusão para os humanos. Sobressai nas suas pesquisas o desejo das qualidades do sexo oposto, possuindo uma vontade carnal, para haver a procriação. Por meio de seus argumentos, foram articuladas outras afirmações que complementavam e reconheciam as ideias do filósofo alemão. É de suma importância comparar argumentos de filósofos da época passada com filósofos da contemporaneidade, para assim formular opiniões próprias sobre o "amor".

PALAVRAS-CHAVE: Amor. Metafísica. Schopenhauer.

\section{REFERÊNCIAS}

CÍCERO, Talita. Não sabemos mais amar?. A crise do amor. São Paulo. Editora Escala. Vol. 01. N3. 2015.

FONTES, Martins. Metafísica do Amor. Tradução Jair Barboza. São Paulo. 2000. . A verdade do amor. Tradução Jair Barboza. São Paulo. 2000. 


\title{
A FILOSOFIA APLICDA AO INDIVÍDUO
}

\author{
ÁREA TEMÁTICA: Filosofia Clínica \\ ANDRESSA DE LIMA LUCENA, estudante, ETSC - UFCG. \\ KENNEDY JOHNSON DE SOUSA DANTAS, estudante, ETSC - UFCG. \\ ANTUNES FERREIRA DA SILVA, professor mestre, ETSC - UFCG.
}

\section{INTRODUÇÃO}

A filosofia clínica é o equivalente a acompanhamento filosófico, na Europa, e filosofia pratica, nos Estados Unidos. Foi introduzida no Brasil pelo médico Lucio Packter como alternativa às abordagens terapêuticas já existentes. Essa analogia trabalha com métodos para conhecer o ser humano e pôr fim aos seus problemas através deste conhecimento.

\section{OBJETIVO DO TRABALHO}

Expor do que se trata e como funciona a terapia filosófica, tendo em mente um contexto histórico e atual e abordando, ante os problemas sócio individuais de cada ser, a sua eficiência.

\section{MATERIAIS E MÉTODOS}

Por meio de pesquisa forma-se um texto de caráter expositor quanto ao histórico e aplicações da filosofia clínica, trazendo a relevância e atuação, utilizando essencialmente o meio virtual, visto que há grande facilidade de acesso à informação, a exemplo do site Filosofia Clínica online.

\section{RESULTADOS E DISCUSSÃO}

"Direciona e elabora, a partir da metodologia filosófica, procedimentos de diagnose e tratamentos direcionados as questões existenciais", Lucio Packter mostra em sua definição a essência da filosofia clínica. Utilizando de conceitos e estudos feitos pela própria filosofia no que faz referência ao indivíduo e à mente, faz - se uma abordagem terapêutica às problemáticas do ser buscando uma resolução que lhe proporcione o conforto existencial. $\mathrm{O}$ partilhante, como é chamado quem é atendido, terá a ajuda do filósofo para a construção de um pensamento autônomo e chegará a raiz de seu problema por meio de questionamentos, respondidos pelo próprio sujeito, como o desenrolar de um emaranhado de linhas que representam os pensamentos. Durante três etapas procura-se chegar a efetiva solução, em primeiro, através dos exames categoriais localiza-se o partilhante, entendendo o contexto que o trouxe a consulta, em seguida, formando uma estrutura de pensamento entende-se a visão da pessoa quanto à si, ao mundo, às pessoas, etc. Por último aplica-se os submodos através dos quais o partilhante compreende a própria estrutura de pensamento, adquirindo, assim, capacidade para enfrentar as questões futuras, tendo em vista que conquistou autoconhecimento. Criando uma metodologia individual a cada partilhante a filosofia clinica objetiva o fim de uma dependência do ser na resolução de suas demandas psicológicas.

\section{CONCLUSÕES}


O individualismo dado a cada caso é o que torna a filosofia clínica diferente das outras áreas de estudo psicológico, como psicanálise e psiquiatria. Os profissionais desta área utilizado da epistemologia, lógica, fenomenologia, entre outros, conseguem dar aos seus partilhantes a técnica e liberdade que não ocorrem em outros acompanhamentos. Desprendendo-se de qualquer preconceito ou modelo de normalidade, as patologias são esquecidas e o campo de trabalho dos filósofos é mais amplo.

PALAVRAS-CHAVE: Filosofia clínica, terapia filosófica, individuo, autoconhecimento.

\section{REFERÊNCIAS}

O que é Filosofia Clínica?. Disponível em: http://www.psicologiamsn.com/2012/03/o-que-efilosofia-clinica.html. Acessado em 14 de novembro de 2016.

Filosofia Clínica. Disponível em: http://www.infoescola.com/filosofia/filosofia-clinica/. Acessado em 14 de novembro de 2016. 


\section{Revista de
Pesquisa
Interdisciplinar}

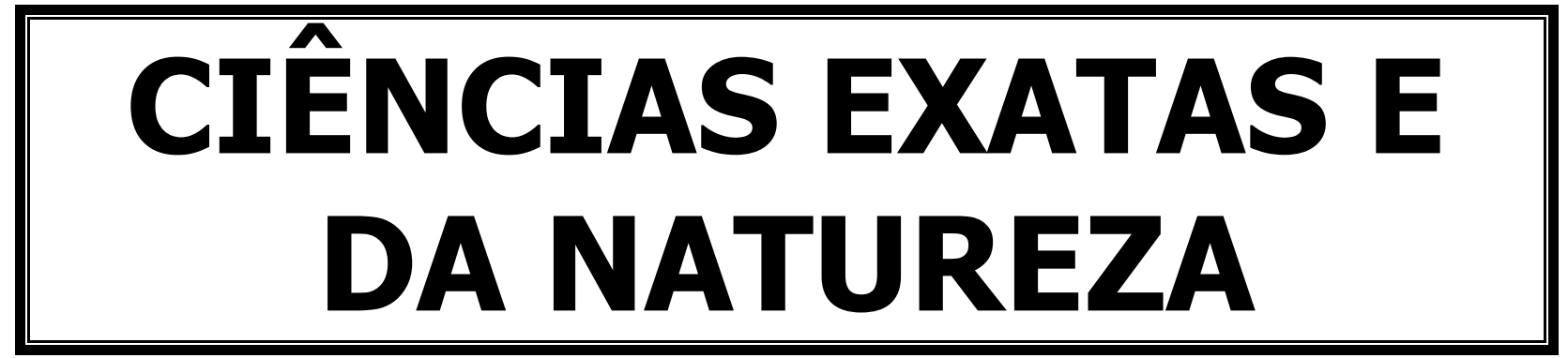

RPI Revista de Pesquisa Interdisciplinar, Cajazeiras, v. 2, Edição Especial, 2017. 


\title{
CULTIVO DE PLEUROTUS SPP. EM RESÍDUOS DE PAPEL DE ESCRITÓRIO: AVALIAÇÃO DO CRESCIMENTO MICELIAL E COLONIZAÇÃO DOS SUBSTRATOS
}

\author{
ÁREA TEMÁTICA: Ciências exatas e da natureza
}

(Banner)

\begin{abstract}
LAURA ALMEIDA DE ARAÚJO 1, Aluna Ensino Médio, ETSC. PEDRO MANUEL NUNES NOGUEIRA 2, Aluno Ensino Médio, ETSC. FABIELLY BEZERRA DE SOUSA 3, Aluna Técnico em Enfermagem,ETSC. FRANCISCA JOYCE PEREIRA DA SILVA 4, Aluna Técnico em Enfermagem,ETSC. ERLAINE DA SILVA ANDRADE 5, Aluna Técnico em Saúde Bucal, ETSC. GILIARA CAROL DINIZ DE LUNA GURGEL, Doutora , ETSC
\end{abstract}

\section{INTRODUÇÃO}

A produção e o consumo de cogumelo comestíveis e medicinais ainda é incipiente no Brasil, concentrando-se nas regiões Sul e Sudeste, e em algumas capitais brasileiras. No entanto, seguindo uma tendência mundial, a demanda de cogumelos no mercado consumidor interno tem aumentado, refletindo a crescente a busca por alimentos alternativos, naturais e com possíveis propriedades nutricionais e funcionais.

Na década de 80, cultivava-se apenas Agaricus bisporus, porém, desde então, a produção vem sendo diversificada pela introdução de outras espécies rústicas de cogumelo com facilidade de cultivo. O gênero Pleurotus spp. é um dos gêneros mais tolerantes às adversidades tropicais como oscilações de temperaturas, doenças de natureza microbiana, além de apresentar menor exigência nutricional. Para a maioria das linhagens de Pleurotus, a temperatura na fase de frutificação varia de 15 a $18^{\circ} \mathrm{C}$, no entanto, algumas linhagens deste foram adaptadas para o cultivo entre 15 a $28^{\circ} \mathrm{C}$ (EIRA; MINHONI, 1997; MARINO, 1997).

Estudos realizados com cogumelos comestíveis do gênero Pleurotus demonstram que estes apresentam cerca de 27 a $48 \%$ de proteínas, 2 a $8 \%$ gorduras, além de vitaminas, minerais, fibras, beta glucanos e compostos com atividades antioxidantes (SAVÓN et al., 2002). De acordo com Soto-Cruz et al. (1999), o cogumelo comestível P. ostreatus apresenta valor nutricional semelhante ao do leite e da carne. Como se sabe, os cogumelos podem ser aproveitados na alimentação por serem ricos em proteína e de baixo valor calórico. Algumas espécies também vêm sendo amplamente exploradas na pesquisa devido as suas propriedades medicinais, tais como antimicrobiana, imunomodulatória e antitumoral. Assim passa a ser de fundamental importância a avaliação biológica das propriedades nutracêuticas dos cogumelos produzidos de forma a fortalecer e buscar a comprovação de sua utilização como alimento funcional.

Para elucidar os problemas apresentados envolvendo a utilização de novos resíduos e formas diferentes de preparo do substrato para o cultivo de Pleurotus spp. faz-se necessário, sobretudo, um intenso trabalho, para simplificar o método de preparo e cultivo, mantendo-se ou aumentando-se os índices de produtividade da cultura.

O objetivo deste estudo foi avaliar o cultivo de Pleurotus spp. em substrato pasteurizado composto por resíduo de papel de escritório , rejeito disponível após a realização de atividades didáticas da Escola Técnica de Saúde de Cajazeiras (CFP/UFCG). O desenvolvimento de uma técnica menos onerosa e simples do preparo de substrato para o cultivo de Pleurotus spp., com 


\section{$\int \begin{aligned} & \text { Revista de } \\ & \text { Pesquisa } \\ & \text { Interdisciplinar }\end{aligned}$}

base em um conjunto de informações tecnicamente consistentes e a possibilidade de utilizar resíduos urbanos no cultivo de Pleurotus spp., disponíveis em quantidade na região e atualmente não aproveitados, minimizando possíveis impactos ambientais, fazem parte das contribuições deste estudo ao desenvolvimento desta cultura em expansão no Brasil.

$\mathrm{O}$ cultivo comercial do fungo comestível $\mathrm{P}$. ostreatus pode representar uma alternativa economicamente viável, com potencial de inserção regional, como também na pequena propriedade rural familiar. Torna-se, portanto, necessária a adaptação da tecnologia de produção às condições regionais de clima e de disponibilidade de resíduos.

\section{OBJETIVO DO TRABALHO}

Avaliar o potencial de utilização do substrato pasteurizado composto por resíduo de papel de escritório, à partir da verificação da velocidade de crescimento micelial, para o cultivo de cogumelos comestíveis do gênero Pleurotus.

\section{MATERIAIS E MÉTODOS}

Foram utilizadas linhagens de Pleurotus spp preservadas em óleo mineral, repicadas para meio ágar batata-dextrose (BDA) e incubadas a $28^{\circ} \mathrm{C}$ por 10 dias, até serem recuperadas. Para manutenção do fungo em laboratório, foi utilizado o meio BDA. O substrato composto por resíduo de papel de escritório foi triturado e umedecido por 02 horas, e em seguida o excesso de umidade foi eliminado durante 04 horas, resultando em um substrato com $70 \%$ de umidade, que foi acondicionado em frascos de vidro, que consistiam em uma unidade experimental cada, sendo estes autoclavados a $121^{\circ} \mathrm{C}$ por 1 hora. Após o resfriamento, cada vidro recebeu o micélio do fungo crescido em BDA e foi incubado a $25{ }^{\circ} \mathrm{C}$, com luz difusa, até a completa colonização do substrato. $O$ registro do crescimento micelial foi feito diariamente, no mesmo horário e à partir do mesmo ponto de referência previamente marcado no frasco. As leituras consistiram em medições do crescimento micelial ao longo do frasco, em três pontos, com intervalo de 24 horas, utilizando-se régua milimetrada. $\mathrm{O}$ experimento foi realizado em triplicata e um frasco foi mantido livre do inoculante para garantir o controle de esterilidade.

\section{RESULTADOS E DISCUSSÃO}

Os resultados quantitativos podem ser observados na tabela 01 . O vigor do micélio foi um aspecto qualitativo observado, haja vista a fácil percepção de micélio de característica densa. Não foram observadas contaminações no interior dos substratos durante o ensaio.A linhagem apresentou, como esperado, crescimento visível somente à partir do $2^{\circ}$ dia, e atingiu $13 \mathrm{~mm}$ de miceliação aos 20 dias de experimentação.

Tabela 01: Resultados do experimento de miceliação em frascos de Pleurotus ostreatus em substrato composto por resíduo de papel de escritório, por meio da média das medições diárias. Dados expressos em $\mathrm{mm}$.

\begin{tabular}{cc}
\hline $\begin{array}{c}\text { Cronologia } \\
\text { das } \\
\text { medições }\end{array}$ & $\begin{array}{c}\text { Média do } \\
\text { crescimento } \\
\text { micelial, em MM }\end{array}$ \\
\hline
\end{tabular}

RPI Revista de Pesquisa Interdisciplinar, Cajazeiras, v. 2, Edição Especial, 2017. 


\begin{tabular}{c|c}
\hline dia 1 & 0,0 \\
dia 2 & 2,06 \\
dia 3 & 4,4 \\
dia 4 & 7,53 \\
dia 5 & 11,6 \\
dia 6 & 16,46 \\
dia 7 & 21,4 \\
dia 8 & 27,73 \\
dia 9 & 35,2 \\
dia 10 & 47,13 \\
dia 11 & 56,96 \\
dia 12 & 67,26 \\
dia 13 & 75,13 \\
dia 14 & 86,93 \\
dia 15 & 96,6 \\
dia 16 & 107,0 \\
dia 17 & 110,93 \\
dia 18 & 120,73 \\
dia 19 & 128,86 \\
dia 20 & 136,80
\end{tabular}

A eficiência da biodegradação por fungos varia em função da linhagem (ROYSE; SANCHEZ-VAZQUEZ, 2001), e diferenças de crescimento micelial entre linhagens fúngicas já foram relatadas por muitos pesquisadores (ANDRADE, 2005; BOYLE, 1998; MAKI et al., 2001; SILVA et al., 2005). Avaliando a velocidade de crescimento micelial de linhagens de Pleurotus spp. em diferentes substratos, DONINI et al. (2005), observaram diferenças significativas na interação entre linhagens, substratos e dias de avaliação. BAYSAL et al. (2003), ao avaliar o crescimento micelial de duas linhagens de L. edodes submetidas a dez tipos de meio de cultura, verificaram diferenças nas médias de crescimento micelial em todos meios de cultura testados.

A peculiaridade dos compostos utilizados para proporcionar o crescimento fúngico quanto à capacidade de retenção de umidade define níveis de umidade diferentes para cada substrato utilizado no cultivo de cogumelos comestíveis. No presente estudo, o resíduo avaliado para a produção do cogumelo Pleurotus spp. apresentou crescimento satisfatório, representado pelos ensaios de miceliação. No que diz respeito à velocidade de crescimento, o desempenho do substrato permitiu velocidade de crescimento reduzida, completando a miceliação aos 20 dias após a inoculação. A redução do tempo de miceliação em substratos pode ser atribuído a fatores tais como composição do meio, aeração e umidade, e tamanho da partícula do substrato. A umidade não só afeta a disponibilidade de nutrientes como também a concentração de oxigênio, pois a água ocupa espaços que podem ser ocupados pelo ar. Desta forma, níveis muito elevados de umidade se tornam limitantes consideráveis para a respiração do fungo.

\section{CONCLUSÕES}

Os resultados do presente estudo confirmam a viabilidade dos substrato à base de papel de escritório para o cultivo de Pleurotus spp. haja vista o satisfatório desenvolvimento e resultados da curva de crescimento por eles apresentada. 
Comparados aos resultados obtidos pelo já consagrado capim-elefante, pode-se observar que o desempenho do substrato submetidos à experimentação laboratorial da miceliação em tubos apresentou resultados semelhantes.

PALAVRAS-CHAVE: biodegradação, Pleurotus spp. , resíduos urbanos.

\section{AGRADECIMENTOS}

Ao programa $\mathrm{CNPq} / \mathrm{PIBIC}$ pelo financiamento do projeto e à ETSC-UFCG pela concessão da bolsa de Iniciação Científica.

\section{REFERÊNCIAS}

ANDRADE, M. C. N. Cultivo de Agaricus blazei Murrill ss. Heinemann. Botucatu: Fundação de Estudos e Pesquisas Agrícolas e Florestais, 2005.

BAYSAL, E.; PEKER H.; YALINKILIÇ, M. K. Cultivation of oyster mushroom on waste paper with some added supplementary materials. Bioresource Technology, v. 89, n. 1, p. 9597, 2003.

BOYLE, C. D. Nutritional factors limiting the growth of Lentinula edodes and other white-rot fungi in wood. Soil Biology Biochemistry, v. 30, n. 6, p. 817-823, 1998.

DONINI, L.P.; BERNARDI, E.; MINOTTO, E.; NASCIMENTO, J.S. Desenvolvimento in vitro de Pleurotus sp. sob a influência de diferentes substratos e dextrose. Arquivos do Instituto Biológico, v.72, n.3, p.331-338, 2005.

EIRA, A.F. \& MINHONI, M.T.A. Manual teórico-prático do cultivo de cogumelos comestíveis. Botucatu. Fundação de Pesquisa Agropecuária e Florestais, 75p. 1997.

MAKI, C. S.; TEIXEIRA, F. F.; PAIVA, E.; PACCOLA-MEIRELLES, L. D. Analyses of genetic variability in Lentinula edodes through mycelia responses to different abiotic conditions and RAPD molecular markers. Brazilian Journal of Microbiology, v. 32, n. 3, p. 170-175, 2001.

MARINO, R.H. Produtividade de Pleurotus sajor-caju (Fr.) Sing. em função dos métodos de isolamento e produção de inoculantes. 1997. 134f. Dissertação de mestrado Instituto de Química do Campus de Araraquara-UNESP, Araraquara, SP., 1997.

ROYSE, D. J.; SANCHEZ-VAZQUEZ, J. E. Influence of substrate wood-chip particle size on shiitake (Lentinula edodes) yield. Bioresource Technology, v. 76, n. 3, p. 229-233, 2001. SAVÓN, R.C.B.; FERNÁNDEZ, C.D.; MANRIQUE, C.E.M.; SEVILLA, E.I.R.; QUEVEDO, H.J.M. Efecto de la luz en la concentración de micoesteroles de Pleurotus ostreatus Var. Florida. Revista Cubana Alimentacion Nutricion v.16, n.1, p.13-18, 2002.

SILVA, E. M.; MACHUCA, A.; MILAGRES, A. M. Effect of cereal brans on Lentinula edodes growth and enzyme acticities during cultivation on forestry waste. Letters in Applied Microbiology, v. 40, n. 4, p. 283-288, 2005. 


\section{$\mathrm{RPP}$}

SOTO-CRUZ, O; SAUCEDO-CASTAÑEDA, G.; PABLOS-HACH, J.L.; GUTIÉRREZROJAS, M.; FAVELA-TORRES, E. Effect of substrate composition on the mycelial growth of Pleurotus ostreatus. An analysis by mixture and response surface methodologies. Process Biochemistry, v.35, p.127-133, 1999. 